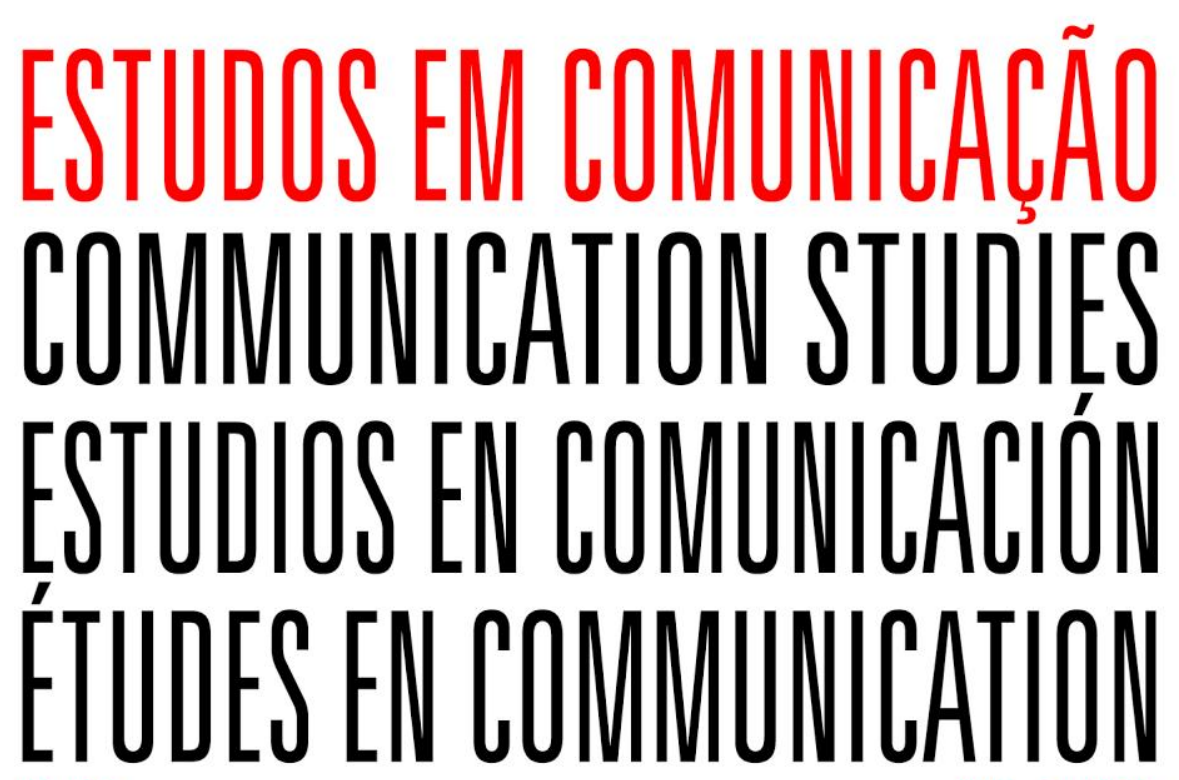
REVISTA . REVIEW . REVISTA . MAGAZINE

N23. DEZ'2016

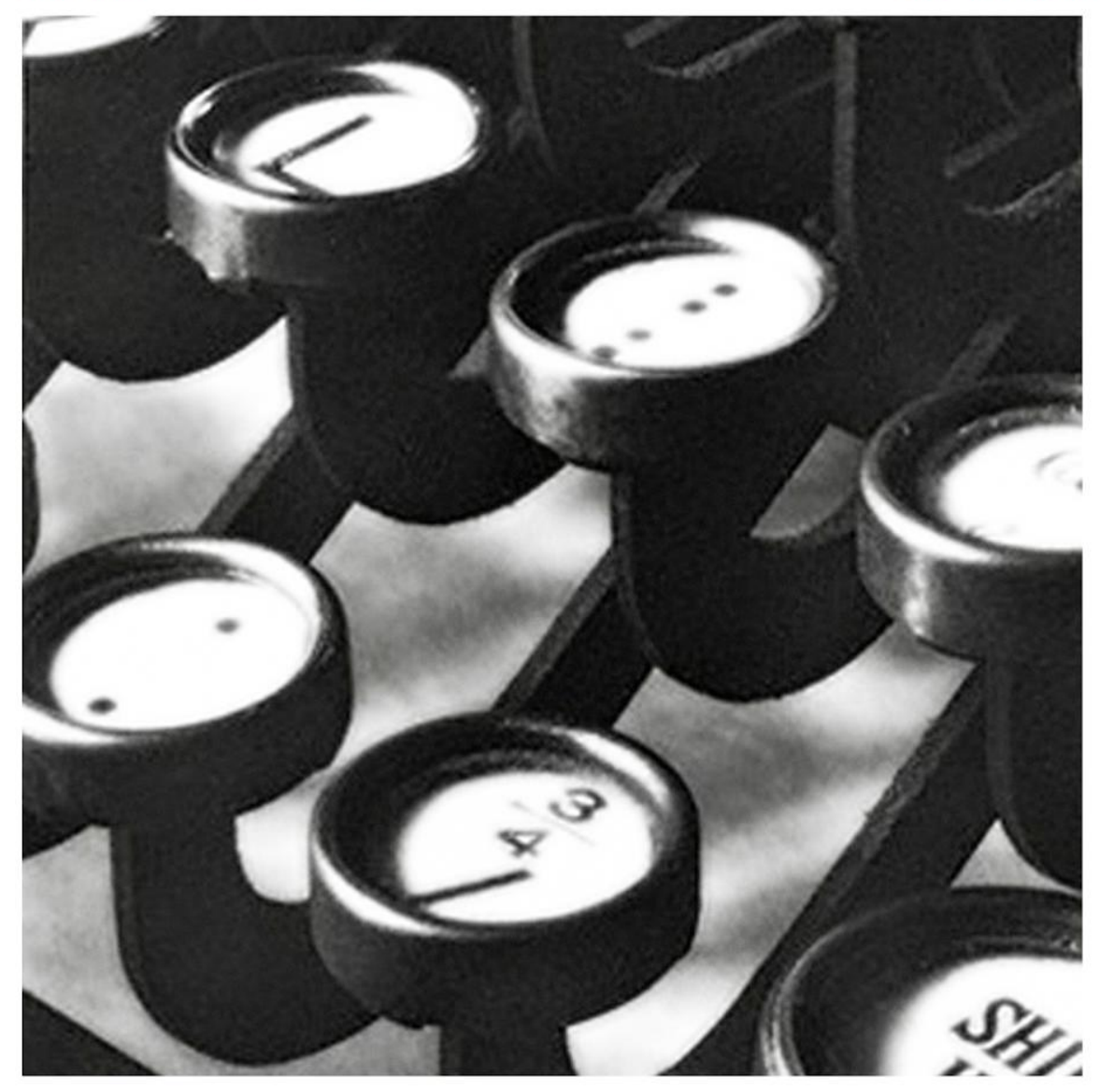


$\bigoplus$

$\bigoplus$

$\oplus$ 
EDITORS [EDITORES]

João Carlos Correia (Universidade da Beira Interior, Portugal)

Anabela Gradim (Universidade da Beira Interior, Portugal)

\section{INTERNATIONAL SCIENTIFIC BOARD [PAINEL CIENTÍFICO INTERNACIONAL]}

António Fidalgo (Universidade da Beira Interior, Portugal)

Afonso Albuquerque (Universidade Federal Fluminense, Brasil)

Alfredo Vizeu (Universidade Federal de Pernambuco, Brasil)

António Bento (Universidade da Beira Interior, Portugal)

Ana Serrano Telleria (Universidade da Beira Interior, Portugal)

Ana Catarina Pereira (Universidade da Beira Interior, Portugal)

Barbie Zelizer (University of Pennsylvania, USA)

Catarina Rodrigues (Universidade da Beira Interior, Portugal)

Catarina Moura (Universidade da Beira Interior, Portugal)

Catarina Moura (Universidade da Beira Interior, Portugal)

Cláudia Alvares (Universidade Lusófona de Humanidades e Tecnologias Escola de Comunica-

ção. Artes e Tecnologias da Informação, Portugal)

Colin Sparks (University of Westminster, United Kingdom)

Eduardo Camilo (Universidade da Beira Interior, Portugal)

Eduardo Meditsch (Universidade Federal de Santa Catarina, Brasil)

François Heinderyckx (Université Libre de Bruxelles, Belgique)

Elias Machado (Universidade Federal de Santa Catarina, Brasil)

Francisco Costa Pereira (Escola Superior de Comunicação Social, Portugal)

Gil Ferreira (Universidade Católica Portuguesa)

Hélder Prior (Universidade de Brasília, Brazil)

Helena Sousa (Universidade do Minho, Portugal)

Ivone Ferreira (Universidade da Beira Interior, Portugal)

Javier Díaz Noci (Universidad del País Vasco, Espanã)

Jean Marc-Ferry (Université Libre de Bruxelles, Institut d'Études Européennes, Belgique)

João Pissarra Esteves (Universidade Nova de Lisboa, Portugal)

João Canavilhas (Universidade da Beira Interior, Portugal)

Joaquim Paulo Serra (Universidade da Beira Interior, Portugal)

Jorge Pedro Sousa (Universidade Fernando Pessoa, Portugal)

José Bragança de Miranda (Universidade Lusófona ; Universidade Nova de Lisboa, Portugal)

Liesbet van Zoonen (University of Amsterdam, Holanda)

Luís Costa Nogueira (Universidade da Beira Interior, Portugal)

Manuel Pinto (Universidade do Minho, Portugal)

Mark Deuze (Indiana University, USA)

Maria João Silveirinha (Universidade de Coimbra, Portugal)

Marisa Torres Silva (FCSH, CIMJ, Portugal)

Mário Mesquita (Escola Superior de Comunicação Social de Lisboa, Portugal)

Marcos Palácios (Universidade Federal da Bahia, Brasil)

Martin Jay (University of California, Berkeley, USA) 
Miguel Rodrigo Alsina (Universitat Pompeu Fabra, España)

Michael Gurevitch (University of Maryland, USA)

Nelson Traquina (Universidade Nova de Lisboa, Portugal)

Nico Carpentier (Vrije Universiteit Brussel -VUB- , Katholieke Universiteit Brussel - KUB)

Nathalie Zaccai-Reyners (Université Libre de Bruxelles, Belgique)

Paula Espírito Santo (Instituto Superior de Ciências Sociais e Políticas, Universidade Técnica

de Lisboa, Portugal)

Peter Dahlgren (Lunds Universitet, Sweden)

Pedro Coelho (SIC, Jornalista; Investigador)

Ramón Salaverría (Universidad de Navarra, España)

Stephen K. White (University of Virgínia, EUA)

Rosental Calmon Alves (University of Texas, USA)

Steve Reese (University of Texas, USA)

Susan Buck-Morss (Cornell University)

Tito Cardoso e Cunha (Universidade da Beira Interior, Portugal)

Todd Gitlin (Columbia University, USA)

Xosé Lópes García (Universidad Santiago de Compostela, España)

GRAPHICAL DIRECTOR [DIREÇÃo GRÁFICA]

Catarina Moura

COLLABORATORS [COLABORADORES]

Susana Costa, Filomena Matos, Cristina Lopes, António Tomé e Manuela Penafria

CREDITS [FICHA TÉCNICA]

(c) Estudos em Comunicação [Communication Studies] - www.ec.ubi.pt

LabCom.IFP - Comunicação, Filosfia e Humanidades - www.labcom-ifp.ubi.pt

UBI - Universidade da Beira Interior - www.ubi.pt

Universidade da Beira Interior - FAL/LabCom.IFP

Rua Marquês D’Ávila e Bolama

6201-001 Covilhã, Portugal

ISSN : 1646-4923

ISSN (suporte electrónico) : 1646-4974

DOI : $10.20287 / \mathrm{ec}$

DOI no $23: 10.20287 /$ ec.n23

Semestral periodicity [Periodicidade semestral]

Contacts [Contatos] : joao.correia@labcom.ubi.pt, anabela.gradim@labcom.ubi.pt

Call for papers : continuous publishing flow

Manuscript Submission : September 30th, 2016

Acceptance Notification : October 23rd, 2016

Publication : December 19th, 2016 
A Revista Estudos em Comunicação é financiada por Fundos FEDER através do Programa Operacional Factores de Competitividade - COMPETE e por Fundos Nacionais através da FCT - Fundação para a Ciência e a Tecnologia no âmbito do projeto Comunicação, Filosofia e Humanidades (LabCom.IFP) UID/CCI/00661/2013.

\section{FCT} COMPETE QR

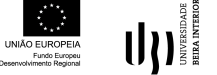

IH. COMPETE EN

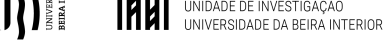




\section{Index [Índice]}

Os 100 primeiros dias do XXI Governo Constitucional através da imprensa generalista: quando as finanças travam uma mudança de ciclo político

por Felisbela Lopes \& Paula Espírito Santo

Papéis dos usuários na circulação jornalística em sites de rede social: os atentados de Paris no Twitter por Gabriela Zago

FIFA World Cup 2014 on Twitter and Facebook: more from less or less from more?

por Ivo Neto \& Felisbela Lopes

O Estado da Arte da Comunicação Organizacional por Rita Monteiro Mourão, Sandra Miranda \& Gisela Gonçalves

El juego en red o el juego enredado: la dimensión interactiva de los juegos de las redes sociales por Carolina Duek \& Gastón Tourn

A Relevância das Novas Tecnologias na Comunicação Organizacional: o Caso dos Websites nas Universidades Portuguesas por Sónia Silva, Teresa Ruão \& Gisela Gonçalves

Representações de morte e desvio em narrativas jornalísticas da Amazônia urbana por Sergio do Espirito Santo Ferreira Junior \& Alda Cristina Costa 139

As especificidades da apuração no processo de produção da reportagem por Paula Melani Rocha \& Mariana Galvão Noronha 
Political Cartoons as communicative weapons - the hypothesis of the "Double Standard Thesis" in three Portuguese cartoons por Samuel Mateus

A corporeidade feminina na publicidade: algumas reflexões sobre representações normativas

por Cristina Santos 
$\bigoplus$

$\bigoplus$

$\oplus$ 


\title{
Os 100 primeiros dias do XXI Governo Constitucional através da imprensa generalista: quando as finanças travam uma mudança de ciclo político
}

\author{
Felisbela Lopes \& Paula Espírito Santo \\ Universidade do Minho; Centro de Estudos de Comunicação e Sociedade / Instituto \\ Superior de Ciência Sociais e Políticas (ISCSP), Universidade de Lisboa; Centro de \\ Administração e Políticas Públicas \\ E-mail: felisbela@ics.uminho.pt/paulaes@iscsp.ulisboa.pt
}

\begin{abstract}
RESUMO
Os 100 primeiros dias de um Governo correspondem a um tempo vital na construção de uma marca. Neste contexto, os media assumem-se como guias de referência de uma opinião pública que vai sendo estruturada em grande parte por influência daquilo que os jornalistas escrevem. Para saber como é que a imprensa generalista mediatizou este período no que diz respeito ao XXI Governo Constitucional, analisamos todos os textos noticiosos dos jornais generalistas que elegeram a ação dos governantes como frame principal. Este conjunto de textos noticiosos totalizou um corpus de 961 artigos jornalísticos e 2165 citações de fontes de informação. Dessa aná-

lise sobressai uma cobertura noticiosa intensa (publicam-se em média 2,4 textos por dia), desenvolvida em textos de tamanho médio ou extenso, declinada maioritariamente pelo ângulo positivo, feita em forma de notícia, refletindo mais de metade dos textos acontecimentos previamente agendados pelos atores políticos. Apesar do esforço deste Governo em proclamar um novo ciclo político afastado do tópico daausteridade que havia dominado o discurso político dos anos precedentes, os jornalistas privilegiaram a tematização financeira e, quando o fizeram, criaram uma cobertura jornalística distinta daquela que se constituiu como padrão da actividade governativa dos restantes mi-
\end{abstract}

Data de submissão: 29-07-2016. Data de aprovação: 23-10-2016.

A Revista Estudos em Comunicação é financiada por Fundos FEDER através do Programa Operacional Factores de Competitividade - COMPETE e por Fundos Nacionais através da FCT - Fundação para a Ciência e a Tecnologia no âmbito do projeto Comunicação, Filosofia e Humanidades (LabCom.IFP) UID/CCI/00661/2013.

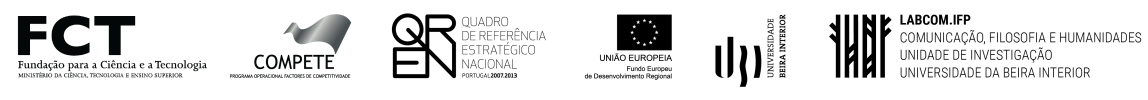


nistérios. Ano e meio depois do fim oficial doPrograma de Assistência Económica e Financeira a Portugal, a imprensa portuguesa continuou a encontrar nas fi- nanças um tópico persistente. Tal aconteceu, porque o calendário político a isso o obrigou, mas porque também os jornalistas não quiseram fazer desvios de rota.

Palavras-chave: jornalismo político; 100 dias de governação; imprensa portuguesa; tematização; fontes de informação.

\begin{abstract}
The first 100 days of a Government constitute a vital period in the making of a brand. In this context, the media assume themselves as reference guides of a public opinion which is structured largely by influence of what journalists write. To get to know how the generalist press publicized this period regarding the 21st Constitutional Government, we have analyzed all the news texts of general newspapers that elected the governors' action as main frame. This set of news texts totaled a corpus of 961 news articles and 2165 quotes from information sources. From this analysis, an intense news coverage stood out (on average 2,4 texts are published every day), developed in medium-sized or extensive texts, declined mostly by the positive an-

than half of the texts reflecting previously scheduled events by political actors. Despite the efforts of this Government in proclaiming a new political cycle away from the topic of austerity that had dominated the political discourse of the preceding years, journalists promoted financial themes and, when they did, they created a news coverage different from the one which was established as standard of the other ministries' government activity. Year and a half after the official end of the Program of Economic and Financial Assistance to Portugal, the Portuguese press continued to consider the finance matter a persistent topic. Such happened, not only because the political calendar forced it, but also because journalists didn't want to make detours.
\end{abstract} gle, made in the form of news, more

Keywords: political journalism; 100 days of governance; the Portuguese press; topicalization; sources of information.

\title{
NOTA INTRODUTÓRIA
}

${ }^{\mathrm{M}}$ cada ciclo político que se renova, a expectativa dos primeiros 100 dias

¿ de governação constitui um marco simbólico, e também pragmático, 
acerca da linha de condução política dos Governos e dos seus protagonistas. O modo como a mensagem é construída através dos media, e da imprensa em especial, marca os traços fundamentais que resultam da relação de construção e do reflexo que os jornais permeabilizam entre os seus públicos e os atores políticos da cena governamental. Quisemos perceber como é que a imprensa portuguesa mediatizou esse período no XXI Governo Constitucional de Portugal. Para isso, analisámos todos os artigos dos jornais generalistas diários que tiveram como ângulo principal a ação dos respetivos governantes. Nesse trabalho verifica-se que, de entre as várias pastas e ministérios sob observação, existem grupos top que acabam por gerar diferentes níveis de interesse por parte da imprensa. As finanças destacam-se amplamente dos restantes campos governamentais, contaminando, em grande medida, a imagem do Executivo como um todo. A demonstração desta tendência abre-nos um conjunto de pistas e focos de atenção sobre não apenas este campo vital da praxis, como da comunicação governamental e política, do Estado no seu composto institucional. Neste tempo, os jornalistas centraram-se na pasta das finanças como foco essencial da governação nacional (totaliza 30,5 dos artigos noticiosos sobre os governantes Portugueses). É sobre este objeto que nos debruçaremos de forma particular, conquanto a sua pertinência transmite e indicia um formato próprio acerca da construção da imagem política do Governo na sua fase de maior expectativa e num dos momentos de maior observação crítica por parte dos media e, consequentemente, da opinião pública.

Neste sentido, a questão de fundo que colocamos é a seguinte: em que moldes se constrói e se torna hegemónico, na imprensa, um objeto político e governamental central? Esta questão abre-nos a porta para a complexidade analítica acerca da construção de um conjunto-chave de categorias e indicadores frequentes na imprensa nacional, os quais poderão indiciar um padrão de produção da mensagem jornalística em relação ao ciclo inicial dos 100 dias de governação do Estado. Assim, procuramos definir o predomínio temático ou categorial dos conteúdos noticiosos sobre a política governamental; analisar o tratamento jornalístico construído acerca do desempenho governamental; identificar as fontes noticiosas, ponderando a sua diversificação, notoriedade e funcionalidade instrumental no contexto da produção noticiosa; e discutir os moldes da organização noticiosa à luz da hipótese da agendasetting. Em termos metodológicos, a técnica de suporte a este estudo é a análise de conteúdo, a qual será utilizada numa vertente quantitativa. O cor- 
pus de análise é constituído pelos textos noticiosos publicados na imprensa diária Portuguesa selecionada nos primeiros 100 dias de governação, ou seja, 961 textos jornalísticos, dos quais 294 artigos são sobre as finanças. Ao longo deste tempo, destacaram-se três importantes acontecimentos, os quais justificam, em grande medida, o foco mediático sobre as finanças: a apresentação do programa do Governo, a crise no Banco Banif e a discussão e aprovação do Orçamento de Estado. O volume de fontes citadas nestes 100 dias de governação foi elevado (2165 fontes), tendo sido analisado e organizado com base no processo categorial e nos indicadores obtidos na organização da análise de conteúdo efetuada. Os resultados esperados desta contribuição apontam para a funcionalidade e instrumentalidade da construção noticiosa política e governamental, identificada através dos focos temáticos e contextuais selecionados num momento central para a governação, os seus primeiros 100 dias. Este percurso de construção noticiosa indicia e, potencialmente, marca a imagem do Executivo, contribuindo de modo permanente para consubstanciar os moldes identitários da imagem pública da governação, dos seus protagonistas, e pastas, ao longo do mandato governativo.

\section{O TEMPO E ESPAÇO DO GOVERNO NA IMPRENSA NOS PRIMEIROS 100 DIAS: FOCOS DE ATENÇÃO E CONSTRUÇÃO NOTICIOSOS}

A construção do tempo e espaços da política nos 100 primeiros dias de governação constituem importantes fragmentos da identidade política da Nação. Este período contribuiu para consolidar o espaço vital das múltiplas cumplicidades políticas, sociais e identitárias não só do Executivo em cada mandato, como do contexto de representação parlamentar que, com este, se ergue nas legislaturas ligadas ao mandato do Governo. O regime político Português, designado semipresidencialista, salienta o importante papel de coabitação política entre três dos quatro órgãos de soberania nacional, o Governo, a Assembleia da República e o Presidente da República, cabendo aos tribunais um papel paralelo no campo do equilíbrio e sustentação legal, fiscalização e controlo da comunidade e das estruturas de funcionamento do Estado. A imagem pública construída através dos media, e da imprensa em especial, constitui, neste sentido, um reflexo de prioridades, de focos de atenção, de dinâmicas de poder, de interesses programáticos, mas também editoriais, tanto quanto o agenda-setting os atende e entende e expõe. Contudo, os valores e conteúdos 
reflectidos nos media constituem-se, sobretudo, como referentes com importância relativa no plano da afetação dos públicos das democracias, aliada a um sentido de focagem de rápida permanência no espaço e visibilidade públicas. Ou seja, os indicadores produzidos pela focagem noticiosa dos media permitem retirar ilações sobre interesses mediáticos, mas, entre estes e o espaço público de retenção e interesse, o hiato tende a constituir-se de modo acentuado.

A discussão sobre as bases políticas de identidade junto dos públicos da imprensa, construídas através dos media, tal como Lippmann (1922), de modo pioneiro, as introduziu e discutiu, projetou a importância da opinião pública, evidenciando o papel dos interesses políticos e da manipulação da mensagem nos meios de comunicação. Segundo Lippmann, apesar da influência das elites na construção da opinião pública, esta mesma opinião pública seria um dos aspetos centrais da comunicação, mas também da política e da democracia. A irracionalidade da construção da 'opinião' e da 'multidão' em Tarde (1901) sublinhava o carater heterógeno e a pouca coesão das massas, as quais seriam desprovidas de reflexão e profundidade, visíveis no plano da ação coletiva. Já na visão de Lippmann (1922), a opinião pública constituía-se como um ente moldado em bases política e democraticamente instituídas, onde a irracionalidade das massas estaria na base da falta de coesão social, da crítica, assim como do desligamento em relação à ação do poder político. As limitações associadas à opinião pública encontravam raízes na incompetência política dos cidadãos, aliadas às suas dificuldades de enraizamento sociocultural, bem como a fatores individuais e psicológicos. Lippmann acentuou ainda a importância da seleção editorial dos ângulos do acontecimento como o principal marco de construção das bases da opinião pública, através da imprensa, assim como da ação fundamental da propaganda e da persuasão políticas, na construção da designada 'manufatura do consentimento', ou seja, num julgamento coletivo contruído, assumido e consentido pelo sistema político.

O papel e valor da imprensa constituem um dos principais motivos de observação no plano político. Neste quadro, reúne indiscutível interesse a relação da imprensa com os seus protagonistas, a opinião pública, mas sobretudo com os editores, os políticos e os públicos. A literatura tem questionado a débil força da opinião do eleitorado, em contraste com a da elite (Neuman, 1986). Segundo Neuman (1986: 3), "o paradoxo da política de massas é o hiato entre a expectativa de uma cidadania informada em face da teoria demo- 
crática e da realidade desconfortante revelada pela sistemática investigação por sondagens". A enfatização do fosso entre a construção mediática e o envolvimento e motivação do eleitorado coloca-se no modo como é construída a imagem do poder em termos noticiosos e os ângulos selecionados como mais urgentes e funcionais. O desinteresse e a desafetação pública em relação aos assuntos da política tendem a vincar-se em simultâneo com maiores níveis de instrução, de educação e de compreensão socioeconómica e política (Patterson, 1997; Norris, 2000; Norris, 2011). Ou seja, o aumento da competência política é acompanhado por uma evolução que tende a ser inversamente proporcional ao interesse gerado pela política, nomeadamente pela informação acerca da política.

O estudo da influência dos partidos na agenda política e o efeito dos media nas agendas partidárias, conduzido por Hopmann et al. (2009), demonstrou que os partidos possuem bastante influência na agenda dos media, mas que estes têm pouca ascendência sobre a agenda partidária. Este estudo também sublinhou que não são sistemáticos os motivos que estão na base da maior influência de alguns partidos, em relação aos demais, sobre o espaço noticioso que lhes é dedicado. De entre os motores da construção da notícia, salientamse alguns aspetos que estão na base da seleção do framing escolhido. A autenticidade, a negatividade e a personalização constituem focos essenciais da relação que os atores políticos constroem com os media (Hopmann, 2014). Estes elementos apresentam-se como ferramentas e instrumentos de mediatização e reflexão acerca dos conteúdos protagonizados na imprensa pelos atores políticos.

Daqueles três aspetos, a negatividade é aquele que tem atraído mais a investigação, pela frequência deste recurso na construção da notícia e pela atratividade e estímulo que gera no seguimento da mesma junto dos públicos dos media. Focando-se no 'tom das notícias', Mortensen, Green-Pedersen e Thesen (2015) sublinham que "a consistência dominante das notícias negativas ao longo do tempo" parece indiciar que as suas causas são estruturais e institucionais, ressalvando-se, contudo, a variação grande na sua intensidade, de acordo com o contexto político. Mortensen, Green-Pedersen, Thesen (2015) acentuam aqui o papel dos media enquanto watch dogs, o qual acaba por fazer salientar, sobretudo, a negatividade na construção noticiosa. Anteriormente Thesen (2013) apontava já as reações e aproveitamentos distintos dos partidos, consoante se encontram no poder e na oposição, em relação às boas e 
más notícias, enfatizando que a responsabilidade política e o tom da notícia constituem aspetos preponderantes quanto à explicação da politização nas notícias. O papel de reforço dos partidos enquanto poder em relação às notícias positivas contrasta com a oposição, que faz eco e amplia as notícias negativas em torno da atuação dos partidos na sede do poder político. A negatividade indicia a capacidade de atração dos recursos editoriais em relação a objetos e argumentos que geram interesse pela sua oposição, crítica, fragilidade em relação a estruturas, eventos, protagonistas, objetos ou fenómenos que o quotidiano comunicacional desencadeia. A personalização centra-se na construção da imagem e identidade política dos protagonistas do sistema político, na sua atuação, nas suas opções estratégicas, problemas e soluções ao longo da sua caminhada e exposição pública perante os desafios e missões para os quais foram mandatados para gerir e governar.

Em segundo lugar, a autenticidade constitui um dos valores aclamados no espaço público como pilar da retórica democrática, facilitador da transparência política entre eleitos e eleitores, base e argumento de proximidade entre as massas e o poder político. É neste âmbito que Harwood (2004) destaca a caminhada do público em busca da autenticidade da informação. A confiança que esta gera nos cidadãos permite e reforça um estado de constante 'julgamento' e contextualização pessoal, por parte de cada um de nós, sobre a veracidade e significado da informação transmitida. O pessimismo e a descrença tendem a acentuar-se à medida que as bases de julgamento não são claras, nomeadamente as fontes utilizadas na construção noticiosa, não identificadas ou pouco claras e a omissão de dados relevantes para o entendimento da história e do papel desempenhado pelos seus protagonistas políticos. Coloca-se a questão sobre a autenticidade da notícia enquanto espelho da realidade, abordagem, como lembra João Carlos Correia, que tende a ser, cada vez mais, substituída pela da notícia enquanto narrativa baseada num dispositivo com vista a "dar forma à experiência tal como um poema, um romance, um livro de histórias ou um conto de fadas (Correia, pp. 57-58). Deste modo, a notícia constitui-se como uma narrativa, cujo contexto, personagens e história são enquadradas, de modo funcional, nas expectativas, tempo e espaço em curso. Ou seja, a construção noticiosa superintende um conjunto de quadros de referência institucionais, económicos e políticos vitais, que formatam, de modo imperativo, os encaixes e limites noticiosos com os quais o jornalista se defronta. Na linha de Maia (2008), Gil Baptista Ferreira (2011) sublinha 
que os "jornais não são canais provedores neutros de informação", mas estão ligados e integrados, institucionalmente, em organizações com relações políticas, económicas, e com culturas profissionais próprias e conflituantes com os demais actores sociais. Como sublinha Rogério Santos (2006), a complexidade da construção noticiosa resulta de um conjunto de dinâmicas e agentes integrantes, cujo produto final, a notícia, nem sempre permite fazer transparecer a forma como o processo foi concebido, assim como os moldes com base nos quais se estabeleceram opções, interacções, ângulos noticiosos. O processo noticioso promove a relação de negociação, nem sempre regular e sistemática, entre jornalista e fontes. Esta relação, na base da construção noticiosa, tende a moldar-se, em cada momento político e social, de acordo com as necessidades atinentes a cada objecto noticioso e personagens envolvidos. Num trabalho centrado na profissão de jornalista (Lopes, 2015), enunciámos a importância da observação próxima e crítica dos constrangimentos e limites económicos colocados à profissão, os quais tendem a constituir-se como condição sine qua non de entendimento e reflexão das opções noticiosas em democracia.

Em terceiro lugar, a personalização da construção noticiosa constitui uma prática frequente com vista ao desenvolvimento de uma identidade próxima com o protagonista e com o objeto da notícia. Para o efeito de personalização, as valências tecnológicas da era digital têm vindo a ser há muito destacadas (Negroponte, 1995, Norris, 2001; Hidman, 2012). No entanto, esta diferenciação nos seus usos está longe de ser massificada, quando se compara a utilização da imprensa no contexto das democracias ocidentais. A personalização na política constitui um objeto que tem vindo a ser destacado pela sua preponderância nos media (Wattenberg, 1995), através da importância atribuída aos desempenhos dos candidatos, sobretudo em tempos de campanha eleitoral, secundarizando a ideologia como tópico de importância política. A personalização na política é patente, em particular, na imprensa partidária, sobretudo associada a partidos de poder e de massas (Espírito Santo, Ferreira Costa, 2016), e menos realçada em partidos onde o coletivo e o partido como um todo constituem o motor fundamental das forças partidárias, como é o caso do Partido Comunista. A personalização na política constitui-se como um elemento constante na construção e seleção noticiosa. Contudo, na imprensa generalista, a personalização tende a ser mais evidente quando os objetos em 
realce poderão carecer de projeção perante a opinião pública, e os seus protagonistas usufruem de um estatuto diferenciado perante a mesma.

Com base neste quadro de referência e a partir da identificação das linhas estruturantes da construção do discurso nos media, e na imprensa em particular, desenha-se um conjunto de questões subsidiárias à investigação, colocadas nos seguintes termos:

- existe um ciclo noticioso autónomo nos 100 primeiros dias de governação que marque uma identidade noticiosa característica do novo Governo? Ou seja, haverá um ciclo noticioso que apresenta estabilidade na tematização, no foco e nas fontes?

- identificam-se valores predominantes (autenticidade, negatividade, personalização...) nos conteúdos noticiosos construídos em torno dos 100 primeiros dias de Governação?

- é possível encontrar pontos fortes e fragilidades na primeira abordagem noticiosa ao novo Governo e de que modo estes podem ser prenunciadores de uma marca de identidade do Governo para o futuro?

- evidenciam-se fontes privilegiadas e, em caso positivo, qual o seu papel e em que medida são centrais no frame selecionado?

- há traços permanentes de representação noticiosa sobre o XXI Governo Constitucional nos seus 100 primeiros dias de governação em termos de definição de uma imagem forte ou frágil em termos políti$\cos$ ?

A possibilidade da definição do ciclo noticioso dos primeiros 100 dias de governação constitui um dos dados noticiosos mais marcantes na construção da identidade dos novos Governos. Entender as bases da construção deste ciclo noticioso abre caminho para possíveis novos patamares de compreensão da noticiabilidade acerca do Governo e da sua relação com os públicos da democracia e com os meios de comunicação social. 


\section{RETRATOS QUE A IMPRENSA GENERALISTA PORTUGUESA CONSTRUIU dos 100 PRimeiros dias do Governo de ANTónio Costa: ESTUdo EMPÍRICO}

\section{Caminhos metodológicos}

Analisámos os 100 primeiros dias do Governo de António Costa através dos jornais diários generalistas portugueses: Diário de Noticias, Público, Jornal de Notícias e Correio da Manhã. Os dois primeiros são jornais de referências e os outros dois apresentam uma linha mais popular. A nossa amostra compõe-se apenas de artigos jornalísticos que têm como ângulo noticioso a ação dos membros do Governo, excluindo-se todos os textos em que o Governo é apenas o alvo da ação de outros atores sociais. A análise compreende o período entre os dias 27 de novembro de 2015 e 4 de março de 2016, totalizando 961 textos e 2165 citações de fontes de informação. A recolha de dados foi efetuada com recurso às versões digitais dos periódicos em causa, selecionando-se os cadernos principais desses títulos e excluindo-se as secções Local (no Público) ou Porto (no $J N$ ). Os textos recolhidos foram sujeitos a uma análise quantitativa dos textos, feita através do programa de análise estatística de dados Statistics Package for Social Sciences (SPSS), centrada em dois eixos de análise.

O primeiro eixo de análise procura caracterizar o texto através das seguintes variáveis: tipo de título (positivo, neutro, negativo), género jornalístico (notícia, reportagem, entrevista, perfil), tema (as categorias seguem os ministérios que compõem o Governo), ângulo (apresentação/discussão de medidas, reversão de medidas, gestão corrente), agendamento (iniciativa dos media, eventos públicos, conferências de imprensa/comunicados, situação em curso), tamanho do texto (breve, médio, extenso), tempo (antecipação, dia anterior, ponto de situação), lugar (dividindo o nacional por regiões e o internacional por continentes).

O segundo nível centra-se nas fontes de informação, analisadas aqui do ponto de vista do leitor dos textos, não transportando o investigador para a análise dos dados os conhecimentos prévios acerca de determinado indivíduo. As fontes são caraterizadas quanto ao tipo (humana ou não humana), identificação (identificada, não identificada ou anónima), geografia, estatuto e ministérios. O estatuto das fontes de informação é encontrado a partir de uma 
tipologia por nós criada e que nos permite saber se estamos a lidar com fontes oficiais, especializadas ou outras.

Neste artigo, separámos os textos que falam de Finanças a fim de se efetuar uma análise mais apurada. Assim, trabalhámos de forma isolada 294 textos e 677 fontes de informação.

\section{Discussão de resultados}

Nos 100 primeiros dias de governação, os jornais diários portugueses publicaram 961 textos noticiosos com o enfoque centrado no trabalho dos governantes portugueses. Destes, 294 artigos elegeram como tematização principal as finanças, ou seja, 30,5 por cento do que foi publicado nesse âmbito. É uma percentagem elevada, também justificada por três acontecimentos que desencadearam uma forte noticiabilidade: a apresentação do programa do Governo, a crise no Banco Banif e a discussão e aprovação do Orçamento de Estado. Neste conjunto de textos que tiveram as finanças como tópico central, citaramse 677 fontes (o total dos textos em estudo somou 2165 fontes). São números elevados quando se fala apenas de um tema e quando existe um discurso político que anuncia um ciclo novo que pretende subalternizar uma ação política comandada pelas finanças, como acontecera no Governo anterior.

Analisando os textos que tratam apenas das finanças, nota-se um certo desvio dos valores-padrão obtidos na análise global dos dados analisados. É como se houvesse um noticiário dentro de outro noticiário. Aliás, é assim que se olha para o ministério das Finanças: como um Governo dentro de outro Governo. Tratamento do tema e escolha de fontes não acompanham a tendência desenhada nos jornais portugueses para a cobertura dos 100 primeiros dias de governação. O novo ciclo anunciado pelo primeiro-ministro pode ter alguns reflexos na totalidade de textos relativos a esse período, mas se a referência for o conjunto de artigos noticiosos sobre finanças é difícil anunciar uma nova era. Porque a realidade política continua a exigir uma intervenção permanente das finanças. Porque o passado recente estruturado por uma difícil conjuntura financeira não pode ser subitamente apagado. Porque a imprensa generalista continua presa a um período de austeridade que vigorou de forma severa a partir de 2011, altura em que Portugal ficou sob o rígido comando do Programa de Assistência Económica e Financeira, não podendo a agenda 
mediática sofrer repentinamente uma revolução no modo como foi pensando o país político.

\section{Finanças: uma tematização em contraciclo}

Da mediatização na imprensa generalista diária dos 100 primeiros dias de governação do executivo socialista liderado por António Costa, sobressai uma cobertura noticiosa intensa (publicam-se em média 2,4 textos por dia), desenvolvida em textos de tamanho médio ou extenso, declinada maioritariamente pelo ângulo positivo ${ }^{1}$, feita em forma de notícia ${ }^{2}$, refletindo mais de metade dos textos acontecimentos previamente agendados pelos atores políticos. Apesar do esforço deste Governo em proclamar um novo ciclo político afastado do tópico da austeridade que havia dominado o discurso político dos anos precedentes, os jornalistas privilegiaram a tematização financeira e, quando o fizeram, houve um desvio de um certo padrão que a cobertura jornalística desse tempo instalou. Ano e meio depois do fim oficial do Programa de Assistência Económica e Financeira a Portugal, acordado em maio de 2011 por um período de três anos entre as autoridades portugueses, a União Europeia e o Fundo Monetário Internacional, a imprensa portuguesa continuou a encontrar nas finanças um frame persistente. Tal aconteceu porque o calendário a isso o obrigou, mas porque também os jornalistas não quiseram fazer desvios de rota.

As finanças foram, sem dúvida, o tópico mais presente nas notícias publicadas nos jornais portugueses a respeito dos 100 primeiros dias de governação socialista, reunindo 30,6 por cento dos textos noticiosos. A seguir, surgem a ação política do Governo (14,9 por cento); a saúde (9,4 por cento); o trabalho, a solidariedade e a segurança social ( 8,9 por cento); a educação $(8,4$ por cento); e o ambiente $(3,1)$. Os restantes temas reúnem percentagens pouco significativas, somando sempre menos de 25 textos nesses 100 dias.

Se o universo estudado apresenta mais de metade dos textos com títulos positivos, quando se isolam as peças que falam de finanças, essa percentagem desce para 37,8 e os títulos negativos crescem de 23,7 para 38,1 . Nota-se

1. Em termos percentuais, $53,1 \%$ dos artigos apresentam títulos positivos, $23,2 \%$ usam títulos neutros e 23,7 têm títulos negativos.

2. Em termos percentuais, $96,8 \%$ dos textos são notícias; 2,4 , entrevistas; 0,7 , perfis; 0,1 , reportagens. 
que a tematização financeira arrasta consigo um enfoque pessimista acerca da capacidade que o poder governativo terá em libertar-se dos anos de crise em que mergulhou a partir da segunda década do século XXI. Ainda que o discurso político insista em resgatar algum ânimo para um futuro mais auspicioso para os portuguesas, o discurso jornalístico mantém-se agarrado a um enfoque pouco confiante na capacidade que o Governo terá para fazer reverter o contexto de crise em que submergiu o país.

Gráfico 1. Distibuição por tema dos textos noticiosos publicados nos jornais generalistas portugueses

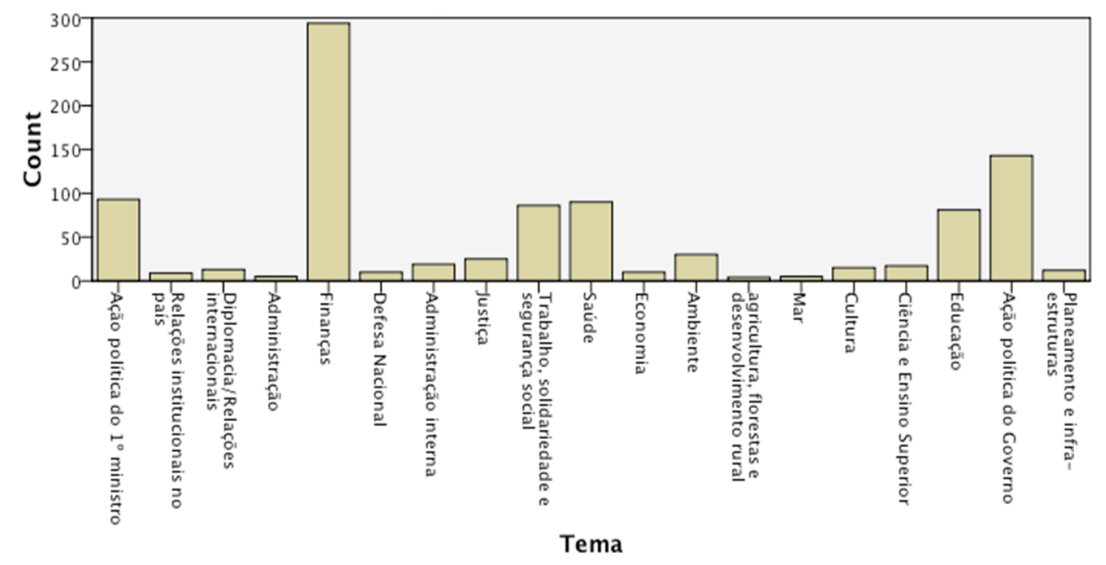

Apresentando-se em tempo de campanha eleitoral com um conjunto de promessas que garantia a reversão de algumas das decisões do Governo anterior, o primeiro-ministro António Costa contou nos primeiros 100 dias de Governo com alguns ministérios para o ajudar a cumprir o que prometera. Em termos globais, 11,4 por cento dos textos noticiosos refletem uma política que reverte deliberações políticas, havendo áreas mais proactivas do que outras. Os cinco ministérios que mais se salientaram a este nível foram os seguintes: Educação (35,8 por cento); Ambiente (35,3 por cento); Justiça (32 por cento); Negócios Estrangeiros $(17,6)$; e Trabalho, Solidariedade e Segurança Social (15,2 por cento). Aí, o ministério das Finanças reuniu uma percentagem de 2,1 por cento, dividindo-se os textos entre a apresentação de novas medidas e a gestão corrente. 
Em termos de agendamento, constata-se que 51,5 por cento dos textos noticiosos destes 100 dias de governação refletem acontecimentos previamente agendados pelos governantes. São eles que promovem ou participam em pseudo-eventos, a maior parte dos quais organizados em função da cobertura mediática que podem suscitar. Os restantes dividem-se entre aquilo que se pode calcular como sendo uma noticiabilidade criada pelos próprios jornais (uma parte reduzida, é certo) ou como correspondendo à gestão corrente da coisa pública (uma parte mais substancial). No entanto, o ministério das Finanças não acompanha aquilo que é o comportamento-padrão do Governo. Ao contrário da generalidade dos ministérios, quem se ocupa das Finanças normalmente não surge nos textos noticiosos enquadrado em eventos públicos. Esta situação apenas soma neste ministério 24,5 por cento dos textos. Em contrapartida, é dos ministérios mais ativos em promover conferências de imprensa ou em divulgar comunicados (16,7 por cento dos textos). É claro que, neste período, houve acontecimentos que contribuíram para fazer crescer a frequência registada a este nível, principalmente a apresentação do Orçamento do Estado feita aos jornalistas, a qual decorreu em dois dias de que resultaram dezenas de artigos nos jornais diários. Acima do ministério das Finanças, apenas se encontra o ministério da Educação que é muito produtivo em conferências de imprensa ou em comunicados. Outros ministérios que se salientam também a este nível são os seguintes: Trabalho, Solidariedade e Segurança Social (15,2 por cento); Ambiente (11,8 por cento); e Saúde (9 por cento).

\section{A força de um conjunto restrito de fontes oficiais na tematização das finan- ças}

Na cobertura noticiosa da governação do país, os jornais portugueses recorreram essencialmente a fontes oficiais. Se àquelas que apresentam traço humano (60 por cento), acrescentarmos os documentos oficiais ( 15,7 por cento), mais de três quartos das citações situam-se a este nível. É uma percentagem demasiado alta, deve reconhecer-se. Acerca das finanças, o primeiroministro fala menos do que na média global do universo estudado (regista-se quase metade das citações) e os responsáveis internacionais falam mais (quase o dobro). No que diz respeito aos deputados que, na média geral, reúnem 15 por cento das citações, quando o tema são as finanças essa percentagem sobe 
para 21,7 por cento. As fontes profissionais mantêm uma certa distância desta tematização. Mesmo os sindicatos que, em média, apresentam uma percentagem de 11,9 por cento das citações, neste âmbito esse valor desce para 6,6 por cento. Nas fontes não-humanas, registam-se valores muito próximos daqueles que se encontram no universo dos textos considerados. Excepto nos documentos oficiais. Enquanto que a nível geral esse tipo de texto soma 10 por cento, aqui esse valor é de 15,7 por cento.

Quando se trata de finanças, quem mais fala desta matéria é o respetivo ministro e são os seus secretários de Estado. Anunciando desde o início do seu mandato um novo tempo político, o primeiro-ministro fez um esforço para não falar (muito) sobre este tópico. Tendo vivido um longo período vergados a uma política de austeridade, os deputados têm mais dificuldade em desprender-se deste tema. Também o calendário político não foi favorável a outras tematizações. Nos primeiros 100 dias de governação, discutiu-se um programa de Governo onde a crise foi sempre uma sombra omnipresente, abriu-se uma crise sistémica no banco Banif e apresentou-se e fez-se aprovar o Orçamento de Estado. Esta agenda muito presa aos números foi, em boa parte, responsável por um noticiário que se encheu de declarações de teor financeiro. 


\begin{tabular}{|c|c|c|}
\hline $\begin{array}{l}\text { Tipo de Fontes } \\
\text { de Informação }\end{array}$ & $\begin{array}{l}\text { Fontes de } \\
\text { Informação }\end{array}$ & $\begin{array}{l}\text { Percentagem } \\
\text { de citações }\end{array}$ \\
\hline \multirow{8}{*}{ Oficiais } & Primeiro-ministro & 3.5 \\
\hline & Ministros & 16.2 \\
\hline & Secretários de Estado & 7.5 \\
\hline & Presidente da República & 0.1 \\
\hline & Responsáveis internacionais & 4.6 \\
\hline & Deputados & 21.7 \\
\hline & Assessores & 0.1 \\
\hline & Outros & 5.3 \\
\hline \multirow{7}{*}{ Profissionais } & Justiça & 1.3 \\
\hline & Economistas/empresários/gestores & 1.8 \\
\hline & Militares & 0.1 \\
\hline & Académicos/investigadores & 0.1 \\
\hline & Assessores & 0.4 \\
\hline & Outros & 1.2 \\
\hline & Sindicatos /Associações & 6.6 \\
\hline Não profissionais & Militantes de partidos & 0.9 \\
\hline \multirow{6}{*}{ Não humanas } & Documentos Oficiais & 15.7 \\
\hline & Documentos especializados & 1.3 \\
\hline & Comunicados & 2.5 \\
\hline & Media generalistas & 4.1 \\
\hline & Media especializados & 0.6 \\
\hline & Sites & 0.6 \\
\hline Cidadãos & desconhecidos & 0.1 \\
\hline Sem identificação & Não sei quem/o que são & 3.2 \\
\hline
\end{tabular}

Quadro 1. Distribuição das fontes citadas nos artigos de finanças (universo de 677 fontes)

Olhando para os ministérios, constata-se uma enorme prudência de todos em relação ao tema das finanças. Por norma, ministros e secretários de Estado evitam este tópico que se concentra, como seria expectável, no ministério das Finanças. Enquanto que a nível global este ministério reúne uma percentagem de 12,4 por cento, em assuntos financeiros a percentagem sobe para 34 por cento. Triplica. Os mais citados são o ministro das Finanças e o secretário de Estado dos Assuntos Fiscais, embora a equipa seja composta por mais 
três secretários de Estado que, no entanto, neste período revelam-se parcos na palavra mediática. Refira-se, porém, que não se nota uma inclinação desta equipa pela promoção de pseudo-acontecimentos. Sente-se a maior parte das vezes que há uma agenda mediática que coloca no topo da atualidade noticiosa assuntos financeiros, procurando ativamente declarações políticas sobre os assuntos que se multiplicam neste campo. As fontes aqui são mais reativas do que proactivas e movimentam-se mais à defesa do que ao ataque.

\begin{tabular}{ll}
$\begin{array}{l}\text { Fontes do Governo } \\
\text { (Primeiro Ministro e Ministérios) }\end{array}$ & $\begin{array}{l}\text { Percentagem } \\
\text { de citações }\end{array}$ \\
\hline Primeiro Ministro & 4 \\
Presidência e Modernização Administrativa & 0.3 \\
Finanças & 34 \\
Defesa Nacional & 0.3 \\
Administração Interna & 0.1 \\
Justiça & 0.3 \\
Adjunto & 0.3 \\
Trabalho, Solidariedade e Segurança Social & 1.2 \\
Saúde & 0.6 \\
Planeamento e Infraestrutura & 0.4 \\
Economia & 0.4 \\
Ambiente & 0.6 \\
Cultura & 0.3 \\
Ciência & 0.6 \\
Educação & 1 \\
Mar & 0.1 \\
Vários ministros & 1.3 \\
Não sei & 0.9 \\
Fontes que não são governantes & 53.2 \\
\hline
\end{tabular}

Quadro 2: Distribuição dos ministérios citados nos artigos de finanças (universo de 677 fontes)

Há alguns aspectos, porém, em que não se notam grandes variações. Na geografia, no sexo e na identificação, as fontes citadas em assuntos de finanças são idênticas àquelas que os jornalistas usam noutros tópicos. A este nível, as fontes de informação são hegemonicamente nacionais e falam desenraizadas 
de um ponto específico. Apresentam-se com uma escala nacional. Quase 90 por cento dos interlocutores ouvidos pelos jornalistas são assim. Quando falam a partir do estrangeiro, situam-se num ponto europeu, principalmente em Bruxelas. No universo em estudo, as fontes europeias reúnem 3,9 por cento das citações; quando o tema são as finanças, esse número cresce para 6,5 por cento. Em relação ao tipo de fontes a que recorrem os jornalistas e à respetiva identificação, os assuntos das finanças seguem o padrão do conjunto de artigos em estudo. Preferem-se as pessoas aos documentos (75,3 por cento das fontes têm o traço humano) e privilegiam-se os homens às mulheres (por cada mulher ouvida citam-se quatro homens). Cerca de 85 por cento das fontes são identificadas, o que é indubitavelmente uma percentagem alta para o jornalismo político, havendo uma reduzidíssima percentagem de fontes anónimas (menos de um por cento). As restantes são fontes não identificadas, ou seja, fontes cuja proveniência é explicitada, embora seja ocultada a sua identidade.

\section{Notas Finais}

O tempo da política é um tempo de expectativas, que se renova nos momentos em que o voto abre um novo ciclo político que se estrutura com diferentes protagonistas. O designado 'estado de graça', que caracteriza os primeiros tempos de qualquer Governo, é certamente um período de observação diligente, crítica mas também auspiciosa, sendo os jornais um importante periscópio para esse trabalho. Foi exatamente isso que procurámos aqui fazer, elegendo os 100 primeiros dias do XXI Governo Constitucional como linha diacrónica em estudo. Trata-se de um ciclo político autónomo em que se apresenta ao sistema político e à opinião pública um novo cenário Governativo com figuras políticas que procuram constituir-se como atrações de um sistema que lutará por durar uma legislatura. Ao nível do enquadramento noticioso, este intervalo de tempo constrói uma determinada tematização, seleciona um conjunto de fontes e escolhe determinados focos que certamente ajudarão a construir uma imagem do Governo e dos seus respetivos governantes.

Do estudo aqui realizado sobressai uma mediatização algo diversificada e declinada num tom maioritariamente positivo, mas ainda com uma forte incidência na tematização das finanças, correspondendo isso a uma informação que funciona numa espécie de contraciclo relativamente àquilo que é a cobertura noticiosa da restante atividade do Governo. É como se houvesse um noti- 
ciário dentro de um outro noticiário, tal como as finanças parecem constitui-se como um Governo dentro do Governo. Seguindo a atividade governativa através da imprensa generalista portuguesa, constata-se uma opção clara por um agendamento noticioso centrado nas finanças que obtiveram 30,6 por cento dos textos noticioso. A seguir, surgem a saúde (9,4 por cento); o trabalho, a solidariedade e a segurança social ( 8,9 por cento); a educação $(8,4$ por cento) e o ambiente ( 3,1 por cento), que reúnem percentagens envergonhadas quando comparadas com o tema predominante. $\mathrm{O}$ valor algo hegemónico das finanças justifica-se pela atualidade política do momento (apresentação do Programa e do Orçamento, por um lado, e crise no Banco Banif, por outro), mas também deve ser lida à luz de um noticiário que se habitou a ler a política governativa com um olhar centrado das finanças. Aliás, seguindo a identificação daqueles que assinam as peças analisadas, sobressai um cruzamento de jornalistas de política com jornalistas da área económica que, nos últimos anos, foram desviados para a cobertura daquilo que se fazia a nível executivo, mas que continuaram a transportar para os seus textos uma permanente preocupação com os números. O início de uma nova legislatura e o aparecimento de um elenco governativo não conseguiram mudar aquilo que se enraizou como um frame privilegiado na cobertura noticiosa da política: as finanças. Este enfoque é apresentada nos jornais portugueses como a principal fonte de desenvolvimento do país, dos seus recursos, das suas decisões políticas internas e internacionais.

Os valores-noticia em torno dos quais se desenvolve a dinâmica noticiosa, na imprensa generalista portuguesa, promove um certo equilíbrio entre a autenticidade, a negatividade e a personalização. A personalização evidencia-se nos casos em que o sistema político já reconhece os protagonistas, criandose um ciclo vicioso nos primeiros 100 dias, de modo a evidenciar o que já é expectável vir a ser reconhecido pela opinião pública. A mensagem política da imprensa é maioritariamente centrada na figura do primeiro-ministro, exceto quando os assuntos são finanças, representados sobretudo através do seu Ministro Mário Centeno e do seu Secretário de Estado dos Assuntos Fiscais (apesar de serem três os Secretários de Estado). Na verdade, numa nova fase do ciclo governativo, a imprensa portuguesa não pontua todos os protagonistas políticos ora porque não estão envolvidos em temas que se colocam no topo dos alinhamentos noticiosos, ora porque ainda não são reconhecidos pelos sistemas político/mediático. 
Se nem todos os governantes têm igual acesso à palavra mediática na imprensa generalista, há dois atores que se distinguem nesse período: os deputados e os sindicatos. A substancial visibilidade dos primeiros faz ressaltar indiretamente o novo ciclo que se anunciara. O poder executivo não mais se exerce de forma solitária em gabinetes ministeriais, mas em permanente negociação com o poder legislativo para se encontrar os consensos necessários que possibilitem a governação. Há aqui uma nova experiência governamental e parlamentar, um novo equilíbrio de forças entre os partidos de esquerda no Parlamento (além do Partido Socialistas -PS, o Bloco de Esquerda- BE, a Coligação Democrática Unitária - CDU, e o partido Pessoas, Animais e Natureza - PAN), que introduz uma original dinâmica política precisamente no ano em que se comemoraram, em Portugal os 40 anos da Constituição da República Portuguesa.

Em termos noticiosos, outros dos pontos relavantes deste período é a evidente capacidade de provocar nos media um agendamento declinado num registo positivo, criando-se assim um período de tréguas noticiosas que poderá também ser estendido aos vários atores envolvidos no processo noticioso político (jornalistas, editores, políticos, assessores, opinião pública). Este estado de graça induzido entre os vários dinamizadores do espaço público noticioso abre a porta a novas identidades e a novos modos de atuação que podem revelar-se permanentes ao longo dos meses, e anos vindouros, de governação. É nesses traços permanentes de representação do Governo que os media refletem que começa a definir-se uma imagem política forte ou frágil perante a opinião pública.

\section{REFERÊNCIAS BIBLIOGRÁFICAS}

Adam, S. \& Maier, M. (2010). Personalization of politics. A critical review and agenda for research. In C. T. Salmon (Ed.), Communication yearbook 34 (pp. 213-257). New York: Routledge.

Correia, J. C. (2011). O admirável mundo das notícias: teorias e métodos. Covilhã: LabCom Books.

Espírito Santo, P. \& Costa, B. F. (2016). Party newspapers perspectives and choices: a comparative content analysis view. Sage Open, (April-June 2016), 6(2): 1-15. 
Ferreira, G. B. (2011). Qual o papel do jornalismo nas democracias contemporâneas: jornalismo público e deliberação política. Exedra Comunicação nas Organizações, (9): 79-92.

Lippmann, W. (1922). Public opinion. USA: Greenbooks Publications (2010).

Harwood, R. C. (2004). In search of authenticity: public trust and the news media. National Civic Review, 93(3): 11-15.

Lopes, F. (2015). Jornalista, profissão ameaçada. Lisboa: Alêtheia Editores.

Hindman, M. (2012). Personalization and the future of news. EUI Working Paper RSCAS 2012/56 (pp. 1-15). Italy: European University Institute. http://hdl.handle.net/1814/24296

Hopmann, D. N. (2014). Politicians, parties and political candidates in the news media. In C. Reinemann (Ed.), Political Communication, vol. 18 (pp. 389-408). Berlin: Mouton de Gruyter.

Hopmann, D. N.; Elmelund-Præstekær, C.; Albæk, E.; Vliegenthart, R. \& Vreese, C. H. (2012). Party media agenda-setting: how parties influence election news coverage. Party Politics, March, 18: 173-191.

Maia, R. (2008). Mídia e deliberação. Rio de Janeiro: Editora FVG.

Mortensen, P. B.; Green-Pedersen, C. \& Thesen, G. (2015). Is the news all negative? Trends in the political tone of the news. CAP conference - The Annual Comparative Agendas Conference. Lisbon (22 June 2015). Draft paper.

Neuman, W. R. (1986). The paradox of mass politics: knowledge and opinion in the american electorate. Cambridge: Harvard University Press.

Negroponte, N. (1995). Being digital. New York: Alfred A. Knopf.

Norris, P. (2000). Virtuous circle: political communications in post-industrial democracies. Cambridge: Cambridge University Press.

Norris, P. (2001). Digital divide: civic engagement, information poverty, and the internet worldwide. Cambridge: Cambridge University Press.

Norris, P. (2011). Political communication. In D. Caramani (ed.), Comparative politics (pp. 352-370). Oxford. Oxford University Press.

Patterson, T. (1997). The news media: an effective political actor?. Political Communication, 14: 445-455. 
Santos, R. (2006). A negociação entre os jornalistas e as fontes. Coimbra: Minerva Editora.

Tarde, G. (1989). L'opinion et al foule. Paris: PUF (1901).

Thesen, G. (2013). When good news is scarce and bad news is good: government responsibilities and opposition possibilities in political agendasetting. European Journal of Political Research: 364-389. 


\title{
Papéis dos usuários na circulação jornalística em sites de rede social: os atentados de Paris no Twitter
}

\author{
Gabriela Zago \\ MIDIARS \\ E-mail: gabrielaz@gmail.com
}

\begin{abstract}
RESUMO
$\mathrm{O}$ artigo aborda os papéis dos usuários na circulação e na recirculação jornalística em torno de um acontecimento específico: os atentados ocorridos em $\mathrm{Pa}$ ris no final de 2015. O estudo é operacionalizado a partir da identificação de elementos da estrutura da rede em torno das postagens sobre o acontecimento, em especial em termos de identificação dos

atores principais e dos diferentes papéis exercidos pelos usuários que tuitaram sobre o evento. Os resultados apontam para um papel proeminente da imprensa tradicional no sentido de dar credibilidade à informação repassada, combinado a um papel fundamental por parte de usuários comuns no sentido de espalhar a informação.
\end{abstract}

Palavras-chave: circulação; recirculação; jornalismo em rede; análise de redes sociais; Twitter.

Data de submissão: 25-04-2016. Data de aprovação: 23-10-2016.

A Revista Estudos em Comunicação é financiada por Fundos FEDER através do Programa Operacional Factores de Competitividade - COMPETE e por Fundos Nacionais através da FCT - Fundação para a Ciência e a Tecnologia no âmbito do projeto Comunicação, Filosofia e Humanidades (LabCom.IFP) UID/CCI/00661/2013. 


\title{
Users roles on news circulation on social network sites: the Paris attacks on Twitter
}

\begin{abstract}
In this article, we discuss the roles that users played on the news circulation and recirculation about a specific event: the attacks that took place in Paris at the end of 2015. For that end, we identified the elements of the network structure around the posts about the event, especially by

rent roles played by the users that tweeted about the event. Our results show a prominent role of traditional media in the sense of giving credibility to the information that was being retweeted, combined with an essential role by ordinary users in the sense of spreading the information.
\end{abstract} identifying the key actors and the diffe-

Keywords: circulation; recirculation; network journalism; social network analysis; Twitter.

\section{INTRODUÇão}

$\mathrm{D}$

IFERENTES tipos de usuários exercem diferentes papéis na circulação de informações pelo Twitter. Essas diferenças se tornam mais evidentes na cobertura de grandes acontecimentos, em que diferentes atores - jornais, órgãos oficiais, usuários comuns, testemunhas do fato - postam e respostam suas impressões em sites de rede social. Nesses casos, mesmo um simples retweet representa um ato relevante na medida em que provê acesso a outras pessoas à informação sendo reproduzida e serve como alerta de que algo aconteceu.

Diante deste contexto, o presente trabalho estuda a circulação e a recirculação jornalística em torno de um acontecimento específico: os ataques ocorridos em Paris no final de 2015. O objetivo é discutir os diferentes papéis desempenhados pelos usuários na circulação de informações sobre o evento no Twitter. Para tanto, utiliza-se dos pressupostos da análise de redes para a identificação desses papéis.

Em um primeiro momento, discute-se a circulação e a recirculação de notícias no contexto de um jornalismo em rede. Na sequência, o foco recai sobre os papéis dos usuários na circulação. Após, discute-se o estudo das redes sociais para a compreensão de estruturas e dinâmicas associadas à circulação de 
informações. Por fim, apresenta-se o caso estudado, os atentados ocorridos em Paris no final do ano de 2015, e discutem-se os papéis identificados na circulação jornalística em torno do mesmo.

\section{Circulação E RECIRCUlaÇão NO JORNALISMO EM REDE}

Heinrich (2011) propõe o modelo de um jornalismo em rede para explicar a complexa relação entre diferentes fontes, produtores e disseminadores de informação do jornalismo contemporâneo. Usuários, ao lado de empresas jornalísticas, podem contribuir com o processo jornalístico, no papel de atores do jornalismo em rede (Heinrich, 2011; Russell, 2011).

O jornalismo em rede se insere em um contexto de mídia espalhável (Jenkins, Ford \& Green, 2013), em que não mais a mídia tradicional detém o monopólio exclusivo de pôr em circulação conteúdos. Para os autores,

À medida em que o material se espalha, ele se refaz: tanto literalmente, através das várias formas de amostragem e remixagem, quanto figurativamente, a partir de sua inserção em conversas em curso ou através de várias plataformas. Esse processo contínuo de reaproveitamento e recirculação está eliminando as divisões percebidas entre produção e consumo (Jenkins, Ford \& Green, 2013, p.27, tradução nossa) ${ }^{1}$.

Postagens sobre um acontecimento podem circular e recircular em espaços públicos mediados como os sites de rede social. Sites de rede social são espaços da web que permitem a articulação de redes sociais, a partir da possibilidade de criar um perfil, adicionar contatos, e interagir com esses contatos através de um fluxo de conteúdos em comum (Ellisson \& boyd, 2013).

Diante dos sites de rede social, a própria maneira como os usuários interagem com o conteúdo se modifica:

$\mathrm{O}$ receptor passivo do passado tornou-se o usuário ativo que interage com as notícias, faz links para elas, conta a amigos, faz críticas. Em suas páginas no Facebook ou no Twitter, os usuários

1. Tradução de: "As material spreads, it gets remade: either literally, through various forms of sampling and remixing, or figuratively, via its insertion into ongoing conversations and across various platforms. This continuous process of repurposing and recirculating is eroding the perceived divides between production and consumption"(p. 27) 
podem postar links para suas notícias favoritas ou engajar-se criticamente com o conteúdo fornecido pela organização jornalística (Heinrich, 2011, p. 169, tradução nossa) ${ }^{2}$.

A circulação jornalística em sites de rede social pode ser tanto suscitada pelo próprio jornal, que, como parte de suas estratégias de comunicação, utiliza perfis em sites de rede social para divulgar notícias (Belochio, 2012; Zago \& Belochio, 2014), como também pelos interagentes, que contribuem para circular e recircular notícias. A recirculação estaria, assim, vinculada à produção de conteúdos que se conectam, os quais, em conjunto, contribuem para a construção e a compreensão do acontecimento. No contexto da circulação jornalística, a recirculação pode ser vista como uma forma de os interagentes participarem do processo jornalístico, ao colocar novamente em circulação conteúdos originalmente distribuídos pelos jornais em seus canais tradicionais de circulação (Zago, 2014). Ainda que dois termos estejam sendo utilizados, a recirculação é aqui entendida como um desdobramento da etapa de circulação jornalística, sendo, portanto, parte integrante da mesma.

Sites de rede social são ambientes propícios para se observar a circulação e a recirculação jornalística na medida em que os rastros desses processos se tornam visíveis ao se acompanhar as postagens feitas pelos usuários. O relatório do Pew Research State of News Media (Mithcell \& Page, 2014, p.5-6, tradução nossa) aponta que "em sites sociais e mesmo em muitos dos sites de notícias nativos digitais, as notícias estão misturadas com outros tipos de conteúdos - as pessoas esbarram nelas quando estão fazendo outras coisas" ${ }^{3}$. Segundo os autores, isso possibilita que as notícias atinjam mais pessoas, mas também significa que a circulação está cada vez menos nas mãos dos veículos. Ainda, conforme o relatório, "Apenas cerca de um terço das pessoas que recebem notícias no Facebook seguem um veículo jornalístico ou jornalista.

2. Tradução de: "The passive receiver of the past has become the active user who engages with stores, linkes to them tells friends, deliver critiques. On their Facebook pages or Twitter accounts, users can post links to their favorite News stories or critically engage with content provided by news organization" (p. 169).

3. Tradução de: "On social sites and even many of the new digital-only sites, news is mixed in with all other kinds of content - people bump into it when they are doing other things" (p.5-6). 
Ao invés disso, as notícias são compartilhadas por amigos em suas redes" (Mitchell \& Page, 2014, p.6, tradução nossa) ${ }^{4}$.

Nesse sentido, o Twitter é um ambiente particularmente profícuo para se observar a relação entre sites de rede social e jornalismo. Para Cha et al (2012, p.1), "o Twitter surge como um meio popular para discutir eventos noticiosos que estão ocorrendo ao redor do mundo" 5 . Bruns e Burgess (2012) apontam três usos do Twitter em relação a eventos jornalísticos: a) narração de eventos em tempo real, b) discussão de eventos de interesse noticioso e c) função ambiente do Twitter como espaço para comentários mais amplos sobre eventos atuais.

Os autores apontam as hashtags e a busca do Twitter como elementos fundamentais que propiciam que qualquer pessoa possa acompanhar uma determinada discussão sem precisar seguir alguém em específico. O retweet também desempenha um papel essencial nesse cenário. Mesmo que o propósito de um retweet varie, "ele reflete um entendimento implícito do funcionamento da estrutura de rede do Twitter, reconhecendo que uma mensagem original isolada atinge apenas um número limitado de usuários, e que repassá-la amplia a sua visibilidade" (Bruns \& Burgess, 2012, p.3) ${ }^{6}$.

$\mathrm{O}$ retweet, assim, exerce o papel de ampliar a visibilidade de uma mensagem para além da rede do criador da mensagem original (Recuero \& Zago, 2012; Zago \& Bastos, 2013). Ao passar mensagens de uma rede a outra, usuários que retuitam atuam como intermediários da comunicação (Bruns \& Burgess, 2012).

A recirculação jornalística no Twitter, nesse sentido, pode ser observada particularmente no retweet, na medida em que, ao retuitar, o usuário subscreve a um determinado conteúdo ou opinião, reproduzindo-o para sua rede pessoal de seguidores. Mas outras ferramentas típicas do Twitter também podem ser utilizadas para a circulação de informações, como no caso da menção. En-

4. Tradução de: "Only about a third of people who get news on Facebook follow a news organization or individual journalist. Instead, stories get shared from friends in their networks" (p.6).

5. Tradução de: "Twitter has emerged as a popular medium for discussing noteworthy events that are happening around the world."

6. Tradução de: "they reflect implicit understanding of Twitter's network structure, recognizing that unaided original messages will reach only a limited number of users, and that further passing-along amplifies their visibility" (p.3). 
quanto o retweet propicia a visibilidade de um determinado conteúdo, a menção confere destaque a um determinado usuário (Bruns \& Burgess, 2012).

\section{Papeis dos usuários na CirculaÇÃo}

Diferentes papéis podem ser exercidos pelos usuários na circulação de informações. Zago, Recuero e Bastos (2015) identificaram três papéis principais na circulação de informações sobre os protestos de junho de 2013 no Brasil: ativistas, celebridades e imprensa. Enquanto ativistas fazem uma grande quantidade de retweets e contribuem para espalhar a informação, celebridades são aqueles usuários que recebem muitos retweets e menções em função de suas postagens sobre os protestos. Já a imprensa tem o papel de organizar a discussão e reportar o que está acontecendo, também vindo a receber muitos retweets de outros usuários (em especial daqueles do grupo de ativistas).

Papéis análogos aos de celebridades e ativistas podem ser exercidos por usuários que servem de conectores ( $h u b s$ ) e de pontes (bridges) para a circulação de informações. Para Smith et al (2014), enquanto os usuários que atuam como conectores se destacam por serem bastante citados e compartilhados, os usuários que atuam como pontes possuem o papel fundamental de interligar a rede. "Eles exercem o papel importante de passar informações de um grupo para outro. Esses usuários são necessários para fazer com que uma mensagem se torne "viral"' (Smith et al, 2014, p.7, tradução nossa) ${ }^{7}$. Os papéis de ponte e conector, entretanto, não são fixos; eles são circunstanciais e variam conforme o tipo de assunto que está sendo discutido e o recorte realizado.

Ao observar os fluxos de informações no Twitter em torno de grandes e pequenos acontecimentos, Cha et al (2012) identificaram três papéis principais no espalhamento da informação: mídia de massa, usuários comuns (grassroots) e especialistas (evengelists). Enquanto o primeiro grupo reúne os veículos de imprensa, o grupo de especialistas reúne líderes de opinião, políticos e celebridades. O restante dos usuários integra o grupo de usuários comuns. No estudo dos autores, entretanto, esses papéis foram observados em termos de potencial de espalhamento da informação, medido através da audiência potencial atingida na rede. Assim, enquanto a mídia de massa pode atingir uma

7. Tradução de: "They play the important role of passing information from one group to another. These users are often necessary to cause a message to 'go viral'." (p. 7) 
grande audiência (muitos seguidores), os perfis dos grandes veículos normalmente não seguem outros usuários. Os usuários comuns não são seguidos por uma grande quantidade de usuários, mas possuem uma grande presença na rede em termos quantitativos. Os especialistas, por sua vez, são socialmente conectados e tomam parte ativamente na circulação de informações, atuando como líderes de opinião. Ainda que a mídia de massa seja importante na produção de conteúdo, especialistas e usuários comuns são fundamentais para o espalhamento da informação (Cha et al, 2012).

Por fim, Lehmann et al (2013) abordam um papel específico: o curador de acontecimentos. Esse papel teria dois desdobramentos: o curador focado em um tópico e o curador não focado em um tópico específico. A curadoria focada é exercida por usuários que abordam um tema específico em seus perfis. A curadoria não especializada é exercida por usuários que postam sobre assuntos diversos, mas são reconhecidos por seu papel de filtro de informações.

Ainda que diferentes papéis possam ser exercidos na circulação de notícias nas mídias sociais, é importante ressaltar que nem todos os usuários participam ativamente ou de forma visível (Lehmann et al, 2013). Assim, na circulação, só é possível observar os rastros visíveis deixados por aqueles que ativamente participaram. A grande maioria dos usuários apenas consome $o$ conteúdo, sem participar de alguma forma visível ${ }^{8}$.

Os papéis exercidos pelos usuários na circulação de informações podem ser identificados a partir das propriedades estruturais das redes.

\section{O ESTUDO DAS REDES SOCIAIS: ESTRUTURA E DINÂMICAS}

Em termos estruturais, uma rede social é composta por atores e suas conexões (Recuero, 2009). Os atores são os nós da rede, indivíduos ou grupos que estão conectados a outros por alguma relação em comum. Por exemplo, em uma redação jornalística, cada profissional envolvido na produção de notícias pode ser considerado um nó, e as diferentes relações trabalhistas representam as conexões.

8. O Twitter mostra estatísticas de visualização de cada tweet, o que permite ter uma noção da proporção entre o número de visualizações de uma mensagem e a quantidade de interações recebidas (curtidas e retweets). Entretanto, esse número apenas é exibido para o criador original da mensagem, não sendo possível obter esses dados no caso de retweets. 
O estudo das redes sociais pode ser operacionalizado através da análise de sua estrutura ou de suas dinâmicas (Recuero, Bastos \& Zago, 2015). Ao olhar para a estrutura, o foco recai nas características da rede em um determinado momento. Analisa-se a rede de forma estática, como um retrato do que ocorreu. Ao olhar para as dinâmicas, busca-se observar os comportamentos coletivos que podem ser observados numa determinada rede social. Analisase como a rede evolui no tempo, na medida em que novos atores e novos nós passam a fazer parte da mesma, alterando recursivamente sua estrutura e estabelecendo novas dinâmicas.

Embora se reconheça que o estudo das dinâmicas das redes seja mais rico e frutífero, neste trabalho o foco recai no estudo da estrutura de uma rede em específico.

Para o estudo da estrutura das redes sociais, um dos métodos que pode ser utilizado é a Análise de Redes Sociais (Recuero, Bastos \& Zago, 2015). A Análise de Redes Sociais é um conjunto de métricas e técnicas de pesquisa utilizado para descrever a relação entre atores e suas conexões (Degenne \& Forsé, 1999; Scott, 2013; Wasserman \& Faust, 1994). A Análise de Redes Sociais pode ser empregada para estudar inúmeras configurações relacionais entre atores e nós, como ao se estudar a propagação de doenças, a rede formada entre uma empresas e seus fornecedores, ou a associação entre diversos atores em torno de um tema em um site de rede social.

As métricas permitem estudar estruturalmente a rede como um todo ou o papel de cada um de seus nós. Neste trabalho, utiliza-se em especial uma métrica para analisar a rede como um todo (modularidade) e duas para o estudo dos nós (grau de conexão e grau de intermediação).

a) Modularidade: A modularidade é uma medida de rede, de agrupamento e vizinhança dos nós. Nós incluídos em um "módulo" têm conexões mais fortes entre si do que com os demais. Cada módulo, assim, reflete um grupo de nós interconectados.

b) Grau de conexão: O grau de conexão refere-se à "força" da conexão entre dois nós. O grau de conexão é uma medida numérica, normalmente referida como o somatório de todas as conexões existentes entre A e B. O grau pode ser desdobrado em conexões recebidas (indegree) e conexões enviadas (outdegree). Assim, um jornal pode receber men- 
ções de outros jornais (conexões recebidas) ou fazer menções a outros veículos (conexões enviadas).

c) Grau de intermediação: O grau de intermediação (betweeness) é outra medida de centralidade do nó e indica o número de vezes que um nó serve de ponte entre outros grupos de nós.

Grau de conexão e grau de intermediação são duas métricas utilizadas para identificar a centralidade de determinados atores em uma rede (Freeman, 1979). Pelo grau de conexão, o nó com maior centralidade seria aquele com o maior número de conexões. Em oposição aos nós centrais, estariam os nós periféricos, com baixo grau de conexão. Pelo grau de intermediação, os nós centrais seriam aqueles que mais serviriam de ponte entre outros nós, conectando outros nós através do menor caminho. Para Freeman (1979, p.221, tradução nossa), "um ponto que se situa nos caminhos de comunicação entre outros pontos exibe um potencial para controlar a comunicação" 9 .

Essas métricas podem ser utilizadas para analisar a estrutura de uma rede e identificar possíveis papéis desempenhados pelos usuários na circulação de informações.

\section{A estrutura da rede em torno dos atentados de Paris}

No dia 13 de novembro de 2015, por volta das 21:45 (hora local), surgiram as primeiras informações de que um tiroteio teria acontecimento em uma área com vários bares e restaurantes em Paris. Pouco tempo depois, também foram reportadas explosões do lado de fora do estádio onde estava acontecendo uma partida de futebol entre França e Alemanha, que contava com a presença do presidente da França, François Hollande. Além disso, também foram reportados tiros no Bataclan, arena de shows onde uma banda norte-americana estava se apresentando (Alter, 2015).

O estudo parte de um recorte aleatório de 10.000 tweets contendo os termos "Paris" e "attacks". Esses 10 mil tweets foram feitos num intervalo de apenas 3 minutos, o que representa mais de 3 mil tweets por minuto contendo esses dois termos nos momentos que se seguiram aos atentados. Essa intensa

9. Tradução de: "a point that falls on the communication paths between other points exhibts a potential for control of their communication" (p.221) 
atividade demonstra o quanto o assunto ainda estava efervescente no momento da coleta de dados.

Os dados foram obtidos através do uso do NodeXL (que se utiliza da API de busca do Twitter). Os tweets foram feitos no dia 13/11/2015, entre 23:57 e 23:59 (hora local), portanto, cerca de duas horas após as primeiras notícias de que ataques estariam acontecendo em Paris.

$\mathrm{Na}$ rede analisada, a unidade de análise são as conexões estabelecidas através de tweets. Há uma conexão quando o usuário A menciona ou retuita o usuário $B$ em um tweet. A rede é direcionada, ou seja, uma menção de A para B não significa necessariamente que B mencionará $\mathrm{A}$. Com isso, é possível identificar nós centrais e diferentes papéis exercidos na circulação de informações. Esses dados foram analisados usando as ferramentas da Análise de Redes Sociais, de modo a identificar os diferentes papéis desempenhados pelos usuários do Twitter na circulação jornalística em torno dos atentados de Paris de 2015.

O grau de conexão indegree foi a métrica utilizada para identificar os atores que receberam mais atenção e foram mais mencionados e referenciados por outros usuários.

O grau de intermediação foi a métrica considerada para identificar os atores que serviram de ponte para conectar a rede (ao retuitar mais de uma fonte, por exemplo).

Já o grau de conexão outdegree foi utilizado para identificar os atores que estabeleceram mais conexões com outros usuários na rede, ou seja, que fizeram mais de um retweet ou mencionaram mais de um ator em uma mesma mensagem.

A Tabela 1 lista os atores com maior grau de conexão indegree, ou seja, que receberam mais retweets ou menções de outros usuários. 


\begin{tabular}{llllll}
$\#$ & perfil & grau & $\#$ & perfil & grau \\
\hline 1 & @bbcbreaking & 2025 & 11 & @jimchapman & 159 \\
2 & @ap & 781 & 12 & @ afp & 130 \\
3 & @ potus & 463 & 13 & @ cnni & 129 \\
4 & @whitehouse & 397 & 14 & @ washingtonpost & 124 \\
5 & @ breakingnews & 307 & 15 & @ histipics & 109 \\
6 & @ skynews & 214 & 16 & @ newsweek & 99 \\
7 & @ cnnbrk & 201 & 17 & @ thedailybeast & 90 \\
8 & @ nytimes & 181 & 18 & @ chilaaq & 77 \\
9 & @michaelh992 & 174 & 19 & @ peterallenparis & 73 \\
10 & $@$ cnn & 172 & 20 & @ cbsnews & 73 \\
\hline
\end{tabular}

Tabela 1. Atores com maior grau de conexão indegree no recorte.

Dentre os 10 primeiros perfis, é possível identificar veículos jornalísticos (@ap, @skynews, @nytimes, @cnn) e perfis especiais voltados para últimas notícias (@bbbreaking, @breakingnews, @cnnbrk). A própria CNN aparece duas vezes na lista, com seu perfil principal e com a versão para últimas notícias. Além dos veículos, também há a presença do perfil do presidente dos Estados Unidos (@ potus)e da autoridade central daquele país (@ whitehouse) e o perfil de um analista geopolítico (@michaelh992, perfil de Michael Horowitz). Em comum entre esses perfis está o fato de que a maior parte possui uma quantidade considerável de seguidores (quatro desses perfis estão na lista dos 100 perfis com mais seguidores no mundo ${ }^{10}$, e ao todo oito estão dentre os 500 mais populares do mundo, com pelo menos 4 milhões de seguidores cada).

Dentre esses dez atores, é possível identificar sete veículos de comunicação (incluindo três perfis dedicados exclusivamente para últimas notícias), duas fontes oficiais norte-americanas (o presidente dos Estados Unidos, @ potus, e o governo dos Estados Unidos, @whitehouse) e um analista político (@michaelh992). É importante destacar o papel dos veículos de imprensa neste caso, na medida em que dos 10 mil tweets coletados no período, 20\% desse total representa retweets à @bbcbreaking. Somente esses 10 atores

10. @ cnnbrk aparece na posição 19, @nytimes na posição 34, @ cnn na posição 40, e @bbcbreaking na posição 49 conforme o ranking do Twitter Counter (Disponível em http://twittercounter.com/pages/100. Acesso em 17 fev. 2016). 
centrais representam quase metade (4.915) do total de conexões identificadas (10.647).

O cenário é um pouco diferente ao se observar os 10 usuários seguintes em termos de grau de conexão indegree. Ao invés de uma predominância de perfis populares, é possível observar alguns atores intermediários. Por exemplo, o Youtuber @jimchapman teve seu apelo por segurança para quem estava em Paris retuitado 159 vezes nos três minutos do recorte. O perfil do jornalista francês @ peterallen também figura nessa lista, por ter feitos tweets em inglês sobre os desdobramentos do caso. O perfil @ histipics, originalmente dedicado a postar fotos históricas, desviou de sua utilização tradicional ao postar telefones de embaixadas de outros países em Paris. Um caso bastante particular está relacionado ao pefil @ chilaaq, que teve a seguinte mensagem retuitada:

RT @ chilaaq: Although two terrorist attacks on Lebanon and Iraq occurred, you will only be hearing about Paris. Regardless, pray for all. ${ }^{11}$

Essa mensagem foi compartilhada particularmente por pessoas das outras regiões mencionadas, como uma forma de ativismo. Esse grupo de usuários está conectado ao resto da rede por um usuário, @alexmujeeb, que retuitou tanto a mensagem de crítica quanto outros tweets de perfis tradicionais de imprensa, como@bbcbreaking e @ cnnbrk.

Esse papel predominante de alguns poucos atores-chave fica mais evidente ao se observar a estrutura da rede em torno desses tweets (Figura 1).

11. Tradução livre: "RT @ chilaaq: Embora dois ataques terroristas tenham ocorrido no Líbano e no Iraque, você irá apenas ouvir falar sobre Paris. Independentemente disso, ore por todos." 
Figura 1. Grafo da rede em torno dos tweets com os termos "Paris" e "attacks" com nós agrupados por modularidade.

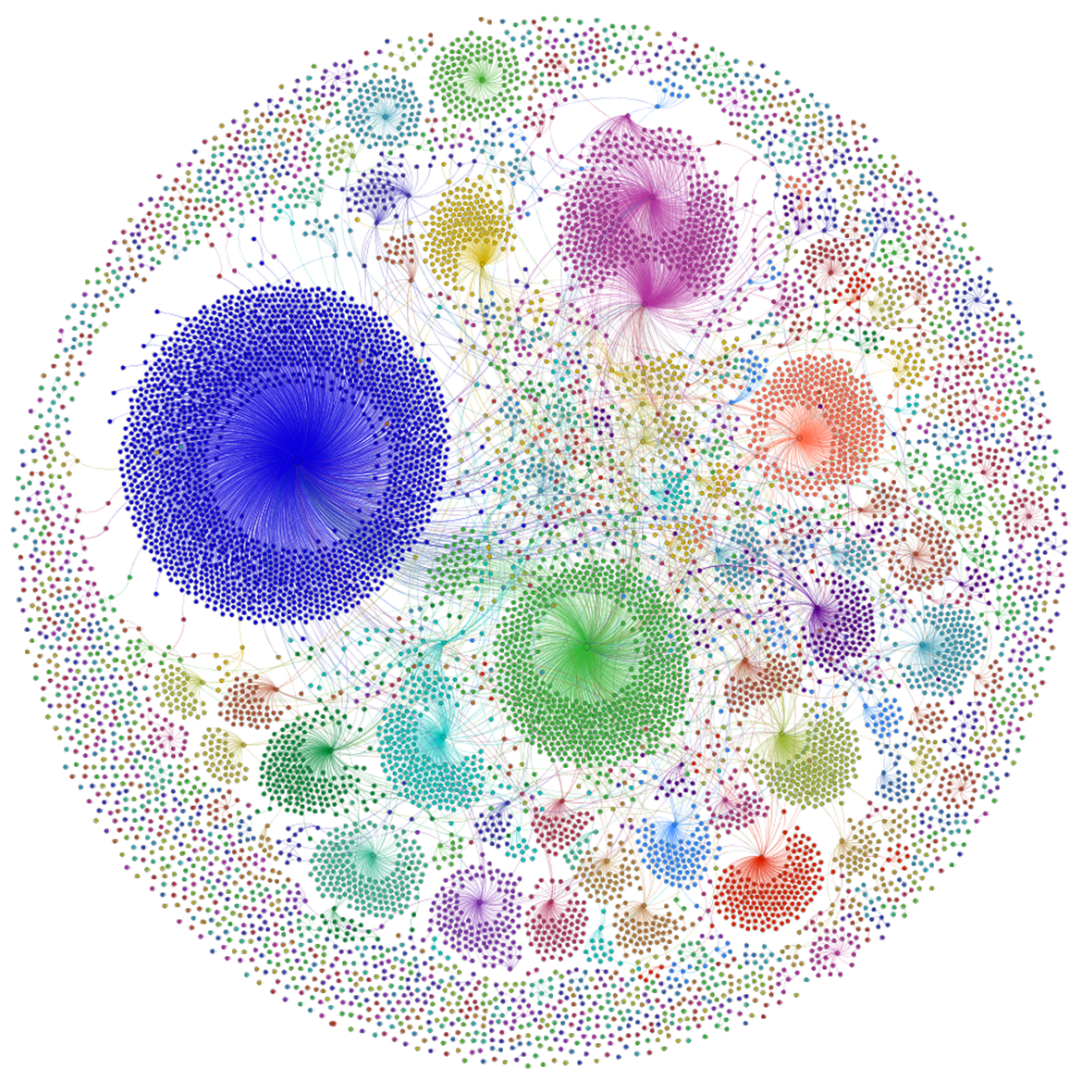

O maior grupo de nós, na cor azul, à esquerda do grafo, tem como nó central @ bbcbreaking. O segundo maior grupo, em verde, na parte central do grafo, reúne tweets em torno do perfil @ap. Alguns usuários conectam este grupo verde ao azul escuro, estabelecendo uma ponte entre as fontes de informação. Essa ligação é feita através de usuários que retuitaram postagens provenientes das duas fontes. O grupo rosa, no topo do gráfico, tem como nós centrais@whitehouse e @ potus. O grupo azul claro está centrado no perfil @ skynews. O grupo laranja, à direita do grafo, possui como nó principal o perfil @breakingnews. 
A presença combinada dos perfis @potuse @whitehouse em um mesmo grupo está relacionada ao fato de que os usuários retuitaram uma mensagem do perfil @whitehouse com menção ao perfil do presidente dos Estados Unidos:

RT@WhiteHouse: Watch the full statement from @POTUS on the attacks in Paris. https://t.co/yQThOvrdxZ ${ }^{12}$

Cerca de $40 \%$ dos tweets presentes no recorte não apresentam link, o que demonstra o caráter de urgência do acontecimento e a necessidade de reportar, mesmo que ainda não se tenham informações completas. Um exemplo pode ser visto no tweet mais retuitado da Associated Press, reproduzido abaixo:

RT @AP: BREAKING: French president says military being deployed around Paris after unprecedented attacks. ${ }^{13}$

Também é possível observar a menção a outros veículos, como em:

RT @CBSNews: NEW: @ AP reports at least 26 deaths in attacks across \#Paris; live updates on @ CBSNLive https://t.co/4PpDbH RAvP https://t.co/x... ${ }^{14}$

Em termos de conteúdos postos em circulação, as hashtags mais frequentes nos tweets foram \#Paris e \#France, indicando a localização geográfica do acontecimento, \#BREAKING, indicando o caráter de urgência do mesmo, \#ParisAttacks, inserindo a mensagem no contexto do acontecimento específico a que se refere, \#fusillade, indicando o caráter violento do acontecimento (atentado, em francês) e \#PrayForParis, indicando uma mobilização mundial em prol das vítimas.

As palavras mais frequentes identificadas nos tweets foram paris, attacks, rt, france, borders, state, emergency, closes, declares, presidente ${ }^{15}$. Essa combinação de termos permite trazer inferências sobre os termos mais frequentes

12. Tradução livre: “RT @WhiteHouse: Assista ao pronunciamento complete de @POTUS sobre os ataques em Paris. https://t.co/yQThOvrdxZ"

13. Tradução livre: "RT @ AP: BREAKING: Presidente francês diz que militares estão sendo posicionados ao redor de Paris após ataques sem precedents."

14. Tradução livre: "RT CBSNews: NOVO: @ AP reporta pelo menos 26 mortes em ataques ao redor de \#Paris; atualizações em tempo real @CBSNLive https://t.co/4PpDbH..."

15. Respectivamente, paris, ataques, rt, frança, fronteiras, estado, emergência, fecha, declara, president. 
nas notícias do período do recorte (como na declaração do presidente francês de fechamento às fronteiras do país por tempo indeterminado).

\begin{tabular}{llllll}
$\#$ & perfil & grau & $\#$ & perfil & grau \\
\hline 1 & @ostrov_a & 26 & 8 & @ nahayatt & 3 \\
2 & @ variety & 11 & 9 & @ theworldpost & 3 \\
3 & @bbcnews & 11 & 10 & @ wbtv_news & 2 \\
4 & @ gmanews & 6 & 11 & @ azfamily & 2 \\
5 & @mannfrednikolai & 5 & 12 & @jamaldajani & 2 \\
6 & @ fox5atlanta & 5 & 13 & @ chrissycole & 2 \\
7 & @ newsone & 4 & & & \\
\hline
\end{tabular}

Tabela 2. Atores com maior grau de intermediação no recorte.

Os tipos de atores envolvidos apresentam maior variabilidade ao se observar os usuários com o maior grau de intermediação. Ao todo, são 13 usuários no recorte com grau de intermediação igual ou maior que 2 (Tabela 2).

Em comum com todos esses atores, está o fato de terem retuitado ou mencionado diferentes atores ao mesmo tempo em que mensagens próprias também foram retuitadas por outros usuários. O usuário @ostrov_a, por exemplo, fez retweets a veículos de imprensa como @ap e @afp, mas também teve um de seus tweets retuitado mais de 700 vezes. Isso colocou o usuário numa posição de intermediário da comunicação. Muitos dos veículos que aparecem na lista (como@gmanews, @ newsone e @wbtv_news) fizeram tweets mencionado a @ap como fonte, e esses tweets foram então retuitados por outros usuários. Há casos mais específicos, como no caso de @ nahayatt e @ chrissycole, repórteres de veículos locais que retuitaram mensagens de seus próprios veículos e também outras fontes de informação, ao mesmo tempo em que tiveram mensagens próprias retuitadas por outros usuários.

Dez desses usuários possuem quantidades intermediárias de seguidores (entre mil e 250 mil seguidores). Apenas 3 possuem mais de 1 milhão.

A maior parte é composta por veículos de alcance local (emissoras de televisão de cidades específicas, por exemplo) ou repórteres desses veículos. Mas há também usuários especialistas em geopolítica internacional (@ostrov_a, @ mannfrednikolai e @jamaldajani). A partir da classificação de Cha et al (2012), é possível inferir uma predominância de usuários do tipo especialistas 
dentre os mais retuitados nesse grupo, com alguns deles exercendo o papel de curador de conteúdos para seus seguidores (Lehamnn et al, 2013).

Por fim, a observação dos usuários com maior grau de conexão outdegree, ou seja, usuários que mais mencionaram ou retuitaram outros usuários no período, indica uma forte predominância de perfis de usuários comuns. Nove usuários estabeleceram conexão com pelo menos cinco usuários diferentes em seus tweets. Desses nove usuários, apenas dois possuem mais de mil seguidores.

\section{DISCUSSÃo}

As métricas de Análise de Redes Sociais podem trazer pistas para compreender os diferentes papéis exercidos na circulação de informações sobre um determinado acontecimento jornalístico. Em termos gerais, os papéis identificados na circulação jornalística em torno dos atentados de Paris podem ser sistematizados em dois grandes grupos: produtores/fontes de informação (que englobam imprensa e comentaristas) e recirculadores/difusores de informação (incluindo pontes e disseminadores). Uma sistematização desses papéis pode ser vista no Quadro 1. 


\begin{tabular}{|c|c|c|}
\hline Tipo & e subtipos & Descrição \\
\hline \multirow{2}{*}{ Produtores } & Imprensa tradicional & $\begin{array}{l}\text { Veículos de mídia que postam atua- } \\
\text { lizações no Twitter. Normalmente, } \\
\text { possuem alto grau de conexão inde- } \\
\text { gree. }\end{array}$ \\
\hline & Comentaristas & $\begin{array}{l}\text { Usuários que postam comentários } \\
\text { sobre os acontecimentos nas redes } \\
\text { (podendo ser especialistas ou usuá- } \\
\text { rios comuns). Podem ter alto grau } \\
\text { de conexão indegree. }\end{array}$ \\
\hline \multirow{2}{*}{ Recirculadores } & Pontes & $\begin{array}{l}\text { Promovem a interligação da rede } \\
\text { não só ao retuitar fontes diversas } \\
\text { de conteúdo, como também ao te- } \\
\text { rem suas próprias mensagens retui- } \\
\text { tadas por outros usuários. Normal- } \\
\text { mente, possuem alto grau de inter- } \\
\text { mediação. }\end{array}$ \\
\hline & Disseminadores & $\begin{array}{l}\text { Em grande quantidade, contribuem } \\
\text { para aumentar a visibilidade de a- } \\
\text { contecimentos através de retweets e } \\
\text { menções. Podem ter alto grau de } \\
\text { conexão outdegree. }\end{array}$ \\
\hline
\end{tabular}

Quadro 1. Papéis desempenhados pelos usuários na circulação jornalística em sites de rede social.

Ainda que exerçam funções diferentes, cada um, a seu modo, contribui para a circulação de informações. Assim, de um lado, a imprensa disponibiliza conteúdo nos sites de rede social. De outro, os usuários contribuem para o espalhamento da informação através de retweets. Ainda que os perfis de imprensa tenham, por si sós, um grande número de seguidores, o retweet contribui para aumentar o alcance das informações, na medida em que, mesmo usuários que não seguem os perfis dos veículos, ou não tenham visto a mensagem original quando esta foi tuitada, podem ter acesso à informação.

O próprio papel de espalhar uma informação é de suma importância para a rede, na medida em que ajuda a conferir visibilidade a certos assuntos (Zago \& Bastos, 2013). Nesse sentido, o RT atua como uma moeda de troca (Recuero 
\& Zago, 2012; Bruns \& Burgess, 2012) - ao escolher retuitar uma mensagem, confere-se visibilidade à informação e ao usuário específico que fez a postagem.

Usuários comuns e especialistas podem tanto atuar como pontes ou como espalhadores de informação. Pontes são usuários-chave que interconectam a rede, ao estabelecer conexão com dois ou mais usuários que do contrário estariam isolados na rede. Já os espalhadores são aqueles usuários que estabelecem várias conexões, buscando informar seus seguidores a partir de diferentes fontes.

O papel específico de curador de conteúdo, abordado por Lehmman et al (2013), situa-se num espaço intermediário entre o produtor e o recirculador de conteúdo, na medida em que pode envolver uma produção (como ao fazer um comentário crítico sobre o acontecimento) ou uma reprodução (retweet) de informações provenientes de outras fontes. Nesse sentido, tanto o comentarista quanto os usuários que atuam como disseminadores e como pontes podem exercer circunstancialmente o papel de curadores de informação, na medida em que proveem acesso à informação a seus seguidores.

No contexto do acontecimento estudado, é possível observar que especialistas atuaram como comentaristas e curadores especializados. Usuários comuns, por sua vez, contribuíram principalmente para o espalhamento da informação (embora também pudessem eventualmente atuar como produtores de conteúdo, curadores, ou comentaristas). A imprensa e os perfis oficiais, por sua vez, apareceram principalmente como fonte de informação, no papel de nós centrais em termos de visibilidade na medida em que seus conteúdos são compartilhados e reverberados por usuários comuns e especialistas.

Esses diferentes papéis se inserem em um contexto de jornalismo em rede (Heinrich, 2011), em que diferentes atores, não apenas o veículo e seus jornalistas, tomam parte no processo jornalístico. Fazer recircular um conteúdo é uma forma de participação na circulação jornalística (Zago, 2014), uma das etapas do processo jornalístico. Essa recirculação é relevante na medida em que pode servir de ponto de acesso à informação pra outros usuários. Nos sites de rede social, pode haver o consumo acidental de notícias (Mitchell \& Page, 2014), na medida em que os usuários "esbarram" em notícias postadas por seus contatos na rede, mesmo que não estejam ativamente à procura de notícias. 
É importante ressaltar que esses papéis são dinâmicos e circunstanciais. O comentarista de um assunto pode se tornar um disseminador em outro acontecimento, da mesma forma que um veículo de imprensa pode atuar como ponte ao mencionar outras fontes de informação. Assim, ainda que os papéis tenham sido identificados em torno de um acontecimento em específico, os mesmos atores podem desempenhar funções distintas na circulação de outros acontecimentos.

\section{CONSIDERAÇões FINAIS}

O trabalho procurou identificar os papéis dos usuários na circulação e recirculação jornalística a partir do estudo de um caso específico. O recorte utilizado se refere aos atentados ocorridos em Paris em novembro de 2015.

Em termos gerais, o estudo apontou para a existência de dois papéis principais complementares: produtores e recirculadores de informação. Enquanto imprensa e especialistas são fundamentais no sentido de produzir conteúdos, especialistas e usuários comuns são importantes ao promover uma maior visibilidade das informações, ao contribuir para espalhar determinados desdobramentos, em detrimento de outros.

No contexto específico observado, há uma predominância de retweets a veículo de imprensa, demonstrando o papel e a relevância desses usuários enquanto produtores de conteúdo no caso de grandes acontecimentos jornalísticos. Do mesmo modo, a grande quantidade de retweets no recorte reflete uma ativa participação de usuários comuns no sentido de promover o espalhamento da informação, ao reproduzi-la para suas redes. Especialistas também desempenham um papel relevante, ao tecer comentários ou selecionar links e informações para repassar para seus contatos, que, por sua vez, podem repassar para outros usuários, e, assim, atingir pontos mais distantes da rede.

$\mathrm{O}$ recorte apresenta algumas limitações. Em termos de abrangência, a busca em inglês limitou os resultados a veículos jornalísticos e usuários que realizaram postagens neste idioma. Além disso, o recorte utilizado abrange um período de tempo extremamente reduzido (3 minutos). Em termos técnicos, uma outra limitação que pode ser apontada é o fato de que só é possível captar os rastros visíveis da participação na circulação (no momento, o volume do consumo não tem como ser medido). 
De qualquer modo, estudos futuros podem lançar luz aos papéis aqui observados em diferentes tipos de acontecimentos, em diferentes contextos culturais e geográficos. Os atores principais envolvidos na circulação e recirculação jornalística podem ser variados e específicos para cada tipo de acontecimento em discussão.

\section{REFERÊNCIAS}

Alter, C. (2015, Nov. 13). What we know about the Paris attacks. TIME. Disponível em http://time.com/4112639/paris-attack-terror-bataclan-hollan $\mathrm{de} /$

Belochio, V. (2012). Jornalismo em contexto de convergência: implicações da distribuição multiplataforma na ampliação dos contratos de comunicação dos dispositivos de Zero Hora. Tese (Doutorado em Comunicação e Informação), Universidade Federal do Rio Grande do Sul.

Bruns, A. \& Burgess, J. (2012). Researching news discussion on Twitter: new methodologies. Journalism Studies, 13(5-6): 801-814. Versão dos autores disponível em http://snurb.info/files/2012/Researching News Discussion on Twitter.pdf

Cha, M.; Benevenuto, F.; Haddadi, H. \& Gummadi, K. (2012). The world of connections and information nflow in Twitter. IEEE Transactions on Systems, Man and Cybernetics, Part A: Systems and Humans, 42(4): 991998. Disponível em http://ieeexplore.ieee.org/xpl/articleDetails.jsp?arnu mber $=6156464$

Degenne, A. \& Forsé, M. (1999). Introducing social networks. Londres: SagePublications.

Ellison, N. B. \& Boyd, D. (2013). Sociality through social network sites. In W. H. Dutton (Org.). The Oxford Handbook of Internet Studies (pp. 151-172). Oxford: Oxford University Press.

Freeman, L. (1979). Centrality in social networks: conceptual clarification. Social Networks, 1: 215-239.

Heinrich, A. (2011). Network journalism. Londres: Routledge.

Jenkins, H.; Ford, S. \& Green, J. (2013). Spreadable media. New York: NYU Press. 
Lehmann, J.; Castillo, C.; Lalmas, M. \& Zuckermann, E. (2013). Finding news curators in Twitter. Proceedings of the 22nd International World Wide Web Conference - WWW'13: 863-869, ACM Press.

Mitchell, A. \& Page, D. (2014). State of the news media 2014: overview. Pew Research Center.

Recuero, R. (2009). Redes sociais na internet. Porto Alegre: Sulina.

Recuero, R. \& Zago, G. (2012). A economia do retweet: redes, difusão de informações e capital social no Twitter. Contracampo, 24.

Recuero, R.; Bastos, M. \& Zago, G. (2015). Análise de redes para mídia social. Porto Alegre: Sulina.

Russell, A. (2011). Networked: a contemporary history of news in transition. Cambridge: Polity Press.

Scott, J. (2013). Social network analysis, 3. ed. Londres: Sage Publications.

Smith, M.; Rainie, L.; Himelboim, I. \& Shneiderman, B. (2014, Fev. 20). Mapping Twitter topic networks: from polarized crowds to community clusters. Pew Research Center. Disponível em http://www.pewinternet.o $\mathrm{rg} / 2014 / 02 / 20 /$ mapping-twitter-topic-networks-from-polarized-crowds- $\mathrm{t}$ o-community-clusters/

Wasserman, S. \& Faust, K. (1994). Social network analysis: methods and applications. Cambridge: Cambridge University Press.

Zago, G. (2014). Circulação e recirculação de narrativas do acontecimento no jornalismo em rede: a copa do mundo de 2014 no Twitter. Tese (Doutorado em Comunicação e Informação), Universidade Federal do Rio Grande do Sul.

Zago, G. \& Belochio, V. (2014). Remediação da experiência de consumo de notícias em sites de redes sociais. Contemporanea, 12(1): 90-106.

Zago, G. \& Bastos, M. T. (2013). Visibilidade de notícias no Twitter e no Facebook: análise comparativa das notícias mais repercutidas na Europa e nas Américas. Brazilian Journalism Research, 9(1): 98-115.

Zago, G.; Recuero, R. \& Bastos, M. (2015). Quem retutia quem? Papéis de ativistas, celebridades e imprensa durante os \#protestosbr no Twitter. Observatorio $\left(O B S^{*}\right), 9(3)$ : 67-83. 
$\bigoplus$

$\bigoplus$

$\oplus$ 


\title{
FIFA World Cup 2014 on Twitter and Facebook: more from less or less from more?
}

\author{
Ivo Neto \& Felisbela Lopes \\ CECS - Uminho \\ E-mail: ivoneto88@gmail.com/felisbeladics.uminho.pt
}

\begin{abstract}
The last FIFA World Cup in Brazil pre- mobile platform, it becomes necessary to sented the ambition of a global event, referring both to the number of audiences and the number of platforms involved in its coverage. Taking the advantages promoted by social media platforms and mobile technologies, media companies had the opportunity to try new strategies in a truly ambient information reality. Taking into account the development of Twitter, assuming itself as an informative and promote a further reflection about the impact of social media in the field of journalism. Applying this research to sport we follow other analyses made about political issues. In this study, we have analyzed 3195 post on Twitter and 665 on Facebook, made by media outlets from seven different countries, during the coverage of 32 matches of the World Cup in Brazil, in June and July 2014.
\end{abstract}

Keywords: social media; ambient information; produser; FIFA WORLD Cup; power and participation.

Data de submissão: 13-01-2016. Data de aprovação: 23-10-2016.

A Revista Estudos em Comunicação é financiada por Fundos FEDER através do Programa Operacional Factores de Competitividade - COMPETE e por Fundos Nacionais através da FCT - Fundação para a Ciência e a Tecnologia no âmbito do projeto Comunicação, Filosofia e Humanidades (LabCom.IFP) UID/CCI/00661/2013. 


\section{FIFA World Cup 2014 no Twitter e Facebook: mais com menos ou menos com mais?}

\section{RESUMO}

O último campeonato do Mundo FIFA, que se realizou no Brasil, apresentou a ambição de um evento global, tanto ao nível das audiências como nas plataformas utilizadas na sua cobertura. Aproveitando as vantagens promovidas pelas plataformas de media social e os periféricos móveis, as empresas mediáticas tiveram a oportunidade de experimentar novas estratégias, numa realidade marcada pela ambient information. Tendo em conta o desenvolvimento do Twitter, que se assume cada vez mais como uma plataforma informativa móvel, é necessário refletir sobre o impato das media sociais no campo do jornalismo. Aplicando esta pesquisa ao desporto, seguimos outras análises feitas em questões relacionadas com a política. Neste estudo, analisámos 3195 posts no Twitter e 665 no Facebook feitos por meios de sete países diferentes, durante a cobertura de 32 partidas do Campeonato do Mundo do Brasil, em junho e julho de 2014.

Palavras-chave: media sociais; informação ambiente; produser; FIFA WORLD Cup; poder e participação.

\section{The World Cup of Multiple Platforms: \#TAKe PART OF \#The} Global Stadium

IFA World Cup, which takes place every four years, is the most awaited 1 moment by all football lovers. For two years, teams from every continent compete for 32 places, dreaming about the presence in this football's world stage. In 2014 it was Brazil to receive stars like Cristiano Ronaldo, Lionel Messi and Arjen Robben. For over a month, the full stadiums are followed by millions of viewers, making this competition a truly global event ${ }^{1}$.

1. Of the 3 million tickets sold for the final stage of the competition, nearly $40 \%$ wer e allocated to foreigners. To this number we may join the spectators from countries not qualified to this stage of the competition. According to the report produced by FIFA, on the very first journey in which 32 teams were still competing, a number of records were broken regarding the television coverage. For example, 27 million TV viewers watched the match between Italy and England, beating records of audience of these two countries. Also the United States, where football still seeks to achieve the popularity of sports like American Football or Basketball, recorded the largest increase in audience during the last World Cup, according to FIFA data. 
In addition to the sportive profile of the most important football competition in the world we paid a particular attention to the media coverage of this event. The development of digital technologies experienced in the 2010's competition, with the focus on social media, raised a number of expectations for the competition in 2014.

FIFA did not miss the opportunity to promote their biggest event by using various information platforms, marked by a multimedia profile, allowing us to send different content within instants. One such example was the official application developed by the institution that manages football all over the world. In June $12^{\text {th }}, 2014$, days before the official start of the competition, it was possible to find the following statement on FIFA's official website:

"The official app of the FIFA World Cup was launched with a worldwide exclusive coverage, which means that fans can take the biggest event of international football to where they are. The application, launched in December 2013, has been fully updated and is ready for the opening match of the tournament".

The justification used to create this official application, according to this organization, is the changing pattern of consumer's habits, promoted by the emergence of "second screen"tools: "Now consumers use smartphones and tablets to get more involved, especially in regard to sports content". Through the multiplatform reality, users were invited to follow the latest news, photos, and videos and to follow in real time, regardless of location, the best moments of each match.

The concern to create a symbiosis between mobile platforms and the potential of social media is even clearer if we consider the creation of the hashtags \#Copa2014 (\#Worldcup2014) and \#Façaparte (\#takeparte), together with others specifically developed for each match. This association between the various platforms, a kind of "virtual ticket"to the "FIFA Virtual Stadium", a social center, online and mobile, aimed to create a community environment enabling "interaction with friends, people all over the world, players, coaches and celebrities in social media feeds (...)".

The Global Stadium concept was the clear evidence of a multiplatform communication, taking advantage of the potential of a media environment marked by the convergence of content and platforms. The real-time and mul- 
timedia communication were the basis for the construction of a virtual community around this event:

"In the Global Stadium you are the first to watch the goals and can also follow the match with a minute by minute narration. Our external social media platforms also include Twitter, Facebook, YouTube and Instagram. We ask everyone to use the hashtag \# FaçaParte to all together experience FIFA World Cup".

If we consider the evaluation made by FIFA we see that this effort was rewarded by the good reception it had. On June $24^{\text {th }}$, 2014, even during the competition, Matt Stone, in charge of digital communication in FIFA, was clear by stating that: "We are on track to exceed the record audience of the FIFA World Cup 2010, 150 million people consuming content of FIFA".

The media, which took the opportunity raised from the World Cup to give their public a new approach to watch a football match, also followed the behaviour promoted by FIFA. Using the case of RTP and the BBC we understand a similar approach to that taken by FIFA.

With regard to RTP, the PSM in Portugal, the strategy developed for this competition held the promise to "show other football angles, either in direct matches or in the repetitions". Users were also asked to compare players and teams and share everything with their friends on social media. The reality of multiplatforms was even clearer by the presence on social media like Facebook, Twitter, YouTube and Instagram. As FIFA, hashtags were also created for the coverage of this competition.

Looking to the example from BBC, the idea of convergence and real-time information was even clearer. In an article entitled World Cup 2014: Digital Coverage was launched the following proposal: "From Manaus to Macclesfield and Rio to Rickmansworth, BBC Sport's dedicated live World Cup page will bring fans together and put them at the heart of the action. It will combine all the BBC's live digital coverage in one place, allowing audiences to access live video, radio and text updates wherever and whenever they want". For this very purpose to be fulfilled, the British operator intended to explore the potential of social networks, the BBC iPlayer and more traditional platforms such as television or radio.

Thus we believe that it is important to understand how the new digital information technologies were used for this competition. In this specific work 
we will pay a particular attention to the strategies used both on Twitter and Facebook. In a ambient information environment is important to understand how social media platforms are being used as an informative tool or as a promotional strategy.

\section{FROM THE CNN'S EFFECT TO THE TWITTER'S EFFECT: THE MICRO- BLOGGING AS AN INFORMATIVE TOOL}

Social media platforms have assumed a prominent role in how we base our lives on the Internet. Facebook and Twitter happen to be two good examples of a social media used in the information field.

According to the work of Boyd and Ellison (2007: 211), social media platforms act as web elements that allow citizens to (1) build a profile, which can be public or semi-public, within a bounded system, (2) articulate a list of other users with whom you can share a connection, and (3) view and navigate through your connections list or lists created by others within those systems. The same possibilities are in line with the idea of Mark Deuze (2013: 115), who explains that the use of the media by persons moves increasingly toward a social and real time technology: "The global adoption of online social networking is part of a larger trend in the dance between media and everyday life towards the predominance of artefacts always on and connected and activities that become the foundation for the arrangement of human sociability".

Despite the higher number of users of Facebook, is in relation to Twitter that we find more studies connecting it to the field of journalism. Analysing the phenomenon of Twitter can be an interesting process. It may help us to understand the emergence and development of new journalistic conventions and understand the impact that the microblogging networks can achieve (Vis, 2013). The profile of this meets one of the most important characteristics of journalism: be anywhere and anytime. Initially designed and built as a messaging system for mobile phones, it developed to the point of being today one of the most important elements in the digital information network. The limitation on the number of characters, 140 per message, is closely related to the compatibility it was intended to create, from the beginning, with the smartphones, elements that have reached a significant capital importance in the dissemination of instant messaging (Van Dijck, 2013). This messaging platform, shared among users, has designed a system that favours viral dis- 
tribution. Those features were proved during the plane crash in the Hudson River, which has strengthened Twitter as a capable element of disseminating last minute information, produced by journalists but also by citizens (Lasorsa, et al, 2011: 20). It is about a social media technology designed for online and instant dissemination of small pieces of data from official and unofficial sources. Part of the family of microblogs, they allow instant communication and the sharing and discussion of events as an expression of collective intelligence (Hermida, 2010).

The brevity of tweets and the increasing use of mobile devices are making more and more easy the process of sharing information from anywhere and at any time. In certain cases, Twitter anticipates the traditional media in the dissemination of breaking news. In addition, we must not forget to point out the multimedia profile of this platform, which, in addition to texts, allows the sharing of video and image. Thus, Bruns and Burgess (2012) intend that Twitter is the most prominent example of a social media technology that combines the convergence of social networking and the sharing of content production. For the authors, Twitter is both a social networking site and a stream of ambient information. We are able to measure this same trend if we look to the work of Alfred Hermida (2013), which gives us some points that help to understand the evolution of this social network as an information vehicle.

An early and clear example was the transformation of the welcoming message to its users. In 2006, at its launch, Twitter prompted users with the following question: "What are you doing?." By 2009, it was possible to read: "What is happening?" In 2012, the company website described this microblogging platform "as a real-time information network that connects you to the latest stories, ideas, opinions and news about what you find interesting". This subtle but meaningful change in Twitter's interface indicates a strategy that emphasises news and information over conversation. In other words, Twitter increasingly assumes rather as an informative tool than a social media platform.

Moreover, the limitation of characters per post (140 characters) makes Twitter a tool related to action, helping broadcasting events at the same time that they occur. Unlike Facebook, which, without a limit characters per post, allows a higher degree of development, the nature of Twitter is more related to the immediacy. That is why it is conceivable to understand Twitter as tool 
to be used in streets, during protests or strikes, and Facebook at home, in a calmer environment, allowing a deeper reflection.

Thus, we see that Twitter has developed as a system in which the news is reported, disseminated and shared online shortly, quickly and with a high degree of frequency (Hermida, 2010: 301). This is exactly what Nicola Bruno intends as the Twitter effect, comparing, at the same time, with the CNN effect:

"The Twitter effect is not only changing the way in which people communicate during crisis events, but also how big news organizations cover them. If the $\mathrm{CNN}$ effect required your own correspondents being on the ground in order to broadcast live footage, then the Twitter effect allows you to provide live coverage without any reporters on the ground, by simply newsgathering user-generated content available online".

While the CNN effect was crucial in centring media and political attention on a global crises, the Twitter effect promises to offer a more in-depth coverage of natural disasters and 'forgotten wars', providing visibility to threatened voices and political protests in less democratic countries.

\section{FROM AMBIENT JOURNALISM TO produsage}

One of the elements that we find at this level is the ambient journalism, which appears many times related to social media like Facebook and Twitter. Hermida (2010: 301) defines this concept as "an awareness system that offers diverse means to collect, communicate, share and display news and information, serving diverse purposes". In parallel, Bruns (2010: 5) intends ambient journalism as an "emerging analytical framework for journalists, informed by cognitive, cybernetic, and information systems research".

As a result, these platforms contribute to the pluralisation of narratives and could present new voices that are not heard through more conventional broadcast media (Papacharissi, 2014). At this level, Twitter, as an ambient journalism tool, provides a mix of news, information and comments that may be connected to current affairs, but without an established order. "This structure thus expands the number of different agents potentially involved in the production of journalistic products, most notably news (Vis, 2013: 29)". 
The role that audiences take in this reality, often reinforced by social media tools, is also highlighted when the team of researchers led by Dominic Lasorsa (2012: 20) explains that the very concept of journalism is becoming ambient, thanks to its ubiquity, often fragmented, and the collective effort involving the audience and journalists. Although most of the daily activities of media's users may not have value as news, when objects appear, a substantial amount of these activities is replaced by a concentrated effort to work the issue, similar to what is defined by journalists as being research. Increasingly influenced by the presence of the public, either through comments or content, the information environment becomes infected, opening new windows of opportunity for those who consume and produce information.

In this sense, we are faced with the emergence of a new concept: the produsage. This is an element that results from the sharing and conversational profile of online media, used by journalists, news organizations and individual users:

"The term is meant to describe, in a theoretically relevant manner, a set of practices that typically develop organically, as people share, forward, and comment on the news. While the resulting patterns of news sharing challenge our existing hierarchies of news production, consumption, and distribution, it is questionable whether people themselves consciously and constantly perceive themselves as produsers within the context of their everyday normality (Papacharissi, 2014: 3)".

This complex and social awareness network evolved beyond traditional journalism ecologies. The way these ecologies mix news production and consumption, changing the environment in which they operate, is understood as produsage. Thus, we can understand that the journalistic practices are changing. This happens due to the transition from a relatively closed system to a more open system, where the news may emerge through public observation, data and information that would be impossible to achieve in earlier times.

This new ecosystem is able to accommodate a wider range of news coming from different providers, employing techniques used in different media such as the press, broadcast, online, blogs and social media. In this very particular environment the flow of information moves with great fluidity through them (Picard, 2014). This same point is addressed by Axel Bruns (2011: 
122), when explains that there are two different aspects that, operating together, could change how journalistic work is performed: the continuous multiplication of channels available for publication and dissemination of news, especially since the emergence of the World Wide Web as a popular media, and the development of collaborative models for user participation and content creation, which currently are often summarized under the label of Web 2.0.

These arguments support the idea of Hermida who argues that the definition of ambient journalism can be applied to social media networks such as Twitter, with messages considered as both the representation of human activity and as artefacts:

"Twitter becomes a system where news is reported, disseminated and shared online in short, fast and frequent messages. It creates an ambient media system that displays abstracted information in a space occupied by the user. In this system, a user receives information in the periphery of their awareness (Hermida, 2010: $301) "$

In this sense social media platforms bring a set of opportunities to give a more active role for citizens in the information process. However it would be completely inadequate to analyse the influence that these platforms have in the field of information, just looking at citizens. Journalists are also influenced by these technologies, opening doors to new ways to put up with a digital environment in constantly bubbling. Furthermore, Henry Jenkins (2014: 284) suggests that more important than the role performed by individual citizens is the result of a commitment that is common and shared by multiple individuals as explained by Gilmor (2004: 54) when referring that new media technologies may contribute to a more diverse media environment, with different voices, that allow citizens to be heard not only as audience but as part of a media's community.

\section{POWER AND PARTICIPATION}

Taking into account all the possibilities made available by the new media technologies it is easy to engage in a speech of optimism regarding questions such as citizenship and participation. However, and using the work of Jen- 
kins (2006), we'd rather be cautious since whenever a new communication platform becomes available it is possible to find ultra optimistic speeches. In media and communication studies, especially where social and political engagement is on the research agenda, a lack of clarity or fixity is notable, making it hard to develop a critical approach regarding participation and new media technologies.

We aim to bring new elements to the debate around participation in the new media environment. In this new ecology the concept of participation and inclusion could be misunderstood. Thus, it is crucial to understand that "inclusion and participation are two different dimensions of public engagement" (Quick \& Feldman, 2011: 274). Considering the idea of inclusion, the two authors explain that it is mainly related to the links from different points of view that are established between groups or individuals and also the developed relationships based on common problems. On the other hand, when we look to the concept of participation, we see that this is much more oriented to the development of decision-making.

Peter Dahlgren (2014: 4) goes in the same direction, stressing that "participation is ultimately about power sharing and if this is structurally absent or systematically undermined, then whatever is being called participation must be seen with utmost skepticism, or indeed labeled fraudulent". Basically, "the difference of participation on the one hand, and access and interaction on the other is located within the key role that is attributed to power, and to equal(ized) power relations in decision-making process" (Carpentier, 2011: 131).

Both statements help to understand what Clemencia Rodriguez intends as citizens' media:

“(R)eferring to 'citizens' media' implies first that a collectivity is enacting its citizenship by actively intervening and transforming the established mediascape; second, that these media are contesting social codes, legitimized identities, and institutionalized social relations; and third, that these communication practices are empowering the community involved, to the point where these transformations and changes are possible (2001: 20)".

This approach is clearly important if we want to have a critical view towards new media technologies. The simple fact that we as citizens have 
more channels to make our voice heard does not automatically mean that we are participating. We risk ourselves to being no more than mere "citizens in waiting" (Livingstone, 2010). Supported by this idea, we may find that media outlets are often unable to effectively respond to comments and questions from followers, reinforcing, rather, a unidirectional profile for the dissemination of newly published content on the Internet pages (Bruns, 2012).

In some particular cases, citizens' actions are seen as an opportunity to gather a higher number of audiences and the new platforms can be perceived as a new way to achieve new incomes. Even with opportunities raised by main media chains such as CNN, with the iReport, it is not common to find content developed by citizens. The few exceptions are related to protests and natural disasters and it normally happens when media companies do not have journalists on that field and citizens are used in order to benefit those main chains (Kperogi, 2010: 326). Even when we look to Facebook and Twitter as an opportunity to raise new and different voices, we can see that the traditional elites are using these new channels to achieve new followers, extending their power networks to this new reality (Willimans \& Carpini, 2004: 1214).

One of these examples is related with the way in which media outlets use Twitter, not as an informative tool but with a promotional element. Much of the content used on social media is not primarily motivated to inform followers about the main issues of the day, but direct them to the main sites in order to achieve more views and better audiences' results. In this case, what we understand is that Twitter is not used as an information platform, promoting real power and participation, but as a means to promote the existing contents, sending followers to the main sites of these organizations (Vis, 2013). Instead of contributing to the creation and development of communities, we are facing the development of audiences:

"An audience is characterized by a unidirectional connection between transmitter and receiver (one to many) and the absence of relationships between receptors. This type of relationship is the characteristic model in traditional media. In the case of communities recorded a two-way communication (many to many), there is some kind of close relationship between its members (Canavilhas, 2010: 6)". 
Observing these elements it is possible to understand that the opportunities raised by new media technologies to achieve the "promise of the empowered user", one that is not "a passive and separate spectator" anymore, but rather an autonomous and capable of "interact in a common world", must be warily taken (Lopes, et al., 2013: 38a).

\section{The World Cup of Social Media: More from LeSS OR LeSS FROM MORE?}

a) Methodological approach

As it was possible to understand with the previous references, the FIFA World Cup 2014 was a global event marked by the multiplatform profile in which information flew through all the continents. A lot of effort was done by FIFA, and then followed by several different media companies worldwide, to take the advantages promoted by digital platforms.

In this specific study we aim to understand how social media platforms were used, both by producers and users, during the most important event in the world, regarding football. We have selected the platforms Twitter and Facebook to understand how information was posted on these two social media platforms and the strategies created for citizens' engagement.

In order to have a broader perspective, we choose a total of seven countries and 13 different media outlets ${ }^{2}$. Our main criterion was to select two media per country. On one hand it had to be a media platform specifically dedicated to sport, on the other hand, we selected the outlets that had acquired the rights to broadcast the matches of this event. Then we paid attention to each one of

2. Argentina: Olé Belgium: RTBF and Sportwereld (SW) ; Brazil: ESPN and Globo; Spain: Marca and Mediaset; France: L'Équipe and TF1; England: BBC and Sky Sports; Portugal: RTP and Maisfutebol (MF). The only exception here was Argentina where we only have selected a media company. This work is part of a more complex analysis that includes other informative platforms such as mobile apps and websites. Taking into account the limit that Apple imposes on the number of stores in the same peripheral it was not always possible to analyse all the cases we wanted. Thus, we only had the option to select one media outlet from Argentina. After deciding the media companies to integrate on our study, we decided to analyse all the games of each one of the involved countries. So, for example, to understand the coverage of the Portuguese national team we used the two Portuguese media companies, and so on. 
the games of the represented countries, making a total of 32 games and the posts published during those games: 3195 on Twitter and 665 on Facebook ${ }^{3}$.

To make our sample viable, we divided the game in three different periods of time ${ }^{4}$ : preview, game and after-game.

This sample was decided to answer to the following research questions:

R1: Did Twitter and Facebook contribute to a more multimedia reality?

R2: Did social media prove to be a useful tool regarding users' participation?

R3: Is there any connection between social media sites and other informative platforms?

After deciding the sample and the research questions to be answered, we have applied three different variables to guide our experience.

V1: Continuity: the total number of posts published by each of the media during the analysed matches;

V2: Multimedia: the profile of the content offered by each of the media forming part of this work;

V3: Autonomy: the possibilities for users' integration regarding a more active consumption.

b) Continuity and multimedia: A football match through the lenses of Social Media platforms

The main objective with this variable was to realize how the different media companies used both Twitter and Facebook to inform their users during the games. We have also tried to understand the variation of the coverage during the different moments of the game: preview, match and after-match.

3. Twitter: Argentina (829); Belgium (427); Brazil (533); Spain (237); France (349); England (325); Portugal (495). Facebook: Argentina (16); Belgium (132); Brazil (151); Spain (57); France (62); England (24); Portugal (223).

4. All the posts collected during the hour before the start of the match were included in the category pre-match. The posts made during the game are inserted in the match. Finally, the category after-match represents all the content published in the one hour after the match. 
Figure 1. Average of posts per game.

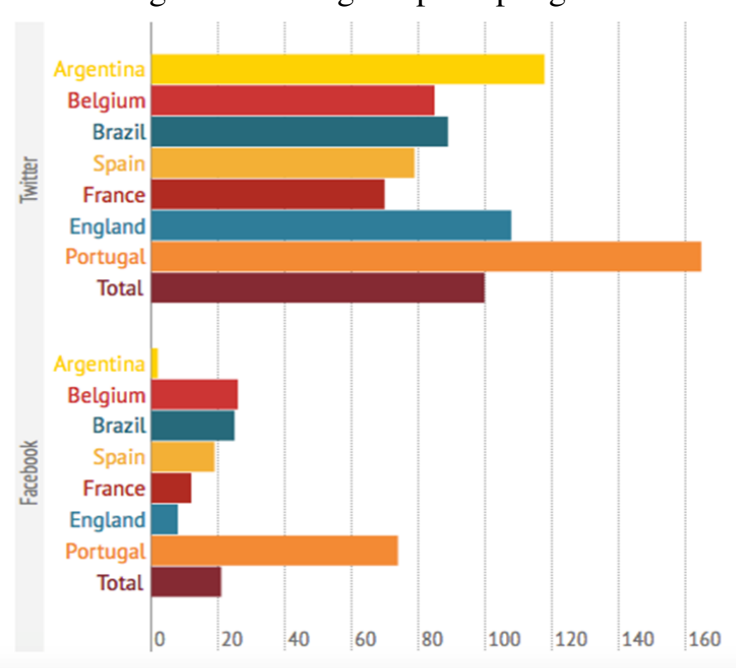

Source: Own source.

Looking to the average of posts per game we understand that there is a much bigger number of post on Twitter than on Facebook ${ }^{5}$. Thanks to its profile that allows live reporting, almost all the outlets used Twitter as a way to narrate some of the most important moments of each game. For instance, Olé, from Argentina, used this platform as a minute-by-minute tool. Since this outlet does not have an app with these characteristics, Twitter was used with that purpose. Assuming that each analysed game has, at least, ninety minutes, it is possible to understand that the average of posts on Twitter is more than one per game, contrasting with the numbers of Facebook.

Analysing these same numbers per country, Portugal and Argentina are the two outstanding countries. If we have already highlighted the performance of Olé, it is also possible to refer how MF, from Portugal, used Twitter. Even having an app designed for smartphones and tablets, this Portuguese media

5. Twitter: Argentina (118); Belgium (85); Brazil (89); Spain (79); France (70); England (108); Portugal (165). Facebook: Argentina (2); Belgium (26); Brazil (25); Spain (19); France (12); England (8); Portugal (74). 
used Twitter to give their users a different perspective about the games of the Portuguese national team.

Once again it is clear the difference between Twitter and Facebook, with all the media having less posts per game in the second platform.

Figure 2. Number of posts per moment of the game.

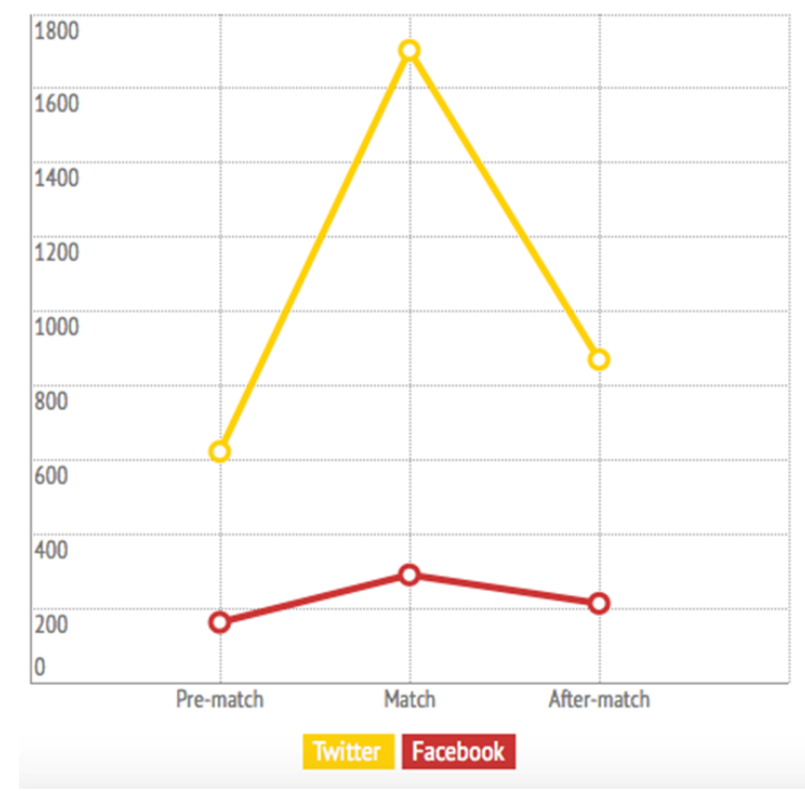

Source: Own source.

Looking to the second figure we understand that the different media outlets used the same pattern during the games ${ }^{6}$. The period of time with more posts was the game. It is mainly possible due to: the total time of that period, at least nineteen minutes instead of the sixty of the other two; it is during this period that the game happens. The period pre-match and after-match were mainly used to call the attention of users for the game in the main platforms of these outlets, assuming a clear promotion profile.

6. Twitter: Pre-match: 412; Match: 1292; After- match: 697. Facebook: Pre-match: 162; Match:290; After-match: 213. 
Figure 3. Thematic of the posts.

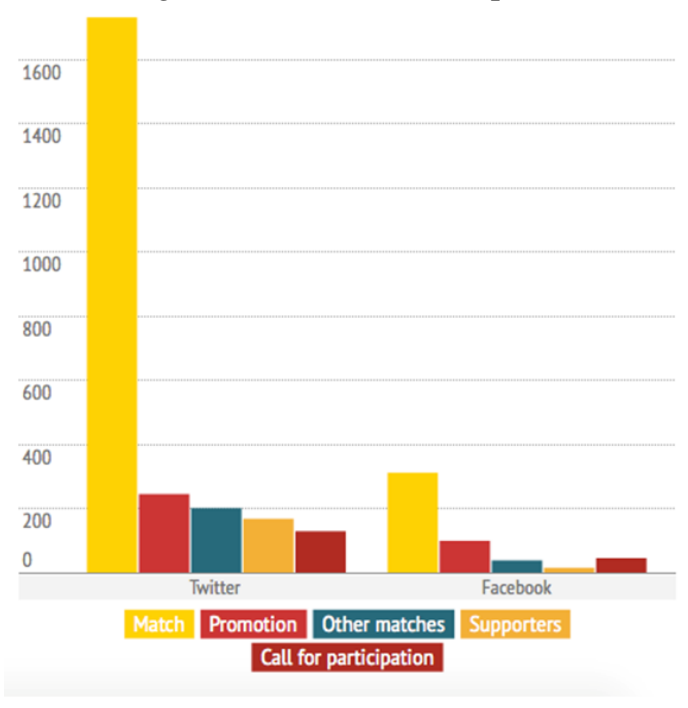

Source: Own source.

In this research we have also tried to understand the most common theme in the analysed posts ${ }^{7}$. As it was expected, the posts regarding the matches were found in most of the cases, following the promotional posts. This last kind of post was used to gather audiences to other platforms: TV, Websites or mobile apps. It is also interesting to mention the considerable number of posts related to supporters. In these posts, media outlets used content provided from their followers, normally after inviting them to send pictures to show how they were watching a certain match. However, even if this was a common topic among all the analysed posts, we rarely found an answer made by the journalists. This could be understood like an echo-chamber room, since users spent part of their time speaking to themselves.

7. Twitter: Match: 1733; Promotion: 245; Other matches: 201; Supporters: 168; Call for participation: 129. Facebook: Match: 312; Promotion: 99; Other matches: 38; Supporters: 15; Call for participations: 45 . 
Figure 4. Main content on the posts.

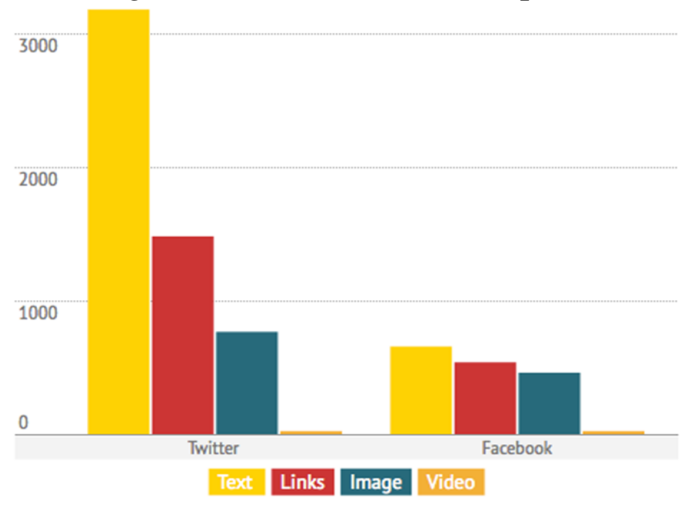

Source: Own source.

In figure 4, we can understand what was the most common content delivered by Facebook and Twitter ${ }^{8}$. Text was found in almost all the posts on both platforms. Curiously, the second type of content found in this study was the link. This can be related to the number of promotional posts, since these links were commonly used to guide users to the main websites, instead of informing them about this competition. Looking to the numbers of image and video it is clear that there is still a long way in order to have a multimedia environment on these both platforms.

c) Twitter and Facebook: New opportunities for citizens' engagement?

8. Twitter: Text: 3179; Links: 1471; Image: 766; Video: 23. Facebook: Text:657; Links: 538; Image: 460; Video: 23. 
Figure 5. Total number of shares.

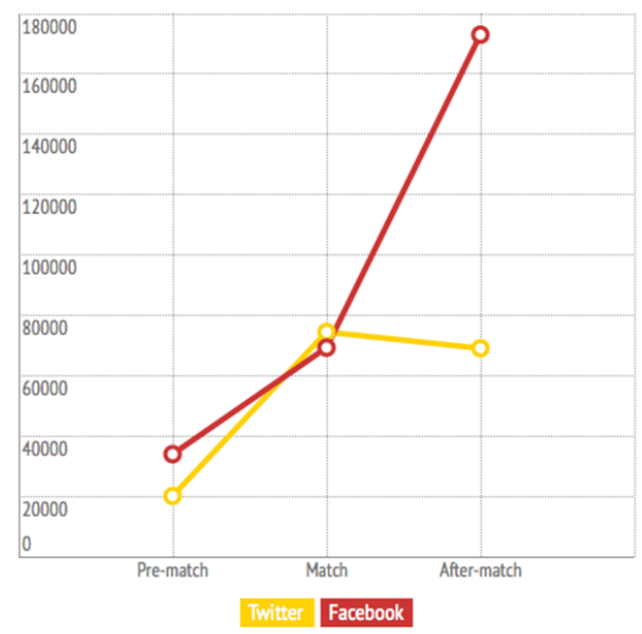

Source: Own source.

Figure 6. Total number of likes.

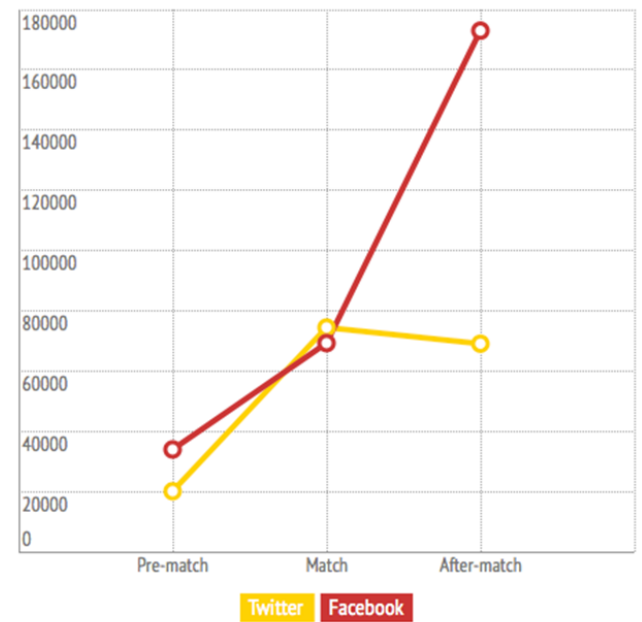

Source: Own source. 
Figure 7. Total number of comments.

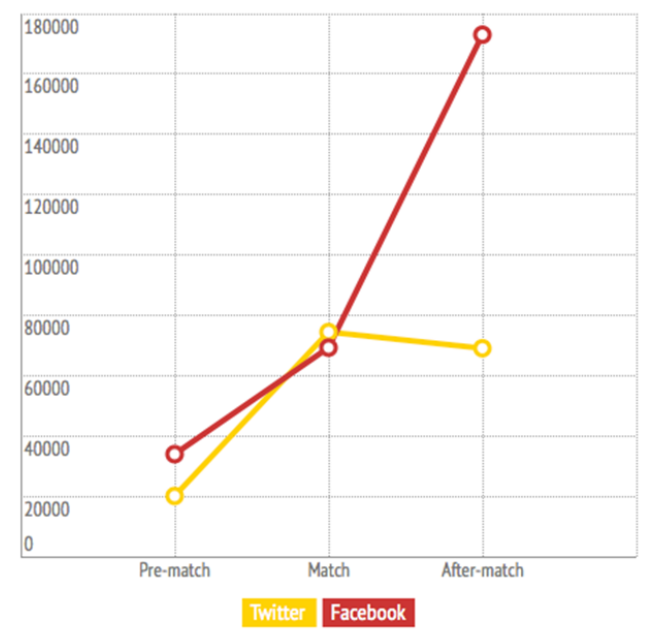

Source: Own source.

During the second stage of our empirical analysis, we tried to understand how users engaged using both Facebook and Twitter. First, we can notice more engagement signs on Facebook than on Twitter ${ }^{9}$. The first platform was used in a more regular way than Twitter. Then, it becomes possible to highlight the different pattern of both platforms. While Twitter reached its peak during the match, Facebook was more use after the match. As we have stated before, Twitter is commonly used as a reporting tool. Due to the limit of characters per post, we can understand Twitter as being a tool for live events, reporting at the same time as it is happening. On the other hand, Facebook without limits in the number of characters per post, allows a more elaborated effort.

Facebook was more used as a like platform, while Twitter had more engagement through the share button. If we pay a closer attention to how people used both platforms, we can understand that the more elaborated possibility for engagement, the comment, was the less used. Moreover, we can assume

9. Shares: Facebook: 276220; Twitter: 163567. Likes: Facebook: 2108804; Twitter: 89204. Comments: Facebook: 175553. 
that even when there is a possibility for users to have a more developed and active role in the informative process, they do not always take that opportunity.

\section{Discussion}

FIFA World Cup represented both for organizers and for media companies a great opportunity to take advantages of the opportunities made available by media technologies, mainly mobile tools and social media platforms.

Regarding these developments, specifically speaking about social media, we tried, in the first RQ to understand how media companies understood the opportunities created for a more multimedia approach. However, and following some of the results from previous analyses (Neto, 2014), the multimedia reality promoted by new media platforms still has a long path ahead before being a reality. Thus, we observed that along with text the most common content in the analysed posts was the link. This result confirms some of the positions presented in our theoretical approach, relating the utilization of social media as a way to achieve more visits on the main websites, instead of being an information tool. Moreover, due to the low numbers of video and images we can also understand that it is still not possible to talk about a truly convergent reality.

In the RQ2 we have tried to understand what were the opportunities created for participation by users. Even with the posts using material from users, when we face the high number of promotional posts, it is possible to explains that social media platforms were used to created an audience instead of a real community. The low number of answers by journalists to the posts made by users also reflects the audience reality. Thus, instead of contribution to real participation, social media tools were used as a way to perpetuate the situation of a empowered user, like in other researchers presented about sport and new media technologies (Lopes, et al., 2013b; Neto \& Lopes, 2014 ).

Taking into account the idea of a global stadium promoted by FIFA, in the RQ3 we tried to understand how media outlets followed this pattern. Apart from the links with connections to the main platforms, with a clear promotional profile, we did not see any major signs of convergence between all the platforms. Instead, the global stadium was substituted by individual stadiums for the same games, annulling any possibility of a common approach for different platfroms, the truly essence of the global stadium. 
Comparing the numbers of Facebook and Twitter becomes easier to understand why Twitter was used in different analyses to understand the relation between social media and political conflits (Meraz \& Papacharissi, 2013; Vis, 2013; França, 2014). The mobile and direct profile of Twitter enables it to be a tool for live information. It's reinforced with the limit of characters per post, making Twitter a more street tools, whereas Facebook is more used for elaborated posts. It's evident in figure 3, where the difference between posts related to the matches and other posts is bigger than on Facebook. Moreover, Twitter was also used as platform to narrate the different matches when the media companies did not have an app for mobile tools.

\section{REFERENCES}

Boyd, D. M. \& Ellison, N. B. (2007). Social network sites: definition, history, and scholarship. Journal of Computer-Mediated Communication, 13(1): 210-230. DOI: 10.1111/j.1083-6101.2007.00393.x

Burns, A. (2010). Oblique strategies for ambient journalism. M/c Journal, 13(2).

Bruns, A. (2011). Gatekeeping, gatewatching, realimentação em tempo real: novos desafios para o jornalismo. Brazilian Journalism Research, 7(2): 119-140.

Bruns, A. (2012). Journalists and Twitter: how australian news organisations adapt to a new medium. Media International Australia Incorporating Culture and Policy, (144): 97-107.

Bruns, A. \& Burgess, J. (2012). Researching news discussion on Twitter: new methodologies. Journalism Studies, 13(5-6): 801-814.

Canavilhas, J. (2010). Do gatekeeping ao gatewatcher: o papel das redes sociais no ecossistema mediático. In II Congreso Internacional Comunicación, vol. 3. Universidad de Salamanca. Retrieved from http://novosmed ios.org/xornalismo/wp-content/uploads/2014/01/mudanzas-gardabarreir as.pdf .

Carpentier, N. (2011). Media and participation: a site of ideological-democratic struggle. Bristol: Intellect Books. 
Dahlgren, P. (2014). Participation and alternative democracy: social media and their contingencies. In P. Serra, E. Camilo \& G. Gonçalves (Eds.), Political participation and WEB 2.0 (pp. 61-87). Covilhã: LabCom.

Deuze, M. (2013). Viver como um zumbi na mídia (é o único meio de sobreviver). MATRIZes, 7(2): 113-129.

França, L. C. M. (2014). “Occupy Brazil”: configurando uma rede de reações. Culturas Midiáticas, 7(1).

Hermida, A. (2010). TWITTERING THE NEWS: the emergence of ambient journalism. Journalism Practice, 4(3): 297-308. DOI: 10.1080/1751278 1003640703

Hermida, A. (2013). \#JOURNALISM: reconfiguring journalism research about Twitter, one tweet at a time. Digital Journalism, 1(3): 295-313. DOI: 10.1080/21670811.2013.808456

Jenkins, H. (2006). Convergence culture: where old and new media collide. New York: University Press.

Jenkins, H. (2014). Rethinking convergence/culture. Cultural Studies, 28(2): 267-297. DOI: 10.1080/09502386.2013.801579

Kperogi, F. A. (2011). Cooperation with the corporation? CNN and the hegemonic cooptation of citizen journalism through iReport.com. New Media \& Society, 13(2): 314-329. DOI: 10.1177/1461444810373530

Lasorsa, D. L.; Lewis, S. C. \& Holton, A. E. (2012). NORMALIZING TwITTER: journalism practice in an emerging communication space. Journalism Studies, 13(1): 19-36. DOI: 10.1080/1461670X.2011.571825.

Livingstone, S. (2010). Interactivity and participation on the Internet: young people's response to the civic sphere. In P. Dahlgren (Ed.), Young citizens and new media: learning for democratic participation (pp. 103-124). London: Routledge.

Lopes, F.; Loureiro, L. \& Neto, I. (2013a). O real (ainda) mora aqui?. Braga: CECS.

Lopes, F.; Loureiro, L. \& Neto, I. (2013b). O ecrã da (hiper) televisão: novos olhares a partir das emissões dedicadas ao Euro 2012 na TV portuguesa. Observatorio $\left(O B S^{*}\right), 7(3)$ : 35-57. 
Meraz, S. \& Papacharissi, Z. (2013). Networked gatekeeping and networked framing on \#Egypt. The International Journal of Press/Politics, 18(2): 138-166. DOI: $10.1177 / 1940161212474472$

Neto, I. (2014). Da TV para o tablet: o processo de convergência dos media portugueses no contexto dos dispositivos de informação móveis. Derecom, (16), 6 .

Neto, I. \& Lopes, F. (2014). Do estádio para a mão: a narração dos jogos da fase final da Liga dos Campeões através das apps para o iPhone. Observatorio $\left(O B S^{*}\right), 8(4)$.

Picard, R. G. (2014). Twilight or new dawn of journalism?: Evidence from the changing news ecosystem. Journalism Studies, 15(5): 500-510. DOI: 10.1080/1461670X.2014.895530

Papacharissi, Z. (2014). Toward new journalism(s): affective news, hybridity, and liminal spaces. Journalism Studies, 16(1): 27-40. DOI: 10.1177/194 0161212474472

Quick, K. S. \& Feldman, M. S. (2011). Distinguishing participation and inclusion. Journal of Planning Education and Research, 31(3): 272-290. DOI: $10.1177 / 0739456 X 11410979$

Rodríguez, C. (2001). Fissures in the mediascape: an international study of citizens' media. NJ: Hampton Press.

Van Dijck, J. (2013). The internet in flux: Twitter and the interpretative flexibility of microblogging. In F. Lee, L. Leung, J. L. Qiu \& D. Ch (Eds.), Frontiers in new media research (pp. 222-241). New York, NY: Routledge.

Vis, F. (2013). TWITTER AS A REPORTING TOOL FOR BREAKING NEWS: journalists tweeting the 2011 UK riots. Digital Journalism, 1(1): 27-47. DOI: $10.1080 / 21670811.2012 .741316$

Williams, B. A. \& Delli Carpini, M. X. (2004). Monica and Bill all the time and everywhere: the collapse of gatekeeping and agenda setting in the new media environment. American Behavioral Scientist, 47(9): 12081230. DOI: $10.1177 / 0002764203262344$ 


\section{Online Sources}

Eurodata TV worlwide. Yearly Sports Key Facts 2014 (September 2013August 2014). Accessed 10 october 2014. www.mediametrie.com/press e/communiques/yearly-sports-key-facts-2014-september-2013-august-2 014.php?id=1141

A Copa do Mundo. De todo o mundo. Accessed 12 october 2014. www.nomi nuto.com/mobile/noticias/copa-do-mundo/a-copa-do-mundo-de-todo-omundo/112335/

Clássico em Manaus bate recorde de audiência na Inglaterra e Itália, diz Fifa. Accessed 12 october 2014 http://globoesporte.globo.com/am/copa-do-m undo/noticia/2014/06/classico-em-manaus-bate-recorde-de-audiencia-n a-inglaterra-e-italia-diz-fifa.html

Primeiros jogos da Copa do Mundo quebram recordes de audiência. Accessed 12 october 2014 http://esportes.terra.com.br/futebol/copa-2014/fifaprimeira-rodada-da-copa-quebra-recordes-de-audiencia,c85b34742ebb6 410VgnVCM3000009af154d0RCRD.html

Estádio global da FIFA abre as portas para que o torcedor \#FAÇAPARTE da \#COPA2014. Accessed 12 october 2014. www.secopa.ba.gov.br/noticias /estádio-global-da-fifa-abre-portas-para-que-o-torcedor-façaparte-da-co pa2014

Fifa oferece conteúdo conectado a redes sociais. Accessed 12 october 2014. www.panoramaaudiovisual.com.br/2014-06-fifa-oferece-conteudo-cone ctado-a-redes-sociais-13550

Mundial somos nós. Accessed 14 october 2014. http://media.rtp.pt/projetos/a pp_mundial/

Details of BBC coverage of the 2014 FIFA World Cup across TV, radio and online. Accessed 14 october 2014. www.bbc.co.uk/mediacentre/mediap acks/worldcup2014/digital

SIC e TVI rompem negociações do Mundial com RTP. Accessed 17 january $2015 \mathrm{http}: / /$ expresso.sapo.pt/sic-e-tvi-rompem-negociacoes-do-mundialcom-rtp=f852478 


\title{
O Estado da Arte da Comunicação Organizacional
}

\author{
Rita Monteiro Mourão, Sandra Miranda \& Gisela Gonçalves \\ Universidade da Beira Interior / Escola Superior de Comunicação Social - Instituto \\ Politécnico de Lisboa / Universidade da Beira Interior \\ E-mail: ritaandreiamourao@gmail.com/smirandadescs.ipl.pt / \\ gisela.ubi@gmail.com
}

\begin{abstract}
RESUMO
A investigação em comunicação organizacional tem vindo a crescer nos últimos anos e a constituir-se como uma necessidade premente para a compreensão da dinâmica e do comportamento organizacional. Porém, o investimento nesta área de estudo e o entendimento da sua complexidade implica a identificação de um percurso histórico e das linhas de investigação que lhe são inerentes. O presente trabalho, tem como principal objetivo revisitar as diferentes linhas de investigação e os respetivos paradigmas que, historicamente, têm atravessado a investigação

em comunicação organizacional até aos nossos dias. Nesse sentido, serão identificados e explicitados os quatro paradigmas principais associados à comunicação organizacional, sendo estes: o paradigma positivista; o paradigma interpretativo; o paradigma crítico e o paradigma dialógico. Esta discussão - praticamente inexistente na literatura, torna-se fundamental não só para percebermos o contexto histórico da comunicação organizacional, mas também para elevarmos o estado de maturidade da disciplina providenciado uma perspetiva integrada da mesma.
\end{abstract}

Palavras-chave: comunicação organizacional; paradigmas; estado da arte.

Data de submissão: 26-04-2016. Data de aprovação: 23-10-2016.

Esta publicação foi apoiada pela Fundação para a Ciência e Tecnologia (FCT), pelo Fundo Social Europeu e fundos nacionais MEC no âmbito da bolsa individual de doutoramento com a referência PD/BD/114005/2015.

A Revista Estudos em Comunicação é financiada por Fundos FEDER através do Programa Operacional Factores de Competitividade - COMPETE e por Fundos Nacionais através da FCT - Fundação para a Ciência e a Tecnologia no âmbito do projeto Comunicação, Filosofia e Humanidades (LabCom.IFP) UID/CCI/00661/2013.

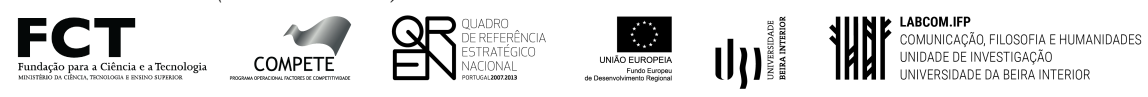




\begin{abstract}
The research about organizational communication has been growing in recent years, because it is necessary to understand the dynamics and organizational behavior. However, the investment in this area of study and understanding of its complexity takes into account the understanding of an historical background and research lines that are inherent. This article aims to revisit the different lines of research and the respective paradigms that historically have crossed the rese-

the present day. In this sense, the four main paradigms associated with organizational communication will be identified and explained, namely: the positivist paradigm; the interpretative paradigm; the critical paradigm and the dialogical paradigm. This discussion - which is little reported in the literature is essential, not only to realize the historical context of organizational communication, but also to understand the discipline mature state considering an integrated perspective.
\end{abstract} arch in organizational communication to

Keywords: organizational communication; paradigms; state of art.

\title{
INTRODUÇÃO
}

definição da comunicação organizacional, enquanto disciplina, tem vindo a constituir-se como uma necessidade (Ruão, 2004). Assim, o seu reconhecimento implica que tenhamos de recuar ao passado (Krone, 2007). Contudo, tal definição tem vindo a ser dificultada pelo facto da comunicação organizacional assumir, ainda, uma identidade pouco clara. As complexidades organizacionais, na qual a comunicação organizacional se enquadra e o seu recente estudo (i.e., remonta às últimas décadas do século $\mathrm{XX}$ ) contribuem para que a questão: O que é a comunicação organizacional? seja, muitas vezes, substituída por Como é que podemos encarar a comunicação organizacional, através de uma determinada perspetiva e em detrimento de uma outra? (Deetz, 2001; Mumby \& Stohl, 1996). Isto porque, sendo este tipo de comunicação um processo dinâmico e complexo, surge a necessidade de enquadrá-la no âmbito de diferentes linhas de investigação, tendo em conta, também, diferentes períodos históricos (Ruão 2004; Ruão, 2008).

De forma a sistematizar o quadro de investigação que envolve a comunicação organizacional, Deetz (2001), identifica as quatro principais tendências 
dos estudos de investigação sobre este tipo de comunicação, considerando o seu legado histórico interdisciplinar. Este autor defende a existência de um conjunto de alternativas, ou seja, um conjunto de sistemas linguísticos úteis para a investigação em comunicação organizacional. Assim, podemos considerar quatro paradigmas que orientam as organizações, a forma de gerir os seus públicos internos e de reportar os eventos organizacionais (SchockleyZalabak, 2012). Estes paradigmas poderão ser representados por um determinado quadrante (figura 1), sendo o eixo vertical constituído pelos extremos Dissensus e Consensus e o eixo horizontal representado pelos extremos Local/Emergent e Elite/A priori.

Segundo a perspetiva de Deetz (2001), cada uma das dimensões acima referidas, poderá ser definida da seguinte forma:

Local/Emergent - dá atenção aos investigadores que trabalham segundo uma linguagem aberta. Neste caso, são considerados sentimentos e intuições. O estudo é guiado mais pela formação de conceito do que pela sua aplicação. $\mathrm{O}$ investigador é encarado como um colaborador na produção de conhecimento ao invés de um expert observador;

Elite/A priori - tem em conta uma linguagem específica da comunidade científica. Neste caso, o processo de investigação considera definições a priori e já existe um conhecimento prévio, contrariamente ao que se verifica na dimensão Local/Emergent;

Consensus e Dissensus - estas expressões não indicam acordo/desacordo, remetendo antes para a unidade vs diferença, continuidade vs descontinuidade. A dimensão Consensus tende a ser encarada como algo normativo, natural e não interpretativo. Nesse âmbito, a linguagem tende a constituir-se como neutra e transparente, para uso partilhado, não podendo existir um desvio. Por sua vez, o conflito e a fragmentação são encarados como problemáticos. A dimensão relativa ao Dissensus remete-nos para aspetos relacionados com o conflito e a tensão. Neste caso, a investigação tende a ser encarada como algo conflitual, por si só, considerando-se uma variedade e alternativas.

Os quatro paradigmas são, cada um deles, constituídos por um dos extremos do eixo horizontal e um dos extremos do eixo vertical. Desta forma, Deetz (2001) considera o paradigma positivista, constituído pelo Consensus e pelo Elite/A priori; o paradigma interpretativo, constituído pelo Consensus e 
pelo Local/Emergent; o paradigma crítico, constituído pelo Dissensus e pelo Elite/a priori e, finalmente, o paradigma dialógico, constituído pelo Dissensus e o Local/Emergent. Para melhor compreensão, cada um dos paradigmas encontra-se identificado na imagem abaixo.

Figura 1. Representação dos 4 paradigmas da Comunicação Organizacional.

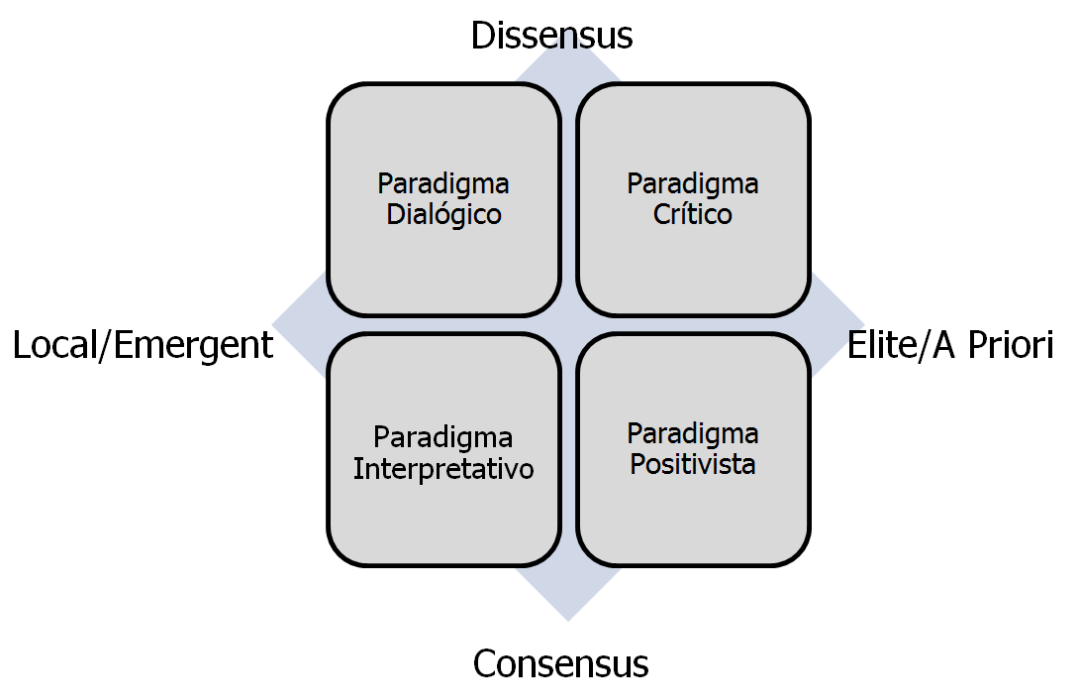

(adaptado de Deetz, 2001, p. 11)

Face ao referido anteriormente, os quatro paradigmas sobre a investigação no âmbito da comunicação organizacional serão explicitados em seguida. Neste caso, ter-se-á em conta não somente os argumentos defendidos por Deetz (2001), como também por outros autores responsáveis pelo estudo da comunicação organizacional enquanto disciplina.

\section{O Estado da Arte da Comunicação Organizacional}

\section{Paradigma Positivista: O discurso dos estudos normativos}

O estudo da comunicação organizacional teve o seu maior enfoque a partir do ano de 1940, dando os seus primeiros passos enquanto disciplina científica entre os anos de 1942 e 1947, designados por Seminal Years (Redding, 1985). 
Contudo, até aos anos 60 não existia um campo próprio de comunicação organizacional, sendo esta muitas vezes associada a disciplinas como a psicologia, a sociologia e a gestão (Redding, 1985; Ruão, 2004). Assim, os seus primeiros estudos realizaram-se entre os anos de 1900 e 1970, designando-se este período por período positivista ou de emancipação (Ruão, 1999).

O paradigma positivista encara as organizações como algo natural e aberto à descrição, à predição e ao controlo, sendo os seus estudos marcados pelo "princípio da racionalidade" (Mumby \& Stohl, 1996). Segundo este princípio, os estudos de comunicação organizacional baseiam-se, essencialmente, num conhecimento instrumental que privilegie a predição e o controlo, com vista à eficácia organizacional (Deetz, 2001; Mumby \& Stohl, 1996; Ruão, 1999; Spence \& Baker, 2007; Taylor, 1993).

A designação de discurso dos estudos normativos, associada ao paradigma positivista, advém do facto de considerar a normalização dos fenómenos comunicativos. Neste caso, assume-se que os objetivos de um grupo específico tendem a ser encarados como os objetivos da própria organização. Nesse âmbito, a organização é encarada como algo pré-existente com determinados fins instrumentais (i.e., gerar dinheiro/lucro), desconsiderando-se, portanto, outros fins organizacionais (e.g. motivação) e as posições dos membros (Deetz, 2001; Redding \& Tompkins, 1988; Schockley-Zalabak, 2012; Taylor, 1993).

A investigação realizada a partir do paradigma positivista, tem em conta as práticas convencionais e os determinantes metodológicos, considerando, por isso, a cobertura de determinadas leis. Neste caso, os objetos construídos através das práticas têm de ser constantes e permanentes. Portanto, têm-se em linha de conta conceções existentes a priori e factos como cómodos. Este paradigma é, também, tendencialmente conhecido como funcionalista, porque utiliza a análise tradicional de variáveis, com vista a generalizações dos fenómenos observados (Deetz, 2001; Redding \& Tompkins, 1988; Ruão, 1999; Wrench \& Punyanunt-Carter, 2012).

No que concerne à comunicação, esta é representada em termos de informação e de administração. Assim, a investigação centra-se, essencialmente, na resolução de problemas relativos à ineficiência comunicativa, sendo as metodologias de investigação utilizadas de cariz, essencialmente, quantitativo (Deetz, 2001; Miller, 2001; Spence \& Baker, 2007). Especificamente, importa frisar que a comunicação organizacional tende a ser encarada como uma transmissão e uma retroação. Assim, o paradigma positivista pressupõe um modelo 
telegráfico deste tipo de comunicação, pois os indivíduos respondem de forma mecânica aos estímulos externos, sendo essencialmente reativos. Por sua vez, a unidade de análise trata-se da entidade organizacional, considerando-se as suas caraterísticas sociais, psicológicas e económicas que são percecionadas como estáticas e não como processos sociais. Nesse sentido, a organização é encarada como uma estrutura concreta e a comunicação como uma substância tangível (Bouzon, 2013). Este tipo de estudos descura, então, as relações estabelecidas no âmbito organizacional. Isto porque estas relações implicam questões subjetivas que não podem ser interpretadas através dos discursos normativos, uma vez que, para isso, seriam necessárias não somente observações, como também entrevistas e questionários auto reportados (Deetz, 2001).

Torna-se relevante referir que o paradigma positivista encontra-se marcado, também, pelo reconhecimento académico da comunicação organizacional. É durante este período que este tipo de comunicação começa a solidificarse enquanto disciplina, diferenciando-se da psicologia, da sociologia e da gestão (Spence \& Baker, 2007). Para além disso, é durante esta época que surgem as primeiras publicações científicas e o primeiro curso de licenciatura (em 1959 - ano de cristalização), bem como a primeira conferência especializada (realizada em 1967 - ano de aceitação oficial) (Redding \& Tompkins, 1988; Ruão, 2008; Taylor \& Trujillo, 2001).

Entre os anos de 1960/1970 o paradigma positivista entra em declínio. Tal deve-se, a algumas limitações deste tipo de abordagem. A primeira limitação refere-se ao facto, das observações serem, inevitavelmente, influenciadas pela posição teórica do investigador, contrariamente à verdade absoluta defendida pelos positivistas. Para além disso, o facto do paradigma positivista ser determinista (i.e., a crença de que os resultados e os fenómenos são o resultado de causas que podem ser duplicadas); reducionista (i.e., o objetivo reduz-se ao fenómeno em si para ser mais fácil estudá-lo); preditivo (i.e., o seu principal objetivo é predizer comportamentos) e empírico (i.e., apenas os dados que se observam podem ser analisados) também se torna alvo de discussão. Assim, a necessidade de distanciar a comunicação organizacional dos estudos de gestão (todos os fenómenos podem ser numericamente medidos) e a necessidade de considerar o holismo, ao invés do atomismo e a causalidade dinâmica, em detrimento da causalidade unidirecional, remete-nos para o surgimento de perspetivas alternativas, surgindo o paradigma interpretativo (Deetz, 2001; Jones, Watson, Gardner \& Gallois, 2004; Krone, 2007; Mumby \& Stohl, 1996). 


\section{Paradigma Interpretativo: $O$ discurso dos estudos interpretativos}

A relevância dada ao paradigma interpretativo torna-se exponencial a partir dos anos 80, ficando conhecido este período, também, como momento de maturidade e de inovação (Redding \& Tompkins, 1988).

De acordo com o paradigma interpretativo, as organizações são encaradas como simbólicas, estruturais e pluralistas. Ou seja, são simbólicas, porque representam relações no processo de mudança; são estruturais, uma vez que podem ter efeitos nas ações diárias dos seus membros; são encaradas como pluralistas, contrariamente à visão unitária da escola funcionalista, porque podem ser compostas por grupos com diferentes interesses e objetivos (Bouzon, 2013). Nesse sentido, para os investigadores interpretativos, a organização trata-se de um espaço social, assumindo-se por isso, como um tipo específico de comunidade que pode partilhar caraterísticas com outras comunidades. Neste caso, o paradigma interpretativo dá ênfase ao cariz social, em detrimento da visão económica das atividades organizacionais, defendida no paradigma positivista. O principal objetivo é o de perceber como é que as realidades particulares, no seio organizacional são produzidas e mantidas ao nível da oralidade, das histórias, dos ritos e rituais e de outras atividades diárias. Ou seja, os discursos interpretativos são, tendencialmente, mais abertos e emergentes e menos ligados à eficiência e à produtividade quando comparados com o paradigma positivista. Nesse âmbito, os indivíduos deixam de ser defrontados como objetos (tratados como todos os outros) e passam a ser encarados como seres ativos, tal como o investigador (Deetz, 2001).

No caso específico da comunicação, pretende perceber-se como é que as pessoas comunicam no seu ambiente natural, contrariamente ao contexto "laboratorial" defendido pelos positivistas (Yanow \& Ybema, 2009). Assim, esta deixa de estar associada à simples transmissão de informação. Isto porque se verifica um interesse em ambas as partes. Ou seja, tem-se em consideração quem dá e quem recebe a informação (i.e., meta-comunicação). Especificamente, pretende compreender-se como é que os indivíduos percebem os seus próprios comportamentos comunicativos e qual o significado que dão a esses mesmos comportamentos (Wrench \& Punyanunt-Carter, 2012).

Por esse motivo, o paradigma interpretativo ficou, também, conhecido por meaning-centered approach (Schockley-Zalabak, 2012), sublinhando-se as dimensões simbólicas e expressivas das organizações, como é o caso da 
cultura organizacional. Nesse âmbito, as organizações passam a ser encaradas como unidades de partilha de valores, práticas e significados, assumindo-se a comunicação não somente como mais uma atividade organizacional, mas antes como um processo subjetivo e socialmente construído e com consequências para as relações sociais (Blair, Roberts \& McKecnie, 1985; Bouzon, 2013; Putnam \& Pacanowsky, 1983; Schockley-Zalabak, 2012; Taylor, 1993). Este paradigma veio descrever a comunicação organizacional como o processo responsável por gerar realidades partilhadas que permitem a tomada de decisão, o consenso, a influência e a cultura, sendo todos estes conceitos encarados como processos de comunicação que ajudam a criar a interação humana (Schockley-Zalabak, 2012).

No que concerne aos métodos utilizados, verifica-se uma utilização dos métodos qualitativos através de estudos de caso, observação prolongada de contextos reais, utilizando-se a observação participante, entrevistas em profundidade e contacto pessoal. Isto porque os investigadores pretendem perceber como é que as culturas organizacionais se desenvolvem e modificam (Blair, Roberts \& McKecnie, 1985; Deetz, 2001; Taylor \& Trujillo, 2001).

O período relativo ao paradigma interpretativo fica marcado pela publicação do livro "The Social Psychology of Organizing" em que Karl Weick (1979) defende a ideia de que as organizações não podem existir sem que exista interação humana e, por isso, sem que exista comunicação. É a partir desta altura que os conceitos de comunicação e de organização passam a ser encarados como sinónimos (Schockley-Zalabak, 2012). Para além disso, esta época fica, também, marcada pelo crescimento da investigação e das premissas teóricas em comunicação organizacional, sendo a partir daí que a disciplina sofre um avultado enriquecimento concetual e metodológico. Tal crescimento deve-se, essencialmente, à concretização de uma conferência sobre as abordagens interpretativas alternativas aos modelos positivistas até então defendidos, realizada no ano de 1981 (Putnam \& Pacanowsky, 1983; Redding \& Tompkins, 1988; Ruão, 2008).

Apesar do enriquecimento concetual da comunicação organizacional, desenvolvido durante o período interpretativo, entre os anos de 1980 e 1990, esta disciplina inicia um processo de crise de legitimidade e de representação. Isto porque surge a necessidade de ter em conta outros aspetos, como por exemplo, como é que se gerem os conflitos no seio organizacional (Deetz, 2001). Neste 
momento, surgem as teorias críticas àquelas até então existentes e defendidas (Taylor \& Trujillo, 2001).

\section{Paradigma Crítico: Discurso dos estudos críticos}

Em 1980, a abordagem interpretativa começa a ser alvo de críticas, tendo em conta a intenção hegemónica de alguns processos comunicativos. Assim, em 1990 surge o paradigma crítico que provém da Escola de Frankfurt. No caso do paradigma crítico, os investigadores encaram as organizações como contextos histórico-sociais, espaços de cariz político e compostos por relações de poder, através dos quais será importante desenvolver teorias relacionadas com as tomadas de decisão (Deetz, 2001). O discurso do paradigma crítico tem em conta questões como: a dominação, a assimetria e a distorção da comunicação. Isto porque, segundo este paradigma, as pessoas, no seio organizacional, tendem a agir, consoante os seus próprios interesses (Alvesson \& Aschcraft, 2009; Deetz, 2001). Assim, estas formas de exercício de poder podem produzir efeitos negativos nas tomadas de decisão, gerando, posteriormente, conflitos organizacionais e, consequentemente, distorções comunicativas, rotinas, normalizações ou falsos consentimentos (Alvesson \& Aschcraft, 2009; Deetz, 2001; Ruão, 2008).

O paradigma crítico centra-se, então, em questões relacionadas com: as ideologias; as instituições; os interesses e as identidades. Nesse âmbito, o envolvimento destes quatro aspetos tem em conta uma ideia que passa a designar-se por Questionando os 4 I's. As ideologias referem-se a crenças, mitos e doutrinas que guiam os indivíduos, os grupos ou as organizações. Os teóricos das perspetivas críticas pretendem examinar até que ponto essas ideologias foram desenvolvidas na organização para serem prejudiciais para alguns (especialmente para os detentores de menor poder). As instituições dizem respeito às instituições dominantes na sociedade, de forma a perceber se estas agem de forma prejudicial para os trabalhadores. Os teóricos do paradigma crítico têm em conta os interesses, para perceber se são ou não incontestáveis e, ao mesmo tempo, prejudiciais para os membros com menos poder. Finalmente, têm-se em consideração as identidades, no sentido de compreender quais é que poderão ser, mais uma vez, prejudiciais para os trabalhadores (Alvesson \& Aschcraft, 2009). 
De acordo com Mumby e Stohl (1996): "a comunicação organizacional não é um processo neutro de transmissão de informação, sendo assim um processo de organização que pode acarretar consequências políticas" (p.60). Considerando os argumentos de Mumby e Stohl (1996), pode mencionar-se que em termos de comunicação organizacional, o principal objetivo do paradigma crítico tem a ver com a criação de sociedades e postos de trabalho livres de um determinado domínio e controlo, onde os membros possam contribuir, de igual forma, para o desenvolvimento da organização. Isto porque este paradigma tem em conta as questões de poder e de abuso de poder, em que existe um processo de controlo baseado num grupo dominante que leva os restantes a acreditar que a submissão é a norma (Mumby, 2001; Schockley-Zalabak, 2012).

No que respeita ao aspeto metodológico, importa referir que, neste caso, já existe uma teoria a priori. Porém, as metodologias utilizadas são as qualitativas e idênticas àquelas que são utilizadas no paradigma interpretativo (Alvesson \& Aschcraft, 2009; Deetz, 2001; Ruão, 2008) Ou seja, a observação de participantes, as entrevistas e os modelos diferenciados de abordagem de resultados (Deetz, 2001). Isto porque, tal como no caso do paradigma interpretativo, também o paradigma crítico tem em conta a subjetividade e a abertura à interpretação (Wrench, 2013).

Finalmente, torna-se pertinente frisar a existência de duas correntes associadas aos estudos críticos, sendo estas: a ideologia crítica e a ação comunicativa. A ideologia crítica surgiu com o autor Marx. Este autor verificou que existe uma coerção, relativamente a quem é o detentor do capital. Nesse âmbito, sugere-se que os interesses específicos falham na sua concretização, uma vez que as pessoas não têm capacidade suficiente para perceber e agir, de acordo com os seus próprios interesses. Portanto, o que se pretende será banir a coerção e promover a adoção de processos sistémicos. No caso da ação comunicativa, consideram-se os estudos sobre distorção comunicativa, do autor Habermas, realizados a partir dos anos 70. Segundo este autor, o ato comunicativo, para constituir-se eficaz terá de considerar não somente o indivíduo que "fala", como também o indivíduo que "escuta". Nesse âmbito são considerados quatro domínios da realidade: a linguagem, o mundo externo, as relações humanas e o mundo interno do indivíduo. O ato comunicativo terá, também, de ter em conta: a apresentação de uma expressão que seja compreendida; ter uma proposição de conhecimento; estabelecer relações sociais 
legítimas; ter em conta a posição/ experiência de quem fala. Estes aspetos podem ser a base de uma comunicação eficaz como, também, da distorção comunicativa. Ainda relativamente à ação comunicativa, importa referir que, para que a participação na resolução de conflitos se torne aberta e livre, têm de considerar-se determinadas condições, sendo estas as seguintes: a existência de uma distribuição simétrica de possibilidade de discurso; a interpretação livre do mundo, para que haja uma conceção e desenvolvimento social da verdade, sendo que o ideal será que os participantes tenham oportunidade de expressar as suas próprias interpretações, gerando-se conflitos resolúveis; os indivíduos deverão ter oportunidade de estabelecer relações sociais legítimas e normas de condução e interação. Assim, conclui-se que as responsabilidades e os direitos devem ser adquiridos, segundo uma negociação e interação. Face aos aspetos mencionados anteriormente, torna-se possível perceber que a ação comunicativa inclui uma conceção de comunicação participativa (i.e., através da qual é possível descrever a possibilidade de tomadas de decisão mútuas) (Deetz, 2001).

Finalmente, importa frisar o papel do paradigma dialógico. Este é idêntico ao discurso dos estudos críticos, embora tenha em conta os processos micropolíticos.

\section{Paradigma Dialógico: Abordagem pós-moderna}

O paradigma dialógico surge no âmbito do pós-modernismo, tendo sido a sua perspetiva realçada em França por autores como Bourdieu, Foucault, Mumby \& Putnam (1992) e Burrell (1988). Este paradigma é idêntico ao paradigma crítico, uma vez que tem em conta questões de assimetria e de poder no âmbito da comunicação organizacional. Contudo, realça o papel dos processos micro políticos, da fragmentação e da resistência (Deetz, 2001; Ruão, 2008). Neste caso, a coerção passa a ser encarada como algo de cariz fluido, situacional, sem um local próprio ou origem (Deetz, 2001). Considera-se que apesar de ter em conta uma perspetiva crítica, o paradigma dialógico tende a ser mais radical do que o paradigma crítico (Krone, 2007). Isto porque o paradigma crítico veio demonstrar situações de domínio e de produção de oposição. Por sua vez, o paradigma dialógico pretende desmascarar e desconstruir mitos e assunções, para abrir o leque de possibilidades de novos entendimentos e processos (Schockley-Zalabak, 2012). Assim, o paradigma dialógico 
baseia-se, sobretudo, nas questões éticas, considerando as perspetivas feministas e raciais (Jones et al., 2004; Taylor \& Trujillo, 2001). As perspetivas feministas têm em conta a marginalização das mulheres no mercado de trabalho; considerando o estabelecimento de relações de poder que desvalorizavam as mesmas. Por sua vez, as perspetivas raciais analisam o domínio de uma raça maioritária e a desvalorização e silêncio das minorias, no seio organizacional (Aschcraft \& Mumby, 2004; Miller, 2012; Schockley-Zalabak, 2012).

Importa referir os 7 aspetos fundamentais sobre os quais se baseia o paradigma dialógico:

A centralidade do discurso - a comunicação passa a ser uma forma de explicar as organizações e as suas atividades;

A fragmentação de identidades - o próprio ser humano tende a ser fragmentado, sendo que o discurso constitui-se como mais heterogéneo, podendo existir uma identidade fluída e conflitual;

A crítica da filosofia da presença - a linguagem torna-se essencial para a produção de objetos. Contudo, esta depende dos contextos social e histórico nos quais se encontram os indivíduos que concretizam a sua interpretação. Portanto, não tem de representar a realidade. Terá de considerar-se, simultaneamente, um entendimento das pessoas e da realidade;

Perda de fundações e das macro narrativas - contra as fundações das "verdades absolutas", como o Marxismo ou o funcionalismo;

A ligação entre o conhecimento e o poder - produção de conhecimento e verdade em sistemas de domínio. Foi o que criou o conceito de disciplina;

A hiperrealidade - as novas tecnologias e os fenómenos de mass media, levam a uma abertura relativamente a elementos externos;

A investigação como algo resistente e indeterminado - diferencia-se, bastante, dos discursos tradicionais, uma vez que tem em conta a área das ciências sociais, a produção de discórdia e de novas formas do conhecimento. Ou seja, tem em conta o papel que a investigação assume, em processos de mudança;

Abertura das ciências sociais modernas - defendendo-se que deverá ser alvo de mudança. 
Face aos aspetos acima mencionados consegue perceber-se que o paradigma dialógico considera os paradigmas positivista e interpretativo como simplistas, uma vez que estes não têm em conta as rápidas mudanças dos contextos e a multiplicidade de significados. Nesse sentido, os teóricos defensores do paradigma dialógico passam a colocar questões como: Como é que os múltiplos significados e as múltiplas interpretações podem influenciar múltiplos e diversos comportamentos? Face ao exposto, torna-se relevante mencionar que o método de análise do paradigma dialógico relaciona-se com aquilo que se designa por desconstrução. Ou seja, este paradigma baseiase em aspetos como: valores de partilha de poder, empowerment (i.e., empoderamento), interdependência, múltiplas interpretações de eventos diários (Schockley-Zalabak, 2012). Dentro dessa desconstrução, alguns autores defendem a existência de duas tendências. Por um lado, as meta-análises, os documentos organizacionais e a investigação organizacional. Por outro lado, os métodos associados à investigação empírica (Taylor \& Trujillo, 2001).

Conclui-se, então que, os aspetos acima frisados, que caraterizam o paradigma dialógico terão um impacto na qualidade da comunicação organizacional, e nas consequentes tomadas de decisão e direções das linhas de investigação.

\section{CONCLUSÃo}

Os diferentes paradigmas que estudam o conceito de comunicação organizacional têm vindo a surgir de forma fragmentada, uma vez que emergem da prática para a academia (Oliveira \& Ruão, 2013). Nesse sentido, perceber a evolução da comunicação organizacional enquanto disciplina torna-se fundamental para que os investigadores possam situar-se e escolher as suas próprias linhas de investigação. O presente trabalho permitiu-nos a identificação de quatro paradigmas principais, sendo estes: o paradigma positivista; o paradigma interpretativo; o paradigma crítico e o paradigma dialógico.

De forma genérica, tornou-se possível concluir que o paradigma positivista considera o estudo da comunicação organizacional e da sua relação com a eficácia organizacional (Mumby \& Stohl, 1996; Ruão, 1999; Spence \& Baker, 2007). Nesse sentido, este paradigma tem em conta modelos que considerem, essencialmente, aspetos relacionados com a formação de competências comunicativas, que possam contribuir para a eficiência das organizações (Red- 
ding \& Tompkins, 1988). Por sua vez, o paradigma interpretativo, considera que cada organização corresponde a uma realidade específica, desenvolvida através de conversas, histórias, ritos, rituais e outras atividades diárias (Deetz, 2001). Neste caso, a resolução de problemas será dada através da afirmação grupal e de uma aculturação social (Blair, Roberts \& McKecnie, 1985; Taylor \& Trujillo, 2001). O paradigma crítico encara as organizações como espaços de cariz político, sendo consideradas questões relacionadas com a hegemonia e com as assimetrias de poder. Este paradigma sugere, então, uma análise das dinâmicas de poder e das questões políticas, aquando do estudo da comunicação organizacional, considerando que estes exercícios de poder podem acarretar consequências negativas para as tomadas de decisão, gerando-se conflitos organizacionais (Alvesson \& Aschcraft, 2009, Ruão, 2008). Finalmente, o paradigma dialógico, ficou conhecido por rejeitar as noções de autoridade e poder, estabilidade de significados e conceitos de eficácia; representando uma alienação relativamente ao passado, um ceticismo acerca das estruturas de autoridade, ambiguidade de significados e cultura de massas (SchockleyZalabak, 2012).

A perspetiva histórica da comunicação organizacional, torna-se útil para a compreender como é que a mesma poderá constituir-se como um campo teórico autónomo, atualmente. Isto porque a investigação em comunicação organizacional não tem vindo a assumir uma identidade clara. O quadro atual reflete todo o percurso acima mencionado, encontrando-se marcado, essencialmente, pelo movimento interpretativo do século XX (Taylor \& Trujillo, 2001). Nesse sentido, sugere-se uma amálgama de paradigmas, adequandose, cada um deles, ao contexto organizacional específico que se pretende estudar. Conclui-se, então que, o futuro da comunicação organizacional, tal como o seu passado, terá em conta a implicação de vários métodos, teorias ecléticas e diferentes pressupostos que deverão ser considerados.

\section{REFERÊNCIAS}

Alvesson, M. \& Ashcraft, K. L. (2009). Critical methodology in management and organizational research. In D. A. Buchannan \& A. Bryman (Eds). The sage handbook of organizational research methods (pp. 61-77). Los Angeles, CA: Sage Publications. 
Ashcraft, K. L. \& Mumby, D. K. (2004). Reworking gender: a feminist communicology of organization. Thousand Oaks, CA: Sage Publications.

Blair, R.; Roberts, K. \& McKecnie, P. (1985). Vertical and network communications in organizations: the present and the future. In R. D. McPhee \& P. $\mathrm{K}$. Tompkins (eds). Organizational communication: traditional themes and new directions (pp. 55-77). U.S.A: Sage Publications.

Bouzon, A. (2013). Theoretical approaches in organizational and strategic communication: a review of the french academic literature. In G. Gonçalves, I Somerville \& A. Melo (eds). Organizational and strategic communication research: european perspetives (pp. 23-45). Covilhã: Livros Labcom.

Deetz, S. (2001). Conceptual foundations. In F. M. Jablin \& L. L. Putnam (Eds). The new handbook of organizational communication: advances in theory, research and methods (pp. 3-46). Thousand Oaks: Sage Publications.

Jones, E.; Watson, B.; Gardner, J. \& Gallois, C. (2004). Organizational communication: challenges for the new century. International Communication Association, 54: 722-750.

Krone, K. (2007). Trends in organizational communication research: sustaining the discipline, sustaining ourselves. Communication Studies, 56 (1): 95-105.

Miller, K. (2001). Quantitative research methods. In F. M. Jablin \& L. L. Putnam (Eds). The new handbook of organizational communication: advances in theory, research and methods (pp. 137-160). Thousand Oaks: Sage Publications.

Miller, K. (2012). Organizational communication: approaches and processes. Boston: Wadsworth, Cengage Learning.

Mumby, D. (2001). Power and politics. In F. M. Jablin \& L. L. Putnam (Eds). The new handbook of organizational communication: advances in theory, research and methods (pp. 585-623). Thousand Oaks: Sage Publications.

Mumby, D. K. \& Stohl, C. (1996). Disciplining organizational communication studies. Management Communication Quarterly, 10: 50-72. 
Oliveira, E. \& Ruão, T. (2013). Os quatro paradigmas da comunicação estratégica e o ensino em Portugal. Atas do VIII Congresso da SOPCOM. Lisboa: Escola Superior de Comunicação Social - Instituto Politécnico de Lisboa.

Putnam, L. \& Pacanowsky, M. (eds) (1983). Communication and organizations: an interpretative approach. Beverly Hills, CA: Sage Publications.

Redding, C. (1985). The emergence of organizational communication as a field of study. In R. D. McPhee \& P. K. Tompkins. Organizational communication: traditional themes and new directions (pp. 15-54). U.S.A: Sage Publications.

Redding, C. \& Tompkins, P. (1988). Organizational communication: past and presente tenses. In G. M. Goldhaber \& G. A. Barnett (eds). Handbook of organizational communication (pp. 5-33). Norwood: Ablex Publishing.

Ruão, T. (1999). A Comunicação organizacional e a gestão de recursos humanos: evolução e actualidade. Cadernos do Noroeste,12(1-2): 179-194.

Ruão, T. (2004). O estado da arte em comunicação organizacional. 19002000: um século de investigação. Atas do III Congresso da SOPCOM, VI LUSOCOM e II Ibérico. Covilhã: Universidade da Beira Interior.

Ruão, T. (2008). A Comunicação organizacional e os fenómenos de identidade: a aventura comunicativa da formação da Universidade do Minho, 1974-2006. Tese de Doutoramento, Universidade do Minho, Braga, Portugal.

Schockley-Zalabak (2012). Fundamentals of organizational communication: knowledge, sensitivity, skills, values ( $\left.8^{\circ} \mathrm{ed}\right)$. Colorado: Pearson Education.

Spence, P. R. \& Baker, C. R. (2007). State of the method: examination of levels of analysis, methodology, representation and setting in current organizational communication research. Journal of the Northwest Communication Association, 36: 111-124.

Taylor, B. \& Trujillo, N. (2001). Qualitative research methods. In F. M. Jablin \& L. L. Putnam (Eds). The new handbook of organizational communication: advances in theory, research and methods (pp. 161-196). Thousand Oaks: Sage Publications. 
Taylor, J. (1993). Rethinking the theory of organizational communication: how to read an organization. New Jersey: Ablex Publishing.

Wrench, J. S. (2013). Communicating within the modern workplace: challenges and prospects. In J. S. Wrench (Ed). Workplace communication for the 21st Century: tools and strategies that impact Bottom line. CA: Praeger.

Wrench, J. \& Punyanunt-Carter, N. (2012). An Introduction to organizational communication. U.S.A: Sage Publications.

Yanow, D. \& Ybema, S. (2009). Interpretivism in organizational research: on elephants and blind researchers. In. D. A. Buchannan \& A. Bryman (Eds). The sage handbook of organizational research methods (pp. 3960). Los Angeles, CA: Sage Publications. 
$\bigoplus$

$\bigoplus$

$\oplus$ 


\title{
El juego en red o el juego enredado: la dimensión interactiva de los juegos de las redes sociales
}

\author{
Carolina Duek \& Gastón Tourn \\ CONICET, Universidad de Buenos Aires / Oxford University, Google \\ E-mail: duekcarolina@gmail.com/gaston.tourn@gmail.com
}

\begin{abstract}
RESUMEN
El objetivo de este trabajo es presentar un análisis de los videojuegos de las redes sociales, en un contexto en el que gran parte de las interacciones digitales se despliegan en estas plataformas. Nos preguntaremos qué características particulares adquieren estos juegos para acercarnos a su sentido en el entramado cultural contemporáneo. De este modo, nos proponemos comprender qué tipos de in-

teracciones sociales se promueven y qué implicancias tiene esta modalidad de interacción en las prácticas lúdicas y sociales en general. Este análisis nos permitirá reflexionar sobre una arista poco explorada de las redes sociales, lo cual nos abrirá nuevos interrogantes para pensar las interacciones digitales y las tecnologías de la información y la comunicación (TICs).
\end{abstract}

Descriptores: redes sociales; videojuegos; TICs; interacciones digitales; comunicación.

Data de submissão: 04-05-2016. Data de aprovação: 23-10-2016.

A Revista Estudos em Comunicação é financiada por Fundos FEDER através do Programa Operacional Factores de Competitividade - COMPETE e por Fundos Nacionais através da FCT - Fundação para a Ciência e a Tecnologia no âmbito do projeto Comunicação, Filosofia e Humanidades (LabCom.IFP) UID/CCI/00661/2013. 


\title{
Network games or entangled games? The interactive di- mension of social games
}

\begin{abstract}
The objective of this paper is to present an analysis of social games in a context in which social media occupies a great part of digital interactions. We inquire which specific characteristics have these games to approach their meaning in the contemporary cultural framework. In this sense, we research which types of social

and what implications this type of interaction has in ludic and social practices in general. This analysis will allow us to reflect on an unexplored edge of social networks, which will open new questions to think about digital interactions and information \& communication technologies (ICT).
\end{abstract} interactions are promoted in these games

Keywords: social media; video games; ICT; digital interactions; communication.

\section{Presentación}

Las redes sociales han adquirido una importancia cada vez mayor en las discusiones sobre nuevas Tecnologías de la Información y la Comunicación (TICs). Resulta indudable que estas páginas de Internet empezaron a acompañar - desde hace unos años - las palpitaciones de nuestra vida cotidiana. Las estadísticas lo corroboran. Facebook, la red social más popular en la actualidad, es el tercer sitio web más visitado luego de Google y YouTube. Una visita típica a la plataforma de Zuckerberg dura alrededor de 20 minutos. Según la consultora comScore, Argentina lidera a nivel mundial el uso de redes sociales, con un consumo de casi 10 horas mensuales por usuario. América Latina destina a este tipo de páginas un 56\% más de tiempo que el promedio global.

En este contexto en el que proliferan las redes sociales, una arista poco explorada - en la bibliografía específica - ha sido el rol que desempeñan los videojuegos en el desarrollo de estas plataformas digitales. La reciente emergencia de diversas investigaciones en este novedoso campo de estudio se vio acompañada por el crecimiento exponencial de este fenómeno en línea. Actualmente, jugar es la quinta actividad más popular de Facebook. Asimismo, 
de las veinte aplicaciones más utilizadas y mejor calificadas en el sitio, dieciocho son videojuegos. Si bien estos juegos electrónicos no se propagan con la rapidez que alcanzan otras herramientas de esta red social, logran una lealtad extraordinaria ya que una vez que un usuario empieza a jugar, tiende a volver asiduamente.

A su vez, algunas de las redes sociales con mayor uso por fuera de Facebook se focalizan casi exclusivamente en el desarrollo de social games [juegos sociales], es decir, videojuegos inscriptos en redes sociales. En el caso argentino, Mundo Gaturro y Club Penguin constituyen dos sitios de referencia a la hora de jugar en Internet. Mundo Gaturro es una plataforma basada en los personajes del humorista gráfico Cristian Dzwonik (Nik) y financiada por la Compañía de Medios Digitales (CMD, empresa del Grupo Clarín S.A.). Club Penguin -creado en octubre de 2005- es una web que se asienta en un mundo virtual desarrollado por New Horizon Interactive (empresa que fue adquirida por The Walt Disney Company en agosto de 2007). Los personajes principales son unos pingüinos que participan en distintos juegos en un entorno similar a la Antártida. Ambas páginas priorizan en sus plataformas los juegos sobre cualquier otra práctica digital.

Si se tiene en cuenta que los juegos constituyen una de las actividades principales en Internet, resulta imprescindible analizar qué características particulares adquieren los mismos en tanto interacción virtual.

El propósito de este trabajo consiste en identificar qué tipo de relaciones, acciones y dinámicas se promueven en los videojuegos de las redes sociales mencionadas e identificar el rol que tienen, para los informantes, estos nuevos espacios de juego. De este modo, buscaremos reflexionar sobre las implicancias de estas interacciones digitales en las prácticas lúdicas y sociales. Asimismo, creemos que este análisis nos abrirá nuevos interrogantes para pensar las interacciones digitales y las TICs.

\section{ESTADO DE LA CUESTIÓN E HIPÓTESIS}

La velocidad con la que se han desarrollado los nuevos dispositivos electrónicos y medios de comunicación ha cambiado el ecosistema comunicativo (Martín-Barbero, 2003) en el que vivimos. Una de las transformaciones más importantes en relación a los vínculos son las redes sociales. Facebook, Twitter, LinkedIn, Instagram, Snapchat, entre muchas otras, han transformado el 
vínculo entre los sujetos, la tecnología y las formas de interacción. Hay varias razones por las que sostenemos esta afirmación. En primer lugar, la transformación de la escala y de la percepción del tiempo y el espacio (Jameson, 1998: VI-XVI) ha modificado las posibilidades de estar en contacto con diferentes personas en todo el mundo. Esto significa que, con un par de clics, podemos conectarnos con alguien del otro lado del planeta. Podemos encontrarnos antiguos compañeros, amigos, compañeros de escuela o ex novios. El contacto social es, en síntesis, la primera transformación.

En segundo lugar, las redes sociales se han convertido en la forma más eficaz de presentarse ante los demás (en el sentido propuesto por Goffman, 1974). A través de la interacción de todos los perfiles, imágenes y pensamientos publicados, configuramos una cierta imagen de nosotros mismos delante de nuestros "amigos"(Livingstone, 2009; Elias, 2015: 133-8).

En tercer lugar, el uso de la palabra "amigo"como sinónimo de añadir a alguien a nuestro perfil haciendo clic un par de veces (Turkle, 2015: 137-176). La idea de amigo, como sostiene Pahl (2003), necesita ser contextualizada ya que la amistad es un concepto informal, dinámico y variable. El tipo de amigos y las relaciones que (podemos) construir con ellos están íntimamente vinculados a las condiciones materiales y simbólicas en las que vivimos. Los amigos explican nuestras vidas y sus cambios. Estamos frente a un nuevo uso de la palabra: un amigo puede ser alguien que nunca conocimos, pero que es un conocido de un conocido en las redes sociales (Telles, 2011).

Fundamentaremos nuestro análisis en el interaccionismo simbólico y la teoría de la comunicación humana. Según Watzlawick et al. (1973), la comunicación posee ciertas propiedades de naturaleza axiomática que llevan implícitas consecuencias fundamentales para el estudio de las interacciones. Watzlawick et al. enumeran cinco axiomas de la comunicación.

1. No es posible no comunicar.

2. Toda comunicación tiene un nivel de contenido y un nivel relacional.

3. La naturaleza de una relación depende de la forma de puntuar las secuencias de comunicación (y del vínculo entre los interlocutores).

4. Las personas utilizan tanto la comunicación digital como la analógica (verbal y no verbal).

5. Todos los intercambios comunicacionales son simétricos o complementarios, según estén basados en la igualdad o en la diferencia. 
Basándonos en algunas dimensiones de estos postulados, analizaremos qué tipos de interacciones se promueven en los juegos de las redes sociales y qué implicancias tienen las nuevas modalidades de interacción en las prácticas lúdicas y sociales en general.

La hipótesis que vamos a sostener en este trabajo es que los social games se construyen como espacios que permiten - a diferencia de los videojuegos tradicionales - conocer nuevas personas y mantener el contacto con "amigos". Si bien estos videojuegos se definen como "sociales", planteamos que la interacción se encuentra restringida por la arquitectura de estas plataformas digitales. A su vez, nos preguntaremos si los intercambios que se promueven en estos videojuegos se asientan sobre mecanismos lúdicos o de contacto "virtual" y si son vínculos recíprocos o competitivos.

En primer lugar, sugerimos que los social games establecen la acumulación de objetos y el exhibicionismo como principales dinámicas de interacción. En este sentido, la mecánica de estas plataformas pareciera operar principalmente como un medio para la institución y la preservación del status, a través de la ostentación de diversos consumos mediante la conformación "automática" de rankings.

En segundo lugar, creemos que la mayor parte de estas características no son exclusivas de las aplicaciones de las redes sociales, sino que replican ciertos esquemas culturales imperantes. Los social games no reemplazarían a los juegos y videojuegos previos, sino que entrañan la supervivencia de rasgos de ciertos juegos "tradicionales". Las prácticas lúdicas en las plataformas virtuales parecieran reciclar algunos elementos del entramado cultural contemporáneo y exacerbar ciertos patrones ligados al consumo, la acumulación y la exhibición.

Para Vigotsky ([1930] 1986: 12), los juegos son una "escuela vivencial" para los niños y niñas. Su importancia es vital para modelar la personalidad de los más chicos y la forma en la que se vinculan con el mundo. En la actualidad, el lugar de los juegos se multiplica por la disponibilidad y portabilidad de los dispositivos, pero, también, por la existencia de plataformas y redes sociales que alientan las interacciones lúdicas a través de diferentes propuestas. Es por ello que analizar los juegos y las interacciones a través de las nuevas tecnologías no sólo nos abre un campo de estudio sobre el juego, sino que da cuenta de la relevancia de los temas y problemas de la cultura infantil contemporánea (Steinberg y Kincheloe, 1997: 26). 
Por último, sugerimos que la creciente interacción por medios digitales reconfigura los modos de sociabilidad contemporáneos, ya que estas prácticas virtuales forman parte de una transformación que tiende a la vinculación por medio de pantallas (Jenkins et al., 2015).

\section{MATERIAL Y MÉTODOS}

La investigación en la que se enmarca este trabajo - y el estudio específico que desarrollaremos aquí de un fenómeno cultural contemporáneo - se propone articular diferentes fuentes y métodos de investigación. Mediante el andamiaje metodológico que se precisa a continuación, buscamos construir distintas interpretaciones que den cuenta de la complejidad que presentan los social games.

\section{Análisis de juegos}

Relevamos la oferta disponible de social games en Facebook, Mundo Gaturro y Club Penguin e identificamos y analizamos los principales videojuegos. Los social games más significativos fueron caracterizados a partir de una grilla que consideraba los siguientes criterios: a) objetivo; b) diseñador; c) empresa desarrolladora; d) año de lanzamiento; e) plataforma; f) género; g) multijugador cooperativo/competitivo; h) rol protagónico; i) rol del usuario; j) presencia o ausencia de niveles; k) tipos de escenarios y l) propagación a otros soportes como bandas de sonido, films, merchandising, etc. (para ampliar, ver Tourn, 2013).

En este trabajo no nos centraremos en los videojuegos de consola dado que trascienden a los objetivos del presente análisis. Un estudio exhaustivo de esos videojuegos puede consultarse en Duek (2012) y Tourn (2012).

A partir de la comparación de las dinámicas, los roles, los personajes, las temáticas y las acciones de los principales videojuegos de las redes sociales, construimos una tipología general de estas prácticas lúdicas.

\section{Entrevistas en profundidad}

Para indagar sobre las prácticas de los sujetos en estas plataformas virtuales, realizamos una serie de entrevistas en profundidad en el proyecto de 
investigación PICT 2011-2013: "Juguetes, consolas y dispositivos electrónicos: ¿los nuevos auxiliares lúdicos infantiles? (un análisis del juego infantil contemporáneo)", dirigido por la Dra. Carolina Duek (UBA/CONICET). Entrevistamos a veintidós informantes de entre 6 y 11 años, que cumplieran con los siguientes requisitos: 1) ser habitantes de la Ciudad de Buenos Aires, 2) estudiar en escuelas públicas de jornada simple, y 3 ) utilizar redes sociales. Teniendo en cuenta que la población a analizar era demasiado amplia, construimos una muestra bajo los criterios de saturación teórica (Glaser y Strauss, 1967: 61).

En estas entrevistas, distinguimos los usos de las redes sociales que hacen los informantes. En esta línea, rastreamos los contextos en los que las usan, si lo hacen solos o acompañados, fuera o dentro del horario escolar, etc. Asimismo, examinamos los tipos de plataformas que prefieren y qué placeres y displaceres encuentran en esta práctica. Mediante este relevamiento, identificamos el lugar que ocupan las redes sociales en la población estudiada.

En este trabajo, no abordaremos las interacciones que suceden en los foros de los social games debido a limitaciones de espacio. Un análisis pormenorizado de estas comunidades digitales puede consultarse en Tourn (2012).

\section{Análisis de discurso}

Luego de examinar los videojuegos de las redes sociales y entrevistar a sus usuarios, identificamos las semejanzas y diferencias entre los usos y apropiaciones de las distintas plataformas. De este modo, observamos las tácticas (en el sentido descripto por De Certeau, 1996: 68) que se llevan a cabo en estas prácticas digitales. Por otra parte, realizamos una descripción de distintos discursos que propician el consumo de niños y niñas, a partir del herramental semiótico de la Teoría de los Discursos Sociales (Verón, 1985). Por medio de este análisis, indagamos el lugar que ocupan las redes sociales en el marco general de las redes de consumo para el mercado infantil. Este ejercicio nos permitió reflexionar críticamente sobre las plataformas que promueven hábitos de consumo en niños de entre 6 y 10 años.

Mediante la utilización de estos métodos y técnicas de investigación, buscamos revisar las hipótesis iniciales y rediscutir ciertos aspectos teóricos del campo de la comunicación y la cultura. 
En el próximo apartado, analizaremos en detalle las interacciones que los niños tienen con los videojuegos de las redes sociales. Identificaremos qué tipos de relaciones, acciones y dinámicas se promueven en los social games.

\section{ANÁlisis Y RESULTADOS}

El abordaje de los resultados de la investigación nos demandó la operacionalización de los cinco axiomas de Watzlawick et al. (1973). En este artículo trabajaremos con algunos elementos de los axiomas que nos permitirán iluminar los resultados de la indagación sobre la que se organiza este trabajo. Probablemente sea el primero de todos el que organizará la presentación de los resultados: "No es posible no comunicar". Esto significa que todo acto es un acto de comunicación. Intencional, involuntario, arbitrario o convencional, somos seres comunicantes que, a su vez, no pueden optar por la no-comunicación. Analizar la relación entre los usuarios y las pantallas exige, en consecuencia, la pregunta por las formas que asumen tanto la interacción como la comunicación en un contexto signado por los accesos, los contactos y los "amigos" virtuales. La afirmación de la imposibilidad de la comunicación jerarquiza nuestro análisis al identificar todo acto (un clic, un "me gusta", una invitación a compartir un espacio) como una forma de comunicación en pos de un objetivo de interacción.

En el año 2006, el Ministerio de Educación de la Argentina condujo una encuesta nacional de consumos culturales y los resultados presentados sostienen que ningún niño o niña mencionó el uso de una red social como una práctica cotidiana (para ampliar los detalles de los resultados ver Morduchowicz, 2012). Seis años después, en 2012, una nueva investigación del Ministerio mostró que más del $95 \%$ de los encuestados visitaban esos sitios y que el $75 \%$ de ellos tenía un perfil activo en la red social Facebook, la página más visitada en la Argentina (Morduchowicz, 2012).

Una visita típica a la plataforma desarrollada por Mark Zuckerberg dura, aproximadamente 20 minutos ${ }^{1}$. En este contexto de proliferación y crecimiento exponencial del uso y de las apropiaciones de las redes sociales, el juego aparece como una dimensión poco explorada por la bibliografía, pero muy

1. Este dato fue relevado por Alexa, una compañía especializada en el análisis de tráfico web. Las métricas actualizadas sobre Facebook pueden examinarse en www.alexa.com/ siteinfo/facebook.com 
relevante en la palabra de los informantes que participaron en nuestra investigación. Jugar en Facebook es, como ya mencionamos, la quinta actividad más popular en la plataforma.

La consultora eMarketer (2013) sostiene que casi la mitad de los usuarios de Facebook utiliza la red para jugar, actividad que está por encima de "ver videos", otra de las actividades más frecuentes por parte de los usuarios. Finalmente, según cifras oficiales de Facebook, 18 de las 20 aplicaciones mejor calificadas son juegos ${ }^{2}$. Según Kirkpatrick (2010: 156), en los casos de juegos no masivos (con una acotada cantidad de jugadores), la fidelidad de los usuarios es tan extraordinaria que la relación con ese juego se sostiene en el tiempo. En síntesis, no se trata solo de analizar las estadísticas de los juegos en línea sino de ver de qué modos se sostiene la interacción con la plataforma en el sentido que Hall (1963) define la relación entre comunicación y espacio. Definir territorios, marcar límites utilizando todos los canales de comunicación disponibles, es un elemento común en la interacción contemporánea (Baylon y Mignot, 1996, Verón, 1987, Graner Ray, 2004). El territorio ha sido clave para el análisis de la comunicación pero, en la actualidad, se extiende, por medio de aparatos y dispositivos, al mundo virtual y se abre a nuevas formas de vinculación, conexión e intercambio.

Una de las invariantes que apareció en la palabra de los informantes se vincula con la socialización y con la puntuación, tal como la definen los axiomas de la comunicación, de las relaciones:

A mí me encantan los juegos en Facebook, me gustan todos (...) pero juego más a los que juegan mis amigos por los rankings y para que estemos todos haciendo algo parecido. No está bueno ser el único que juega a ese juego porque no puedo intercambiar cosas con nadie y no te ayudan nada.

(Tomás, 8 años)

Tomás sintetiza varias dimensiones que aparecieron con recurrencia en los testimonios de los informantes. Jugar es una actividad que identifica como placentera, pero hay una clave que va más allá de las peculiaridades del juego: la relación con otros a través del juego. Facebook propone, desde sus comienzos, una manera de organizar las relaciones virtuales bastante particular; no

2. Las cifras oficiales de Facebook pueden consultarse en www.facebook.com/appcenter 
se trata solamente de tener "amigos", sino que cada vez que habilitamos una aplicación o juego nuevo, nos muestra quiénes están jugándolo, cuáles son sus mayores puntajes y cómo se compone la tabla de resultados entre nuestros contactos. Es decir, jugar a un juego en la red social no se limita a esa actividad, sino que implica exponerse, exhibirse y competir. En ese sentido, Goffman (1974) identifica el trabajo de la cara [el facework] como una de las dimensiones a través de la cual los sujetos sociales construyen sus interacciones. Evalúan qué aspectos serán valorados por pares, qué beneficios pueden obtener y de qué formas pueden construirse vínculos en un espacio novedoso.

"No está bueno ser el único que juega", dice Tomás y despliega una gran cantidad de elementos a tener en cuenta a la hora de analizar la relación con la red social. Por un lado, la valoración del contacto con otros; por otro, la necesidad de colaborar con otros y de contar con su ayuda. Y es aquí donde aparece una de las claves ya no sólo de Facebook sino también de Mundo Gaturro y Club Penguin. Los tres sitios encabezan la lista de los más visitados por parte de niños y niñas de la Argentina (Duek, 2014), y se caracterizan por presentar juegos e interacciones que "necesitan" de un otro-usuario que contribuya al cumplimiento de los objetivos: en los tres espacios los juegos, los objetos y objetivos pueden lograrse por medio de "donaciones" de otros usuarios y se reciben atributos y elementos que sólo pueden enviarse por medio de vínculos virtuales. Por ejemplo, en Mundo Gaturro, la vestimenta más "exclusiva" no se compra sino que se "comparte" con otros jugadores. Al enviar a un "amigo" un objeto, inmediatamente el receptor debe responder de manera equivalente con un envío similar. Interacción, conveniencia e igualación son algunas de las claves para comprender las relaciones en estas plataformas.

Los juegos en redes sociales comparten características que los diferencian de otros tipos de juegos electrónicos. O’Neill (2008: 4) los define como:

Una actividad estructurada con reglas contextuales a través de las cuales los usuarios se vinculan. Los social games deben ser multi-jugadores y tener al menos una de las siguientes características: basados en turnos, en plataformas que brindan la posibilidad de componer un usuario temporal que interactúa con otros por el mismo canal de contacto.

Los social games desarrollados por Facebook, Mundo Gaturro y Club Penguin presentan patrones comunes en diferentes aspectos. En todas las pla- 
taformas, los jugadores encuentran mundos virtuales de simulación con reglas propias. Los sitios mencionados crean un entorno digital en el que los usuarios se vinculan unos con otros. En estos ambientes simulados, los usuarios pueden jugar diferentes videojuegos diseñados con gráficos simples y un grado de dificultad baja en términos de resolución de obstáculos. Los social games priorizan la simplicidad y la repetición de las acciones por sobre la complejidad y la innovación (Tourn, 2013: 37).

Sarlo (1994) define a los videojuegos como ficciones "de acción sin una historia" que se despliegan mientras se introduce un argumento en el que todo ocurre en términos de movimientos pero no queda nada en lo profundo del relato. Hay hilos conductores pero vinculados a la inmediatez de la resolución de conflictos y en pos de un fin, de una misión breve y no compleja (claro que esto no ocurre para todos los tipos de juego sino que se identifica claramente en los social games). Urresti (2008) agrega que este tipo de juegos requieren planeamiento y velocidad para resolver objetivos relativos al plano visual antes que a la dimensión lingüística: las acciones se "leen" desde las imágenes que se despliegan en la pantalla. Los social games en general no tienen diferentes niveles de complejidad y los usuarios los identifican de este modo:

Los juegos son una pavada. Pero me divierten. Me da risa cuando Gaturro se mueve como loco en la pantalla.

(Sofía, 9 años)

Si me preguntás por los juegos, son una porquería. Prefiero un millón de millones de veces los de la Play [Station] pero los de Gaturro son buenos porque están en Mundo Gaturro haciendo cosas todo el tiempo. Pero jueguitos posta, son los de la Play.

(Ulises, 9 años)

Los usuarios identifican claramente las diferencias entre los social games y los de las consolas. La PlayStation ${ }^{3}$ se vincula con la calidad de los juegos mientras que los social games se organizan en torno de la interacción con pares. Watzlawick et al. (1973) sostienen en uno de los axiomas que "toda

3. La PlayStation es una consola de juegos de Sony, la más popular en su segmento comercial con 15 millones de dispositivos vendidos en 2014, según la consultora económica VG CHARTZ. 
comunicación tiene un nivel de contenido y un nivel relacional" y es interesante reflexionar sobre la forma en la que los entrevistados han diferenciado, no sólo las plataformas, sino los espacios destinados a la interacción en y a través de ellas. Si los social games son espacios de socialización bajo la excusa del juego, los juegos en las consolas tienen otras particularidades, tramas y dinámicas que se relacionan más con el juego y sus características que con las formas de interacción a través de él.

En síntesis, los juegos en las redes sociales presentan una baja calidad en los gráficos y en sus términos narrativos comparados con otros productos de la industria de los videojuegos (cfr. Kafai et al., 2008 y Casell y Jenkins, 1998 para más precisiones). Es por ello que la experiencia de "jugabilidad" se vincula más a los llamados casual games que a los juegos de inmersión o de múltiples niveles. Los casual games son juegos en los que los objetivos son muy sencillos y no se articulan con otros niveles de dificultad. Pensemos, por ejemplo, en la "Carrera de embolsados" de Club Penguin o en "El juego de los penales" en Mundo Gaturro: en ambos, el objetivo es cumplir un objetivo simple [llegar a la meta o marcar un gol] y, una vez logrado, el juego termina y no tiene continuación.

Los casual games son juegos que demandan una baja dedicación por parte del jugador y una alta participación de la interacción entre usuarios dado que, mientras juegan, se habilitan chats entre quienes compiten, se permite conocer a los rivales, interactuar a través de movimientos en la pantalla o por medio del uso de frases o emoticones ${ }^{4}$. $\mathrm{Y}$ es aquí donde el juego como práctica queda desplazado por parte de las interacciones entre usuarios. No es tan importante lo que ocurre en el juego como aquello que pasa entre los jugadores.

Complementariamente, si Facebook se organiza en torno de los rankings de desempeño y sugiere acciones para intercambiar o ayudar a jugadores (como mencionaba Tomás, nuestro informante), en Mundo Gaturro y en Club Penguin la clave radica en la acumulación de puntos que se obtienen jugando. Los puntos sirven para comprar objetos en el mercado virtual de la plataforma. Ropa para los pingüinos (en Club Penguin) o para "Gaturro" o "Agatha" (en Mundo Gaturro) y accesorios o decoración para las "casas" de los personajes. La obtención de puntos es clave para la diferenciación: cuantos más puntos

4. Los emoticones son dibujos preexistentes que apuntan a transmitir emociones o pensamientos. 
obtiene un usuario, más "especial" es su personaje. Y, a la hora de interactuar con pares, se construye la diferencia de la que hablan Watzlawick et al. (1973) sobre las relaciones complementarias o simétricas. En las redes sociales y plataformas de juego que estamos analizando, el objetivo es imponerse ante los otros por medio de la seguridad que brindan, a los usuarios, las posesiones digitales de sus personajes. El personaje mejor vestido, el que tiene una tarjeta de crédito (virtual) VISA, un celular o algún auspicio en su casa, es aquel que tiende a ser más valorado por sus pares:

Facu tiene pasaporte y, ¿te digo? Es in-cre-í-ble la ropa de su Gaturro, la casa cómo la tiene (...) Todos quieren jugar con él porque ir a una fiesta en su casa es lo más de lo más (...) Y Facu cada vez invita a menos gente porque se cree el líder de todos.

(Marina, 8 años)

Una segunda dimensión de diferenciación aparece con los accesos privilegiados: tener una tarjeta de crédito vinculada a una cuenta de Facebook (y usarla para comprar vidas, crédito o lo que haga falta), pasaporte en Mundo Gaturro o ser socio en Club Penguin es una marca de "clase" al interior de las plataformas. Quienes abonan para ingresar (es decir, aquellos que no utilizan el modo "básico" de las plataformas) acceden a productos preferenciales, decoración peculiar y personajes deseados. Tal como plantean Revuelta y Esnaola (2012), las compañías desarrolladoras de social games hacen uso del modelo freemium ${ }^{5}$ para atraer a más usuarios.

Si bien todo ocurre en el mundo virtual, la exhibición aparece como clave a la hora de asumir roles de grupo (Turkle, 2011). Mostrar la ropa y los puntos obtenidos, saber quién es usuario "básico" y quién es "premium" es una manera de ingresar a un universo en el que la diferenciación y la asunción de roles específicos es la clave para comprender las interacciones entre pares. Cantora y Molinari (2012: 56) identificaron la competencia y la exhibición como las dos dimensiones más importantes en las plataformas de juego para niños y niñas:

5. Freemium es un modelo de negocios que funciona ofreciendo servicios básicos gratuitos, mientras se cobra por otros más avanzados o especiales. La palabra freemium es una contracción en inglés de las dos palabras que definen el modelo de negocios: "free" y "premium". 
Yo juego a Club Penguin porque todos mis amigos juegan ahí y no me sirve no conocer a nadie ni poder compartir ni mostrarle a los otros lo que hago, lo que hace mi personaje y lo que le compro.

(Sabrina, 9 años)

Sabrina (y los informantes de la muestra a los que ella representa) nos explica su relación con Club Penguin a partir de las siguientes dimensiones:

I. La relación con sus pares.

II. La importancia de que todos jueguen en la misma red o plataforma.

III. El rol de la exhibición como forma de interacción.

IV. Las compras que hace para su personaje.

V. La noción de utilidad ("no me sirve").

Las cinco claves del testimonio de la informante nos ubican en un universo en el que los juegos son una excusa para la socialización y la vinculación con pares. Jugar en Facebook, en "Club Penguin" o en "Mundo Gaturro aparece, en nuestros resultados de investigación, como un puente para reforzar lazos, roles, jerarquías y relaciones.

Una dimensión fundamental en este análisis es la presencia (o ausencia) de controles parentales en las diferentes plataformas digitales. Tanto Mundo Gaturro como Club Penguin establecen fuertes regulaciones respecto a la seguridad de los jugadores en Internet. En ambas plataformas, los niños deben ingresar la dirección de correo electrónico de sus padres al momento de registrarse. La cuenta no se activa hasta que el adulto acepte la participación del chico. A su vez, los padres deben elegir entre dos modos de seguridad que buscan limitar las interacciones posibles en la red social. En Mundo Gaturro, estas modalidades de acceso se denominan "Moderado" y "Lista Blanca":

- Moderado (Seguridad Media): el texto escrito es validado contra un conjunto de palabras prohibidas antes de ser mostrado y luego revisado por el equipo de moderadores. (Nota: el filtro de palabras prohibidas se actualiza constantemente, no obstante pueden filtrarse mensajes que ofendan a ciertos jugadores.)

- Lista Blanca (Seguridad Alta): limita lo que se puede escribir o leer a un conjunto predeterminado de textos (mensajes, saludos, preguntas, 
comentarios, etc.) seleccionables por menú, restringiendo la interacción solo a usuarios que elijan el mismo modo de chat.

(www.mundogaturro.com)

En Club Penguin, aparecen las mismas opciones y se denominan "Chat de seguridad estándar" y "Chat de alta seguridad", respectivamente. En todos los casos, los adultos están habilitados a revisar las interacciones que mantienen sus hijos. Asimismo, son notificados si el niño dice un insulto o grosería. Pese al rigor de estos controles parentales, todos los chicos entrevistados violan las disposiciones, al colocar sus propias casillas de correo, en lugar de la dirección de sus padres.

¿Escribiste el mail de tus papás?

Yo siempre puse el mío.

$¿$ Recibiste la nota de seguridad?

Sí, la firmé yo.

(Tomás, 8 años)

Por el contrario, Facebook no posee un modo de vigilancia estricto ni estipula diferentes tipos de seguridad. Asimismo, no permite que los adultos puedan observar la actividad de sus hijos en la web.

La legislación en materia de privacidad nos impide otorgar acceso a nadie que no sea el titular de la cuenta. Animamos a los padres a supervisar el uso que hacen sus hijos de Internet y proteger sus equipos.

(www.facebook.com/help)

Esta amplia ausencia puede deberse a que Facebook dispone - a diferencia de Mundo Gaturro y Club Penguin - que es obligatorio tener 13 años o más para unirse al sitio. Sin embargo, los chicos encontraron una vez más las formas de vulnerar esta regla: nuestros entrevistados se hicieron pasar por más grandes al momento de registrarse o utilizan las cuentas de hermanos mayores y otros adultos.

Empezamos el análisis con la presentación del primer axioma del interaccionismo: "No es posible no comunicar". Hemos recorrido algunos aspectos de los otros axiomas y lo que encontramos es que muchos de los postulados 
que vinculan comunicación e interacción se conjugan nuevamente en las nuevas redes y plataformas. Los social games nos brindan aspectos de la relación entre pares, de los vínculos con los padres, de las formas diversas de la comunicación multicanalizada (digital/verbal, analógica/no verbal), la puntuación de la relación y la simetría o complementariedad de los intercambios.

La investigación se organizó en torno de la pregunta por los juegos y las nuevas tecnologías y lo que encontramos, en la indagación, son diferentes formas de caracterizar y de nombrar la interacción a través de las nuevas plataformas y redes sociales. García y Monferrer (2009: 84) sostienen que la comunicación no es el modo de recibir la cultura sino el instrumento utilizado para su construcción y es en esa línea en la que se ordenarán nuestras conclusiones.

\section{DiscuSión DE RESULTADOS}

Este trabajo comenzó con la presentación de un nuevo espacio lúdico para los niños y las niñas y se orientó hacia la identificación de las formas de interacción convocando la palabra de los entrevistados. Indagamos las relaciones, las dinámicas y las acciones que suponen los social games para ver, en ellos, las maneras en las que se caracterizan los juegos, las plataformas y las formas de conexión con pares. La hipótesis del artículo sostenía que los social games se construyen como espacios para conocer nuevas personas y mantener el contacto con "amigos" virtuales.

Hemos identificado, a lo largo de la investigación, la importancia que tiene para los niños y las niñas la pertenencia a espacios comunes con sus pares. Un informante ya citado mencionó la importancia de jugar a los juegos que sus amigos eligen porque "no me sirve no conocer a nadie". Esta afirmación sintetiza gran parte de los hallazgos sistematizados: los social games no se valoran por las características propias del juego sino por los pares que los eligen y convierten en una "tendencia" de ese grupo. Una vez elegido un juego - y dado que todos los "amigos" que juegan se ubican en rankings por nivel de performance - comienza un tipo de interacción que se vincula específicamente a las demandas del juego (el "envío" de objetos necesarios o deseados) y con la exhibición de los logros obtenidos. Mencionamos que los logros pueden relacionarse con los puntajes obtenidos y con los objetos y vestimentas que tenga nuestro personaje en las plataformas de juego. La mirada de los 
otros se ordena, también, por la valoración esperada de terceros de los logros alcanzados. Es, en un punto, la reactualización de la tradicional frase "mirá, [destinatario: madre, padre, amigos, docentes] lo que soy capaz de hacer", pero multiplicada a todos los contactos que ven las publicaciones y se vinculan por medio de las plataformas mencionadas (Duek, 2014).

Nos preguntamos al comienzo si los mecanismos de intercambio se organizaban en torno del valor lúdico de los social games o si prevalecía el eje del contacto y la definición de las relaciones con pares. Encontramos, en la investigación, que lo más relevante para los informantes se relacionaba con seguir las tendencias pero, también, con la importancia de mantener abiertos todos los canales de contacto.

Quedarse fuera de las interacciones aparece como una gran amenaza que debe ser minimizada. Es por ello que "jugar a lo que todos juegan" no tiene tanto que ver con la valoración de los juegos y sus características lúdicas, sino con los pares que se suman a dichas interacciones. Es conveniente, a los fines de la obtención de puntos, contar con personas que envíen objetos o regalos en la plataforma del juego pero lo es, también, saber que todo lo que ocurre (y es valorado por el jugador) puede ser exhibido no sólo en el sitio específico sino en todas las redes sociales vinculadas (hay un botón de "compartir" que extiende los desempeños y exhibiciones en una plataforma a Facebook y Twitter).

\section{CONCLUSIÓN}

Exhibir, competir, valorar y ser valorado son cuatro de las claves que identificamos en nuestro trabajo. La escuela de Palo Alto define, en su primer axioma, la imposibilidad de no comunicar. Si no es posible no comunicar, en época de redes sociales y de conexión, cada clic, cada intercambio, sugerencia o emoticón se develan cruciales para la puntuación de la relación, para la definición del vínculo (complementario o simétrico) pero, también, para la construcción de una imagen de nosotros mismos frente a los otros. ¿Quiénes somos?, ¿cómo elegimos mostrarnos?, ¿qué acciones imaginamos serán valoradas por terceros?, ¿qué perfil asumimos? Estas preguntas constituyen, para nosotros, las claves para el análisis de las interacciones contemporáneas. Y serán las respuestas (temporales y provisorias) que podamos construir por medio de la investigación científica, las que nos ayudarán a definir, en diferentes 
momentos de la historia, las dinámicas, acciones y relaciones que pueden (o no) construirse en los diferentes espacios de la vida social.

\section{REFERENCIAS BIBLIOGRÁFICAS}

Baylon, C. \& Mignot, X. (1996). La comunicación. Madrid: Cátedra.

Cantora, A. \& Molinari, L. (2012). Jugar a "Mundo Gaturro". Acerca del juego, la exhibición y el consumo en la plataforma online. Tesina de licenciatura en Ciencias de la Comunicación, Facultad de Ciencias Sociales, Universidad de Buenos Aires.

Cassell, J. \& Jenkins, H. (2000). Chess for girls? feminism and computer games. In From Barbie to Mortal Kombat. Gender and computer games, Boston: MIT Press.

De Certeau, M. (1996). La invención de lo cotidiano I. Artes de hacer. México: Universidad Iberoamericana.

Duek, C. (2012). El juego y los medios. Autitos, muñecas, televisión y consolas. Buenos Aires: Prometeo Libros.

Duek, C. (2014). Juegos, juguetes y nuevas tecnologías. Buenos Aires: Capital Intelectual.

Elias, H. (2015) Brandware. When brands and digital media collide. Consultado en www.herlanderelias.com

García, M. \& Monferrer, J. (2009). Propuesta de análisis teórico sobre el uso del teléfono móvil en adolescentes. Comunicar, 33. Huelva: Grupo Comunicar.

Glaser, B. \& Strauss, A. (1967). Discovery of grounded theory: strategies for qualitative research. Chicago: Aldine Publishing Company.

Goffman, E. (1974). Frame analysis. Boston: Northeastern University Press.

Graner Ray, S. (2004). Gender inclusive game design: expanding the market. Hingham: Charles River Media.

Hall, E. (1963). Proxemics: the study of man's spatial relations. In Galdston (ed.) Man's image in medicine and in anthropology. Nueva York: International Universities Presses. 
Jameson, F. (1998). Preface. In Jameson \& Mayoshi (eds.) The cultures of globalization. Duke University Press.

Jenkins, H.; Ito, M. \& Boyd, D. (2015). Participatory culture in a networked era: a conversation on youth, learning, commerce and politics. Cambridge: Polity Press.

Kafai, Y., Heeter, C., Denner, J. \& Sun, J. (2008). Beyond Barbie and Mortal Kombat: new perspectives on gender and gaming. Boston: MIT Press.

Kirkpatrick, D. (2010). The Facebook effect. New York: Simon \& Schuster.

Livingstone S. (2009). Children and the Internet. Cambridge: Polity.

Marc, E. \& Picard, D. (1992). La interacción social: cultura, instituciones y comunicación. Barcelona: Paidós.

Martín-Barbero, J. (2003). Retos culturales de la comunicación a la educación: elementos para una reflexión que está por comenzar. In R. Morduchowicz (comp.) Comunicación, medios y educación. Barcelona: Octaedro.

Morduchowicz, R. (2012). Los adolescentes y las redes sociales. Buenos Aires: FCE.

O'Neill, N. (2008). What exactly are social games?. Consultado en www.soci altimes.com/2008/07/social-games

Pahl, R. (2003). Sobre la amistad. Madrid: Siglo XXI.

Revuelta, F. \& Esnaola, G. (2012). Videojuegos en redes sociales: perspectivas del edutainment y la pedagogía lúdica en el aula. Barcelona: Laertes.

Sarlo, B. (1994). Escenas de la vida posmoderna. Buenos Aires: Ariel.

Steinberg, S. \& Kincheloe, J. (1997). Cultura infantil y multinacionales. Madrid: Morata.

Telles, A. (2010). A revoluçao das mídias sociais. San Pablo: M.books.

Tourn, G. (2012). Ludomorfosis: una reflexión sobre la dimensión lúdica de los videojuegos. Question, primavera, 36.

Tourn, G. (2013). Del face to face al face to Facebook: redes sociales, videojuegos e interacciones digitales. Tesina de licenciatura en Ciencias de la Comunicación, Facultad de Ciencias Sociales, Universidad de Buenos Aires. 
Turkle, S. (2011). Alone together: why we expect more from technology and less from each other. Boston: MIT Press.

Turkle, S. (2015). Reclaiming conversation: the power of talk in a digital age. New York: Penguin.

Urresti, M. (2008). Ciberculturas juveniles. Buenos Aires: La Crujía.

Verón, E. (1987). Cuerpo y metacuerpo en democracia audiovisual. París: Après.

Vigotsky, L. S. ([1930] 1986). La imaginación y el arte en la infancia. Madrid: Akal.

Wark, M. (2007). Gamer theory. Cambridge: Harvard University Press.

Watzlawick, P.; Helmick Beavin, J. \& Jackson, D. (1973). Algunos axiomas exploratorios de la comunicación humana. In Teoría de la comunicación humana. Buenos Aires: Tiempo Contemporáneo.

\section{Juegos electrónicos}

Farmville

Creador: Zynga

Plataforma: Facebook

Año de lanzamiento: 2009

Pet Society

Creador: Playfish, Electronic Arts

Plataforma: Facebook

Año de lanzamiento: 2009

Mundo Gaturro

Creador: Compañía de Medios Digitales, Grupo Clarín

Plataforma: Mundo Gaturro

Año de lanzamiento: 2010

Club Penguin

Creador: Disney Interactive Solutions

Plataforma: Club Penguin

Año de lanzamiento: 2005 


\title{
A Relevância das Novas Tecnologias na Comunicação Organizacional: o Caso dos Websites nas Universidades Portuguesas
}

\author{
Sónia Silva, Teresa Ruão \& Gisela Gonçalves \\ Universidade da Beira Interior e Universidade do Minho / Universidade do Minho / \\ Universidade da Beira Interior \\ E-mail: sonia.c.melo.silva@gmail.com/truaodics.uminho.pt / \\ gisela.goncalves@labcom.ubi.pt
}

\section{RESUMO}

A revolução digital protagonizada pelo aparecimento da internet motivou um conjunto de transformações económicas, politicas, culturais e sociais, que provocaram profundas alterações no contexto em que se desenvolvem todas as atividades humanas. A sociedade de informação, fruto do advento desta nova tecnologia, representou um momento de importantes e decisivos progressos quer na comunicação individual quer na comunicação organizacional. É precisamente no contexto organizacional que este estudo pretende focar-se, ao discutir as potencialidades que as novas tecnologias trazem para a comunicação organizacional, tendo como particular enfoque a relevância dos websites como meios de comunicação e, as instituições de ensino superior portuguesas como estudo de caso. Para compreender se, de facto, as páginas de internet carecem de particular importância no panorama comunicativo das universidades portuguesas, utilizaram-se

Data de submissão: 09-05-2016. Data de aprovação: 23-10-2016.

Publicação realizada no âmbito da Bolsa de Doutoramento com a referência PD/BD/114002/ 2015 co-financiada pelo Fundo Social Europeu (FSE), pelo Programa Operacional Potencial Humano (POPH) e por fundos nacionais do Ministério da Educação e Ciência (MEC), através da FCT - Fundação para a Ciência e Tecnologia.

A Revista Estudos em Comunicação é financiada por Fundos FEDER através do Programa Operacional Factores de Competitividade - COMPETE e por Fundos Nacionais através da FCT - Fundação para a Ciência e a Tecnologia no âmbito do projeto Comunicação, Filosofia e Humanidades (LabCom.IFP) UID/CCI/00661/2013. 
como métodos a análise documental e a recolha de dados. Os resultados desta investigação sugerem a relevância das páginas web no contexto comunicacional

Palavras-chave: internet; websites; comunicação organizacional; universidades. das universidades portuguesas, como veículos de informação de primeira instância.

\section{RESUMO}

The digital revolution led by the rise of the internet led to a set of economic, political, cultural and social transformations which caused profound changes in the context in which all human activities are developed. The information society, the result of the emergence of this new technology, consisted of a moment of important and decisive progress in both individual and organizational communication. It is precisely the organizational context this study intends to focus on, by discussing the potential that new technologies bring to organizational com- munication, with particular focus on the relevance of websites as means of communication and Portuguese higher education institutions as a case study. To understand if, in fact, internet pages are in need of particular importance in the communicative scene of Portuguese universities, document analysis and data collection were the methods that have been used. This investigation's results suggest the relevance of web pages in the Portuguese universities communicational context, as first instance information carriers.

Palavras-chave: internet; sites; comunicação organizacional; universities.

\section{INTRODUÇÃO}

"A sociedade em que vivemos é caracterizada por um desenvolvimento tecnológico contínuo que investe no sector informático e, por consequência, nos meios de comunicação, o que modifica o estilo de vida das pessoas, as interacções sociais e as estruturas presentes (...)".

Cardoso, 2008, p. 181

O trabalho de investigação que se propõe apesentar, em seguida, trata o tema da relevância das novas tecnologias para a comunicação organizacional. 
As profundas alterações que o aparecimento da internet protagonizou em todas as esferas da sociedade e que parecem não ter fim suscitou o interesse de compreender as alterações e oportunidades que esta tecnologia trouxe para o sistema de comunicação das organizações.

Tendo-se noção de que seria muito ambicioso, tratar, nesta investigação, todas as vertentes sobre o impacto da internet na comunicação organizacional, pretende-se abordar, apenas, uma pequena parte das possibilidades trazidas por esta tecnologia. Assim, focar-se-á este estudo na relevância dos websites como meios de comunicação das organizações, utilizando como estudo de caso a importância das páginas web num tipo de organização específico, nomeadamente as universidades portuguesas.

Tiveram-se como ponto de partida para o estudo de caso as instituições de ensino superior portuguesas, pois, a experiência de investigação tem seguido o interesse em estudar o desenvolvimento da comunicação organizacional nestas instituições. Por outro lado, este tema é interessante, pois, não existem muitos estudos específicos que discutam a importância dos websites na comunicação organizacional, particularmente no contexto comunicacional das instituições de ensino superior.

Assim, a pergunta que orientará o presente trabalho é: porque é que os websites devem ser um meio de comunicação privilegiado no âmbito da comunicação organizacional, em particular nas universidades? Para responder à questão traçaram-se um conjunto de objetivos, que são eles: contextualizar e compreender o aparecimento da internet; analisar as transformações ocorridas na sociedade, em particular no seu modo de comunicar, fruto da aparição desta tecnologia; perceber o grau de penetração da internet em Portugal e o tipo de utilização que tem sido feita da mesma; examinar o impacto e as potencialidades da internet no contexto comunicacional das organizações; discutir a importância dos websites como meios de comunicação nas empresas e instituições; e debater a relevância destas páginas no seio da comunicação praticada pelas universidades portuguesas.

A metodologia utilizada neste estudo caracterizou-se pelo seu carácter qualitativo. Incluiu a análise documental de relatórios acerca da apropriação da internet pela população portuguesa, tendo-se estudado os que foram produzidos pelo OberCom - Observatório da Comunicação - nos últimos dez anos, nomeadamente: a Internet em Portugal (2003-2007); a Sociedade em Rede - A Internet em Portugal 2012; a Internet em Portugal - Sociedade em 
Rede 2014; e a Internet e o consumo de notícias online em Portugal 2015. Realizou-se, ainda, uma recolha de dados que pretendeu verificar se todas as instituições de ensino superior portuguesas (públicas, privadas e politécnicas) possuíam um website próprio. Esta recolha foi realizada com a consulta do portal da Direção Geral de Ensino Superior, onde é possível consultar a lista de todas as instituições de ensino superior portuguesas, sejam elas públicas, privadas ou politécnicas. Assim, verificou-se se as 148 instituições de ensino listadas apresentavam websites.

O presente trabalho trata-se de um estudo exploratório e organiza-se da seguinte maneira: na primeira parte abordar-se-á a história do aparecimento da internet e as transformações que trouxe para a sociedade; na segunda secção será apresentado e discutido o grau de penetração desta tecnologia em Portugal e analisado o uso que lhe é dado pelos internautas; em seguida discutirse-ão as transformações que a internet trouxe para a comunicação das organizações; na quinta parte debater-se-á pertinência dos websites como meios de comunicação para empresas e instituições; e, por fim, a última secção abordará a relevância dos websites como meios de comunicação privilegiados nas universidades portuguesas.

Com este estudo não se pretende a formulação de hipóteses rígidas, deseja-se, antes, apresentar uma discussão que possa representar uma nova e valiosa contribuição para o campo de estudo da comunicação organizacional.

\section{ReVoluÇão Digital: O AdVento da Internet}

"A criação e desenvolvimento da Internet é uma extraordinária aventura humana."

Castells, 2007, p. 25

As origens da internet são apontadas para o período da Guerra Fria, nos longínquos anos 50 e 60 do século passado. O seu aparecimento ficou a deverse a uma falha encontrada no sistema de telecomunicações dos Estados Unidos da América, que poderia comprometer o sucesso das operações militares. Foi neste contexto que os EUA procuraram desenvolver um novo sistema de comunicação.

A ARPANET surgiu neste período, como uma tecnologia de distribuição da informação em rede, criada pela Advanced Research Projects Agency (ARPA), uma agência de projetos de investigação fundada pelo Departamento 
de Defesa norte-americano. Foi desenvolvida como um sistema de comunicação militar capaz de resistir à incursão nuclear, cujo principal objetivo era interligar as bases militares e os departamentos do governo americano em rede, em tempo de guerra, bem como, “(...) alcançar a superioridade tecnológica militar sobre a União Soviética (...)” (Castells, 2007, p.26). A APARNET representou, então, a primeira manifestação e o ponto de partida para aquilo que hoje se chama de internet. Esta tecnologia atraiu o interesse da comunidade académica e científica que, ao longo de duas décadas, foi responsável pelos avanços a que se foi assistindo.

Assim, e após um período de desenvolvimentos tecnológicos, a internet tal como é atualmente conhecida surgiu nos anos 90 pelas mãos de Tim Berners - Lee, criador da World Wide Web, que possibilitou a ligação em rede entre os computadores do mundo inteiro. Berners - Lee “(...) definiu e elaborou o software que permitia tirar e introduzir informação em qualquer computador ligado através da internet (...)" (Castells, 2007, p.32).

Parece, então, que a internet teve a sua origem no contexto da investigação militar alicerçada pelo desenvolvimento científico. Apesar de a sua história ser, já, longa, o aparecimento desta tecnologia no seio das organizações e da sociedade em geral não acompanha esta longevidade:

Apesar de a Internet estar já na mente dos informáticos desde princípios dos anos 60, de em 1969 se ter estabelecido uma rede de comunicações entre computadores e, desde final dos anos 70, se terem formado várias comunidades interactivas de cientistas e hackers, para as pessoas, as empresas e para a sociedade em geral, a Internet nasceu em 1995. (Castells, 2007, p. 33)

Foi a partir deste momento que a internet ganhou expressão como meio de comunicação e, desde então, esta tecnologia tem sido protagonista de uma evolução sem precedentes. Em Portugal, tal como na generalidade dos países, a internet apareceu na década de 80. Contudo, neste período, existia apenas acesso remoto por terminal a computadores de universidades estrangeiras. Este acesso era quase exclusivamente utilizado por ex-estudantes dessas instituições de ensino superior, que mantinham as suas contas nesses sistemas (Evolução da Informática TIC - Moimenta da Beira). Porém, a ligação à internet, tal como hoje se conhece, em Portugal, também aconteceu nos anos 90, no seio universitário. A Universidade de Lisboa foi a primeira instituição 
a ter ligação a esta rede, seguindo-se, a ela, a Universidade do Minho no ano de 1993 (Origens da Internet, 2011). A partir de meados dos anos 90, quer em Portugal, quer no resto do mundo, esta nova tecnologia iniciou uma evolução sem precedentes, a que ainda se assiste nos dias de hoje. "De 1993 até à atualidade a web não tem parado de crescer, um estudo da Science, de Junho de 2011, indicava que existiam mais de 340 milhões de sites" (Carrera, 2012, p. 20).

Mas o desenvolvimento da internet não deve apenas classificar-se pelo número de aplicações e de possibilidades de utilização que foram surgindo ao longo destes 20 anos. Tal como afirma Caraça:

(...) O conjunto de mudanças experimentadas a todos os níveis, do económico ao político, do social ao cultural - e a que se foi chamando de «globalização» por uns, de «sociedade de informação» por outros, de «novo paradigma de comunicação» por outros ainda - foi de tal maneira poderoso que provocou uma alteração do contexto em que se desenvolveram as atividades humanas. (2005, p.7)

De facto, esta tecnologia de informação e comunicação deve ser pensada como palco de uma nova forma de vida em sociedade: a sociedade em rede na era da informação. Poderia falar-se apenas de sociedade em rede, porém, tal como declara Castells "as redes são formas muito antigas de actividade humana, mas actualmente estas redes ganharam uma vida nova, ao converterem-se em redes de informação, impulsionadas pela Internet" (2007, p. 15). Na verdade, a internet foi a grande impulsionadora da sociedade de informação que hoje se conhece e que impôs um conjunto de reajustamentos nos comportamentos, para que se tornasse possível beneficiar dos progressos resultantes da alteração do paradigma informacional, cujo protagonismo deixou de ser analógico para passar a ser digital. Esta nova tecnologia possibilitou desenvolvimentos antes inimagináveis, permitindo, pela primeira vez, a comunicação de muitos para muitos à escala global (Castells, 2007), abolindo as fronteiras do tempo e do espaço. A sociedade em rede na qual todos habitam é um resultado do desenvolvimento da internet.

Contudo, ainda que as novas tecnologias de informação e comunicação sejam abordadas como as principais responsáveis pela criação desta nova forma de sociedade, é de extrema relevância não descurar que o seu surgimento teve, 
por trás, um contexto histórico e cultural específico que, determinou a sua evolução. (idem). Pode, então, dizer-se que a internet transformou a sociedade no seu todo, todavia, é ela própria um produto resultante das evoluções históricas, científicas, culturais e sociais tendo surgido como um meio para suprir determinadas necessidades no seio da humanidade. Deve, portanto, ter-se em conta a existência de uma interação entre as tecnologias da informação e a sociedade, na qual ambas se influenciam mutuamente, aceitando, desta forma, que o desenvolvimento tecnológico seja algo que tenha efeitos sociais relevantes, mas que, ao mesmo tempo, é também o resultado de uma moldagem social onde interferem as características políticas, económicas e sociais do contexto onde se insere (Nunes, 2004). Não se pode, portanto, ignorar a relação de mútua influência que existe entre a internet e o meio social onde esta se insere. Um sistema mediático não se caracteriza apenas pelas tecnologias que o suportam, mas é também a própria cultura que instiga essas mudanças (Jenkins, Green \& Ford, 2014). Tal tese e corroborada por Castells que assegura que:

(...) As pessoas, as instituições, as empresas e a sociedade em geral, transformam a tecnologia, qualquer tecnologia, apropriandoa, modificando-a e experimentando-a - espacialmente no caso da Internet, por ser uma tecnologia de comunicação. (...) Como a actividade humana está baseada na comunicação e a Internet transforma o modo como comunicamos, as nossas vidas vêm-se profundamente afectadas por esta nova tecnologia de comunicação. Por outro lado, ao utilizarmos a internet para múltiplas tarefas vamos transformando-a. (2007, p. 19)

A internet deverá, então, ser continuamente pensada como um instrumento que, ao mesmo tempo, produz e é produzido por novos comportamentos da sociedade.

Contudo, esta asserção não torna menos verdade o facto de que "no one today disputes that the Internet is likely to have a significant impact on social life" (Bargh \& McKenna, 2003, p. 575). Vários autores têm vindo a estudar o impacto da internet nas várias esferas da sociedade e, parecem não restar dúvidas de que "o nosso mundo e as nossas vidas estão a experimentar uma mudança profunda no âmbito da tecnologia, economia, cultura, comunicação, política e da relação entre pessoas" (Cardoso et al, 2005, p. 13). 
Apesar do desenvolvimento da internet não ter sido propriamente veloz, a sua incursão nos modos de vida da sociedade contemporânea foi célere e discreta. Pode, até, afirmar-se que, não se sabendo muito bem como é que ela entrou na experiência quotidiana, percebe-se que é já impossível imaginá-la sem a influência desta tecnologia.

"Com a chegada da Internet, o paradigma de comunicação alterou-se por completo" (Póvoas, 2009, p. 141) e, atualmente, esta tecnologia já não é apenas um instrumento de partilha e acesso à informação para o qual foi criada. Esta primeira dimensão está ultrapassada e a internet é, agora "uma tecnologia social, onde milhares e milhões de diversos atores e sujeitos sociais interagem, criando, portanto, dimensões novas de relação social e projetando, até, porventura, novas formas de organização social" (Comunicarte, 2010, p. 14).

Como já referido, neste estudo, pretende-se dar enfoque a um tipo específico de atores sociais, que são eles as organizações. É um dos objetivos compreender o papel da internet nas empresas e instituições, em particular no que diz respeito à alteração dos seus padrões comunicativos, em consequência da adoção desta nova tecnologia, utilizando, como exemplo, a adoção dos websites pelas universidades portuguesas. Esta é uma análise interessante, pois, "actualmente, as principais actividades económicas, sociais, políticas e culturais de todo o planeta estão a estruturar-se através da Internet (...)" (Castells, 2007, p. 17) e as organizações têm vindo a estruturar as suas atividades de comunicação de acordo com as potencialidades desta tecnologia.

\section{A Internet e os seus Utilizadores em Portugal}

"A Internet, enquanto agente aglomerador de informação, é a mais intensa experiência comunicacional que a sociedade humana já viveu."

Cardoso, Mendonça, Lima, Paisana \& Neves, 2014, p. 4

Antes de se aprofundar a questão da utilização da internet como um novo paradigma para a comunicação organizacional é importante fazer-se uma pequena abordagem ao uso que os indivíduos fazem desta tecnologia, em particular a população portuguesa (uma vez que o presente estudo visa refletir sobre a importância dos websites nas universidades em Portugal). A justificação para este facto é simples: o investimento pela comunicação online por 
parte de uma organização justifica-se, apenas se o seu público-alvo estiver familiarizado com a mesma plataforma e a incluir nas suas práticas quotidianas.

Uma leitura atenta pelas conclusões dos relatórios anuais do uso da internet em Portugal (neste caso analisaram-se os que foram produzidos pelo OberCom - Observatório da Comunicação, nomeadamente: a Internet em Portugal (2003-2007), a Sociedade em Rede - A Internet em Portugal 2012, a Internet em Portugal - Sociedade em Rede 2014 e a Internet e o consumo de notícias online em Portugal 2015) permitem concluir que a utilização destas tecnologia registou grandes evoluções ao longo da primeira década do século XXI, e que, atualmente, o recurso à internet se apresenta como uma prática disseminada entre a generalidade da população portuguesa. "Cada vez mais os portugueses se relacionam com os restantes meios de comunicação e com outros formatos de visualização através da Internet" (Cardoso, Espanha, Lima \& Paisana 2012, p. 4).

Porém, a leitura dos quatro relatórios chama a atenção para a existência de uma fração de indivíduos que apresenta taxas de não utilização da internet, nomeadamente pessoas mais velhas e com menos escolaridade. Denota-se um decréscimo na utilização desta plataforma à medida que a idade aumenta e o nível de escolaridade diminui (Cardoso et al, 2012), mas, é fundamental ter em conta que nem todos têm a mesma oportunidade de acesso às tecnologias ou, as habilidades necessárias para as utilizar (Jenkins, et al, 2014). Por outro lado, são os indivíduos na faixa etária entre os 15 e os 24 anos, que apresentam também maior grau de formação académica, os maiores utentes desta tecnologia (a taxa de utilização neste grupo é 94,1\%) (Cardoso et al, 2014). Contudo, neste momento,

(...) A utilização da internet tende cada vez mais a ultrapassar as barreiras demográficas, ditas «tradicionais», que se impõe na utilização de novas tecnologias. (...) Cada vez mais surgem recursos que procuram atrair novos públicos, mesmo que pouco literados em termos tecnológicos". (Cardoso, Mendonça, Lima, Paisana \& Neves, 2014, p. 8)

Embora ainda se registe a presença de grupos omissos na utilização desta plataforma, é também um facto que a maioria dos portugueses a utiliza diariamente, tendo vindo a registar-se um aumento dos acessos à rede nos últimos anos (Cardoso et al, 2014). Pode mesmo afirmar-se que recorrer aos serviços 
da internet se tornou num ato tão simples como utilizar o telefone (Marcelo, 2005). Hoje em dia "o ciberespaço é o lugar (...) onde as pessoas acessam, recupera, organizam, ensinam, disseminam e compartilham informação e conhecimento" (Luvizotto, Fusco \& Scanavacca, 2010, p. 26).

No que respeita aos usos atribuídos à internet, estes são vários. Estabelecer comunicação com outrem, procurar atividades de entretenimento, aceder aos conteúdos dos média tradicionais e procurar informação sobre diversos bens e serviços são as ações mais procuradas pelos internautas portugueses. Na verdade, os utilizadores da internet “(...) são pessoas comuns que se ligam à rede com o intuito de desenvolverem com mais facilidade as suas tarefas do dia a dia, como seja, por exemplo, comunicar ou procurar informações (...)" (Marcelo, 2005, p. 275). Pode declarar-se, então, que a internet é, principalmente, um meio de consulta de informação, a que os indivíduos recorrem para saber mais sobre determinados produto e serviços, facilitando a sua escolha (Cardoso et al, 2012). Nesta função de procura de informação tem sido atribuído algum destaque aos websites. "A segunda fonte online com mais importância atribuída são os sites em geral (...). Os sites oficiais de instituições públicas também obtêm avaliação positiva (...)” (Cardoso et al, 2014).

Tendo em conta o contexto acima descrito parece que as organizações encontram um contexto favorável para o desenvolvimento da sua comunicação online, em particular dos seus websites. Pode até dizer-se que a sua presença no mundo online é essencial para chegar aos seus públicos. Quando se fala de instituições de ensino superior este facto assume especial relevância, pois, como se constatou, os indivíduos entre os 15 e os 24 anos são os que mais recorrem à internet para as suas atividades do quotidiano e, com certeza, utilizá-la-ão para procurar informações sobre as universidades onde pretendem ingressar ou sobre a instituição que já se encontram a frequentar.

Assim, daqui em diante será relevante analisar a internet como um paradigma recente para a comunicação organizacional, em especial, para as instituições de ensino superior em Portugal.

\section{A Internet como um Paradigma para a Comunicação Orga- NIZACIONAL}

"Numa sociedade onde as empresas (...) são a principal fonte de criação de riqueza, não deveria surpreender-nos que, assim que 
a tecnologia da Internet ficou disponível, nos anos 90, a difusão mais rápida e ampla das suas utilizações tivesse tido lugar no âmbito da empresa. A Internet está a transformar a prática empresarial (...). O uso apropriado da Internet converteu-se numa fonte fundamental de produtividade e competividade para todo o tipo de empresas."

Castells, 2007, p. 87

O termo comunicação organizacional apresenta uma vastidão de definições. Para a presente investigação ter-se-á em conta o sentido proposto por Mumby, 2001, que expõe a comunicação organizacional como "o processo de criação de estruturas de significado, colectivas e coordenadas, através de práticas simbólicas orientadas para atingir objectivos organizacionais" (citado em Ruão, 2008, p. 27). Comunicação organizacional é, pois, a criação e gestão de representações e sistemas simbólicos capazes de gerar efeitos em públicos específicos (Poupinha \& Espanha, 2005).

Atualmente os termos comunicação organizacional, comunicação empresarial e comunicação institucional são reconhecidos e estão bastante difundidos, pois, também as organizações dão cada vez mais atenção às suas práticas comunicacionais. Não quer isto dizer que a existência de atividades de comunicação nas empresas e instituições seja algo relativamente recente. $\mathrm{Na}$ verdade, a comunicação está no âmago da existência de qualquer organização, tal como afirma Ruão:

(...) A comunicação é anterior ao estabelecimento de uma organização e que constitui uma dimensão que acompanha toda a sua vida, porque as organizações necessitam permanentemente de partilhar informações, ideias ou pensamentos. Aliás, a comunicação parece estar na base de todas actividades de cooperação entre os seres humanos, que é a noção que preside às organizações". (2008, p. 27)

Contudo, por vezes, a noção de comunicação organizacional aparece estritamente ligada à gestão de ações de comunicação por parte das organizações, destinadas a promover a sua atividade quando, na verdade, se trata de toda a interação que as organizações desenvolvem com o ambiente que as rodeia (Ruão, 2001). É possível declarar que a comunicação nas organizações não é algo isolado ou separado da sua natureza e, portanto, pode ser visto como 
algo estritamente ligado à sua existência. A comunicação é crucial na vida humana e nas organizações, porque ela constitui o processo central de organizar. É a comunicação que permite às pessoas gerar e partilhar informações, e por, neste sentido, que lhes permite constituírem-se através de organizações (Ruão, Salgado, Freitas e Ribeiro, 2014).

No entanto, só mais tarde as organizações começaram a dar atenção as suas atividades comunicativas que são, atualmente, uma prática disseminada no cerne da sua atuação diária. Tal como defende Ruão:

(...) Ao longo da década de 1990, assistimos à multiplicação das actividades organizacionais destinadas a promover a visibilidade e o reconhecimento público das empresas, através de programas de comunicação que geriam as impressões, os activos intangíveis, a competência simbólica ou a dimensão expressiva das organizações". (2008, p. 12)

O aparecimento da internet, nos anos 90 veio revolucionar a atividade das organizações. O surgimento desta tecnologia representou um fator central da nova forma de organização social, que trouxe alterações substanciais nas práticas comunicacionais (Cardoso et al, 2005). As empresas e instituições descobriram um instrumento privilegiado para comunicar com os seus públicos pois, a internet trouxe múltiplas possibilidades de contacto. As organizações tiveram que se reestruturar em função desta nova tecnologia, que veio alterar as suas formas de relacionamento. (Castells, 2007).

Tal como aconteceu com os indivíduos, a penetração da internet no seio das organizações foi acontecendo de forma gradual. Mas, nos dias de hoje é impensável imaginar uma empresa ou instituição fora desta plataforma, que é já uma extensão da própria organização, sem a qual a mesma põe em risco a sua existência. "De facto, a exclusão destas redes é uma das formas de exclusão mais graves que se pode sofrer na nossa economia e na nossa cultura" (Castells, 2007, p. 17).

Atualmente, é raro encontrar uma empresa ou instituição que não possua um website e uma página em, pelo menos, numa rede social, sendo que, a maioria prefere difundir a sua atividade em várias redes, nomeadamente $o$ Facebook, o Twitter, o Instragram, o Linkedin, e em muitas outras que vão surgindo diariamente. "As redes são e serão os componentes fundamentais das organizações” (Castells, 2001, p. 188). Estamos perante um momento 
em que a utilização da internet se expandiu a todo o tipo de organizações, em operações de diversas índoles. Pode-se, portanto, concluir que se está perante um novo mundo organizacional (Castells, 2007), onde as empresas e instituições ganham autonomia para comunicar com os seus públicos (Póvoas, 2009).

Este contexto torna-se ainda mais relevante quando as organizações percebem que os seus públicos também estão na internet. Assim, “(...) dão-lhe agora mais atenção do que nunca - desejam marcar presença, porque reconhecem que os seus públicos estão «ligados» à rede (...)” (Comunicarte, 2010, p. 14).

Parece, pois, que a internet se constitui como um mundo privilegiado de oportunidades, onde as organizações podem explorar novas formas de negócio, promovendo, ao mesmo tempo, um contacto mais pessoal, direcionado e interativo com os seus públicos (Marques, 2012). Hoje em dia, em qualquer organização “(...) a web é uma ferramenta essencial para a divulgação, promoção e comercialização de produtos/ serviços; para a interação com o consumidor final; para o desenvolvimento de estratégias de comunicação, marketing e publicidade (...)" (Comunicarte, 2010, p. 91) e, por isso, o espaço online tornou-se uma ferramenta extremamente relevante nas suas práticas comunicacionais, um meio de a privilegiar no âmbito da comunicação institucional (Suarez, Moreira \& Carrapatoso, 2006).

Todavia, a internet constitui-se, também, como um grande desafio para as empresas e instituições. Ela não para de evoluir, é um planeta em constante mutação, "o futuro acontece todos os dias, está ao virar da porta. As tecnologias web encontram terreno fértil para surgirem e para se desenvolverem" (Comunicarte, 2010, p. 222). Esta é uma área sem certezas, que se caracteriza pela evolução constante, onde a organizações, para obterem o pretendido sucesso, necessitam de estar na linha da frente, estando sempre a par das novas tendências e acompanhando as necessidades e as pisadas que os seus públicos vão dando neste meio, múltiplo de oportunidades.

Para esta investigação, sabendo que é impossível debater todas as potencialidades trazida pela internet, pretende-se dar um pequeno contributo para a discussão acerca da importância dos websites como elementos presente nas práticas de comunicação das organizações, pois acredita-se que têm uma pertinência particular. Tratar-se-á, de seguida, essa questão. 


\section{OS Websites Como um Meio de CoMUniCAÇÃo POR EXCELÊNCIA}

“(...) Quando os websites corporativos surgiram, em meados dos anos 1990, ninguém percebeu por inteiro como eles iriam mudar substancialmente a relação da empresa com o seu público. Poucas empresas, que nessa época criaram websites parecendo brochuras, consideravam completamente que as marcas tinham ali a oportunidade de contar sua história diretamente para um público (...)".

Jenkins, Green \& Ford, 2014, p. 49

Não se pretende, de forma alguma, reduzir a crescente relevância de outros meios de comunicação que surgiram com a internet, como as redes sociais ou os blogs. Deseja-se, apenas, mostrar que, em determinados tipos de organizações, os websites, pelas características que possuem, poderão apesentar-se como plataformas bastante importantes para a comunicação com os seus públicos.

Nos dias que correm é um desafio encontrar organizações que não tenham uma página web (Carrera, 2012). Com os websites, “(...) as organizações têm agora um espaço próprio de definição do seu discurso e do seu universo, podendo posicionar-se tanto esteticamente quanto a nível do conteúdo" (Poupinha e Espanha, 2005, p. 214). Estas páginas na internet tornam-se um bom meio de comunicação, permitindo uma comunicação mais eficaz e atrativa, que inclui conteúdos como o vídeo, a imagem, o som e, claro, o texto. Por outro lado, este meio de comunicação oferece mais liberdade aos utilizadores. Os públicos interessados podem permanecer o tempo que desejarem em cada website, e podem ser eles próprios a definir o seu padrão de consulta de informação, navegando livremente entre páginas (Marques, 2012).

É verdade que nem sempre foi assim, os primeiros websites eram bastante simplistas e pouco atrativos, privilegiando-se o texto como veículo de informação, o que resultava em páginas entediantes e desinteressantes do ponto de vista estético. Porém, tal como a própria internet, também os websites têm sido alvo de profundos progressos. Atualmente o texto deu lugar à imagem $\mathrm{e}$ ao vídeo e as possibilidades em termos de conteúdos são muito mais diversas. A sua constante atualização, quer em termos de informação, quer em termos de layout são uma preocupação contínua das empresas e instituições, pois, os websites também representam, cada vez mais, importantes fatores de concor- 
rência. Não há dúvida que, “(...) o consumidor espera uma boa experiência no âmbito da Web (...) os utilizadores da internet mudam para um site concorrente quando o site que estão a ver tem uma má performance" (Marques, 2012, p. 36). Assim, para adquirirem um lugar de destaque, as organizações devem ter o cuidado de preparar e colocar, frequentemente, novos conteúdos nas suas páginas sendo capazes de renovar, periodicamente, as informações que sobre si circulam na internet (Póvoas, 2009).

Mas, atualmente, a tónica não é apenas colocada na atualização de informações. Os consumidores procuram mais possibilidades. Buscam conteúdos mais interativos e dinâmicos. Um bom website deverá conter diversos formatos informativos, assim, deverá incluir notícias, informações úteis, hiperligações, elementos áudio, vídeo, imagem, texto e possibilidade de alguma interação com a organização (Marques, 2012). Tal aspeto é referido por Poupinha et al:

A actualização das informações dos sites tem que ser rápida (...) sob pena de não responder à demanda daqueles que lá procuram informação (...). Uma vez fornecida a informação necessária, a ênfase é necessariamente colocada no âmbito da retórica e da estética dos sites, neste caso, ou outras formas de comunicação pela net, pelo modo como permitem, por um lado, uma relação mais agradável entre público e organização (...). (2005, p. 215).

Os websites são plenos em termos de oportunidades de comunicação e adquiriram uma importância impar na sociedade atual. É possível, até, dizer-se que têm a mesma relevância do que o contacto direto ou que o contacto telefónico com uma organização. Com isto não se quer aferir que as páginas da internet substituem estas formas tradicionais de comunicação, mas antes que poderão ser o primeiro ponto de contacto entre os públicos e as empresas e instituições, pois, geralmente incluem as informações mais importantes sobre as mesmas. "Deste modo, considera-se o sítio Web com a mesma importância, ou mais, do que outras formas de alcançar o público-alvo, deve ser construído e aperfeiçoado com pelo menos os mesmos cuidados e investimentos dispensados a outros média" (Suarez et al, 2006, p. 3).

Com as páginas web as organizações encontram um espaço próprio para a definição e difusão do seu discurso e do seu universo, podendo eleger o seu posicionamento quer em termos de conteúdo, quer em termos estéticos 
(Poupinha \& Espanha 2005) e, têm ainda a vantagem de chegar de forma mais rápida, eficaz e económica a um maior número de indivíduos. Os websites permitem que as empresas e instituições se apresentem aos seus públicos, sem intermediário.

Por outro lado, os websites têm acompanhado as constantes evoluções no mercado tecnológico, tendo-se tornado responsives, ou seja, páginas nas quais os seus elementos sejam adaptáveis aos tamanhos dos diferentes ecrãs que hoje são utilizados para aceder à internet, nomeadamente os tablets e os smartphones. Desta forma, fazem com que o seu acesso seja ainda mais isento de tempo e espaço, possibilitando aos públicos a consulta em qualquer hora e lugar.

A comunicação com os indivíduos é favorecida com este meio, pois, hoje em dia a internet é o tecido do quotidiano (Castells, 207), o que significa que grande parte das atividades diárias se fazem com o seu auxílio. Desta forma, não parece estranho que, quando procuram informação sobre algum produto ou serviço, os indivíduos procurem, numa primeira fase, obter informação através dos websites das organizações. Tal facto é compartilhado por Jenkins et al:

Ocorreria então uma mudança fundamental na maneira como todos «consomem», na maneira como as pessoas interessadas poderiam buscar conteúdo nas empresas quando quisessem - justapondo e avaliando as mensagens corporativas diretamente obtidas da fonte e publicando o que encontrassem on-line entre seus círculos de amigos, familiares, colegas e até desconhecidos. (2014, p. 49)

É com base nestes pressupostos que se atribui uma grande relevância aos websites como meios de comunicação das organizações. Claro que, a sua importância será variável consoante o tipo de empresa ou instituição que se trata. Assim, a pertinência do website poderá ser maior consoante o peso da componente informação na organização em causa. Quando se fala de instituições de ensino superior - é a este ponto que se pretende chegar - fala-se de organizações em que o elemento informativo é extremamente significante. É por isso mesmo que se acredita que, para estas instituições, o website poderá ser o seu meio de comunicação online mais importante. 


\section{Os Websites na Comunicação das Universidades Portuguesas}

"As tecnologias da Web estão redesenhando e redefinindo a transmissão (...) de conteúdos informacionais, criando novas e interessantes oportunidades de divulgação, mais personalizadas, sociais e flexíveis, com um carácter de compartilhamento de informações que vem sendo de grande valia para instituições educacionais (...)."

Luvizotto, Fusco \& Scanavacca, 2010, p. 38

O sistema universitário português é bastante jovem, remontando as suas origens para os anos 70 do século passado. A consciência da importância da comunicação organizacional nestas instituições é ainda mais recente. A preocupação com a gestão das atividades de comunicação surgiu em meados dos anos 90, quando as universidades viram a sua sobrevivência ameaçada devido à falta de financiamento por parte do Estado, à diminuição do número de alunos e à crescente concorrência entre estas instituições, fruto da proliferação de estabelecimentos de ensino públicos, privados e politécnicos. De facto, "Em menos de três décadas (...) as instituições académicas passaram de um cenário e futuro previsível e fácil recrutamento de estudantes, sem grande concorrência, para um clima de grande instabilidade" (Ruão, 2005, p. 3).

Foi, então, num contexto de crise no ensino superior que a função de comunicação se tornou mais visível nestas instituições e passou a fazer parte das suas opções estratégicas, tendo surgido, nesta altura, os primeiros gabinetes de comunicação, exclusivamente responsáveis por estas tarefas. Tal aspeto é referido por Ruão:

As instituições de ensino superior público em Portugal despertaram para a gestão controlada da comunicação e da identidade, em meados da década de 1990. (...). Nessa época, as universidades nacionais começaram a alargar os seus departamentos de comunicação, a modernizar as suas simbologias, a apostar em novos meios, o usar estratégias de segmentação e a promover activamente o trabalho científico. (2008, p. 153)

Nesta altura, as instituições de ensino superior portuguesas adotaram um novo paradigma de comunicação, mais próximo do modelo empresarial pois, precisam de desenvolver uma vantagem competitiva baseada num sistema de 
características únicas e comunicá-las, de uma maneira eficaz, a todos os públicos (Carrillo e Ruão, 2005). Para tal, estas instituições começaram a considerar novos públicos, a desenvolver novos eixos de comunicação e a apostar em novas estratégias de comunicação.

No conjunto das novas estratégias de comunicação adotadas, as novas tecnologias assumiram um papel de relevância, até porque, o incremento das atividades de comunicação nas universidades portuguesas se fez a par do surgimento da internet, em meados dos anos 90. Assim, o aparecimento das novas tecnologias marcou o início do século XXI e o período de reforma do sistema universitário português:

(...) A emergência da chamada "Sociedade do Conhecimento" (ou "da Informação"), na segunda metade do século XX, trouxera consigo extraordinárias Oportunidades (...). Referimo-nos a uma sociedade baseada na informação e dominada pela revolução tecnológica, que se tornaram eixos do desenvolvimento sustentável e da competitividade das nações. (Ruão 2008, p 157)

Acerca deste aspeto é importante ter-se como referência que, em Portugal, as universidades foram as primeiras instituições a adotar a internet, aliás, a comunidade académica foi pioneira na utilização desta tecnologia. Portanto, não é de estranhar que, cedo, tenha sido atribuída importância às potencialidades da internet como meio de comunicação.

No seio das instituições de ensino superior portuguesas a criação de websites institucionais representou uma das primeiras medidas relacionadas com o incremento das novas tecnologias. Com a proliferação de páginas de internet por parte de organizações das mais variadas áreas, as universidades perceberam que esta poderia representar uma boa oportunidade de comunicação. Por outro lado, as instituições de ensino superior de países vizinhos e, em particular, da Europa tinham, já, começado a adotar esta tendência. Na verdade, a adoção "(...) das novas tecnologias e da capacidade de inovação são traços que existiram sempre na Universidade. Eram já preocupações iniciais, mas que não se puderam concretizar logo, ou concretizaram-se à dimensão da época (...)" (Lúcio Craveiro da Silva citado em Ruão, 2008, p. 430).

Como consequência desta conjuntura, atualmente, todas as instituições de ensino superior têm o seu website (tal como se pode comprovar pela análise da tabela 1) e este é, talvez, o seu elemento de comunicação mais importante. 
“(...) The World Wide Web (WWW) and print media are perceived to be the most important sources of university information (...)" (Gray, Fam \& Llanes, 2003: 112). A recolha de dados realizada (tabela 1), permitiu constatar que, das 148 instituições de ensino superior nacionais (listadas na página web da Direção Geral de Ensino Superior), todas possuem uma página oficial. Este facto comprava a importância que este meio de comunicação possui no seio das universidades. E, é necessário referir que, neste estudo, não foram analisados os websites de cada faculdade, dentro das próprias universidades. Quer isto dizer, que, atualmente é também muito comum que as próprias faculdades possuam as suas próprias páginas web, extrapolando-se, já, a existência de apenas um website oficial da instituição de ensino superior como um todo. Pode-se justificar este contexto pela constante necessidade de informação mais específica sobre cada faculdade ou instituto.

De facto, grande parte das vezes, as páginas web das instituições de ensino superior representam o primeiro elemento de contacto com os potenciais estudantes. Não raras vezes, quando procuram informações sobre os cursos e universidades para procederem à sua candidatura ao ensino superior, os estudantes fazem-no através da internet primeiro, e só depois procuram outras fontes para se esclarecerem, como o contacto telefónico ou presencial. Este aspeto não é estranho, pois, as páginas web das instituições de ensino superior agregam informação essencial sobre seus projetos de ensino e investigação, e sobre todos os serviços de apoio aos estudantes. Desta forma, pode afirmarse que os websites são a porta de entrada para as universidades e, por isso a sua construção deve ser "(...) integrada e coerente com uma boa imagem corporativa da organização (...)” (Suarez et al, 2006, p. 3).

As instituições de ensino superior portuguesas têm demonstrado consciência da importância destes meios de comunicação. Uma pequena visita pelas páginas das universidades portuguesas permite perceber isso mesmo, denotando-se um grande investimento na frequente atualização de conteúdos e, também, na constante alteração de layouts, com vista a torná-los mais apelativos e interativos.

Porém, ainda que aqui se apresentem os websites como elementos de comunicação muito importantes para as universidades portuguesas é preciso ter em conta que estes não são os únicos. As universidades têm feito grandes desenvolvimentos nas suas atividades promocionais e, atualmente, 
Os formatos de comunicação mais usados para atingir estes públicos podem classificar-se em ações de relações públicas (que incluem as feiras e exposições, visitas a escolas, dias de portas abertas ou publicações), de publicidade (nos jornais, rádio, televisão, outdoors, cartazes ou flyers) e de merchandising (que incluem lembranças institucionais e peças de vestuário). (Ruão, 2008: 456)

Em jeito de conclusão deste capítulo pode-se referir que as universidades têm todo o interesse em apostar na qualidade dos seus websites pois, apesar de não serem um meio de comunicação recente, não deixam de ser decisivos para o contacto com os públicos. Todavia, as páginas web não devem ser tidas como o único meio de comunicação a privilegiar. Preferencialmente, estes devem ser parte de uma estratégia de comunicação que congregue outros formatos de comunicação online e offline, onde devem constar os tradicionais meios como as brochuras, os cartazes ou o merchandising, mas também, as ferramentas online mais recentes, onde as redes sociais, como fenómeno relevante de partilha e interação com os públicos, tem assumido protagonismo.

\begin{tabular}{|c|c|c|c|c|}
\hline Instituição & Pública & Politécnico & Privada & Website \\
\hline Instituto Universitário de Lisboa & $\mathrm{X}$ & & & Sim \\
\hline Universidade Aberta & $X$ & & & Sim \\
\hline Universidade dos Açores & $X$ & & & Sim \\
\hline Universidade do Algarve & $\mathrm{X}$ & & & Sim \\
\hline Universidade de Aveiro & $\mathrm{X}$ & & & Sim \\
\hline Universidade da Beira Interior & $\mathrm{X}$ & & & Sim \\
\hline Universidade de Coimbra & $\mathrm{X}$ & & & Sim \\
\hline Universidade de Évora & $\mathrm{X}$ & & & Sim \\
\hline Universidade da Madeira & $X$ & & & Sim \\
\hline Universidade do Minho & $\mathrm{X}$ & & & Sim \\
\hline Universidade Nova de Lisboa & $\mathrm{X}$ & & & Sim \\
\hline Universidade do Porto & $\mathrm{X}$ & & & Sim \\
\hline Universidade Técnica de Lisboa & $\mathrm{X}$ & & & Sim \\
\hline $\begin{array}{l}\text { Universidade de Trás-os-Montes e Alto } \\
\text { Douro }\end{array}$ & $\mathrm{X}$ & & & Sim \\
\hline $\begin{array}{l}\text { Escola Superior de Enfermagem de Coim- } \\
\text { bra }\end{array}$ & & $X$ & & Sim \\
\hline
\end{tabular}


Escola Superior de Enfermagem de Lisboa Escola Superior de Enfermagem do Porto Escola Superior de Hotelaria e Turismo do Estoril

Escola Superior Náutica Infante D. Henrique

Instituto Politécnico de Beja

Instituto Politécnico de Bragança Instituto Politécnico de Castelo Branco Instituto Politécnico do Cávado e do Ave Instituto Politécnico de Coimbra Instituto Politécnico da Guarda Instituto Politécnico de Leiria

Instituto Politécnico de Lisboa

Instituto Politécnico de Portalegre

Instituto Politécnico do Porto

Instituto Politécnico de Santarém

Instituto Politécnico de Setúbal

Instituto Politécnico de Tomar

Instituto Politécnico de Viana do Castelo

Instituto Politécnico de Viseu

Escola Superior Artística do Porto

Escola Superior de Atividades Imobiliárias

Escola Superior Gallaecia

Escola Universitária das Artes de Coimbra

Escola Universitária Vasco da Gama

Instituto de Arte, Design e Empresa

Instituto Superior Bissaya Barreto

Instituto Superior D. Afonso III

Instituto Universitário de Ciências da Saúde

$\mathrm{X}$

$\mathrm{X}$

$\mathrm{X}$

X

Sim

Sim

Sim

Sim

$\mathrm{X}$

Sim

$\mathrm{X}$

Sim

$\mathrm{X}$

Sim

X

Sim

X

Sim

X

Sim

Sim

Sim

Sim

Sim

Sim

Sim

Sim

X

Sim

$\mathrm{X}$

Sim

$\mathrm{X}$

X Sim

X Sim

X Sim

X Sim

X Sim

X Sim

X Sim

X Sim

X Sim

Instituto Superior de Ciências da Saúde

X Sim

Egas Moniz

Instituto Superior de Educação e Trabalho

Instituto Superior de Estudos Interculturais

e Transdisciplinares - Almada
X Sim

X Sim 
Instituto Superior de Estudos Interculturais

e Transdisciplinares - Viseu

Instituto Superior de Gestão

Instituto Superior de Línguas e Administra-

ção de Leiria

Instituto Superior de Serviço Social do

Porto

Instituto Superior Manuel Teixeira Gomes

Instituto Superior Miguel Torga

Instituto Universitário da Maia

Instituto Universitário de Ciências Psicoló-

gicas, Sociais e da Vida

Universidade Atlântica

Universidade Autónoma de Lisboa Luís de

Camões

Universidade Católica Portuguesa - Centro

Regional das Beiras

Universidade Católica Portuguesa - Escola das Artes

Universidade Católica Portuguesa - Escola

Superior de Biotecnologia

Universidade Católica Portuguesa - Facul-

dade de Ciências Económicas e Empresari-

ais

Universidade Católica Portuguesa - Facul-

dade de Ciências Humanas

Universidade Católica Portuguesa - Facul-

dade de Ciências Sociais

Universidade Católica Portuguesa - Facul-

dade de Direito

Universidade Católica Portuguesa - Facul-

dade de Direito (Porto)

Universidade Católica Portuguesa - Facul-

dade de Economia e Gestão

Universidade Católica Portuguesa - Facul-

dade de Educação e Psicologia

\begin{tabular}{|c|c|}
\hline$X$ & Sim \\
\hline$X$ & Sim \\
\hline$X$ & Sim \\
\hline$X$ & Sim \\
\hline$X$ & Sim \\
\hline$X$ & Sim \\
\hline$X$ & Sim \\
\hline$X$ & Sim \\
\hline$X$ & Sim \\
\hline$X$ & Sim \\
\hline$X$ & Sim \\
\hline$X$ & Sim \\
\hline$X$ & Sim \\
\hline$X$ & Sim \\
\hline$X$ & Sim \\
\hline$X$ & Sim \\
\hline$X$ & Sim \\
\hline$X$ & Sim \\
\hline$X$ & Sim \\
\hline$X$ & Sim \\
\hline
\end{tabular}


Universidade Católica Portuguesa - Facul-

X Sim

dade de Filosofia

Universidade Católica Portuguesa - Facul-

dade de Teologia

Universidade Católica Portuguesa - Facul-

dade de Teologia (Braga)

Universidade Católica Portuguesa - Facul-

dade de Teologia (Porto)

Universidade Católica Portuguesa - Insti-

tuto de Bioética

Universidade Católica Portuguesa - Insti-

tuto de Ciências da Saúde

Universidade Católica Portuguesa - Insti-

tuto de Ciências da Saúde (Porto)

Universidade Católica Portuguesa - Insti-

tuto de Estudos Europeus

Universidade Católica Portuguesa - Insti-

tuto de Estudos Políticos

Universidade Europeia

Universidade Fernando Pessoa

Universidade Lusíada

Universidade Lusíada do Porto

Universidade Lusíada de Vila Nova de Fa-

malicão

Universidade Lusófona de Humanidades e

Tecnologias

Universidade Lusófona do Porto

Universidade Portucalense Infante D. Hen-

rique

Academia Nacional Superior de Orquestra

CESPU Escola Superior de Saúde de Vale

do Ave

CESPU Escola Superior de Saúde de Vale

do Sousa

Conservatório Superior de Música de Gaia

\begin{tabular}{ll} 
X & Sim \\
X & Sim \\
& \\
X & Sim \\
& \\
X & Sim \\
& \\
X & Sim \\
& \\
X & Sim \\
& \\
X & Sim \\
& \\
X & Sim \\
& \\
X & Sim \\
X & Sim \\
X & Sim \\
X & Sim \\
X & Sim \\
X & Sim \\
& \\
X & Sim \\
& \\
\hline & \\
& \\
& \\
X Sim \\
X
\end{tabular}


Escola Superior Artística do Porto (Guima-

rães)

Escola Superior de Artes Decorativas

Escola Superior de Artes e Design

Escola Superior de Educação de Almeida

Garrett

Escola Superior de Educação de Fafe

Escola Superior de Educação de João de

Deus

Escola Superior de Educação de Paula Frassinetti

Escola Superior de Educação de Torres Novas

Escola Superior de Educação Jean Piaget de

Almada

Escola Superior de Educação Jean Piaget de

Arcozelo

Escola Superior de Educação Jean Piaget de Arcozelo (Viseu)

Escola Superior de Educação Jean Piaget do Nordeste

Escola Superior de Educadores de Infância Maria Ulrich

Escola Superior de Enfermagem da Cruz Vermelha Portuguesa de Oliveira de Azeméis

Escola Superior de Enfermagem de S. José de Cluny

Escola Superior de Enfermagem de Santa Maria

Escola Superior de Enfermagem Dr. José Timóteo Mantalvão Machado

Escola Superior de Enfermagem S. Francisco das Misericórdias

Escola Superior de Saúde da Cruz Vermelha Portuguesa

\begin{tabular}{|c|c|}
\hline X & Sim \\
\hline$X$ & Sim \\
\hline$X$ & Sim \\
\hline$X$ & Sim \\
\hline$X$ & Sim \\
\hline$X$ & Sim \\
\hline$X$ & Sim \\
\hline$X$ & Sim \\
\hline$X$ & Sim \\
\hline$X$ & Sim \\
\hline$X$ & Sim \\
\hline$X$ & Sim \\
\hline$X$ & Sim \\
\hline$X$ & Sim \\
\hline$X$ & Sim \\
\hline$X$ & Sim \\
\hline$X$ & Sim \\
\hline$X$ & Sim \\
\hline$X$ & Sim \\
\hline
\end{tabular}


Escola Superior de Saúde de Alcoitão

Escola Superior de Saúde Egas Moniz

X Sim

Escola Superior de Saúde Jean Piaget - Al-

X Sim

garve

Escola Superior de Saúde Jean Piaget de

X Sim

Vila Nova de Gaia

Escola Superior de Saúde Jean Piaget de Vi-

X Sim

seu

Escola Superior de Saúde Jean Piaget/ Nor-

deste

Escola Superior de Saúde Ribeiro Sanches

Escola Superior de Tecnologia e Gestão

X Sim

Jean Piaget do Litoral Alentejano

Escola Superior de Tecnologias de Fafe

Escola Superior de Tecnologias e Artes de

X Sim

Lisboa

Instituto de Estudos Superiores Financeiros

e Fiscais do Porto

Instituto Português de Administração de

X Sim

X Sim

Marketing de Lisboa

Instituto Português de Administração de

Marketing do Porto

Instituto Português de Administração de

X Sim

X Sim

Marketing de Aveiro

Instituto Superior Autónomo de Estudos

Politécnicos

Instituto Superior D. Dinis

Instituto Superior de Administração e Ges-

X Sim

tão

Instituto Superior de Administração e Lín-

X Sim

X Sim

X Sim

guas

Instituto Superior de Ciências da Adminis-

tração

Instituto Superior de Ciências da Informa-

ção e da Administração

Instituto Superior de Ciências Educativas

X Sim

X Sim

X Sim

X Sim

X Sim

X Sim

X Sim 
Instituto Superior de Ciências Educativas do Douro

Instituto Superior de Comunicação Empresarial

Instituto Superior de Educação e Ciências

Instituto Superior de Espinho

Instituto Superior de Gestão Bancária

Instituto Superior de Novas Profissões

Instituto Superior de Paços de Brandão

Instituto Superior de Saúde do Alto Ave

Instituto Superior de Tecnologias Avança-

das de Lisboa

Instituto Superior de Tecnologias Avança-

das de Lisboa (Porto)

Instituto Superior Politécnico de Oeste

Instituto Superior Politécnico Gaya - Es-

cola Superior de Ciências e Tecnologia

Instituto Superior Politécnico Gaya - Es-

cola Superior de Desenvolvimento Social e

Comunitário

Instituto Superior Politécnico Gaya - Es-

cola Superior de Educação de Santa Maria

ISLA - Instituto Politécnico de Gestão e

Tecnologia

ISLA - Instituto Superior de Gestão e Administração de Santarém

Universidade Atlântica - Escola Superior

de Saúde Atlântica

Universidade Católica Portuguesa - Escola

Superior Politécnica de Saúde (Lisboa)

Universidade Católica Portuguesa - Escola

Superior Politécnica de Saúde (Porto)

Universidade Fernando Pessoa - Escola Su-

perior de Saúde

\begin{tabular}{|c|c|}
\hline X & Sim \\
\hline$X$ & Sim \\
\hline$X$ & Sim \\
\hline$X$ & Sim \\
\hline$X$ & Sim \\
\hline$X$ & Sim \\
\hline$X$ & Sim \\
\hline$X$ & Sim \\
\hline$X$ & Sim \\
\hline$X$ & Sim \\
\hline$X$ & Sim \\
\hline$X$ & Sim \\
\hline$X$ & Sim \\
\hline$X$ & Sim \\
\hline$X$ & Sim \\
\hline$X$ & Sim \\
\hline$X$ & Sim \\
\hline$X$ & Sim \\
\hline$X$ & Sim \\
\hline$X$ & Sim \\
\hline
\end{tabular}

Sim

im

m

Sim

m

iim

im

$\operatorname{Sim}$

$\operatorname{sim}$

im

m

im 
Tabela 1. Tabela de verificação da presença de websites nas 148 instituições de ensino superior portuguesas.

\section{CONCLUSÕES}

"A Internet é o tecido das nossas vidas."

Castells, 2007, p. 15

O presente estudo pretendeu compreender a relevância das novas tecnologias, em particular dos websites, para a comunicação no contexto organizacional, a partir da análise do caso das páginas web nas universidades portuguesas.

Parecem não restar dúvidas de que o aparecimento da internet trouxe consigo um conjunto de transformações que se sentiram a todos os níveis, desde o cultural, ao económico, ao político e ao social. O principal impacto desta tecnologia foi, talvez, o incremento da sociedade de informação que foi responsável por progressos decisivos na forma de comunicação das sociedades. A internet tornou possível, pela primeira vez a comunicação de muitos para muitos, através de qualquer parte do mundo, abolindo, de vez, as barreiras do tempo e do espaço. Desde o seu aparecimento, esta tecnologia não tem parado de evoluir e todos os dias assistimos a novas possibilidades, que ela nos oferece.

A internet é uma tecnologia que veio para ficar e, são poucos os indivíduos que, atualmente não a incorporam nas suas práticas quotidianas. A sua utilização é tão natural que se pode afirmar com alguma segurança que ela é, já, uma extensão do próprio indivíduo. Em Portugal, assistiu-se a este fenómeno, sem, contudo, ignorar que existe sempre um grupo de resistentes à utilização desta tecnologia, que são, geralmente, os indivíduos mais velhos e com níveis de escolaridade mais baixa. Ainda assim, a maioria dos portugueses incorporou esta tecnologia nas suas práticas diárias, dando-lhe usos várias, onde o fator de comunicação e de procura de informação sobre temáticas várias, assumem particular relevância.

Tendo em conta este contexto, pode-se, também, aferir que é profícuo que a "internet seja abordada como o meio a privilegiar no âmbito da comuni- 
cação institucional" (Suarez et al, 2006, p. 3). As organizações encontram inúmeras vantagens de comunicação no mundo online, onde o contacto com os seus públicos é favorecido. A empresas e instituições têm, agora, um meio onde lhes é possível contruir o seu próprio discurso, sem intermediários e, onde podem comunicar com os seus consumidores em qualquer momento e a partir de qualquer lugar, de uma forma mais personalizada a interativa. " $A$ Internet é vista como um meio privilegiado de contacto entre empresas e clientes" (Marques 2012, p 29).

No conjunto de possibilidades de comunicação implementadas pela internet, concluiu-se que os websites devem ser ferramentas privilegiados na comunicação entre as organizações e os seus públicos, pelas vantagens e possibilidades que apresentam e que foram discutidas. Quando se fala de comunicação das universidades, estes meios de comunicação parecem assumir particular relevância, uma vez que se tratam de instituições onde o carácter informativo assume um papel decisivo, nas quais as páginas web se mostram como um dos primeiros meios onde os potenciais alunos ou estudantes procuram a informações desejadas.

Terminado este pequeno estudo acredita-se que os objetivos propostos foram alcançados, tendo-se encontrado resposta para a questão de partida, que era ela: porque é que os websites devem ser um meio de comunicação privilegiado no âmbito da Comunicação organizacional, em particular pelas universidades? Acredita-se, portanto, que o presente estudo representa um contributo relevante para as áreas de estudos das novas tecnologias e da comunicação organizacional.

Neste estudo apenas se discutiu uma pequena parte da importância da internet para a comunicação organizacional. Existe ainda muito terreno por desbravar neste campo de estudo. Assim, investigações futuras poderão focar-se na importância dos websites noutro tipo de empresas ou instituições ou, abordando as suas potencialidades e os desenvolvimentos que se têm registado neste meio de comunicação.

\section{REFERÊNCIAS BIBLIOGRÁFICAS}

Bargh, J. \& McKenna, K. (2004). The internet and social life. Annual Review of Psychology. 55: 573-590. 
Caraça, J. (2005). Prefácio. In G. Cardoso, A. F. Costa, C. P. Conceição \& M. C. Gomes, A Sociedade em Rede em Portugal (pp. 7-12). Porto: Campo das Letras - Editores, S.A.

Cardoso, A. (2008). A comunicação política na internet. Análise dos websites dos partidos políticos em Itália. Observatório $\left(O B S^{*}\right), 7$ : 180-204. Disponível em: http://obs.obercom.pt/index.php/obs/article/view/173/212.

Cardoso, G.; Mendonça, S.; Paisana, M. \& Lima, T. (2015). A Internet e o consumo de notícias online em Portugal 2015. Lisboa: OberCom Observatório da Comunicação.

Cardoso, G.; Mendonça, S.; Lima, T.; Paisana, M. \& Neves, M. (2014). A Internet em Portugal - sociedade em rede 2014. Lisboa: OberCom Observatório da Comunicação.

Cardoso, G.; Espanha, R.; Lima, T. \& Paisana, M. (2012). A sociedade em rede em Portugal 2012 - A internet em Portugal. Lisboa: OberCom Observatório da Comunicação.

Cardoso, G.; Firmino da Costa, A.; Palma Conceição, C. \& Carmo Gomes, M. (2005). A sociedade em rede em Portugal. Porto: Campo das Letras - Editores, S.A.

Cardoso, G.; Espanha, R. \& Gonçalves, A. (2007). A internet em Portugal (2003-2007). Lisboa: OberCom - Observatório da Comunicação.

Carrera, F. (2012). Marketing digital na versão 2.0: o que não pode ignorar. ( $2^{\mathrm{a}}$ ed). Lisboa: Edições Sílabo, Lda.

Carrillo, V. \& Ruão, T. (2005). La reputación en las universidades: de la identidad local a la reputación europea. Actas do V Congresso de Comunicação Local: 14-16, Universitat Jaume I De Castellón, Espanha.

Castells, M. (2007). A galáxia da internet reflexões sobre internet, negócios e sociedade. (R. Espanha, Trad.). (J. Oliveira \& G. Cardoso, Coord.). $\left(2^{\mathrm{a}}\right.$ ed). Lisboa: Fundação Calouste Gulbenkian. (Obra originalmente publicada em 2001).

Castells, M. (2001). A era da informação: economia, sociedade e cultura. (R. Venancio Majer \& K. Brandini Gerhardt, Trad.). (5 ed). (Vol. 1: A Sociedade em Rede). São Paulo: Editora Paz e Terra S.A. (Obra originalmente publicada em 1999). 
Comunicarte Publishing. (2010). Web trends - 10 cases made in web 2.0. Gaia: Edições Sílabo.

Direção Geral de Ensino Superior. (s.d.). Instituições de Ensino Superior Portuguesas. Disponível em: www.dges.mctes.pt/DGES/pt/Reconheciment o/NARICENIC/Ensino+Superior/Institui\%C3\%A7\%C3\%B5es+de+Ens ino+Superior+Portuguesas/

Evolução da Informática TIC - Moimenta da Beira. (s.d.). A internet em Portugal. Disponível em http://infoevo.escolasmoimenta.pt/9d06m01.

Gray, B.; Fam, K. \& Llanes, V. (2003). Branding Universities in Asian Markets. Journal of Product \& Brand Management, 2 (12): 108-120.

Jenkins, H.; Ford, S. \& Green, J. (2014) Cultura da conexão: criando valor e significado por meio da mídia negociável. (P. Arnaud, Trad.). São Paulo: Editora Aleph. (Obra originalmente publicada em 2013).

Luvizotto, C.; Fusco, E. \& Scanavacca, A. (2010). Websites educacionais: considerações acerca da arquitetura da informação no processo de ensino-aprendizagem. Educação em Revista, Marília, 11(2): 23-40.

Marques, M. (2012). Marketing e comunicação: a web como ferramenta para a promoção turística dos hotéis da Costa do Estoril. (Dissertação de Mestrado). Universidade Lusófona de Humanidades e Tecnologias, Portugal.

Marcelo, A. (2005). Novos media: inauguração de novas formas de sociabilidade. Actas do III Sopcom, VI Lusocom e II Ibérico. Covilhã: Universidade da Beira Interior.

Nunes, F. (2004). A apropriação das tecnologias de informação e comunicação na sociedade portuguesa. Scripta Nova Revista Electrónica de Geografía e Ciencias Sociales Universidad de Barcelona. 8(170): 40. Disponível em: www.ub.edu/geocrit/sn/sn-170-40.htm .

Origens da Internet. (2011). O aparecimento da internet em Portugal. Disponível em: http://otiblog1.blogspot.pt/2011/01/o-aparecimento-da-interne t-em-portugal.html.

Poupinha, L. \& Espanha, R. (2005). A existência net: o valor da net para relações públicas/ comunicação estratégica. Comunicação e Sociedade - Comunicação Estratégica, 8: 209-217. 
Póvoas, R. (2009). Relações públicas sem croquete: uma visão moderna das $R P$. Lisboa: Gestão Plus Edições.

Ruão, T.; Salgado, P.; Freitas, R. \& Ribeiro, P. (2014). Comunicação organizacional e relações públicas, numa travessia conjunta. Comunicação Organizacional e Relações Públicas: horizontes e perspetivas. Relatório de um debate, Centro de Estudos de Comunicação e Sociedade, 16-39.

Ruão, T. (2008). A comunicação organizacional e os fenómenos de identidade: a aventura comunicativa da formação da Universidade do Minho, 1974-2006. (Tese de Doutoramento em Ciências da Comunicação). Universidade do Minho, Portugal.

Ruão, T. (2005). O papel da identidade e da imagem na gestão das universidades. IV Congresso da SOPCOM - Associação Portuguesa de Ciências da Comunicação, Universidade de Aveiro, 20/21 de outubro.

Ruão, T. (2001). O conceito de identidade organizacional: teorias, gestão e valor. II Congresso da SOPCOM - Associação Portuguesa de Ciências da Comunicação, Fundação Calouste Gulbenkian, Lisboa.

Póvoas, R. (2009). Relações públicas sem croquete: uma visão moderna das $R P$. Lisboa: Gestão Plus Edições.

Suarez, A.; Moreira, R. \& Carrapatoso, E. (2006). Comunicação institucional no ensino superior: visitas virtuais e usabilidade. Conferência Ibérica de Sistemas e Tecnologias de Informação, Esposende. 
$\bigoplus$

$\bigoplus$

$\oplus$ 


\title{
Representações de morte e desvio em narrativas jornalísticas da Amazônia urbana
}

\author{
Sergio do Espirito Santo Ferreira Junior \& Alda Cristina Costa \\ Universidade Federal do Pará \\ E-mail: esferreira.sergio@gmail.com/aldacristinacosta@gmail.com
}

\section{RESUMO}

O objetivo deste artigo é analisar como as narrativas jornalísticas produzidas na Amazônia Paraense apresentam as mortes por violência urbana, ancorando-as às representações sociais do bem e do mal, definindo e participando da construção social do fenômeno da violência e da rotulação de desviantes. As narrativas estão inseridas na rotina cotidiana de repercussões em um ambiente sociossimbólico, cujas representações sociais são alimento para as narrativas das mídias jornalísticas e são por elas alimentadas. Pensamos como a comunicação midiática rearranja o fenômeno, na produção de experiência social em uma cotidianidade.
Analisamos as narrativas dos principais jornais impressos da região, Amazônia, Diário do Pará e O Liberal, cujo modus narrandi é permeado pela reiteração dualista das mortes por violência urbana, apresentadas como a morte inesperada dos bons e a morte naturalizada dos maus. Pensamos as representações sociais a partir do pensamento de Moscovici e Jovchelovitch, como sistema interpretativo formado por formas de conhecimento socialmente partilhadas, que ordenam e governam as condutas dos indivíduos, face aos objetos sociais da vida cotidiana, constituindo-a, por meio de processos de ancoragem e objetivação.

Palavras-chave: representações sociais;narrativas jornalísticas; morte; desvio; violência; Amazônia Paraense.

Data de submissão: 11-05-2016. Data de aprovação: 23-10-2016.

A Revista Estudos em Comunicação é financiada por Fundos FEDER através do Programa Operacional Factores de Competitividade - COMPETE e por Fundos Nacionais através da FCT - Fundação para a Ciência e a Tecnologia no âmbito do projeto Comunicação, Filosofia e Humanidades (LabCom.IFP) UID/CCI/00661/2013.

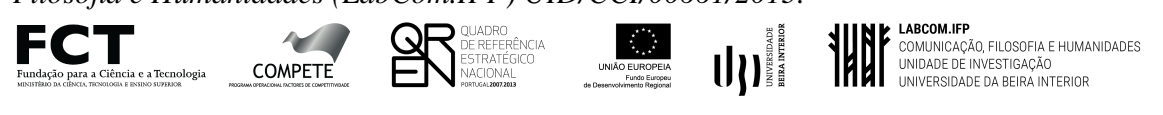




\begin{abstract}
The purpose of this article is to analyze how the journalistic narratives produced in Pará Amazon present deaths from urban violence, anchoring them to the social representations of good and evil, while defining and participating in the social construction of the phenomenon of violence and labeling deviants. The narratives are embedded in everyday routine repercussions in a socio-symbolic environment, whose social representations are food for the narratives of news media and are fed by them. We think how media communication rearranges the phenomenon, in the production of social expe-

major newspapers in the region are analyzed. They are Amazônia, Diário do Pará e O Liberal whose modus narrandi is permeated by dualistic reiteration of deaths from urban violence, presented as the good of unexpected death and naturalized death of the wicked. The social representations from the thought of Moscovici and Jovchelovitch as interpretive system formed by forms of knowledge socially shared, that order and govern the conduct of individuals, given the social objects of everyday life, making it through processes anchoring and objectification are used throughout this article..
\end{abstract} rience in a daily life. The narratives of

Keywords: social representations; journalistic narratives; death; deviance; violence; Amazon from Pará.

\title{
INTRODUÇÃO
}

$\mathrm{N}^{\circ}$

O Brasil, a violência começa a ser pauta de discussão, nos idos de 1960, quando o cineasta Glauber Rocha começa a trabalhar em seus filmes a temática do cinema revolucionário, do auge do "populismo engajado" e também do golpe militar. A violência entra em cena no debate nacional, quando já não se podia negar o conflito presente nas diversas esferas da sociedade, as várias formas de exclusão social, os preconceitos em relação a diferentes minorias e mesmo algumas evidências da tensão entre classes sociais no país. A partir disso, os brasileiros começam a ter ideia do Brasil e da violência, que hoje, assume a totalidade das discussões tanto no dia-a-dia social quanto no imaginário coletivo. Em 1980, com a intensificação do processo de redemocratização, a discussão em torno do fenômeno da violência ganha um grande espaço, ocupando boa parte dos noticiários da mídia, "pulando" das páginas 
policiais para os cadernos mais importantes e para os telejornais e programas diários televisivos.

A onipresença do crime e da violência na mídia brasileira tem estimulado uma série de debates a respeito do quanto essa mídia pode alimentar ansiedades, formar atitudes, definir valores ou incentivar comportamentos diversos no público, já que é nessa intrincada relação que os indivíduos percebem as representações construídas pelas narrativas midiáticas textuais, visuais, orais ou imagéticas.

Considerando o cenário de complexificação da problemática urbana e da questão social, as mídias jornalísticas têm procurado dar respostas - espetacularizadas ou não - à população, que se queda atônita diante da dificuldade de compreensão das bases societárias geradoras da incivilidade e violência crescentes (Telles, 2010). A população brasileira acompanhou o nascimento de narrativas midiáticas, jornalísticas ou não, que passaram a explorar o fenômeno da violência. Não seria ruim se esse crescimento levasse a sociedade a refletir sobre o problema social. Percebe-se, no entanto, que as narrativas, quase sempre, ficam no campo da encenação do real e do reforço simbólico da segregação social. Ao discutir esse problema social é preciso contextualizá-lo num mundo social permeado de contrastes, mas além dos valores em oposição, tais como riqueza e pobreza; coletivo e individual; inclusão e exclusão; bem e mal; modernidade e atraso; ter e ser.

Violência nas ruas, nas escolas, nos estádios, nos lares, no trânsito, na mídia, entre outros lugares, criam um clima de instabilidade e de insegurança constantes. Violência que passa a povoar o imaginário das pessoas, mudando hábitos e transformando os espaços de convivência. Diante disso, realizamse esforços de compreender a relação entre violência-mídia-sociedade. Nesse processo, a mídia participa ativamente da construção do imaginário e experiência sociais, no interior dos quais os indivíduos percebem-se em relação a si mesmos e, sobretudo, em relação aos outros. Dessa percepção vem a visualização do sujeito como parte de uma coletividade e de outros sujeitos como marginais a ela.

A mídia entra numa disputa direta ou indireta de poder com o Estado. É ela que "vê", "ouve" e "fala" pelas e para as pessoas, gerando esvaziamento, conforme argumenta Marcondes Filho (2008), entre população, de um lado, e Estado e instituições político-sociais, do outro; de modo que os meios de comunicação "tomaram" seu lugar. A comunicação midiática "passa a ocu- 
par" simbolicamente o lugar das instituições, fato esse que provoca distorções significativas: a população em vez de se dirigir à justiça para garantir seus direitos, à polícia para obter mais segurança, às escolas e universidades para aprender e melhorar sua formação, recorre à mídia, para "defender" e "proteger" seus direitos, por meio da visibilização.

Ocorreram avanços na produção de narrativas sobre a violência no Brasil na última década, por meio da reformulação das linguagens e modelos utilizados para tratar da temática, da extinção de parte dos cadernos de polícia ou, pelo menos, de um afastamento da exposição sensacional e espetacular sobre a violência na mídia de alguns estados brasileiros (Ramos \& Paiva, 2007). No entanto, não se podem ignorar os usos da violência urbana feitos em âmbitos local e regional mesmo hoje, já que a relevância da cobertura sobre segurança pública é enviesada. Há a consolidação de modos de narrar espetaculares e ampla negação do debate sobre segurança pública e sobre a violência como problema social complexo; deslocamentos se operam pela espetacularização das violências espetaculares, em que as mortes por homicídios ou outras motivações representam ainda uma das chaves da narrativa e principal alimento noticioso.

Há no Brasil, portanto, uma lógica industrial da violência na mídia, cujos usos priorizam a produção de narrativas textuais e imagéticas sobre as mortes, a face mais evidente das representações da violência. As narrativas jornalísticas inserem-se em um processo de produção e difusão de representações, nas quais se inscrevem deslocamentos e interpretações sobre violência e realidade social. Consideramo-las inseridas em um processo de repercussões em um ambiente sociossimbólico, do ponto de vista da difusão de representações que virtualmente se relacionam a representações além e aquém das narrativas midiáticas, e que se rearranjam na produção de experiência social em uma cotidianidade.

Institucionalizou-se na mídia do estado brasileiro do Pará, que configura a Amazônia Paraense ${ }^{1}$, um modus narrandi em que a violência urbana e segurança pública são dadas a ver como ocorrências de criminalidade e seus en-

1. A Amazônia Paraense é um termo usado para identificar o estado brasileiro do Pará, considerando a sua inserção no ambiente heterogêneo da Amazônia. Do ponto de vista das categorias administrativas, o estado do Pará é parte da Amazônia Oriental, sub-região da Amazônia Legal, que é composta pelos estados do Amapá, Maranhão, Pará e Tocantins. O território que compreende toda a Amazônia Legal é formado pelos estados do Acre, Amapá, Amazonas, 
volvidos. A linguagem pode apresentar gradações em suas linhas editoriais, que vão de um tratamento menos espetacular e supostamente mais objetivo até o mais banalizado, agressivo e chulo. No Pará, no entanto, todas as mídias jornalísticas apresentam em suas narrativas um "painel da violência diária", construídos como se fossem relatos policiais sobre Belém, capital do estado, a sua região metropolitana e sobre o interior do estado. Elaboram um panorama interpretativo que pontua determinados elementos da realidade social violenta, ancora-os a territórios, apresenta seus agentes e pacientes, em um processo de reiteração e autorreferência diárias e constantes.

A partir do mapeamento dos impressos da região, analisamos neste trabalho como o processo de narrativização da morte por violência urbana ancora a violência a representações do bem e do mal, objetivando-as. Observamos que as narrativas construídas sobre as mortes decorrentes da violência urbana evidenciam as ocorrências violentas concentradas na periferia da cidade, mobilizando a percepção desses espaços urbanos como locais cada vez mais perigosos, dominados pelo crime e tráfico, ou mesmo personalizando-os, relacionando a violência diretamente a indivíduos e grupos, que seriam seus causadores. Desse modo, essas narrativas participam de uma construção social do desvio, da definição do mal e dos maus na sociedade, que habitam espaços marcados por sociabilidades violentas, assim como de seus contrários.

Partimos de uma perspectiva que compreende as narrativas midiáticas implicadas em repercussões sociossimbólicas (Ferreira Junior \& Costa, 2016) ou naquilo que Correia (2009) aponta como processos sociocognitivos em torno do jornalismo e da sua produção discursiva. Em nossas análises, realizamos uma aproximação teórico-metodológica entre representações sociais (Jovchelovitch, 2000, 2008, Moscovici, 2011) e narrativas jornalísticas (Motta, 2013), para compreender a difusão de conhecimentos sobre a violência urbana. Pensamos, assim, como as mortes decorrentes da violência urbana emergem nesse processo de narrativização e difusão de representações. Discussões adjacentes acrescentam-se a essa, à medida que, para compreender as representações sociais, são apresentados "outros" sociais, identificados como desviantes ou outsiders (Cohen, 2011; Becker, 2008), que não se alinham a ideais normati-

Pará, Rondônia, Roraima, Tocantins, Mato Grosso e parte do Maranhão, sendo área demarcado pela Superintendência do Desenvolvimento da Amazônia (SUDAM), em 1966. (Brasil, 2012). 
vos, que não fazem parte da ordem social, porém são vítimas dessa violência na Amazônia Paraense.

A perspectiva que pretendemos dispensar às narrativas sobre a morte na mídia impressa da Amazônia Paraense é resultado de reflexões realizadas no âmbito do projeto de Pesquisa Mídia e Violência: as narrativas midiáticas na Amazônia Paraense ${ }^{2}$. Selecionamos 12 edições entre 42 jornais retirados do acervo do projeto, que continham as maiores quantidades de fotografias com marcas de violência. Os jornais que constituem o corpus do projeto e aparecem neste artigo são: O Liberal e Diário do Pará, do primeiro e do segundo semestre de 2012; e Amazônia, do primeiro e do segundo semestre de 2013.

\section{AS REPRESENTAÇÕES COMO AMBIENTE SOCIOSSIMBÓLICO}

Ao falar da violência urbana no Brasil, referimo-nos a um fenômeno contextualmente localizado, condicionado pela formação da sociedade brasileira e suas dinâmicas. $\mathrm{O}$ atual ambiente sociossimbólico em que se delineia uma cultura do medo da violência, que ordena praticas cotidianas, movimenta uma economia do medo, é formado por um processo complexo de circulação de referências e interpretações sobre o ambiente urbano, em que as representações se tornam uma espécie de mapa para orientar os indivíduos da sociedade. Um mapa, poderíamos inferir, que se sobrepõe ao território, como afirma Baudrillard (1991), em um processo de simulação na qual já não se consegue definir o real, na qual a sociedade é projetada por meio de imagens que se perfazem na ubiquidade de simulacros. Segundo Baudrillard, os "simuladores atuais" engendram simulacros que compõe uma espécie de realidade que já não é claramente distinguível, pois que toda a vida e a sociedade passam hoje pelo seu filtro. Em uma relação entre as "ordens do real" e "ordens do hiper-real", o simulacro é da ordem do hiper-real, uma vez que se trata de uma realidade que se sobrepõe ao real, por meio da superabundância das imagens, marcadamente, das imagens midiáticas.

2. O Projeto de pesquisa Mídia e Violência: as narrativas midiáticas na Amazônia Paraense foi realizado em parceria entre Universidade Federal do Pará (UFPA) e Conselho Nacional de Desenvolvimento Científico e Tecnológico (CNPq), durante a qual foi analisado um ano de edições dos três grandes jornais impressos paraenses que circulam na região: Diário do Pará, O Liberal e Amazônia. 
Podemos, no entanto, ir além de pensar do ponto de vista do simulacro, de uma realidade imagética e simulada, para pensar as mídias jornalísticas e a narrativização da violência urbana, considerando o caráter refratário dessas narrativas, os deslocamentos que instauram, mas também os processos de forjamento de subjetividade social complexos nos quais se inserem. Buscamos pensar o lugar da comunicação midiática na construção de narrativas, que organizam simbolicamente a realidade cotidiana e que se espraiam no tecido social, como partícipes da configuração do ambiente sociossimbólico relacionado à violência. Falamos, assim, não de representações que têm efeitos diretos e totalizantes nos usuários nem de simulacros que sozinhos configuram toda a realidade, mas de narrativas que participam de uma organização simbólica da vida social e têm relevância contemporânea, ao fazer emergir a violência, em um contexto do qual ela é um elemento percebido e representado cotidianamente.

Aquilo que chamamos de ambiente sociossimbólico trata-se de um ambiente de pensamento formado por representações sociais, conhecimentos da vida cotidiana e de outros espaços da vida social, possuidoras de uma dimensão social e simbólica (Jovchelovitch, 2008; Moscovici, 2011). O conceito de representações sociais é elaborado por Moscovici, que as entende como conceito de uma teoria e também como o fenômeno das formas de conhecimento da sociedade. Para ele, essas representações são produzidas constantemente pela interação e pela comunicação, transformando-se em senso comum, parte de um mundo comum do cotidiano no qual habitamos. Elas circulam nas mídias, nas interações face-a-face, e são produzidas por pessoas inseridas em circunstâncias especificas. Moscovici pensa o lugar da comunicação, do ponto de vista relacional, para demarcar os processos constituidores dessas representações, considerando mesmo a comunicação midiática, cujo papel na produção e difusão de representações sociais outros autores têm reconhecido (Jodelet, 2001; Jovchelovitch, 2000; Porto, 2014).

Assim, as representações, diz Moscovici, orientam-nos frente àquilo a que temos que responder e àquilo que é visível, relacionando aparência e realidade, definindo tal realidade. Forjam-se e se inserem em um ambiente social e cultural, uma atmosfera, pois se constituem em uma espécie de mundo da realidade, não são produzidas por um indivíduo, mas são "partilhadas por tantos, penetram influenciam a mente de cada um, elas não são pensadas por eles; melhor, para sermos mais precisos, elas são re-pensadas, re-citadas e 
re-apresentadas" (Moscovici, 2011, p. 37), operando simbolicamente na prescrição das percepções, de modo a constituir um mundo real e concreto. Para ele, na sociedade contemporânea, agentes como os meios de comunicação de massa respondem à necessidade de re-construir um senso comum, que é o substrato de imagens e sentidos das coletividades. Nesse processo, na relação entre a sociedade e seus mundos, os indivíduos transformam as representações em um fenômeno à parte, mas com estrita relação com aquilo que elas identificam, descrevem e objetivam. Desse modo, esse ambiente, essa realidade partilhada e relacionada à interação entre pessoas, corporifica ideias em experiências dentro de uma sociedade pensante, na qual

Pessoas e grupos criam representações no decurso da comunicação e da cooperação. Representações, obviamente, não são criadas por um indivíduo isoladamente. Uma vez criadas, contudo, elas adquirem vida própria, circulam, se encontram, se atraem e se repelem e dão a oportunidade ao nascimento de novas representações, enquanto velhas representações morrem. Como consequência disso, para se compreender e explicar uma representação, é necessário começar com aquela, ou aquelas, das quais ela nasceu. [...] sendo compartilhada por todos e reforçada pela tradição, ela constitui uma realidade sui generis. Quanto mais sua origem é esquecida e sua natureza convencional ignorada, mais fossilizada ela se torna. O que é gradualmente ideal, gradualmente torna-se materializado. Cessa de ser efêmero, mutável e mortal e torna-se, em vez disso, duradouro, permanente, quase imortal. Ao criar representações, nós somos como o artista, que se inclina diante da estátua que ele esculpiu e a adora como se fosse um deus (Moscovici, 2011, p. 41, grifo do autor).

O ambiente do pensamento é, portanto, o mundo das representações sociais, por elas constantemente formado e reformulado. Essas representações integram um sistema cognitivo formado por formas de conhecimento socialmente partilhadas, que ordenam e governam as condutas dos indivíduos, face aos objetos sociais. As representações sociais emergem como fenômeno no processo de definição do conhecimento e dos saberes sobre a vida social. Jovchelovitch, a respeito delas, afirma que as representações não são uma cópia do mundo, elaborada por um único indivíduo, mas "uma forma dialó- 
gica gerada pelas inter-relações eu/outro/objeto-mundo" (2008, p. 28). Para ela, os processos representacionais, em sua dimensão sociossimbólica, formam e expressam mundos subjetivos, intersubjetivos e objetivos, que podem emergir de diferentes esferas, com múltiplas dimensões. Como problema de conhecimento, essas representações são saber sobre objetos sociais específicos, transformados pela comunicação e pela interação social. Esses saberes são produzidos na e pela vida cotidiana, podendo ser definidos como um conhecimento que fala sobre história, tradições, identidades e modos de estar no mundo de um grupo. Esse conhecimento não é limitado, é partilhado por comunidades que possuem sistemas representacionais. Nessa perspectiva, o social é um elemento relevante no condicionamento das origens desse saber, em uma dinâmica em que representação e contexto se imbricam, e se constituem mutuamente. "É o contexto social que propicia o ponto de partida-chave para a compreensão de formas especificas de comunicação, de inter-relações, de práticas que formam e transformam os processos psicossociais que configuram as representações sociais". (Jovchelovitch, 2008, p. 92).

Essa mesma questão sobre o conhecimento nos guia ao pensarmos as narrativas das mídias jornalísticas e a sua relação com o fenômeno da violência. Não é uma nova perspectiva a de que o jornalismo se constitui como uma atividade produtora de formas de conhecimento sobre a realidade social. Para Tuchman, as notícias não podem ser definidas nos termos de um espelho da sociedade, mas no processo de uma rotinização dos acontecimentos pelo jornalismo, por meio do qual essas notícias constituem a realidade como "como fenômeno social partilhado, dado que no processo de descrição dos acontecimentos, as notícias definem e moldam o acontecimento" (Tuchman, 2002, p. 92). Essa conceptualização do jornalismo a partir do fornecimento de conhecimento social também é encontrada em Correia (2009), que defende uma abordagem sociocognitiva sobre o jornalismo, compreendendo a necessidade de pensar a definição dessa realidade e seus acontecimentos, e mesmo a discursividade dessa atividade.

Correia delineia um quadro que permite compreender como o jornalismo se constitui como uma atividade produtora de conhecimento cotidiano sobre o mundo social. Refere-se, pois, a um processo de objetivação da experiência, em que o jornalismo atribui significados aos acontecimentos, comportando também uma dimensão discursiva. Para o autor, a origem dos conhecimentos é fundamentalmente social e se dá pela experiência cotidiana, que produz esse 
acervo de conhecimentos socialmente disponíveis que se manifestam em um "conjunto de saberes, informações e operações do dia-a-dia de que o agente dispõe para interagir com o mundo, interpretá-lo e adaptar-se a ele" (Correia, 2009, p. 57). Assim como falamos da representação social nos termos de um saber cotidiano, organizador de condutas e socialmente partilhado, Correia afirma que

O conhecimento sociocultural pode ser definido como o conjunto de todas aquelas crenças que são partilhadas virtualmente por todos os membros competentes de uma dada cultura e que são definidos como verdade pelos membros que partilham os mesmos critérios [...] o conhecimento sociocultural é um grande conhecimento próprio do mundo da vida quotidiana, na medida em que se recusa a se submeter-se à crítica do próprio conhecimento, aceitando, antes, as evidências socialmente partilhadas

Desse modo, percebemos o jornalismo como um meio que se apropria, difunde e faz circularem representações em torno do fenômeno da violência urbana, que delineiam um campo de investigação que vai além da ocorrência factual da violência urbana, com a qual se ocupam as instituições do Estado, do ponto de vista organizacional, e âmbitos como Direito e outras Ciências Sociais, do ponto de vista científico. Não negamos haver, no entanto, mesmo nessa factualidade, o problema das representações, pelo contrário, reconhecemo-lo nela. Por isso mesmo, parte da investigação relacionada às representações sociais precisa compreender as suas condições de emergência, as especificidades do objeto social e do ambiente sociossimbólico que se estrutura em torno desse objeto, assim como as rotinas organizacionais cujo trabalho instaura o trânsito das representações.

\section{VIOLÊNCIA, MEDO E DESVIO NA "FOBÓPOLE"}

As narrativas jornalísticas sobre violência são elaboradas em relação a um ambiente sociossimbólico do medo da violência urbana. É nesse ambiente de representações que se constrói a fobópole (Souza, 2008), fenômeno em que a experiência da cidade no Brasil se constitui como uma experiência do medo, que emerge de um contexto no qual a violência urbana se faz sentir além da ocorrência localizada, em que todos os espaços urbanos caracterizam 
uma "cidade dominada pelo medo da criminalidade violenta", que se manifesta em práticas diversas, como as reações de autoproteção da classe média e das elites, a produção de narrativas midiáticas e a militarização do cotidiano, sobretudo, em relação aos habitantes das áreas periféricas, espaços que, no imaginário da classe média e da elite, são os causadores da violência, devem ser contidos, vigiados e controlados.

O sentimento de medo generalizado caracteriza a relação com a cidade. Nessa dinâmica há "uma situação de violência difusa, ações e reações de ressentimento, ódio e violência de cidadão contra cidadão em uma multiplicidade de situações no interior de uma cidade e de um país" (Souza, 2008, p. 36), que organiza a fobópole, a "cidade em que grande parte de seus habitantes, presumivelmente, padece de estresse crônico [...] por causa da violência, do medo da violência e da sensação de insegurança" (Souza, 2008, p. 40).

É nessa fobópole brasileira, marcada pelo medo, que habitamos. Essa fobópole é o espaço social que se desenvolveu face à emergência da violência urbana. Conquanto a violência urbana seja parte visível desse contexto ${ }^{3}$, a sua transposição para o ambiente sociossimbólico comporta distorções e exageros. Podemos falar, a partir de perspectivas similares, de uma cultura do medo (Glassner, 2003) ou mesmo de pânicos morais (Cohen, 2011). Em Glassner, a cultura do medo é caracterizada por um alarmismo em torno de matérias sociais como crime e violência, gerando um pânico que dialoga com ansiedades culturais, com conservadorismo, com o processo de produção de "outros" sociais, no qual as mídias jornalísticas e seus produtos são relativamente bemsucedidos em construir um cenário do medo que deve ser alimentado. Em Cohen, o pânico moral é um processo de construção social do desvio e da reação exacerbada face a eles. De acordo com Cohen, inferir sobre o pânico moral não significa que se refere a fenômenos que não ocorreram ou que as reações são baseadas em histeria, fantasia ou ilusão. Antes, o que se opera são

3. A violência urbana no Brasil é parte indissociável do contexto democrático brasileiro. De acordo com Cerqueira (2014), na década de 1980, mesmo antes do término da ditadura militar (1964-1985), a recessão econômica, o crescimento das populações urbanas, a manutenção dos padrões de concentração de renda e o aumento da desigualdade social, fez com que houvesse um aumento nos "incentivos a favor das atividades criminosas" (2014, p. 42). O quadro se manteve na década de 1990, só apresentando alterações significativas a partir do início do século XXI, com a contenção da violência letal, e o reforço nas políticas públicas de segurança no âmbito do Governo Federal. 
exageros e distorções em torno da significação ou extensão dos acontecimentos.

Uma condição, episódio, pessoa ou grupo de pessoas emerge para se tornar uma ameaça aos valores e interesses sociais; sua natureza é apresentada de modo estilizado e estereotípico pelos meios de comunicação de massa; as barricadas morais são ocupadas por editores, políticos e outras pessoas com direito de pensamento; especialistas socialmente creditados expõe seus diagnósticos e soluções; [...] às vezes o objeto do pânico é bastante novo e, em outras, é algo que já existe, mas repentinamente aparece sob holofotes. Às vezes o pânico passa e é esquecido, exceto no folclore e na memória coletiva. Em outras, ele tem repercussões mais sérias e duradouras, podendo produzir mudanças, como em políticas sociais, ou mesmo no modo como a sociedade concebe a si mesma (Cohen, 2011, p. 1, tradução nossa).

A si mesma e aos outros. Isso insere sobremaneira o problema do desvio, à medida que por meio desse processo passa-se às encarnações estereotípicas da violência e aos comportamentos ou tipos sociais a ela relacionados. $\mathrm{O}$ desvio, como o concebe Cohen (2011), é construído como forma de exercício do controle social, à medida que ele é construído socialmente sempre definido por alguém, em relação a algo, nunca sendo um modo de ser a priori. Ele perpassa a dimensão, portanto, de algo definido como um problema social, em condições de acordo com as quais os comportamentos dos indivíduos são descritos como disfuncionais, ameaçadores ou perigosos. Becker (2008) estabelece o desvio a partir do outsider, resultado de um processo de rotulação pelos grupos sociais por meio da "criação de regras cuja infração constitui desvio" (2008, p. 22). Desse modo, o ser desviante não é qualidade dele ou de seu ato, mas é consequência da aplicação de sanções ao indivíduo considerado infrator e da maneira como o grupo reage a ele.

Esse processo de identificação e definição dos desviantes, nas próprias mídias jornalísticas do Brasil, define-se por narrativas que, segundo Matheus (2011), apresentam a morte, marcadamente, morte de um outro, negro ou pobre, como instância objetiva do medo do desconhecido, da incivilidade, da ameaça à sociedade. Em um grau maior de especificação e identificação, o outro é comumente representado pelos traficantes e usuários de drogas, que 
encarnam a culpa; cuja morte ou prisão não representa uma ruptura, mas uma resolução ao problema da ordem, instaurado pela existência de tais desviantes. Desse modo, a narrativa midiática constrói o medo na esfera urbana por meio de uma articulação entre medos da violência e narrativização desse fenômeno, realimentando-o.

\section{AS MORTES VIOLENTAS NA CULTURA MIDIÁTICA DO ESPETÁCULO}

Desse modo, pensar as narrativas jornalísticas e a sua relação com os fenômenos da violência urbana conduz-nos a pensar os elementos que as constituem, que as condicionam. Ao pensar as representações sociais, como o fizemos acima, como formas de conhecimento partilhadas, que definem nossas relações com os objetos sociais, organizadoras de condutas e de práticas, demarcamos implicitamente duas dimensões que devem levadas em consideração quando estudamos as narrativas de violência: a do fenômeno social e do ambiente sociossimbólico em relação à violência na sociedade brasileira. "Nesse sentido, o problema é de como representações sociais e a vida pública se relacionam, ou seja, como a vida pública dá origem a representações que se tomam, elas mesmas, constitutivas do objeto que originalmente as formou" (Jovchelovitch, 2000, p. 32).

Os três maiores impressos paraenses, Amazônia, Diário e O Liberal ${ }^{4}$, estão inseridos em uma cultura do espetáculo, mas também são produzidos em mercado de comunicação marcado pela concentração midiática, por uma guerra político-empresarial em torno dos grupos proprietários dessas empresas de mídia, no qual as versões sobre a realidade social da região e seus problemas sociais estão condicionados aos tensionamentos entre público e

4. O Amazônia e O Liberal são jornais das Organizações Rômulo Maiorana (ORM), da família Maiorana. O primeiro tem formato berliner, com ênfase em notícias sobre programação televisiva, esportes e violência; foi criado em 2000, para fazer frente ao Diário do Pará, com linha editorial similar. O Liberal foi criado em 1966, pela aquisição de maquinário gráfico de um antigo jornal e se alinhou ao regime militar; ele tem formato broadsheet, e se apresenta como um jornal para a elite, ainda que tenha a editoria de polícia, com notícias de violência. Já o Diário do Pará, pertence à Rede Brasil Amazônia de Comunicação (RBA), da família Barbalho, e foi fundado em 1982, para apoiar a candidatura de Jader Barbalho, sobrinho do dono do jornal, ao governo do estado do Pará. Em 2003, o jornal passa a publicar notícias de violência urbana em um caderno em formato tabloid, destacável do resto do impresso, em formato broadsheet. 
privado, expresso nas rotinas narrativas do jornalismo (Castro, 2012, Costa, 2011, Veloso, 2014). É nesse cenário que nos questionamos sobre o problema da violência na mídia, as representações de que se alimenta e que faz circular. Esse fenômeno midiático e representacional é particularmente presente no que Costa (2011) identifica como "modelos midiáticos do espetáculo", cujos aspectos se aplicam aos muitos níveis de rotinas narrativas da mídia brasileira, mas também são fenômeno predominante na mídia da Amazônia Paraense.

O que se percebe é que a violência tornou-se fato comum, notícia corriqueira, com o interesse de comover, mexer com os sentimentos, não importando de que forma está sendo apresentada a informação. O importante é padronizar comportamentos, tratar as notícias como "produtos" sujeitos à "lei de mercado", recorrendo dessa forma ao sensacionalismo e à violência, glamourizando o crime e criando estratégias de sedução para os telespectadores [e leitores], aproximando e eliminando as fronteiras entre jornalismo, entretenimento e publicidade. Como mercadoria, a violência passa a ser consumida, integrando o processo de sua produção, ainda que como representação. Os fatos são tirados de seu contexto concreto e transmitidos como se fossem eventos fragmentados (Costa, 2011, p. 180).

Em relação à violência, esses modelos se caracterizam por fronteiras borradas, por dinâmicas de infoentretenimento, em que o caráter de espetáculo, de imagem-mercadoria, é dominante e uma das únicas fontes de informação sobre o fenômeno social. São as imagens e narrativas midiáticas que inserem a violência em parte da vida pública da Amazônia Paraense, rotulando os espaços, transcendendo o aqui e agora dos indivíduos, participando da formação de uma experiência mediada ampla sobre a violência, mas calcada nas representações e nos deslocamentos inscritos nos artefatos midiáticos.

O modus narrandi dos modelos midiáticos do espetáculo reproduz lógicas de relatos policiais, privilegiando as Polícias Civil e Militar como como fonte principal, apresentado os casos e os crimes, etapas da ação policial, expondo os acusados, citando as vítimas, apontando a origem da violência nas regiões periféricas e mostrando as evidências da violência cotidiana. Tais narrativas identificam, reiteram e reapresentam agentes, pacientes e espaços de violência urbana. 
Podemos dizer que as linhas editoriais do Diário do Pará, de O Liberal e do Amazônia definem a maneira como abordam a violência, os estilos narrativos, os ângulos da fotografia de cadáveres, a maior ou menor agressividade nas manchetes, entre outros aspectos presentes no tratamento da violência em seus cadernos de Polícia. Devido ao que as ORM e a RBA projetam como seu público, elas realizam escolhas editoriais que, como já dito, oscilam entre o supostamente objetivo e o chulo, com a violência sendo mais ou menos escancarada, mas sempre evidente.

Nessa relação entre a cultura do espetáculo e do medo, a morte nas narrativas jornalísticas desses diários é apresentada como parte de um cotidiano social organizado ao modo de um terreno maniqueísta. Nele, de um lado, há o bem e o bom, representados por indivíduos nomeados como o "trabalhador", o "inocente", o "empresário", o "morador", que são vítimas ou de uma fatalidade, - eventualidade em que a morte é uma consequência imprevisível - ou de uma violência incontrolável presente nos espaços da cidade ou do interior do estado; todos pacientes de uma violência tanto mais brutal quanto mais inesperada para eles. Do outro, há também o mal e o mau, cujas figuras são dos indivíduos que estão em relações perigosas com o tráfico de entorpecentes ou com o crime, que representam um risco à sociedade, pela sua localização marginal e desalinhada de um ideal produtivo, que são vítimas das próprias escolhas pela violência e pelas relações regidas por ela; todos são apresentados como os agentes da violência cujas mortes são consequências de seu "caminho", do seu desvio. Desta forma, essas mortes são esperadas, e mais do que isso, são naturalizadas.

Esse tipo de construção é possível pelos aspectos da própria narrativa jornalística, que para Motta (2013) constitui uma modalidade de ação simbólica com a finalidade de organizar a experiência de um contexto, a partir de elementos que se tornam presentes na sua constituição, por meio de estratégias relativas a um pano de fundo social e simbólico. Por isso, as narrativas não são só relatos representativos: dialogam com compósitos de referências no âmbito das "metanarrativas", cujos significados simbólicos profundos se ligam a uma ordem, moral ou às crenças compartilhadas, justamente o âmbito das representações. É por essas características que essa ação da mídia elabora e reitera imagens, narrando a morte, representando-a desse modo dualista, como a morte inesperada dos bons e a morte naturalizada dos maus. À guisa 
de exemplo, observemos os seguintes trechos retirados da mesma edição de um dos jornais:

Dupla mata feirante a tiros; vítima saía de casa para trabalhar. Natalino foi atingido na cabeça, em uma das pernas e nas costas. Após os disparos os dois bandidos fugiram do local sem levar nada da vítima. A esposa e a filha caçula do feirante, que estavam na casa, ficaram, desesperadas e pediram ajuda aos vizinhos. [A vítima] morava na rua há mais de 10 anos e era um homem trabalhador [...] 'Esse vizinho era uma pessoa alegre, gentil e um trabalhador. E de repente vem uma pessoa e tira a vida dele, não dá para acreditar', disse o vizinho. (Amazônia, 21 maio 2013, p. 42).

"Thoki" morre atingido por quatro balaços. O envolvimento com drogas pode ter sido o motivo do assassinato de um rapaz identificado apenas pelo prenome Alexandre. Ele foi morto com quatro tiros ontem, no bairro da Marambaia. [...] Segundo o sargento Vinente, testemunhas disseram que já tinham visto a vítima pela área, mas ninguém soube informar onde ele morava. 'Nos informaram que ele era usuário de drogas e possivelmente foi isso que motivou o crime' disse. (Amazônia, 21 maio 2013, p. 47).

Há decerto uma dimensão das representações, à medida que o jornal evidencia, no primeiro texto, que há uma morte com um caráter incógnito, pois é de alguém que é "pessoa alegre, gentil e um trabalhador", que, portanto, não merecia morrer. Ao contrário do segundo texto, em que a morte se mostra como resultado inevitável da ordem das motivações bem definidas, porque a vítima era supostamente usuário de drogas, caracterizando o desvio. Olhar esses jornais permite-nos a observação de que essa leitura maniqueísta da realidade é o que dá sustento à reiteração das representações sobre a morte e o desvio nesses impressos. De modo que procuramos entender as referências dos acontecimentos e do social que são acionados a partir das representações sobre a fatalidade e de naturalidade nas narrativas sobre a morte e o morrer nos cadernos de polícia.

Compreendemos a ação das mídias jornalísticas nesse circuito simbólico, de captação dessas representações que circulam no tecido social, integrado às rotinas narrativas, partícipes de uma construção social da violência, do medo e do desvio como fenômeno de dimensões simbólicas e subjetivas. A mídia 
não constrói de modo totalizante os fenômenos, mas os tematiza de determinados modos, condicionando a percepção social do fenômeno. A mídia, como pontuado anteriormente, é um dos dispositivos que participam dessa construção social, à medida que o sentido da nossa realidade e da experiência passa também por ela, em uma relação em que as vivências diretas, cotidianas e imediatas com a violência são menos recorrentes e disseminadas do que as experiências objetivadas nas representações (Michaud, 2001).

\section{Modus narrandi MIDIÁTICO E OS PROCESSOS REPRESENTACIONAIS}

À medida que compreendemos o jornalismo na configuração do mundo representacional a partir do fenômeno da violência, podemos pensar como as representações são inscritas nessas narrativas jornalísticas, a fim de podermos mapear o quadro a que nos propomos, sobre morte e desvio. As narrativas jornalísticas, como infere Motta (2013), são atividades socioculturais de constituição da realidade, operando pela recriação de um sentido público dos acontecimentos. Essas narrativas constituem o mundo à medida que reafirmam e reiteram o canônico, legitimam e estabilizam o desviante nos acontecimentos; elas "constituem experiências essenciais para indivíduos e sociedades porque tornam natural o mundo social, tal como ele se apresenta" (Motta, 2013, pp. 54-55, grifo do autor). $\mathrm{O}$ autor defende que as narrativas jornalísticas devem ser pensadas também como representações sociais, que falam sobre o mundo material e social, porque "instituímos representativamente o mundo e nele performativamente atuamos" (2013, p. 32).

As representações nas narrativas são também o que está em circulação no ambiente representacional, não prescindindo, portanto, dos processos expressos na função social delas, quais sejam a ancoragem e a objetivação. Nas narrativas dos impressos da Amazônia Paraense, as representações da morte, mesmo que sejam parte de uma atividade de narrar o crime ou eventos que resultam em óbito, evidenciam questões que se inserem em um âmbito social das concepções partilhadas pela sociedade e vividas pela mediação que a mídia enseja.

Para Jovchelovitch (2000), na comunicação em que as representações se inserem, é preciso pensar como elas se desenvolvem a partir de um objeto social e alimentam a sua constituição. Esse aspecto nos permite pensar a produção das representações sobre a violência, à medida que as representações se 
desenvolvem sobre o fenômeno da violência e, a partir da sua difusão, passam a integrar não só as relações com tal fenômeno, mas a compor seus aspectos subjetivos. Por isso mesmo, pensá-lo a partir do local tem a ver com pensar as diferenças, o oculto e compreender complexidade de uma teia simbólica (Jovchelovitch, 2000).

Assim, pensamos a narrativa, nesse processo de organização simbólica da realidade da violência e na definição dos indivíduos como bons e maus, a partir dos dois processos acima citados, conforme os expõe Moscovici (2011): a ancoragem e a objetivação, entendidos como processos de classificação e nomeação, que tornam fenômenos, pessoas e acontecimentos não familiares em familiares, reconhecíveis, fazendo-os existir em um mundo conceitual e consensual, no qual são transformados em uma realidade vivível, tangível, concreta, em que às imagens são conferidas significações, de modo que o difuso e profuso são organizados.

A ancoragem ocorre, segundo o autor, dentro de alguns parâmetros, quais sejam o da categorização, transformando aquilo que potencialmente nos desestabiliza em um sistema de categorias, que comparamos com paradigmas de categorias já existentes, cuja relação julgamos adequadas, de modo que esses objetos ou pessoas adquirem, no nível representacional, as características dessa categoria, sendo "re-ajustado" a ela. Assim, o processo da ancoragem insere o problema da classificação e da nomeação, que estabilizam o estranho, o não familiar, porque o categorizam por meio de um nome e por meio da sua inserção em sistema de classificações, de modo que "nós podemos representar o não usual em nosso mundo familiar, reproduzi-lo como uma réplica de um modelo familiar" (Moscovici, 2011, p. 62).

A classificação e a criação de classes instauram um procedimento de definir comportamentos e práticas que são ou não permitidos em relação a essa e as demais classes. Isso se dá por meio do "protótipo", modelo representacional para comunicar o paradigma a que foi ancorado. Pessoas ou acontecimentos são comparados a um protótipo, socialmente aceito, na representação de uma classe, por meio da seleção das características mais significativas desse protótipo, que passam a se aplicar a toda classe de objetos sociais membros dessa categoria, sobretudo, a partir de uma dimensão normativa.

Quanto à nomeação, implica a inserção do objeto social em um complexo de palavras que conferem identidade a ele, sobretudo, porque "o que não pode ser nomeado não se pode tornar uma imagem comunicável ou ser facilmente 
ligado a outras imagens" (Moscovici, 2011, p. 66). Procede-se no estabelecimento da relação entre palavras e coisas, que torna possível representar a realidade, fazer com que determinadas características adiram à pessoa ou coisa e permitam a sua descrição, diferenciando-as e distinguindo-as de outras, tornando-as parte de convenções partilhadas, compondo e realimentando uma espécie de vocabulário ancorado ao da vida cotidiana. "Seu principal objetivo é facilitar a interpretação de características, a compreensão de intenções e motivos subjacentes às ações das pessoas, na realidade, formar opiniões (Moscovici, 2011, p. 70).

Quanto à objetivação, refere-se ao processo de transformação desses elementos ancorados em uma realidade, em que aquilo que pode ser percebido como incomum pode passar a integrar a experiência do vivido; o não familiar se torna realidade, é representado como um nível de realidade, consistindo, pois, na materialização de abstrações, em "transformar uma representação na realidade da representação; transformar a palavra que substitui a coisa, na coisa que substitui a palavra" (Moscovici, 2011, p. 71). Objetivar é reproduzir conceitos em imagens representacionais, preenchendo vazios com sentidos concretos que sejam equivalentes aos objetos a que as palavras e referem. Isso se manifesta no que o autor chama de "núcleo figurativo", um complexo dessas imagens que gera um complexo de ideias, um paradigma de sentidos, encapsulado em imagens, clichês e fórmulas criados pelas palavras que a ele se referem.

É esse complexo que se constitui a realidade, dando forma e sentido às personalidades dos sujeitos e às suas ações. Por meio dessas imagens, o conceito se descola do objeto originário, indo do abstrato para a existência independente, permitindo tensionar imagem e realidade, no âmbito da aparência. Isso instaura o problema da percepção, pois as imagens integram uma dimensão real, não só do pensamento, em que "a defasagem entre a representação e o que ela representa é preenchida, as peculiaridades da réplica do conceito tornam-se peculiaridades dos fenômenos, ou do ambiente ao qual se referem, tornam-se a referência real do conceito" (Moscovici, 2011, p. 74). Isso demarca a passagem das imagens de um ambiente meramente conceitual, entre palavras e objetos, para um âmbito de existência como os próprios objetos que elas significam.

Nesse processo, determinados procedimentos e instrumentos são empregados para transformar as representações em realidade, por meio de recursos 
como, por exemplo, a linguagem. Pensamos, assim, as narrativas jornalísticas sobre morte por violência urbana implicadas nesses processos de ancoragem e objetivação, nos termos já descritos: da demarcação da existência dos bons e dos maus. Essa reflexão sobre a representação da morte violenta pensa como ela aparece em um processo de fornecimento de experiência e conhecimento sobre a realidade social, a partir da tematização e narrativização especificas, que analisamos a seguir.

\section{A MORTE Violenta NA Mídia PARAEnSE}

Tópicos como o aumento da violência e da sensação de insegurança são projetados nas narrativas midiáticas e evidenciados nesses impressos a partir da exposição reiterada da morte. As representações nas narrativas englobam definições da realidade e dos sujeitos sociais, de modo que vemos a reapresentação do mal e dos maus, representados por "bandidos", usuários de drogas, entre outros; e do bem e dos bons, representados por trabalhadores, estudantes, donas de casa, etc. Uma vez constituídas, as narrativas das mídias paraenses reapresentam, rearranjam e reconstroem as representações que cercam essas mortes por violência urbana no Pará, pondo-as novamente em circulação no ambiente sociossimbólico do qual emergem, integrando a elas referências e valores tanto midiáticos quanto da vida cotidiana dos contextos em que a violência é fenômeno social.

Ao falar de morte - que aparece de formas variadas de acordo com o contexto do meio e da cobertura - a mídia evidencia sentidos que se aproximam de uma profusão de mortos célebres que desfilam em um cortejo, do qual os mortos banais estão apartados (Mouillaud, 2002); de mortes naturais de personagens que, sendo célebres, são igualmente queridos, contrastando a imagem de um morto anônimo por uma causa externa violenta ou ainda do registro de um morto que ao ser vítima de morte violenta é apresentado como inimigo da cena pública (Matheus, 2011). Todas essas mortes, porém, ao se projetarem em narrativas midiáticas, inscrevem-se no cotidiano, na experiência, pela sua dimensão representacional.

Assim, os processos simbólicos que participam da construção social das representações nos ajudam a pensar o que está presente nas narrativas sobre violência e se espraia a partir delas, os conhecimentos expressos pelos fenômenos enquadrados pela narrativa midiática. Pensamos isso dentro do quadro 
maniqueísta já destacado, em que a morte é preenchida de significado, os indivíduos são representados a partir de determinadas características e ações, classificados, nomeados, de modo que as mortes são objetivadas a partir de duas grandes categorias: a fatalidade da morte inesperada dos bons e a normalidade da morte naturalizada dos maus.

\section{A Fatalidade da MORTE Violenta}

A categorização que se opera nos termos da ancoragem faz com que essas mortes ostentem a marca do comum, na virtualidade do cotidiano, na virtualidade do risco da cidade. As causalidades apresentadas são da ordem do acidente de trânsito ou da brutalidade de assaltantes e criminosos. Essa morte na narrativa se distingue tanto pelas circunstâncias quanto pelos indivíduos a quem afetou. Procede-se à sua nomeação, identificando "trabalhadores", "donas de casa", pessoas "queridas pela comunidade", personagens e vítimas dessa violência. Há também a ênfase, maior ou menor, na imagem do morto como alguém que é atingido por um acontecimento fora do controle, acidental ou brutal, do qual ele não faz parte, mas pelos quais são afetados. É em razão dessa ancoragem que se encontra uma maior presença na narrativa de nuanças dramáticas, ao mesmo tempo indicando a fatalidade dos eventos e a perplexidade diante deles.

No caso dos acidentes e da ancoragem da morte, são narrativizados como a perda do controle, evidenciando uma falha, regida por uma casualidade. Elas reforçam a dimensão de uma violência virtual que pode atingir a todos, sem os atingir por razões especificas, a partir de uma ordem de causalidades morais ou das consequências de engajamento em um risco. É nesse sentido que podemos falar das seguintes narrativas.

Motociclista morre em batida. Luís Fernando Alves Pinheiro, de 53 anos, morreu após a moto que pilotava se chocar contra uma caminhonete na noite de ontem, por volta de 19 horas, na avenida Magalhães Barata, às proximidades da avenida Alcindo Cacela, São Brás. Uma ambulância do Corpo de Bombeiros foi acionada, mas não houve tempo de socorrer a vítima. "Eu estava em um táxi pela Magalhães Barata e o motorista do carro deixou ele [piloto da moto] passar porque ele já vinha correndo muito. Aí um pouco mais à frente, entre a 14 de Março e a Alcindo Cacela, ocorreu o acidente. A senhora do carro não teve 
culpa", afirmou Magna [testemunha]. (Amazônia, 22 mai. 2013, p. 41).

Dona de casa morre atropelada próximo à BR-316. A dona de casa Raimunda Ângela, 49 anos, mãe de cinco filhos, morreu atropelada por um veículo de passeio quando tentava atravessar a rodovia BR-316, no sentido São Brás/Entroncamento, distante apenas cerca de 100 metros do pórtico de Belém, onde existe uma passarela para a travessia de pedestres. [...] Ela estava na companhia do marido Jurandir Alves de Souza, de 48 anos. "[...] Acho que a culpa foi nossa, não sei, ficamos tão confusos. Deveríamos ter atravessado na passarela. Não sei nem o que dizer e pensar, mas já sinto a falta dela, pois vivíamos juntos há seis anos", disse, emocionado. (O Liberal, 16 mar. 2012, p. 1)

Motoqueiro bate em caminhão e morre na BR-316. Na madrugada de ontem, um acidente entre uma motocicleta Honda Broz e um caminhão caçamba, no KM 3 da rodovia BR-316, em Marituba, deixou uma vítima fatal. O motociclista Walber Luis Borges da Silva, 24 anos, teve morte instantânea ao colidir com a traseira de um caminhão carregado de areia. A força da colisão foi tanta que pedaços de massa encefálica da vítima ficaram espalhados no para-choque da caçamba. (Diário do Pará, 14 mar. 2014, p. 7)

Uma morte por acidente do qual não se teve culpa, no primeiro excerto; a morte de uma mãe, acompanhada pelo marido, que se culpa e fala sobre a morte da esposa, no segundo; uma "vítima fatal" cuja vida se perdeu em um acidente brusco e brutal. Essas narrativas todas fazem mais do que narrar sobre o acidente, elas alimentam no saber cotidiano a ideia do perigo urbano. Organizam essas ocorrências difusas por meio da nomeação de cada ocorrência como um acidente, que permite a construção narrativa da morte como abrupta e súbita ruptura, em que o humano é mais ou menos um coadjuvante, ou seja, uma ruptura que se sobrepõe aos envolvidos, na ideia de que houve exatamente a falha na situação, causada por um acaso ou uma imprudência.

Um itinerário narrativo cujos elementos são dispostos e arranjados com vistas a destacar um modo de morrer específico, moderno e dessacralizado. Esses elementos são responsáveis pela ancoragem do acontecimento a essa definição do fatal, em que "não houve tempo de socorrer a vítima"; " "acho que a culpa foi nossa [...] já sinto a falta dela"” e mesmo "deixou uma vítima 
fatal" de cada um dos casos, respectivamente. A nomeação do acidente se constitui como conferência de identidade a ele, permitindo a organização desses eventos difusos, por meio da classificação das referências de um tempo e um espaço, dos indivíduos cuja morte constitui o objeto narrativo, das relações dos indivíduos com as mortes. Essa classificação tem o papel de restringir e alimentar a representação da fatalidade, do morrer como elemento de um cotidiano de risco, passível de atingir os indivíduos indistintamente.

Ela projeta a representação de um morrer definido com causalidade identificada, mas em uma casualidade de fenômenos, ainda que nos registros de segurança pública, as mortes decorrentes por acidente de trânsito sejam parte das estatísticas de crimes contra a pessoa e homicídios. Essa representação não deixa de evidenciar que esse evento se projeta como uma pequena tragédia privada, causada por uma situação não motivada, - mas muito mais como uma violência não motivada - podendo assumir um caráter violento ao afetar a vítima e seu entorno. É nessa descrição que se operam a classificação e a nomeação.

O outro lado dessas representações, ainda com a classificação do fatal, é em relação às mortes que resultam de um crime proposital, já da ordem da violência intencional, tida como motivada, porém imerecida, decorrente de homicídios, da força da violência que rege certos espaços e dos indivíduos que fazem parte deles: a periferia da cidade e os bandidos/criminosos que dela emergem, respectivamente. Rótulos como o de "trabalhador" são recorrentes em narrativas como essas, que nos fornecem alguns indícios do que seriam tais pessoas: alinhadas à ordem da produtividade e da ocupação, indicam pessoas potencialmente "boas", à medida que não se alinham com o tráfico ou com o crime predominante, em oposição àquelas de que são vítimas. Neste caso, a representação se complexifica, pela ancoragem de outros elementos além das circunstâncias, englobando também estereótipos de comportamentos sociais em oposição.

Trabalhador é sepultado. Ontem de manhã, durante velório da vítima na casa da família, parentes e vizinhos lamentaram a morte trágica do autônomo, "Era um trabalhador que não se envolvia e confusão e era muito querido no bairro. Gostava de beber a cervejinha dele, mas não brigava com ninguém" disse José Mesquita, cunhado da vítima (Amazônia, 22 mai. 2013, p. 41). 
Polícia apura assassinato em Icoaraci. Até ontem a Polícia Civil, em Icoaraci, não tinha pistas dos homens que, armados, executaram a bala o funcionário público Robson Clóvis Monteiro Campos. O fato se registrou anteontem quando a vítima foi atingida com três tiros. Foi um tiro no queixo e dois na cabeça. [...] O delegado descartou a possibilidade de que o crime tenha ido motivado por um acerto de contas, já que as informações disponíveis indicam que Robson era um homem trabalhador. (O Liberal, 30 abr. 2012, p. 6)

Professor é assassinado com quatro tiros. O professor Raimundo Lucier Marques Leal Junior, 59 anos, foi morto a tiros dentro de seu veículo, no início da tarde de sábado, na avenida Duque de Caxias, entre as travessas Eneias Pinheiro e Pirajás, bairro do Marco. Segundo informações da polícia, o homem que efetuou os disparos estava aguardando a vítima sair de uma oficina mecânica, próximo do local. [...] Os familiares da vítima ficaram desolados com a situação e receberam apoio de amigos e colegas do professor que foram ao local do homicídio. Bastante emocionados, os parentes de Raimundo Lucier preferiram não conversar com a imprensa. (Diário do Pará, 06 ago. 2012, p. 4)

Morte lamentada por família, parentes e vizinhos; morte violenta por arma de fogo, mas de um homem trabalhador; morte de um professor, que causa desolação na família. Nos casos acima, a aparição de designativos em "lamentaram a morte trágica do autônomo", "era um homem trabalhador" e "familiares da vítima ficaram desolados com a situação e receberam apoio de amigos e colegas do professor", serve para ancoragem dos papéis sociais das vítimas, funciona como elemento que as distingue, à medida que são pessoas que se alinham com bem, são o bom indivíduo, cuja presença na sociedade é o avesso da violência que os afeta, cuja existência social não é marcada por uma marginalização extrema, pois, mesmo nos nichos periféricos, os ideiais produtivos e distintivos do trabalhador e do indivíduo com uma profissão o afastam de ser parte integrante da sociabilidade violenta.

A fatalidade aqui é evidenciada pelo encontro do indivíduo que nada tem a ver com a violência, mesmo que ele esteja no espaço que é definido por uma ordem social marginal, "naturalmente" a periferia violenta, em que sua morte é causada por essa sociabilidade e potenciais gestões de conflito violentas, externas a ele. Há um movimento simbólico de personificação dessa violência 
que vitimiza as pessoas das regiões periféricas. É tão somente a morte violenta pelas mãos de "bandidos", assaltantes. Trata-se de um perigo que, na narrativa, é bem definido.

Do ponto de vista de uma construção narrativa sensacional, que dialoga com as representações, isso se exprime na apresentação dos elementos de lamento, da dor, representada pela própria vítima e a realidade que ela evoca, pois na medida em que ela pode ser um ente individual, pode também, simbolicamente, ser um conjunto de outros entes, potenciais vítimas ou afetados pelo fato; a experiência da dor colaborando com o medo. Deste modo, a leitura que os impressos em análise nos fornecem é que realidade cotidiana de quem está nas regiões periféricas é cercada de uma potencialidade do morrer, uma fatalidade a que estão mais ou menos suscetíveis os moradores dessas regiões.

Isso se insere em um quadro maior de classificação, que implica na objetivação das representações. Do ponto de vista que as mortes por fatalidade constituem uma totalidade de imagens, arranjadas em similitude, fazendo-as familiares, de modo a se reconhecer o ambiente da cidade como o ambiente do perigo, tal como na cidade do medo. A sua constituição como núcleo figurativo interfere no problema da percepção da violência, pela objetivação das representações que afirmam o quão violenta a sociedade se tornou. Passamos a ver nessas ocorrências, espalhadas no tecido social, a violência que pode potencialmente nos atingir diariamente, com a qual convivemos e que tememos. Em última instância, podemos dizer, essas narrativas, como objetos acessíveis socialmente, instauram uma ordem simbólica, em relação às mortes inesperadas dos bons, que define aquilo que é apropriado, os tipos sociais não desviantes, ancorados a uma categoria representacional do bem na sociedade que tem medo de si.

\section{A NORMALIDADE NA MORTE VIOLENTA}

Esse quadro representativo não se confunde com o anterior, pois os elementos ancorados buscam mostrar que, ao contrário de inscrever a morte em uma situação indesejada, que enseja lamento e perda, ruptura daquilo que se espera da vida dos indivíduos, a morte aqui é sempre de pessoas que encarnam a violência, que fazem parte de uma rede de relações marcadas por reciprocidade negativa, com um "fim" esperado. Falam-se, então, de mortes 
normalizadas, naturalizadas. Os casos de desentendimentos entre "bandidos", de dívidas com o tráfico, de acertos de conta são representados a partir deste viés. É a rotinização da realidade de um outro que é violento, causador da violência e eliminado por ela mesma. É o caso mais típico das narrativas midiáticas. É a construção de uma alteridade perigosa. Elas apresentam uma grande quantidade de indivíduos, de assaltantes a usuários de drogas, que representam potencialmente o perigo para aqueles em relação ao qual ele é o outro. Tomemos alguns exemplos.

Viciado tomba a tiro. Mauricio Ferreira Farias, 21 anos, foi morto na madrugada de ontem na passagem Nossa Senhora das Graças, na Pratinha II, logo após sair de uma festa. Ele era usuário de drogas e já havia sido preso pelo crime de roubo, informação que foi confirmada pela mãe dele, Antônia Ferreira, que esteve no local do crime. [...] A polícia não descarta a hipótese de acerto de contas na investigação do homicídio. A equipe da Divisão de Homicídios esteve no local do crime para levantar informações sobre o homicídio (Amazônia, 18 jun. 2013, p. 45).

Bandido tomba em acerto. Luan Santos Moreira, de 23 anos, foi morto com três tiros, ontem à noite, no bairro da Condor, em Belém. Segundo a polícia, a vítima tinha envolvimento com crimes e a principal suspeita é que o assassinato tenha sido um acerto de contas. [...] "No momento que ele desceu da van e entrou aqui na passagem, os motoqueiros o perseguiram alguns metros e um deles efetuou os disparos contra a vítima", complementou o PM. "Luan do Guamá", como era conhecido, morreu na hora. Segundo denúncias recebidas pela polícia, o rapaz era considerado perigoso, já que tinha envolvimento com assaltos e homicídio. "Temos a informação de que ele já foi preso por homicídio. Em 2011, ele matou o próprio comparsa. Ele era perigoso, muito conhecido no Guamá pela prática de crimes", afirmou o policial. (Amazônia, 14 set. 2013, p. 47)

Usuário de drogas inadimplente é executado por traficantes. Um homem foi assassinado, sábado à noite, na Cabanagem, em Belém. André dos Santos Corrêa, 29 anos, estava caminhado na passagem Bom Jesus, do Conjunto Panorama XXI, quando um homem a pé se aproximou e efetuou um disparo que atingiu a nuca da vítima. Segundo a polícia, o 
motivo da execução foi acerto de contas por dívida com traficantes do bairro. André era usuário de drogas. (O Liberal, 20 ago. 2012, p. 5)

Técnico em refrigeração assassinado porque devia $\mathrm{R} \$ 50,00$ ao criminoso. Um homem foi assassinado quando estava às proximidades da residência cia onde morava, na Marambaia. [...] A informação que chegou à polícia é que a vítima tinha passado a madrugada em um bar na companhia do assassino. E o crime teria sido motivado por dívidas de droga. [...] "Quando ele estava a caminho de casa, foi atacado pelo criminoso. Eles brigaram por uma dívida de $\mathrm{R} \$ 50,00$ gasto em droga", disse o cabo. O assassino puxou a faca e golpeou a vítima 28 vezes José ficou ferido até na cabeça. (O Liberal, 03 set. 2012, p. 1)

Sevilha: cinco tiros ceifaram a vida de Bruno. Um homicídio com sinais evidente (sic) de execução, Bruno Péricles de França Alves, 21, foi executado friamente em um beco do Jardim Sevilha, às margens da Augusto Montenegro, conhecido como "beco do me rouba"por dois homens em uma motocicleta que dispararam uma rajada de tiros contra a vítima. [...] Uma informação repassada ao DIÁRIO por uma testemunha dá conta que Bruno Péricles teria cometido um delito no bairro dos 40 Horas, em Ananindeua, e estaria com sentença de morte decretada pelos possíveis vingadores de sua vítima. (Diário do Pará, 23 abr. 2012, p. 3)

Assaltante é liquidado com oito tiros. Na noite da última quarta-feira (10), por volta das 21h30, Cherllesso Santos da Silva, 25, Foi morto com pelo menos oito tiros, na rua Getúlio Vargas, bairro Água Boa, na ilha de Caratateua, mais conhecida como Outeiro, que é distrito de Belém. De acordo com informações da polícia, a vítima pode ter sido morta por acerto de contas entre assaltantes. [...] Conforme apurações da polícia, Cherllesso além de ter sido envolvido em assaltos, também era viciado em entorpecentes. (Diário do Pará, 12 out. 2012, p. 3)

O usuário de drogas que já havia sido preso, morto após sair de uma festa; a vítima com envolvimento em crimes, que é morta por acerto de contas com os traficantes de drogas, mas uma vítima que já matou; morte por arma de fogo por mais um suposto acerto de contas; morte por uma briga causada pelo dinheiro gasto em entorpecentes; uma morte violenta de um ladrão, expressa em uma "sentença de morte", em um lugar marcadamente perigoso; e mais 
uma morte cuja vítima é "liquidada" pela agressividade voraz dos executores, também assaltantes nas tramas da violência urbana.

Com exemplos dos três impressos, percebemos recorrências nas narrativas, no modo de apresentar seus elementos e encadeá-los simbolicamente. Uma rotina da narração da violência que projeta representações da morte dos indivíduos à margem da ordem social. Os elementos de ancoragem da situação são esquemáticos e tautológicos. Há a repetição da ideia da suspeita de execução, do designativo "acerto de contas", de uma espécie de histórico de envolvimento com a criminalidade, como elementos justificadores da morte nesse contexto periférico e do morrer proveniente dessa gestão da violência, realizada pelos próprios indivíduos violentos, com vistas a regular as relações nesses espaços.

Trata-se da representação do bandido armado ou os congêneres que com ele compactuam, encarnando uma personificação do mal. São o mal no sentido de serem um signo da própria violência que afeta a sociedade, para a qual representam um risco iminente. É na construção narrativa que nos deparamos com a representação da morte como castigo pelas relações em que a vítima, voluntária e conscientemente, teria se inserido. Uma consequência de um desvio social, legal e moral, que, ainda que não confirmado em alguns casos, apenas atestado por depoimentos, reforça a noção de uma violência e uma brutalidade com finalidades e causalidades bem demarcadas, em todas as possíveis facetas naturalizada.

Essa naturalização e ideia da normalidade da morte dos maus se operam à medida que esses indivíduos e suas mortes passam a integrar um paradigma representacional, por meio da objetivação, que faz com que o núcleo figurativo das imagens seja percebido como o fenômeno ele mesmo. Desse modo, nas narrativas se encontram os elementos que compõem todo o quadro da morte naturalizada: explicações de que as mortes acontecem por acertos de contas, de dívidas com o tráfico, com as quais estabelece uma relação de causalidade, que delimita, reduz e facilita qualquer interpretação sobre aquele evento. Não obstante, essas representações passam a integrar um contexto típico, o familiar, o próximo, a realidade dos espaços urbanos da vida comum, no qual a ideia da periferia da cidade marcada por violências espetaculares e explosivas é a representação predominante, espalhando o medo pelos outros espaços.

Isso insere, da ancoragem à objetivação, o problema da identificação e da definição dos desviantes da Amazônia urbana. Se, nas representações da fa- 
talidade, os indivíduos a quem a violência urbana atinge, são os tipos sociais apropriados e alinhados, os indivíduos nas representações da morte normalizada são os tipos desviantes, que representam desalinho, perigo, desequilíbrios à ordem. São os agentes da violência objetivados pelas representações. Desse modo, a mídia reitera as imagens já circulantes de que determinados indivíduos têm uma morte definida e, em certa medida, ao realizar o movimento simbólico de os afastar do espaço ao qual pertencem e no qual não merecem viver, joga-os no meio de um espetáculo em que a morte deles é impressa nas páginas dos jornais com todas as marcas da violência e da sua suposta desumanidade, reforçando as formas de perceber a realidade, nas quais a morte para eles é a norma, cujo cumprimento é esperado e quase inevitável.

\section{CONSIDERAÇÕES FINAIS}

No contexto da Amazônia urbana, assim como de outras regiões do Brasil, as narrativas jornalísticas sobre violência são relatos nos quais se inscrevem representações, que as fazem circular e que constituem, em grande medida, os conhecimentos desse objeto social. Elas estabelecem parâmetros interpretativos a partir dos quais perspectivamos a cidade, seus indivíduos, seus perigos e o medo em relação a eles. Elas se inserem em uma dimensão de fornecimento de conhecimento social a respeito do fenômeno, porque os integram ao familiar, à vivência, ao perceptível, ainda que não se tenha experiência direta e imediata com a violência urbana. Elas fazem com que esse fenômeno da vida social brasileira circule, de modo dinâmico, aumentando a extensão e o potencial das representações sociais. Nessa circularidade, as representações dos fenômenos são ainda mais estabilizadas e consolidadas, pela formação de núcleo figurativos e paradigmas representacionais cada vez mais amalgamados, organizando os eventos difusos que são percebidos como a manifestação dessa problemática social.

Especificamente, as mortes por homicídios ou acidentes constituem o alimento principal dessas narrativas, ao mesmo tempo que constituem a face mais visível e visibilizada dessa violência urbana. À dimensão do espetáculo deve-se somar a dimensão constitutiva de um ambiente sociossimbólico, que, marcado pelo medo do perigo, do outro, do risco, condiciona os nossos modos de habitar o mundo, de percebermos a nós mesmos, de percebemos os outros. A comunicação midiática é um partícipe relevante na manutenção 
da sociedade pensante. No contexto que analisamos, as narrativas jornalísticas operam um processo de construção social das representações da violência: ancorando e objetivando tanto a morte quanto o desvio. Apontando aqueles que do crime estão apartados, os bons, que, no entanto, podem ser potenciais vítimas; assim como aqueles que são dele parte intrínseca, os maus, demarcando os espaços periféricos da cidade como o lugar de onde surgem e estabelecem relações com as dinâmicas dessa violência. Essas representações resultam na perspectivação de mortes que devem ser lamentadas, pelo seu aspecto de ruptura, e mortes que devem ser naturalizadas e reiteradas, pelo seu aspecto já convencional.

Desse modo, diante do ambiente sociossimbólico do medo da violência urbana, pensamos as narrativas como indissociáveis dele e um dos seus principais formadores. Opera-se um ciclo na constituição desse objeto social: à medida que as violências e o medos se generalizam, as narrativas falam deles para a sociedade; e à medida que falam neles, as narrativas generalizam os medos e a violência. O contexto é complexo, e o fenômeno social marca a vida urbana nas últimas décadas. A dimensão midiática da violência, constituída nas representações, aponta para o lugar central das mídias na objetivação, na construção dessa realidade, relativamente a esse fenômeno-problema. Do ponto de vista das repercussões sociossimbólicas que pontuamos neste trabalho, a narrativização de mortes por meio das representações maniqueístas, que categorizam o bem e o mal, encarnando-os em estereótipos, é o meio que instaura distorções de tematização, rotinização de deslocamentos e a negação do entendimento do fenômeno da violência como problemática que requer abordagens além do crime, da morte e do desvio.

\section{REFERÊNCIAS BIBLIOGRÁFICAS}

Baudrillard, J. (1991). Simulacros e simulação. Lisboa: Relógio d'Água.

Becker, H. (2008). Outsiders: estudos de sociologia do desvio. Rio de Janeiro: Jorge Zahar.

Brasil (2012). Seminário de segurança da Amazônia. Brasília: Secretaria de Assuntos Estratégicos da Presidência da República.

Castro, F. F. (2012). Comunicação, poder e democracia. Belém: Labor Edições. 
Cerqueira, D. R. (2014). Causas e consequências do crime no Brasil. Rio de Janeiro: BNDES.

Cohen, S. (2011). Folk devils and moral panics: the creation of the Mods and Rockers. London: Routledge.

Correia, J. C. (2009). Teoria e crítica do discurso noticioso: notas sobre jornalismo e representações sociais. Covilhã: Livros LabCom.

Costa, A. C. (2011). A violência e os modelos midiáticos de espetáculo. In M. Malcher et al. (Org.). Comunicação midiatizada na e da Amazônia (pp.179-204). Belém: Fadesp.

Ferreira Junior, S. \& Costa, A. C. (2016). Enquadramentos e representações sociais da violência urbana na imprensa da Amazônia paraense. Revista Estudos de Jornalismo, 5: 99-114.

Glassner, B. (2003). Cultura do medo. São Paulo: Francis.

Jodelet, D. (2001). Representações sociais: um domínio em expansão. In D. Jodelet (Org.). As representações sociais (pp.17-44). Rio de Janeiro: Ed. UERJ.

Jovchelovitch, S. (2000). Representações sociais e esfera pública: a construção simbólica dos espaços públicos no Brasil. Petrópolis: Vozes.

Jovchelovitch, S. (2008). Os contextos do saber: representações, comunidade e cultura. Petrópolis: Vozes.

Marcondes Filho, C. (2008). Para entender a comunicação: contatos antecipados com a nova teoria. São Paulo: Paulus.

Matheus, L. C. (2011). Narrativas do medo: o jornalismo de sensações além do sensacionalismo. Rio de Janeiro: Mauad.

Michaud, Y. (2001). A violência. São Paulo: Ática.

Moscovici, S. (2011). Representações sociais: investigações em psicologia social. Petrópolis: Vozes.

Motta, L. G. (2013). Análise crítica da narrativa. Brasília: Editora Universidade de Brasília.

Mouillaud, M. (2002). As grandes mortes na mídia. In M. Mouillaud \& S. D. Porto (Org.). O jornal: da forma ao sentido (pp.349-361). Brasília: Editora Universidade de Brasília. 
Porto, M. S. (2014). Violência e representações sociais. In R. S. Lima, J. L. Ratton \& R. G. Azevedo (Org.) Crime, polícia e justiça no Brasil (pp.60-70). São Paulo: Contexto.

Ramos, S. \& Paiva, A. (2007). Mídia e violência: tendências na cobertura de criminalidade e segurança no Brasil. Rio de Janeiro: IUPERJ.

Souza, M. L. (2008). Fobópole: o medo generalizado e a militarização da questão urbana. Rio de Janeiro: Bertrand Brasil.

Telles, V. S. (2010). A cidade nas fronteiras do legal e ilegal. Belo Horizonte: Argumentvm.

Tuchman, G. (2002). As notícias como uma realidade construída. In J. P. Esteves (Org.). Comunicação e sociedade: os efeitos sociais dos meios de comunicação de massa (pp.91-104). Lisboa: Livros Horizonte.

Veloso, M. S. F. (2014). Imprensa e contra-hegemonia: 20 anos de Jornal Pessoal (1987-2007). Belém: Paka-Tatu.

\section{Fontes}

Amazônia, n. 4762, 21 maio 2013.

Amazônia, n. 4763, 22 maio 2013.

Amazônia, n. 4790, 18 jun. 2013.

Amazônia, n. 4878, 19 set. 2013.

Diário do Pará, n. 10108, 14 mar. 2012.

Diário do Pará, n. 10148, 23 abr. 2012.

Diário do Pará, n. 10253, 06 ago. 2012.

Diário do Pará, n. 10320, 12 out. 2012.

O Liberal, n. 33508, 16 mar. 2012.

O Liberal, n. 33553, 30 abr. 2012.

O Liberal, n. 33665, 20 ago. 2012.

O Liberal, n. 33679, 03 set. 2012. 


\title{
As especificidades da apuração no processo de produção da reportagem
}

\author{
Paula Melani Rocha \& Mariana Galvão Noronha \\ Universidade Estadual de Ponta Grossa \\ E-mail: paulamelani@gmail.com/mariana.gnoronha@gmail.com
}

\begin{abstract}
RESUMO
$\mathrm{O}$ artigo propõe uma reflexão sobre o processo de produção de reportagem investigativa, com o propósito de aferir se há uma metodologia própria que perpassa por todo esse processo desde a seleção da pauta até a construção e veiculação. Traz um esforço em tentar definir o que seria essa metodologia conceitualmente, suas idiossincrasias. A discussão dialoga com autores que analisam $o$ jornalismo enquanto objeto de estudo, entre eles Otto Groth, Adelmo Genro Filho, Joaquim Fidalgo e Eduardo Me-

investigativo como um gênero, com especificidades tanto de forma quanto de conteúdo, o qual difere-se da cobertura factual e de atualidade. A discussão teórica fundamenta-se na teoria do interacionismo, em especial, newsmaking, percebendo o processo de produção do conteúdo jornalístico pela perspectiva da construção social. Os resultados apontam para um método de produção, constituído por determinados procedimentos articulados a uma apuração, porém com marcas de autoria.
\end{abstract} ditsch. Para isso, entende-se o jornalismo

Palavras-chave: jornalismo investigativo; produção jornalística; conhecimento em jornalismo; newsmaking; metodologia de apuração.

Data de submissão: 12-05-2016. Data de aprovação: 23-10-2016.

A Revista Estudos em Comunicação é financiada por Fundos FEDER através do Programa Operacional Factores de Competitividade - COMPETE e por Fundos Nacionais através da FCT - Fundação para a Ciência e a Tecnologia no âmbito do projeto Comunicação, Filosofia e Humanidades (LabCom.IFP) UID/CCI/00661/2013.

FCT COMPETE

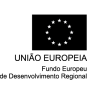

|l)点

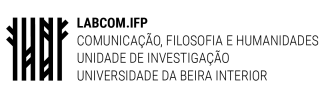




\title{
The specificities of research in the production of the investigative report
}

\begin{abstract}
The article proposes a reflection on the production process of investigative reporting, in order to assess whether there is a methodology that permeates throughout the hole process, from the selection of the subject to the construction and placement of the investigative report. Brings an effort to try to define what would it be this methodology conceptually, its idiosyncrasies. The discussion dialogues with authors who analyze journalism as an object of study, including Otto Groth, Adelmo Genro Filho, Joaquim Fidalgo

and Eduardo Meditsch. For this, the article Works withe the journalism investigativa as a genre, with specificities of both form and content, which differs from the factual coverage. The theoretical discussion is based on the interactionism theory, in particular newsmaking, realizing the production process of news content from the perspective of social construction. The results point to a production method, constituted of certain procedures articulated to a especific method, but with authorship marks.
\end{abstract}

Keywords: investigative journalism; journalistic production; journalism knowledge; newsmaking; research methodology.

\section{INTRODUÇÃO}

\begin{abstract}
A prática do jornalismo investigativo vem ganhando notoriedade não apenas no Brasil, mas também internacionalmente, sobretudo a partir do final do século XX. A queda de regimes não democráticos aliado a políticas de acesso a informação, internet, aplicativos e globalização favoreceram uma maior visibilidade e divulgação de conteúdo noticioso. Despontou-se uma tendência de favorecimento do exercício do jornalismo investigativo, simultaneamente a tecnologia e o modelo pós-industrial atingiram o modo de gestão em vigor até então do jornalismo e retraíram o staff das redações. Com estruturas mais enxutas, as empresas cortaram gastos, e o jornalismo investigativo, que é dispendioso, também foi atingido pelos cortes das redações brasileiras. No Brasil, entre os anos de 2011 e 2013, os grupos de comunicação do Paraná (rádio, TV, impressos) somaram 287 demissões. Em agosto de 2013, o Grupo Abril fechou quatro revistas. Na cidade de São Paulo, 280 demissões foram
\end{abstract}


homologadas de janeiro a abril de 2013, índice 37,9\% maior do que o mesmo período em 2012. ${ }^{1}$ Em 2015, segundo dados dos sindicatos dos Jornalistas dos estados de São Paulo e Paraná, o grupo Estado de São Paulo demitiu mais de 100 funcionários, o jornal Folha de S. Paulo demitiu quase 50, a TV Bandeirantes Litoral e o jornal Gazeta do Povo de Curitiba também demitiram 11 jornalistas cada um (Rocha, 2016). Ao todo, em 2015 foram computadas mais de 1400 demissões de jornalistas no país. Apesar de abalado dentro das redações, o jornalismo investigativo encontrou oportunidades fora delas, em iniciativas colaborativas, ONGs, coletivos, apoio de fundações e projetos independentes, além de ainda manter um espaço simbólico em alguns veículos nacionais. Por sua relevância social e interesse público, as reportagens investigativas são essenciais para os regimes democráticos e utilitárias para a transformação e denúncias em regimes não democráticos.

A reflexão proposta versa sobre a prática do jornalismo investigativo, busca-se aferir se há ou não uma metodologia própria que atravessa todo o processo de produção e se pode inclusive ser denominado como metodologia. É válido ressaltar que o método de apuração em discussão não é sinônimo de método científico, pois entende este último como um conceito acompanhado de pelo menos uma fundamentação teórica (Mendras, 1975, p.14). Porém, como será exposto na discussão, entende-se que a apuração jornalística investigativa pode em determinado momento utilizar-se de método científico, ao apropriar-se do Jornalismo de precisão, o qual de acordo com Meyer (1973, 1991), faz uso de métodos científicos das investigações sociais e psicossociais, principalmente no campo das ciências sociais, para coletar e analisar dados em reportagens investigativas. Também denominado como Reportagem com Auxílio de Computador (RAC).

A discussão faz parte da pesquisa "As especificidades do Jornalismo Investigativo - um estudo sobre a metodologia do processo de produção jornalística investigativa", desenvolvida junto ao Programa de Pós-graduação Mestrado em Jornalismo da Universidade Estadual de Ponta Grossa (UEPG). Utilizou-se de pesquisa bibliográfica para fundamentar os conceitos apresentados: jornalismo investigativo, processo de produção jornalística, conhecimento em jornalismo, metodologia, apuração jornalística e newsmaking.

1. Dados da reportagem "A revolta dos passaralhos", considerando apenas jornalistas registrados. www.apublica.org/2013/06/revoada-dos-passaralhos 
Optou-se por uma abordagem qualitativa considerando o levantamento e interpretação de dados. Nesse primeiro momento, cruzou-se pesquisa bibliográfica e documental, análise de reportagens investigativas e entrevista com profissionais que atuam em jornalismo investigativo. O percurso bibliográfico é o que permite identificar não somente os avanços desse gênero jornalístico, mas também os marcos em seu desenvolvimento e constituição nas especificidades que hoje permeiam esse processo de produção específico, como a diferenciação no método de apuração e nos temas das reportagens, que normalmente trazem irregularidades político-administrativas, tanto de governo quanto de outras autoridades (Nascimento, 2010).

A estrutura do artigo contempla três etapas de discussão interligadas na construção da reflexão proposta com o propósito de identificar se há uma metodologia própria no processo de produção da reportagem investigativa e tentar classificá-la. A primeira etapa justifica-se por apontar os atributos em contemplar o jornalismo pela suas especificidades na tentativa de compreender sua complexidade e idiossincrasias. A segunda parte traz referências bibliográficas que mencionam o mesmo objeto proposto aqui: jornalismo investigativo e apuração investigativa. Nesse sentido, apresenta o jornalismo investigativo como um gênero jornalístico, com características próprias e em transformação. Assim, ela é o aporte que sustenta o caminho a ser percorrido pela análise pontuada na terceira parte do texto, a qual versa sobre o processo de produção da reportagem investigativa, desde a seleção da pauta, o que a constitui e todo o percurso de produção da reportagem, pela perspectiva do newsmaking, procurando observar suas marcas, diferenciais, interações, repetições na busca de apreensão do objeto investigado. Para isso, considera-se tanto a discussão teórico conceitual quanto depoimentos de jornalistas investigativos proferidos no $10^{\circ}$ Congresso Internacional de Jornalismo Investigativo promovido pela ABRAJI (Associação Brasileira de Jornalismo Investigativo), em São Paulo, no período de 2 a 4 de julho de 2015, bem como documentos publicados por associações internacionais de jornalismo investigativo, mencionadas ao longo do texto. ${ }^{2}$

2. Entre os documentos analisados estão: Manual de verificação. Um guia definitivo para verificação de conteúdo digital na cobertura de emergências Disponível em www.verificationhandbook.com/book_br/index.php; e A investigação a partir de histórias. Um manual para jornalistas investigativos. Disponível em http://unesdoc.unesco.org/images /0022/002264/226456POR.pdf. 


\section{O JORNALISMO COMO OBJETO DE PESQUISA}

Um dos autores a discutir o Jornalismo como ciência, considerando objeto de pesquisa e metodologia, foi Groth (2011) pela perspectiva da Ciência dos Jornais, que iniciou no fim do século XIX na Alemanha, país que apresentou pioneirismo acadêmico no Jornalismo. Na obra, Groth (2011, p.29) apresenta um panorama do surgimento da disciplina na Alemanha, defendendo que "novas ciências especificas, nascem, via de regra, das necessidades, da urgência da vida". O autor expõe que a Ciência dos Jornais precisou então buscar por um espaço de reconhecimento entre as ciências já instituídas.

O primeiro passo para a conquista de um objeto próprio é, como dissemos, o destacamento do seu conteúdo do todo natural e sociocultural, o isolamento de determinadas manifestações iguais ou isoladas - no nosso caso, jornais e revistas - e a sua condensação em um grupo especial (...) Primeiro, cada ciência tem que comprovar, ter um "objeto próprio" que as outras ciências até agora não analisaram e cuja análise as intenções destas ciências também não permitem. Este modo especial de contemplação e elaboração de um objeto nos proporciona um conhecimento específico do objeto, que é ordenado segundo princípios específicos de classificação. Isto quer dizer que este conhecimento tem que ser colocado em um "sistema" e só então a nova ciência está fundada, só então ela pode reivindicar o reconhecimento de sua autonomia (Groth, 2011 p. 32).

O autor trata da Ciência dos Jornais para defender que o jornalismo deve ser analisado sob uma perspectiva particular, um olhar ainda não adotado nas metodologias desenvolvidas por outras ciências. Isso porque o jornalismo tem seu próprio objeto de pesquisa, o produto jornalístico, o qual apresenta uma complexidade de características e categorias próprias como universalidade, periodicidade, atualidade e difusão (Groth, 2011), aplicáveis a diferentes veículos (Genro Filho, 1987) sejam revistas, jornais ou mesmo outras plataformas.

Oliveira (2014) dá destaque à pesquisa da essência, defendida por Groth, afirmando que "a primeira tarefa da disciplina teórico-sistemática é submeterse à pesquisa da essência, se quiser enfim ser reconhecida como ciência" (Oliveira, 2014, p.07). 
Ao investigar a essência do objeto da Ciência dos Jornais, nós nos deparamos primeiro com a periodicidade como a característica manifesta e, portanto, imediatamente saliente e incondicionalmente evidente. Ao infiltrarmo-nos no conteúdo dos objetos, nós reconhecemos as características da universalidade e nela contida atualidade, e por fim identificamos a qualidade da publicidade, que nos dá a direção, o objetivo da obra e com isso nos conduz ao seu sentido (Groth, 2011, p. 144).

Com relação ao método, Coelho Sobrinho (2013) pondera que embora Groth (2011) tenha criticado a falta de um método científico específico à ciência dos jornais para apreensão do objeto científico, Genro Filho (1987) se propõe a resolver esta questão ao distinguir o objeto teórico do objeto real.

Ao primeiro dá o sentido do conhecimento, da essência do saber, e ao segundo associa a forma de manifestação bruta, reduzindoo ao suporte sensível e concreto do jornalismo. Portanto, Genro Filho faz uma distinção entre a natureza e a forma do jornalismo, dando ao objeto teórico a capacidade de oferecer e acumular conhecimentos vinculados aos princípios jornalísticos e atribuindo ao objeto real o sentido de fragmento do fenômeno (Coelho Sobrinho, 2014, p. 139).

O jornalismo tem uma forma de conhecimento de direito próprio. Não é apenas um instrumento para transmitir conhecimentos produzidos por outrem e nem tão somente um meio de comunicação, mas é também um meio de conhecimento com relevância e responsabilidade do seu papel social (Meditsch, 2002). Dessa forma, Coelho Sobrinho (2014, p.140) direciona a discussão sobre a prática do jornalismo, ao demonstrar que o fazer jornalístico "tem um campo nitidamente delimitado, apesar de amplo". Em consonância, Sponholz (2009) caracteriza o jornalismo como um tipo de processo de conhecimento envolvendo os seus produtores e receptores. No entanto, segundo a autora, os jornalistas precisam trabalhar o conteúdo que produz de forma crítica e com responsabilidade social, o que demanda uma concepção teórica de conhecimento que possibilite aos profissionais conhecer a realidade, lembrando que "o conhecimento total da realidade continua sendo uma utopia, a busca deste é, no entanto, o que nos leva a ir adiante" (Sponholz, 2009, p.13). Pode-se 
considerar aqui que o processo de produção jornalística demanda um conhecimento ao transformar um fato em acontecimento jornalístico. Para Fidalgo (2008, p.11) jornalismo é uma profissão que exige um saber complexo com dimensões reflexivas, o qual denomina como "saber profissional". São diferentes saberes adquiridos a partir do conhecimento formal e do exercício da prática.

(...) um tipo de trabalho "técnico-intelectual", que vai para além de uma mera lógica "técnico-instrumental" (Caria, 2005 p.198). E isto por três motivos essenciais: (1) nesta acção profissional estão inscritos também "valores e orientações morais" que fazem com que os critérios de interação com "o outro" não sejam desvalorizados; (2) os conhecimentos mobilizados não são uma mera aplicação da ciência adquirida em educação formal prévia e, pelo contrário, obrigam a "operações sócio-cognitivas de recontextualização profissional do conhecimento"; e (3) a autonomia no contexto de trabalho implica o "desenvolvimento de uma reflexividade profissional própria" que saiba lidar com a incerteza e a singularidade das situações (Fidalgo, 2008, p.14).

Assim, associa-se à teoria do construcionismo, pela perspectiva do newsmaking, na medida em que o processo de produção do conteúdo, desde a seleção, apuração, construção e veiculação envolve uma série de escolhas, procedimentos, atores sociais, tensionamentos, pressão do tempo, atuação da estrutura organizacional, cultura profissional e cabe ao jornalista conduzir este processo com conhecimento e competência profissional para que o processo se concretize com eficiência. $\mathrm{O}$ jornalismo não deslumbra um trabalho técnico, mecânico e meramente reprodutivo. O conhecimento reproduzido perpassa pela administração das informações contidas nos fatos jornalísticos, que são determinados por padrões, valores morais, epistemológicos e deontológicos da profissão.

O jornalista trabalha com a divulgação de fatos de informações, as quais, de acordo com Chaparro (2001, p.41), devem produzir "alterações significativas na realidade presente das pessoas". Para o autor, caracteriza-se uma reação em cadeia, na qual os atos comunicativos do jornalismo desencadeiam comportamentos e as ações sociais realimentando "(...) o processo social, provocando transformações nos cenários da atualidade e da ordenação ética e 
moral da sociedade"(Chaparro, 1994, p.30 30). E os fatos jornalísticos também não são isolados, fragmentos sociais que encerram em sim mesmos, eles fazem parte de uma continuidade de ações e movimentos da sociedade. Como coloca Genro Filho (1987, p.186-188):

Os fatos jornalísticos são um recorte do fluxo contínuo, uma parte que, em certa medida, é separada arbitrariamente do todo. (...) A verdade se resume a um processo de revelação e constituição do fato exposto pelo jornalista, isto é o fato deve ser entendido na sua forma polissêmica por se tratar de uma versão traduzida com o poder de valores e interesses.

Assim, o jornalismo é uma atividade intelectual em que toda ação exige um pensar, um aprender e um inovar. Pode-se dizer que cada cobertura mobiliza determinadas capacidades reflexivas na busca de respostas necessárias para o contexto da ação. Nesse sentido, a competência profissional não caracteriza-se somente pela ação, mas por uma ação reflexiva, a qual sustenta os "saberes de ação", caracterizados por Schön (1996, apud Fidalgo, 2008) como "uma nova epistemologia do agir profissional". Como pontua Fidalgo (2008), as competências jornalísticas demandam um saber prático, o qual congrega o "saber conhecer", "saber fazer" e "saber-ser".

Aqui estabelece-se constantemente uma relação com a experiência, com o trabalho concreto e com a aprendizagem que (também) se realiza nele e através dele, num processo que não significa mera justaposição de saberes, mas o seu relacionamento dialético (Fidalgo, 2008, p. 9).

A ação e a reflexão sobre ela gera novos saberes. Ao pensar nas coberturas jornalísticas concebe-se assim que os "saberes de ação"vislumbrados nas reportagens investigativas não são os mesmos aplicados em uma cobertura diária. Ettema e Glasser (1984), apontam que no seu estudo sobre as rotinas do jornalismo, Tchuman ao discutir sobre a tipificação da "programação", referente a como um evento será tratado, o "head news"é qualificado como jornalismo investigativo. O tópico seguinte discute pontualmente as especificidades da reportagem investigativa e parte da prerrogativa que os procedimentos empregados no processo de produção caracterizam sobretudo um movimento contínuo de apuração. A discussão trata esses procedimentos como 
uma metodologia de apuração, porém é válido mencionar que não se trata de um método científico, já descartado pela ciência dos jornais, mas sim um método que constitui também o "saber profissional".

\section{O JORNALISMO INVESTIGATIVO E SUAS DELIMITAÇÕES: BUSCA DO MÉTODO DE APURAÇÃo}

Pensar o jornalismo investigativo pela perspectiva do método não é pioneirismo desta reflexão. O próprio documento $A$ investigação a partir de histórias. Um manual para jornalistas investigativo publicado em 2013, pela UNESCO, traz os métodos e as técnicas do jornalismo investigativo, sem se limitar à busca de informações ou de como encontrá-las, mas por um viés holístico envolvendo todo o processo de produção da reportagem investigativa.

Não pensamos que a questão básica seja como encontrar informações. Ao invés disso, pensamos que a tarefa central é como contar uma história. Isso nos leva à inovação metodológica básica deste manual: Usamos as histórias como o cimento que mantém a coesão entre cada passo do processo investigativo, desde a concepção até a pesquisa, redação, controle de qualidade e publicação. Também nos referimos a essa abordagem como a investigação a partir de histórias, porque começamos formulando a história que esperamos redigir como uma hipótese que será ou verificada ou refutada. Esse é o primeiro passo em um processo integrado (Hunter et. al., 2013, p.4).

Nesse sentido, o ponto inicial é o fato que será narrado, ou seja a pauta a ser investigada. É a pauta que define o método investigativo. Porém, para os autores todas as pautas partem do pressuposto de uma hipótese para a história, estratégia já utilizada por empresas de consultoria, pelas ciências sociais e pelas investigações policiais. A partir da hipótese são desenhados os seguintes passos (Hunter et. al., 2013, p.5):

- o repórter consegue visualizar as informações que necessita buscar;

— o profissional de edição pode "avaliar mais facilmente a factibilidade, os custos, as recompensas e o avanço"do projeto investigativo; 
- já durante o processo de produção, os profissionais envolvidos organizam o material coletado para a redação e começam a construir partes específicas do texto final;

- esse procedimento auxilia no controle e permite uma visão "mais perspicaz sobre o quão bem a história atende a critérios legais e ético";

- o resultado é uma história "que pode ser resumida em algumas poucas frases de impacto - uma história que possa ser promovida, defendida e lembrada"(Hunter et. al., 2013, p.4).

Percebe-se, assim, que o processo de produção e construção do conteúdo informativo não caracteriza-se por um movimento linear e sim pendular, mesclando de forma contínua, porém finita, apuração, redação do texto e verificação. É válido mencionar, como os próprios autores colocam, que essas constatações sobre um procedimento metodológico não são embrionárias e sim fruto de estudos e observações práticas por um conjunto de profissionais. Em 1990, a tese de Mark Lee Hunter trouxe uma comparação entre os métodos investigativos franceses e norte-americanos. Posteriormente, durante 12 anos, Hunter trabalhou no Instituto Francês de Imprensa da Universidade de Paris/Panthéon-Assas, e junto com os colegas testou na prática os métodos apontados no manual para jornalistas investigativos (Hunter et. al., 2013).

Juntamente com alguns colegas, entre eles Yves Doz, Luk Van Wassenhove, Ludo Van der Hayden e Kevin Kaiser, refletiram sobre as práticas e processos no campo do jornalismo. Em 2001, com o surgimento da Rede Global de Jornalismo Investigativo, motivada por uma rede de membros de diferentes entidades como do Instituto Dinamarquês para a Cobertura Jornalística Auxiliada por Computador e do Repórteres e Editores Investigativos Inc., criou-se um fórum "para o intercâmbio de boas práticas"(Hunter et. al., 2013, p.5). Contudo, como o próprio autor coloca, esse movimento de observar os elementos de investigação a partir das histórias eclodiu em diferentes lugares, como Holanda e Dinamarca.

Já na década de 1970, o jornalista americano Philip Meyer, ao defender o Jornalismo de Precisão, referia-se à aplicação de métodos científicos das ciências sociais para levantar e analisar dados, em movimento contrário ao New Jornalism impulsionado a partir da década de 1960.

O jornalismo de precisão foi uma forma de expandir o arsenal de ferramentas do repórter para tornar temas antes inacessíveis, ou 
parcialmente acessíveis, em objeto de exame minucioso. Foi especialmente eficiente para dar voz à minoria e grupos dissidentes que estavam lutando para se verem representados (Meyer, 1993, p.15).

Antes mesmo de Philip Meyer utilizar dados na reportagem sobre as manifestações em Detroit para mostrar que os participantes não eram pessoas de baixa escolaridade da região sul, em 1952 a TV americana CBS usou-se de análise de dados para prever o resultado das eleições presidenciáveis. Iniciava uma nova forma de fazer jornalismo, na década de 1960, jornalistas, sobretudo nos Estados Unidos, passaram a visitar bases de dados públicas com métodos científicos para fiscalizar o poder de forma independente. Denominado de Jornalismo de interesse público, os defensores das técnicas baseadas no auxílio do computador procuram revelar tendências, contrariar o senso comum e desnudar injustiças perpetradas por autoridades e corporações (Gray, et. al., 2012)

Nos anos de 1980, a pesquisadora Quesada (1987 apud Sequeira 2005, p.74) defende que a diferenciação do jornalismo de atualidade e o jornalismo investigativo não está no formato do texto ou na apresentação gráfica do material, mas está justamente no processo de trabalho do profissional, mais especificamente, as estratégias que ele usa para a apuração do material.

O simples fato de um texto jornalístico conter cifras, estatísticas, porcentagens econômicas, documentação e declarações não o define como jornalismo investigativo, já que todas essas informações podem ser obtidas de uma fonte oficial, extraída de documentação ou entregue em forma de press-release. "Só no momento em que o repórter passa a utilizar técnicas e estratégias que não fazem parte das rotinas dos trabalhos jornalísticos de atualidade a reportagem se transforma em reportagem investigativa" (Sequeira, 2005, p.74).

A brasileira Sequeira (2005) mostra que o jornalismo investigativo demanda métodos de pesquisa e estratégias operacionais. Lopes e Proença (2003, p. 10) seguem a mesma lógica ao defenderem que no jornalismo investigativo o levantamento de informação é algo susceptível de ser "trabalhado mais a fundo, de ser documentado, ampliado, verificado, contextualizado, indagado e investigado sob todos os ângulos". 
Sobre as técnicas e passos que permeiam o processo de produção e que se caracterizam como uma metodologia da reportagem investigativa, o jornalista Fortes (2005) menciona o uso das fontes, entrevistas, levantamento de dados e documentação, porém há uma alternância no compasso da sequência das etapas do processo de investigação jornalística, já que o jornalismo investigativo depende do cruzamento das informações obtidas por meio de todas essas estratégias.

Uma boa investigação é demorada e, normalmente, recheada de documentos, dados, estatísticas, legislações e códigos de onde se tira o extrato necessário para a notícia. Muitas vezes, não é de uma fonte ou de um documento que se obtém a informação, mas do cruzamento de vários deles. Os dados estatísticos devem ser lidos com cuidado, pois escondem tratamentos técnicos e avaliações que passam despercebidos pelos leigos (Fortes, 2005, p.31).

Ao analisar o jornalismo investigativo na web, na sua dissertação Martins (2011) aborda o processo de produção e traz procedimentos como pesquisa documental, fontes consistentes, planejamento do espaço, relevância do tema, técnicas de apuração (câmera escondida e prática de infiltração). O interessante é que a autora também traz o aspecto da autoria na escolha dos procedimentos adotados no processo de produção da reportagem.

O uso de procedimentos de apuração diferenciados no processo de produção de reportagens investigativas datam de iniciativas notórias como a de Ida Tarbell na série de reportagens The History of Standard Oil Co publicadas entre 1902 e 1904 na revista americana McClure's Magazine, em que denunciou práticas ilícitas das empresas de John Rockfeller, durante anos facilitando a instalação e hegemonia das empresas no território nacional. O trabalhou de apuração iniciou em 1900 com o levantamento de documentação oficial envolvendo irregularidades nos acordos firmados entre a empresa e o governo, entrevistas com magnatas do petróleo, funcionários das empresas de petróleo e especialistas. Uma investigação minuciosa e morosa.

Na década de 1950, o jornalista argentino Rodolfo Wash com a investigação que resultou na obra Operação Massacre, é outro exemplo que merece ser mencionado por suas particularidades na apuração. Ao deparar-se com um sobrevivente de um possível fuzilamento clandestino realizado pela polícia argentina em junho de 1956, contra 12 pessoas, o jornalista vai atrás da 
recomposição dos fatos. Ele busca os outros sobreviventes, seus familiares, volta à cena do episódio, entrevista moradores e também policiais. O trabalho é incessante. Durante décadas o jornalista investiga o ocorrido e amplia a apuração para as irregularidades que o governo praticou contra peronistas e durante a ditadura no país. Rodolfo Wash articula acontecimentos em momentos diferentes, investiga os pareceres judiciais, cruza informações e confronta dados. O jornalista desenvolveu métodos de apuração e checagem de informações precisos e elaborados. O livro Operação Massacre foi publicado com três edições diferentes, ao longo de 20 anos, acrescentando prólogos e notas de atualização numa busca incansável de dados sobre a ditadura argentina (Walsh, 2010). Os dois exemplos ilustram as especificidades adotadas por cada profissional durante o processo de produção da investigação jornalística.

Percebe-se procedimentos similares como levantamento e leitura de documentos, realização de entrevistas com fontes primárias e secundárias, não limitam-se a fontes oficiais, pelo contrário, buscam ouvir uma pluralidade de fontes, confrontam dados, e foram publicados de forma diferenciada, a princípio em séries, contudo isso só é conhecido porque ambos os trabalhos estão publicados em livro, os quais detalham o esforço e os movimentos realizados pelos jornalistas. Portanto, a análise não pode fundamentar-se apenas pelo produto, reportagem publicada. Como mostrou anteriormente a produção jornalística é processual e a apuração está presente em grande parte das etapas, caracteriza-se um movimento de idas e vindas, de escolhas e decisões, a entrevista com o repórter é essencial para tomar ciência desse processo e conseguir identificar suas marcas.

Assim, ao buscar identificar a metodologia da produção e construção de reportagens investigativas, com o propósito de aferir os procedimentos e técnicas que a constituem e suas peculiaridades, vislumbrou a necessidade em ouvir os profissionais que trabalham nesse tipo de cobertura pela necessidade em entender o processo. Ao ouvir os profissionais acredita-se que irão auxiliar na verificação das técnicas possíveis, suas articulações, razões de escolha ao longo das etapas que envolvem todo o processo da reportagem investigativa, desde a seleção da pauta, apuração e produção das informações bem como a construção do texto investigativo para veiculação, para identificar se há um protocolo padrão, ou não e o que determina as escolhas dos procedimentos de investigação. A reflexão parte do pressuposto de que esse processo é en- 
volvido por técnicas e procedimentos diferentes dos que são tradicionalmente usados no jornalismo diário.

\section{A AUTORIA E O PROCESSO DE PRODUÇÃO DA REPORTAGEM INVESTI- GATIVA}

Para a análise das reportagens foram pensadas categorias com o intuito de identificar se o conteúdo realmente se enquadra nos moldes de reportagem investigativa, que caracteriza-se principalmente pelo protagonismo do repórter na descoberta de um fato e informações até então não divulgados (Rosenstiel e Kovach, 2004), a pauta é resultado do trabalho de investigação do repórter e não de outra instituição, como Ministério Público ou Polícia Federal. Escavar um tema até então submerso é uma característica determinante na investigação jornalística. Em seguida partiu-se das seguintes variáveis: a classificação das fontes em 'categoria', 'grupo' e 'critério', identificando nas reportagens investigativas quais as fontes primárias e secundárias, empresariais ou especialistas, como forma de perceber pluralidade de fontes nas reportagens investigativas; os critérios de noticiabilidade que determinam a cobertura, denúncia e políticas públicas; e uso de recursos como infográficos e imagens. A análise das reportagens contribuiu também para identificar nos textos outras especificidades do gênero investigativo, que não foram mapeadas durante o levantamento bibliográfico, além de revelar aspectos de regularidade no processo produtivo.

A classificação das fontes segue a proposta de Schmitz (2011): categoria, grupo e crédito. $\mathrm{Na}$ 'categoria', as fontes dividem-se entre primárias e secundárias. São primárias aquelas fontes que estão diretamente envolvidas aos fatos, que fornecem a essência da reportagem. As fontes secundárias são aquelas que contextualizam e complementam as informações que foram apresentadas pelas fontes primárias. Há uma adaptação na classificação das fontes no que se refere à categoria. Devido a complexidade de informações nas reportagens investigativas, foi acrescentada a definição de importância que Pereira Junior (2006) dá aos personagens do acontecimento jornalístico. As fontes primárias foram divididas naquelas que são fulcrais, cuja reportagem não existe sem elas, e as primárias de média importância.

A classificação 'grupo', também segue a divisão de Schmitz (2011). Por fonte oficial, entende-se alguém em função ou cargo público e se pronuncia por órgãos do Estado. Como empresarial, compreende aquela fonte que repre- 
senta corporação empresarial, seja indústria, comércio ou serviços. Institucional é aquela fonte que responde por uma organização sem fins lucrativos ou grupo social. A fonte popular é aquela que aparece como vítima de determinada situação, que fala por si mesma, diferente da fonte testemunhal, que fala sobre o que viu acontecer com outro. A fonte especializada é aquela que apresenta um saber específico ou reconhecido, geralmente relacionada a alguma profissão ou área de atuação. A fonte referencial é definida como qualquer bibliografia ou documentos que são usados na constituição da reportagem.

Quanto ao 'crédito', o artigo usa a classificação de Sousa (2001), que divide as fontes da reportagem em on the record, on background, on deep background e off the record. Isso porque as reportagens investigativas contam com uma variedade de fontes maior que a classificação entre 'identificada' ou 'anônima'.

On the record (atribuição directa, para publicação) - A fonte é identificada e tudo o que ela profere pode ser objeto de enunciação jornalística. É a regra comum e aquela que deve ser usada quando a fonte não pede confidencialidade. On Background/not for attribution (atribuição com reserva) - A fonte não é totalmente identificada, embora sejam dadas algumas pistas superficiais sobre os meios em que ela se movimenta. [...] On deep background (atribuição com reserva total) - Não só a fonte não é identificada como também não pode ser referido o meio em que ela se movimenta, embora as informações fornecidas pela fonte possam ser difundidas. [...] Off the record (confidência total) - A fonte não pode ser identificada e a informação que ela fornece não pode ser divulgada. Contudo, esta informação auxilia, frequentemente, o trabalho do jornalista (Sousa, 2001, p. 67-68).

De certa maneira, o caminho metodológico do jornalismo investigativo é seguir os dados, cruzá-los e interpretá-los. As fontes humanas, primárias ou secundárias, são usada apenas como uma das técnicas e não a única, para confirmação das informações levantadas em bancos de dados ou documentos oficiais. O jornalismo factual diário costuma limitar-se às informações e dados repassados pelas fontes humanas, em geral oficiais ou especialistas. Entretanto, devido às temáticas, bem como a profundidade e complexidade dos assuntos pautados nas reportagens investigativas, a apuração que não cruza as 
informações obtidas pode ficar superficial, rasa e até mesmo incompleta. E a publicização da informação incorreta causa um dano irreparável aos envolvidos.

Para esta publicação, foram selecionadas para análise quatro reportagens premiadas da Agência Pública ${ }^{3}$, de autoria feminina, publicadas no período de 28/08/13 a 29/05/14. Nesta análise, constatou-se o uso de 63 fontes, sendo 18 primária fulcral, 15 primária média importância e 30 secundárias. Com relação à classificação por grupo o resultado foi:

\begin{tabular}{lc} 
Grupo & Número de fontes \\
\hline Oficial & 17 \\
Institucional & 10 \\
Popular & 8 \\
Especializada & 12 \\
Referencial & 8 \\
Testemunhal & 5 \\
Empresarial & 3 \\
\hline Total & 63 \\
\hline
\end{tabular}

Tabela 2. Atores com maior grau de intermediação no recorte.

As reportagens são extensas, variando entre 11 mil e 55 mil caracteres. $\mathrm{O}$ tamanho dos textos representa um aumento proporcional no número de fontes. Na reportagem Dor em Dobro, por exemplo, o texto com 55 mil caracteres é construído com base em 25 fontes identificadas; em Severinas: as novas mulheres do Sertão são 10 fontes em um texto com 11 mil caracteres; Em Guerra Contra a Nestlé constam 15 fontes em uma reportagem com 28 mil caracteres; e Quanto mais presos maior o lucro conta com 19 mil caracteres, embasada em 13 fontes identificadas.

Entretanto, a quantidade de fontes não necessariamente implica em pluralidade ou profundidade da informação. Com exceção da maior reportagem analisada todos os textos apresentam número maior ou igual entre fontes primárias fulcrais e as de média importância. Na reportagem em questão, com 25 fontes, somente duas dela são fulcrais, sendo seis de média importância e

3. http://apublica.org/2014/05/dor-em-dobro-2/; http://apublica.org/2013/08/severinas-n ovas-mulheres-sertao/; http://apublica.org/2014/04/em-guerra-contra-a-nestle/; http://apublic a.org/2014/05/quanto-mais-presos-maior-o-lucro/. 
17 fontes secundárias de contextualização. Nenhuma outra reportagem apresenta número de fontes secundárias superior ao número de fontes primárias (fulcrais e média importância).

A análise ainda revelou que, na classificação por grupo, as fontes que mais se sobreassem são as oficiais, institucionais, especializadas, testemunhais e populares, nessa sequência. Em entrevista ${ }^{4}$, a jornalista Marina Almeida que fez a reportagem "Em guerra contra a Nestlé"informou que fez cerca de 30 entrevistas, entre elas estavam conversas com moradores e frequentadores do parque que não acompanhavam a questão das águas, "mas não aproveitei as entrevistas porque não acrescentaram muito - alguns concordavam que o parque já foi melhor, outros não sabiam responder, não tinham notado... ". Ela também descartou a entrevista de vereador e de um funcionário da secretaria de Turismo, "porque não acrescentavam nada às outras entrevistas citadas na matéria. O critério foi esse: o que as entrevistas tinham a acrescentar à discussão".

Quanto aos procedimentos de apuração, Marina Almeida utilizou levantamento e análise documental, fontes secundárias, fontes primárias, entrevistas, observação in loco, cruzamento e interpretação de dados e checagem e rechecagem sobretudo das questões mais técnicas. Sobre o processo de apuração, ela discorre como percorreu as etapas:

(...) primeiramente li as notícias que encontrei sobre as águas de São Lourenço, uma tese sobre o movimento de 2000 que também dava um bom histórico da região e das discussões sobre a superexploração e fiz algumas pré entrevistas por telefone. Em novembro passei uma semana na cidade entrevistando os moradores, políticos, Ministério Público, entre outros. Visitei o parque algumas vezes e tinha conseguido agendar uma visita guiada à fábrica, que foi desmarcada. Também fui à cidade de Cambuquira que tem um grupo forte de defesa das águas. Já em São Paulo fiz outras entrevistas por telefone, com o movimento de Caxambu que não pôde me receber em novembro, deputado mineiro, Ministério Público da área cultural de Minas, que fica em BH, entre outros. Tentei por diversas vezes uma entrevista com o DNPM nacional, sem sucesso, mas levantei alguns dados por meio da

4. Entrevista realizada por email em 02/06/2015. 
lei de acesso à informação e falei com um funcionário do CPRM mineiro, por telefone. Nessa fase, analisei vários documentos dos processos, atas de reuniões, teses, estudos sobre as águas da região etc. Entrevistei pesquisadores sobre hidrogeologia, formação da água mineral, etc. Para entender e traduzir melhor alguns termos técnicos utilizei alguns manuais, como o Manual de Construção de Poços Tubulares. Depois de todo esse processo, redigi a matéria.

O relato da jornalista Arbex (2012) sobre sua investigação do Caso Koji (uma empreiteira de Juiz de Fora (MG)) mostra bem a importância de cruzar as informações obtidas por meio dessa metodologia de apuração para garantir o material final mais confiável. A pauta chegou até ela em abril de 2008, numa conversa informal com um motorista de táxi. Quando o taxista comenta sobre o andamento da política em Juiz de Fora, afirmando que até vereador é dono de construtora, ela se interessa em levantar a história. "Nunca tinha ouvido falar sobre a Koji e nem que a tal empresa pudesse pertencer a um dos políticos mais influentes da região: Vicente de Paula Oliveira, presidente da Câmara Municipal há 20 anos no poder" (Arbex, 2012, p. 171).

Numa pesquisa superficial, Arbex identifica o nome da empreiteira em licitações da Prefeitura de Juiz de Fora. Os Atos do Governo, documento oficial, indicavam que a empresa havia ganho licitações em todas as secretarias municipais entre os anos de 2005 e 2008, mesmo período em que o referido vereador estava à frente da Câmara Municipal. Apesar da conexão imediata, a jornalista reconhece que a prova era muito fraca para a divulgação em reportagem. A partir disso, inicia-se um longo processo de verificação de documentos e confirmação do esquema de forma inegável. A primeira medida foi procurar provas na Junta Comercial do Estado de Minas Gerais, em busca dos sócios da construtora, uma consulta que pode ser realizada por qualquer cidadão, pois tratam-se de informações públicas (Arbex, 2012).

Com o nome de sete sócios em mãos, a autora parte para o Ministério do Trabalho e descobre que os sócios tinham baixa qualificação profissional, ocupando cargos como auxiliares e vigilantes. Apesar de identificar quem seriam os 'laranjas' no esquema, a apuração ainda não havia identificado o elo entre o vereador e a construtora. Foi numa consulta à Justiça do Trabalho que a jornalista encontrou um processo trabalhista contra o vereador, que nomeou 
no processo uma mulher como sua preposta. O nome em questão era tanto da secretária executiva na presidência da Câmara Municipal como também secretária executiva da empreiteira Koji. A partir daí, com outras consultas e acesso a novos documentos, todos eles públicos, a jornalista consegue provar a ligação existente entre o vereador, sua construtora e as licitações ganhas na Prefeitura. Foi somente com todo esse material em mãos que a jornalista saiu a campo, para entrevistar os envolvidos no esquema (Arbex, 2012).

A conversa, inicialmente amistosa, foi ficando tensa, na medida em que Vicentão foi percebendo a qualidade das provas que tínhamos em mãos. Num dos momentos mais delicados, o fotógrafo Fernando Priamo conseguiu flagrar o instante em que Vicentão apontou o dedo indicador para nós, simulando uma arma. Ameaça clara, flagrada por Priamo num competente trabalho de equipe (Arbex, 2012, p.174).

Marina Almeida também comenta o acesso às fontes envolvidas, após ter coletado as informações e a reação não receptiva em atender a imprensa. Contudo, ela recorreu à lei de acesso à informação para obter os dados:

A maior dificuldade foi para entrevistar a Nestlé, que só respondeu a algumas perguntas por e-mail e não respondeu a algumas questões alegando sigilo comercial, cancelou a visita à fábrica e também não divulgou um estudo que realizou na região. Também foi difícil conversar com os deputados envolvidos na comissão do novo Código de Mineração, apenas o presidente da Comissão falou comigo. O DNPM também não colaborou com entrevistas, apesar das inúmeras tentativas, e só respondeu às questões enviadas pela Lei de Acesso à Informação.

A documentação é crucial no jornalismo investigativo, principalmente quando são utilizadas fontes off the record. Esse levantamento documental dos antecedentes do fato em questão serão a base da estratégia do restante do processo de apuração, permitindo conhecer a totalidade da história, suas implicações e que tipo de abordagem terá a reportagem.

(...) o levantamento documental em torno do tema que está sendo investigado é uma das etapas mais importantes do processo de 
construção de uma reportagem investigativa. Tornar públicos fatos que grupos desejam esconder da sociedade exige necessariamente do repórter um conhecimento profundo sobre eles, que só um trabalho documental exaustivo e preciso poderá fornecer (Sequeira, 2005, p. 92).

Com o levantamento de todo material que encontra sobre o tema abordado para a produção de uma reportagem investigativa, outro processo importante no jornalismo investigativo é a rechecagem das informações, mesmo que elas não pareçam imprecisas ou inconsistentes. "Faz parte do bom jornalismo, sobretudo quando se trata de notícia sensível, abortar uma reportagem, por mais doloroso que seja, se ela tem falhas ou incongruências apresentadas na apuração" (Fortes, 2005, p.34).

Outro procedimento relevante na apuração jornalística investigativa é não se perder no acúmulo de informações e saber filtrar as que realmente correspondem à pauta investigada e não se perder no processo de investigação. De acordo com um levantado do Investigative Reporters and Editors (IRE) (apud Fortes, 2005, p.28), a quantidade de informações dobra a cada cinco anos, desde o final de década de 1990. "Esse quadro obrigou os jornalistas, sobretudo aqueles ligados à atividade investigativa, a criar métodos capazes de garantir uma seleção correta das informações, além de instrumentos racionais de avaliação, análise e comunicação" (Fortes, 2005, p.28).

\section{CONSIDERAÇÕES}

Este artigo buscou realizar uma discussão teórico conceitual sobre o jornalismo como objeto de pesquisa científica, considerando as peculiaridades e especificidades da produção jornalística investigativa. Propôs pensar um percurso metodológico de análise da mídia noticiosa nas produções investigativas, como forma de identificar quais são os métodos produtivos específicos do jornalismo investigativo, considerando um levantamento bibliográfico, aliado a entrevistas com profissionais da área e uma análise da produção jornalística investigativa.

Esse percurso metodológico foi pensado como estratégia que contempla as especificidades e características próprias do jornalismo. Com os dados obtidos ao final dessas três etapas do processo metodológico, a pesquisa espera 
aferir o conhecimento específico que norteia a prática do jornalismo investigativo e como se estabelece o diálogo entre teoria e prática no exercício desse gênero do jornalismo. A interpretação dos dados permitirá ainda encontrar um padrão na produção do jornalismo investigativo e a possível interferência das subjetividades dos profissionais na orientação de um protocolo de apuração.

A discussão faz parte de uma pesquisa de mestrado em andamento e traz algumas considerações preliminares com um padrão de técnicas e percurso na produção do jornalismo investigativo e onde há inferências das subjetividades dos jornalistas que atuam na área, ainda que haja um protocolo de apuração. Considera-se que as informações levantadas pela análise dos textos e pelas entrevistas têm relação direta com o processo de produção e produto final. Por isso, é possível que após conversar com mais profissionais, a análise seja retomada para avaliar outros aspectos. Com essas estratégias, a pesquisa quer mapear onde existem padrões no processo de produção do jornalismo investigativo e onde existem exceções, determinadas pela subjetividade dos profissionais.

\section{REFERÊNCIAS}

Arbex, D. (2012). Métodos de pesquisa e investigação. In R. Christofoletti \& S. Lima (orgs.) Reportagem, pesquisa e investigação. Florianópolis: Editora Insular.

Caria, T. H. (2005). Trajectória, papel e reflexividade profissionais: análise comparada e contextual do trabalho técnico-intelectual. In T. H. Caria (Org.). Saber profissional. Coimbra: Almedina.

Chaparro, C. (s.d.). De como a ciência pode ajudar a notícia. Revista PJ: $\mathrm{Br}$ (Jornalismo Brasileiro). São Paulo: ECA/USP, Edição 2. Disponível em: www2.eca.usp.br/pjbr/arquivos/forum2_a.htm. Recuperado em 20 de fevereiro de 2015.

Ettema, J. S. \& Glasser, T. L. (1984). On the epistemology of investigative journalism. Presented to the Qualitative Studies Division of the Association for Education in Journalism and Massi Communication, Gainesville, Florida, August. 
Fidalgo, J. (2008). Jornalistas e saberes profissionais. I Colóquio BrasilPortugal de Ciências da Comunicação - XXXI Congresso Brasileiro de Ciências da Comunicação.

Fortes, L. (2005). Jornalismo investigativo. São Paulo: Editora Contexto.

Genro Filho, A. (1987). O segredo da pirâmide - para uma teoria marxista do jornalismo. Porto Alegre: Ed. Tchê.

Gray, J; Bounegru, L. \& Chambers, L. (org) (2012). Manual de jornalismo de dados. Disponível em www.datajournalismhandbook.org/pt/ Acessado em 05 de março de 2016.

Groth, O. (2011). A tarefa da pesquisa científica sobre a cultura. In $O$ poder cultural desconhecido: fundamentos da ciência dos jornais. Petrópolis: Editora Vozes.

Hunter, M. L. (2013). A investigação a partir de histórias - um manual para jornalistas investigativos. Montevideo: Oficina Regional de Ciencias de la UNESCO para América Latina y el Caribe.

Kovach, B. \& Rosenstiel, T. (2004). Os elementos do jornalismo: o que os jornalistas devem saber e o público exigir. São Paulo, Geração Editorial.

Lopes, D. F. \& Proença, J. L. (2003). Jornalismo investigativo. São Paulo, Publisher Brasil.

Meditsch, E. (2008). O jornalismo como forma de conhecimento: uma abordagem qualitativa. In J. M. Melo, et al. Jornalismo, história, teoria e metodologia da pesquisa: perspectivas luso brasileiras (pp. 7-12). Porto: Universidade Fernando Pessoa.

Mendras, H. (1975). Princípios de sociologia: uma iniciação a análise sociológica. 4. ed. Rio de janeiro: Zahar.

Meyer, P. (1973). Precision journalism. Bloomington: Indiana University Press.

Nascimento, S. (2010). Os novos escribas: o fenômeno do jornalismo sobre investigações no Brasil. Porto Alegre, Arquipélago Editorial.

Oliveira JR, C. R. (orgs). (2012). Pesquisa em ciências sociais: interfaces, debates e metodologias (pp. 49-77). Ponta Grossa: Toda Palavra.

Pereira Jr, L. C. (2006). A apuração da notícia: métodos de investigação na imprensa. Petrópolis, Ed. Vozes. 
Rocha, P. M. (2015). Os impactos da tecnologia na produção jornalística e a formação do profissional. Artigo apresentado no XIV Congresso Internacional IBERCOM 2015, realizado em São Paulo no período de 29 de março a 2 de abril de 2015.

Schmitz, A. A. (2011). Fontes de notícias: ações e estratégias das fontes no jornalismo. Combook.

Sequeira, C. M. (2005). Jornalismo investigativo: o fato por trás da notícia. São Paulo: Ed. Summus.

Sobrinho, J. C. (2013). A essência do jornalismo está na apuração. In Moraes Júnior, et al. (org). Antes da pauta: linhas para pensar o ensino do jornalismo no século XXI. São Paulo: ECA.

Sousa, J. P. (2011). Elementos do jornalismo impresso. BOCC - Biblioteca On-Line de Ciências da Comunicação. Disponível em: http://www.bocc. ubi.pt/pag/sousa-jorge-pedro-elementos-de-jornalismo-impresso.pdf.

Sponholz, L. (2009). Jornalismo, conhecimento e objetividade: além do espelho e das construções. Florianópolis: Insular.

Walsh, R. (2010). Operação massacre. São Paulo, Companhia das Letras. 
$\bigoplus$

$\bigoplus$

$\oplus$ 


\title{
Political Cartoons as communicative weapons - the hypothesis of the "Double Standard Thesis" in three Portuguese cartoons
}

\author{
Samuel Mateus \\ Madeira Univertsity / Labcom.IFP / CIC.Digital \\ E-mail: samuelmateus@uma.pt
}

\begin{abstract}
Political cartoons are a powerful communicative weapon. They can distract, joke but they can also provide social commentaries on key aspects of reality. Although not always acknowledged, cartoons are a key element on political communication. In this paper, we investigate editorial cartoons potential to political communication and take them as communicative artifacts capable of enhancing political comprehension and reconceptualization of events, through specific frames of understanding. By looking into the double standard thesis, by which cartoonists tend to contrast the posturing, destructive, wastage of politics with the pur-

ness (Morris, 1992: 254), we try to assess if that same tendency to frame politics and business befalls as well in Portuguese political cartoons. Based on a notrepresentative sample, we proceed to a rhetorical analysis of three contemporary Portuguese political cartoons in which business tends to be associated with purpose and efficiency, while politics is portrayed as a wasteful, vain, otiose activity. By representing politics and business in such a dissimilar way, these cartoons tend to validate in Portugal the double standard thesis, and raises the possibility it can actually be applied to trans-national contexts.
\end{abstract} posive, constructive efficiency of busi-

Keywords: political cartoons; double standard thesis; visual rhetoric; framing; political communication.

Data de submissão: 22-07-2016. Data de aprovação: 23-10-2016.

A Revista Estudos em Comunicação é financiada por Fundos FEDER através do Programa Operacional Factores de Competitividade - COMPETE e por Fundos Nacionais através da FCT - Fundação para a Ciência e a Tecnologia no âmbito do projeto Comunicação, Filosofia e Humanidades (LabCom.IFP) UID/CCI/00661/2013.

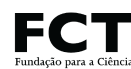




\section{RESUMO}

Os cartoons políticos são uma arma poderosa e comunicativa. Estes podem entreter, gracejar, mas também podem fornecer comentários sociais sobre aspetos importantes da realidade. Embora nem sempre reconhecidos como tal, os cartoons são um elemento-chave na comunicação política. Neste trabalho, investigamos os cartoons editoriais com potencial para a comunicação política e tomamolos como artefactos comunicativos capazes de melhorar a compreensão política e a reconceptualização de eventos, por meio de estruturas específicas de entendimento. Através da análise da tese de dois pesos e duas medidas, pela qual os cartunistas tendem a contrastar o desperdício maneirista e destrutivo da política com a eficiência intencional e constru- tiva das empresas (Morris, 1992:254), é nosso intuito avaliar se essa mesma tendência para a censura política e empresarial também recai sobre os cartoons políticos portugueses. Com base numa amostra não-representativa, procedemos a uma análise retórica de três cartoons políticos contemporâneos portugueses, em que as empresas tendem a ser associadas à ideia de objetivo e eficiência, enquanto que a política é retratada como uma atividade esbanjadora, fútil e desnecessária. Representando a política e as empresas de forma tão dissimilar, estes cartoons tendem a validar em Portugal a tese de dois pesos e duas medidas e levantam a possibilidade de que na verdade esta pode ser aplicada a contextos transnacionais.

Palavras-chave: cartoons políticos; tese de dois pesos e duas medidas; retórica visual; censura; comunicação política.

\section{INTRODUCTION}

A

$\mathrm{S}$ members of modern societies we are familiar with cartoons. From comics and graphic illustrations to the editorial cartoons found in most newspapers around the world, cartoons can amuse, make us laugh but also to provide social observations on key aspects of reality.

The first known political cartoon dates from 1360 BC in which Ikhnaton, the father in law of Tutankhamon, is lampooned. Rudimentary forms of political cartoons have also been found on Ancient Greek pottery depictions that ridicularized political leaders and lauded Olympian gods (Danjoux, 2007: 245). We also found scattered throughout the Roman Empire (for example, in Pompeii) many graphical inscriptions on walls mocking incompetent military 
commanders or public officials. The invention of the printing press marked a keystone on political cartoons since it led, in Renaissance Europe, to the emergence of the broadsheet (Danjoux, 2003: 245). Broadsheets were editorial loose-pages designed for a wide circulation. By offering readers a brief and simples account on current events, they were designed for mass consumption.

With the gradual incorporation of broadsheets in the 19th century American and European newspapers (Danjoux, 2003: 245), cartoonists were offered a solid professional life, a steady flow of income and a wide-ranging distribution, while accepting editorial scrutiny and production deadlines. As consequence, creativity was, by then, restricted to the serial production of graphical representations as artistic freedom fell under the influence of larger newspapers editors (Press, 1981: 44). Thus, as cartoonists conquered its own profession they became intellectual workers who were expected to consistently produce social satire.

Political cartoons are symbolic artistic illustrations making a witty or humorous point containing comments on social issues, events or personalities, typically (but not always) combining satire and hyperbole to question authority and social mores. A good definition is given by Edwards \& Winkler (1987): a "graphic presentation typically designed in a one-panel, non-continuing format to make an independent statement or observation on political events or social policy". In other words, the political cartoon can be defined as a satirical comment (using humor and caricature) about a political person, institution or event reflecting the cartoonist's own values and opinions on that issue. It is, hence, a subjective observation on a political matter.

Even if some authors distinguish between social comment cartoons and proper political cartoons within the editorial cartoon (Ashfaq \& Bin Hussein, 2013: 266), we will use "editorial cartoon" meaning both a social commentary visual representation and a strict political visual representation. We can distinguish two different types of editorial or political cartoon (we will use the terms interchangeably): the traditional visual-metaphor based cartoon; and a more recent text-heavy style cartoon. The types may overlap and are just useful if we see them as pedagogical and classificatory tools to an idealized form of cartoons. In our analysis we will deal specifically with the first type: a topical single-panel, single-column drawing, sometimes also referred as "pocket cartoons". In these cases, the political cartoon will usually have a subtitle 
and may comprehend some text. But its main effect comes from the visual representation. The text has in those cases an anchoring function providing a linguistic context to the drawing.

One of the most appealing factors on political cartoons lies in its seemingly innocent - sometimes subtle and refined - humor whose message can be easily assimilated. Because many times it is built under an entertainment aura, the cartoon can be embraced without much reflection or critical resistance (Walker, 2003: 16). And since its point can be (although not exclusively) visually apprehended and quickly transmitted, cartoons have a distinct persuasive dimension contributing to the emergence and development of political themes or cultural topics. It is this instantaneous message delivery as well as a sophisticated but fierce criticism that makes the political cartoon such a powerful communicative weapon. Nevertheless, cartoons' role is not always acknowledged as important. Since they are linked with humor, entertaining, comical effect, they tend to be an overlooked means of political communication. Contrariwise, they perform a prominent role on political communication (Walker, 2003: 16) and public opinion formation. Even if they apparently do not constitute a vehicle for political participation, the way it deconstructs social issues can have a vital effect on the public understanding of a political candidate or topic (cf. Rosa, 2012).

Political cartoons may generally be seen as source of distraction rather than information. Its "dissimulated" message that softens the impact force of the satire may, as well, hinder cartoon's effectiveness and does not guarantee the message's endorsement. However, cartoons may be an incredible source to access the political climate and instigate public opinion. Editorial cartoons gain momentum due to its optimal ambivalence. They are visual inscriptions of a particular time and ephemeral political situation that can surpass texts. This symbolic freedom can be of and incomparable advantage while putting the cartoons virtually into a meaning-spiral. Cartoons should, then, figure as graphic editorials, much more than mere illustrations to tickle public opinion.

In this paper, we investigate editorial cartoons potential to political communication and take them as communicative artifacts capable of enhancing political comprehension and recontextualization of events. Particularly, we survey the amplitude of editorial cartoons taken as a medium to political communication. In what sense, may we refer to them as elements of political 
communication? What is the nature of its ferocious denunciation and lampooning?

In order to start answering these complex and lengthy questions, we will concentrate in a common perspective advocated by some authors: the double standard thesis. Departing from the claim that editorial cartoons usually (Morris, 1992) depict positively business leaders as seriousness persons, while government officials are usually depicted negatively as foolish, we will look upon three different Portuguese political cartoons authored by three distinct cartoonists. Our focus will be to confirm, or not, this double standard thesis.

The main question is, thus, to determine if there are, in political cartoons, two separate frames to consider politicians and business persons (chairmans, CEO, business managers, bank leaders). More specifically, we want to know if the double standard thesis is easy to observe on trans-national European contexts or if it is an anglo-american feature of political cartoons. In that case, the double standard thesis could be seen not just as a possible frame to represent politics but the leading one.

Starting with a concise discussion about political cartoons' functions, this paper will address the double standard thesis before proceed to the analysis of three Portuguese political cartoons. The scrutiny will be rhetorical-informed and it will have a special focus on the role of humor in political cartoons.

\section{Political Cartoons' Framing Functions'}

One of the most comprehensive suggestions on the roles political cartoons may comprise is given by the classical paper of Medhurst and DeSousa (1982). They identify four main basic functions in social life dealing with entertainment, aggression-reduction, agenda-setting and framing. Political cartoons have generally speaking the ability to amuse and joke about personalities. At the same time, Medurst and DeSousa (1982) claim that political cartoons provide readers with a special kind of catharsis and mental purging that reduces social frustration and prevents the escalation of conflict. It is as if the symbolic discharge taking place in political cartoons could replace negative (emotional or physical) releases. In third place, political cartoons contribute to set the pace to agenda-setting. By satirically highlighting certain facts, events or personalities, they give substantial relevance that may follow or influence the public agenda. Political cartoons, in this case, would be key 
aspects of political communication because they help to create public awareness and concern of salient issues many times filtering and shaping them in ways that constitute the basis to public opinion formation. By emphasizing how political cartoons may shape reality, we are already insinuating the fourth function identified by Medhurst and Desousa (1982): framing. It is this feature we will be more attentive in the analysis of Portuguese editorial cartoons.

Political cartoons provide specific frames about certain issues in a specific time or place. The "frame" denotes how something is presented to and impacts the choices people make about how to process that information. Framing is related to the agenda-setting theory but expands the research by focusing on the essence of the issues rather than on a particular topic. In this sense, it is a second-level agenda-setting. In other words, political cartoons put events within a field of meaning. We call "frames" to those cognitive structures that work to organize or structure message meaning that lead the public in a certain direction. Frames guide our perception towards a specific interpretation. Political cartoons offer frameworks under which readers can examine, approach and evaluate the political life of a society. By portraying selected aspects of a perceived political reality, they promote particular problem definitions, causal interpretation and moral evaluation (Entman, 1993).

Political cartoons' framing has to do with mediation, that is, how media connect with society and are able to produce meaningful discourse about common reality. In fact, media may be said to mediate between public policy and social discourse by feeding public opinion information that may incorporate anticipated needs or motives of diverse social (public and private) institutions. "Cartoons «frame» phenomena by situating the «problem» in question within the context of everyday life and, in this way, exploit «universal values» as means of persuading readers to identify with an image and its intended message" (Greenberg, 2002: 182). Indeed, political cartoons' framing works when they offer condensed claims about putative problems or disorders that draw upon or reinforce taken-for granted meanings.

This means that by working upon taken-for granted meaning, political cartoons will be more persuasive with people sharing the same social, historical, political or economic circumstances (Greenberg, 2002: 183). Moreover, since they operate as frames for the organization of social knowledge, they are 
particularly subject to ideological appropriation for what renders political life intelligible.

At this point we should bring to the discussion the double standard thesis since it constitutes a singular frame to apprehend a multitude of aspects related to political life. If we accept political cartoons' framing function may supply fundamental clues to the preferred meanings in a society, we must envisage the double standard thesis as a specific frame to apprehend two different sets of social actors: politicians and business managers. Without considering its framing operations, the double standard thesis would not last as a self-sufficient and solid interpretative hypothesis to explain political representation of editorial cartoons. The linking political cartoons' framing with the double standard thesis may have important consequences since they function as mental frameworks. The double standard thesis, seen at this light, could impact the way cartoons historicize the present and build the social imagination (cf. Edwards \& Winkler, 1997: 8). By dividing political life in a dual (positive-negative) perspective, the double standard thesis could possible impair public understanding and hinder the complexities involved in political life. This would mean public opinion would be exposed to a deeply simplified view of political problems and a stereotypical description of personalities. This is even more significant given that cartoons can promote the symbols of national consensus while conveying values, attitudes and beliefs (Cahn, 1984).

If we accept the framing may elicit a culture-creating or culture-maintaining process, the confirmation of the double standard thesis would have a tremendous effect on those small steps of creation, reproduction and mediation of a political public culture. These claims would be illustrative of whether a specific society would see itself as a homogeneous collective of different social actors or a fractured, dispersed and splintered collection of different social groups battling each other.

\section{The Double Standard Thesis}

Aesop once wrote a fable named "The Ass and the Lapdog" (Jacob's translation, 1894):

«A Farmer one day came to the stables to see to his beasts of burden: among them was his favourite Ass, that was always well fed and often carried his master. With the Farmer came his Lapdog, 
who danced about and licked his hand and frisked about as happy as could be. The Farmer felt in his pocket, gave the Lapdog some dainty food, and sat down while he gave his orders to his servants. The Lapdog jumped into his master's lap, and lay there blinking while the Farmer stroked his ears. The Ass, seeing this, broke loose from his halter and commenced prancing about in imitation of the Lapdog. The Farmer could not hold his sides with laughter, so the Ass went up to him, and putting his feet upon the Farmer's shoulder attempted to climb into his lap. The Farmer's servants rushed up with sticks and pitchforks and soon taught the Ass that Clumsy jesting is no joke.»

This latin fable contains a moral dictum: it is foolish one to be something that he is not. But, at the same time, this allegory entails also a double standard since the farmer did not treat two domestic animals in the same way. Because the Ass saw himself as having the same rights as the lapdog, he could not figure that the farmer would rush him up with sticks at the moment he tried to imitate the lapdog. However, given the farmer's double standard to farm animals it was just that that occurred. In this case, two similar beings (two four-legged farm animals) in the same situation were dealt in a distinct manner.

A double standard is the application of diverse sets of principles for two or more similar situations. It can be described as a biased or morally unfair view of the principle that all are equal. In some respects, it describes an imperfect assessment of a phenomenon by dealing differently with the same kind of occurrences. Double standards violate the impartiality principle in which the same standard should be exactly applied to all people without regard to prejudice or favoritism based on social class, rank, ethnicity, gender, religion, sexual orientations, age, etc.

The double standard resembles the classic locus: "Quod licet Iovi, non licet bovi" (literally "What is permissible for Jove is not permissible for an ox"). It indicates the existence of a double standard (will it be defensible or nor) that ultimately means: "what is acceptable to one person or group is not permitted to everyone".

The application of the double standard thesis to the political cartoons studies was put forth by Raymond Morris in a book called Behind the jester's 
mask (1989) to describe the dissimilar modes Canadian cartoonists contrasted the posturing, destructive, wastage of politics with the purposive, constructive efficiency of business (Morris, 1992: 254). He concluded that cartooning misrepresented politics and business as well-balanced rivals (Morris, 1989: 167-169) simplifying the interchange between them, their mutual dependency and masking the nature of their activities. Morris claimed that both politics and business were mocked in very divergent ways masking possible overlaps between them. In accordance with Morris, Walker (2003: 16) advocated that "political cartoons are a resource of the dominant, not the minority, and serve to reinforce the opinions of the media ownership and the dominant in society". Although she does not deepen how is that obtained, nor works upon the framing theory, she confirms in her own research that the only exceptions she has found to the double standard thesis in political cartoons were cases of extreme corporate greed or scandal (ex: Enron) (Walker, 2003: 18).

These two Canadian authors stress that business is not normally shown as deviant unlike politics who are traditionally object of great lampooning. This may be related to the economic ties of newspapers to major business companies buying their advertising space. One possible explanation has to do the dependence of editorial cartoons to editorial pressure and the need newspapers have to attract revenues from the business industry. This means that Canadian contemporary newspapers developed a double, yet very different, activity towards differences social groups: by one hand, the newspapers continue their historical role as critics of public policies and politic personalities; on the other hand, the newspaper tend to adopt a reverential attitude to business stressing the role of economy on the country's development. In the first case, they tend to satirize negatively politics, while in the second case, they tend to adopt a more conservative, a-critical, prudent approach to business.

This double attitude towards politics and business has a great importance and should be investigated given that cartoonists are expected, since the 19th century, to publicly criticize politics. One could expect this role - comparable to the role of journalists as watchdogs asking accountability from the politicians - would be extended to other domains associated with political life such as business and the lobby effect it has on public policies. Maybe one of the reasons this is not occurring in Canadian political cartoons has to do with the commodification of the news and the press discourse which pushes them 
not to confront, criticize or conflict business corporations (that are in today's economic role of newspapers, the major patron).

In the section following the methodological considerations, we question the nature of the double standard thesis on political cartoons.

\section{Methodological Considerations}

The following analysis will be taken, not as a textuality approach of the political cartoon discourse, but mainly as a visual discourse approach. This means we will not offer grounded views on reader's response to them or speculate what such responses would be. We do not undertake an audience reception study but an exam of the visual discourse contained in the political cartoon. So, we will be offering some possible interpretations to the political meaning of the cartoons but they are only possible ones. Then, we look to these three examples from a double standard standpoint.

The sparse selection of the Portuguese political cartoons does not configure a representative sample, so we cannot extrapolate that every Portuguese political cartoons present these same tendency, to work upon or reject, the double standard. It is clear that three examples do not exhaust all the diversity of political cartoon in Portugal. Nonetheless, each cartoon gives us important orientations to assess the social-political climate and offer crucial clues to the framing of politics and business.

Moreover, the political cartoons were not randomly selected. Instead, they correspond to the following criteria: political cartoons are authored by Portuguese cartoonists; they exemplify the artistic and graphical satire style of each of the cartoonists; its main theme is politics and business; they were published as editorial cartoons either in press, either in online Portuguese portals. They do not figure only in the personal gallery of the cartoonist but were indeed object of publication by major Portuguese newspapers (written and online).

The analysis will be informed by two methodological lines. By one hand, a pragmatical approach to the cartoon given that to literally understand a cartoon is very different of "getting it". One can apprehend the graphic forms, give them a meaning, and even so, one could not be able to situate it in the appropriate socio-political context. Without the ability to make correct inferences on the sense of the cartoon, readers could feel confused in how to give meaning to that representation. For example, one can identify a blue flag 
containing a circle of dozens of yellow stars and a woman pushing it. But without the awareness of a social context, political situation, and personalities involved, the cartoon may just be a funny drawing. To emerge as a political cartoon, the reader should relate the drawing to concepts and apply a correct pragmatic framework in order to infer the meaning intended by the cartoonist.

$\mathrm{Bu}$ other hand, we will also undertake a rhetorical approach to the political cartoons analysis. There are two main reasons for this.

First, cartoons assist in defining the significant issues that in each time are object of public scrutiny and debate. They have an intrinsic rhetorical nature because they can be seen as argumentative artifacts visually (and many times textually) dealing with discussion of the current political events or personalities. In fact, most authors agree that the rhetoric of political cartoons contain elements of both visuocentric (visually based) or logocentric (language-based) rhetoric (Matthews, 2011: 12). In this paper, we take a visual rhetoric perspective assuming both logocentric and visuocentric methods and dealing with visual metaphors, symbols and other rhetorical elements. We also adopt the methodological approach of Morris (1993: 199-202) concentrating in four rhetorical devices that affect the contents, intended and negotiated meanings of political cartoons. First, condensation denoting a juxtaposition of disconnected (sometimes) unrelated events to a common singular frame (Football's European Cup and the Migrants, for example). Second, combination denotes the organizations of various elements of different domains with different and perhaps conflicting meanings (ex: a student giving a less to the teacher). Third, opposition involves the reduction of a complex issue to a binary struggle between two parties (ex: ideological conflict between political party's reduced to the combat between its leaders). Finally, domestication occurs when events remote to everyday life of the reader are translated into concrete happenings that can be experienced as close and familiar (ex: the political leader preaching in the market as a visual metaphor to the need he as to "sell" his ideas).

Although we will not be specifically detailing Morris' four rhetorical devices, they will be present in the current analysis of the double standard thesis in Portuguese political cartoons. 


\section{Analysis of Humorous Political Cartoons}

Humor may be considered a journalistic tool comparable to the editorial column (Rosa, 2012: 736) by which opinion are expressed and judgments are stated that not strictly obey to the objectivity standard governing journalism.

The political cartoons examined all encompass a humoristic frame to seize the political and economic events they represent. Hence, these cartoons are valuable resources to study how, in Portugal, the Financial and Economic Crisis (knows as "A Crise" or "The Crisis") was evaluated and how political and business personalities, above all, bank leaders, were represented. The humor is, in these cases, a vehicle to frame political and financial events.

By treating serious issues with an apparent levity and indiscretion, the humoristic political cartoons we scrutinize exemplify how political communication can be operated multi-dimensionally. But, probably what is most prominent is that humor may give represent cultural attitudes and shared beliefs in a vernacular, direct and unpretentious way. One of its central characteristics has to do with its capacity to attract readers that are not able to participate in political debate on the sophisticated level taken by hard-news. In fact, political cartoons only entail a "minimum cognitive strain" (Giarelli, 2006: 74) by being summarized in mini-narratives and idealizations, implement rhetorical devices that simplify the presentation of points of view and delivering its content in a matter of seconds (in contrast with the reading of a lengthy newspaper article).

\section{BPN - New Season by ANTónio Jorge GonÇALVES}

This political cartoon was published in April, 7th 2014 in Inimigo Público (a weekly humor supplement in Público newspaper). It shows the President of the Portuguese Republic, Dr. Anibal Cavaco Silva, the President of Portugal National Bank, Dr. Vitor Constâncio and the President of the European Commission, Dr. Durão Barroso, at the time, wearing fashionable clothes and in feminine poses in a way we can associate with poster of television fiction series. In the upper left side, we read "That's life" in a clear allusion to the television broadcaster "Fox Life" (same lettering). In the title figures: "BPNNew season", the second literal reference to a television show. It must be said the P stand out in italic perhaps pointing to the first letter of "Portugal". 
To understand this cartoon, one has to contextualize it in the proper political-economical setting since "to decode the cartoon, one must be somewhat familiar with the literary and cultural source to which it refers" (Medhurst and DeSousa, 1981: 201).

At the time, public agenda was marked by the collapse of BPN (Banco Português de Negócios), a private bank who was nationalized following the criminal investigation that brought allegations of corruption, money laundry and influence peddling. Every media was insistently covering this case and helped to give it a great impact on Portuguese society. The discussion revolved around the adequacy of public intervention (and money) on a private bank.

At a symbolically level, António Jorge Gonçalves chose to portrait the feminine version of Dr. Durão Barroso with a dress with the pattern of European Union flag. Even if the cartoon's reader in order to apprehend it, had to recognize the other two major figures of political life, he had not to know the President of European Commission since the dress symbolically refers to it. The tone is obviously a satirical one. But, in this case, the political satire does not imply any depreciation of these particular political persons. The cartoon is, on the contrary, oriented to the BPN case and the impact it had on Public Opinion. Dressing men in women's clothes seems to have the purpose to build an allusion television fiction series' glamour and drama. It puts political and Economic actors as Fiction actors. They are represented as the main characters of this "season". The cartoon, hence, uses the humor to establish a parallel between the development of BPN case and the development of a television series as if one could follow the evolution of the events as a plot segmented in several episodes. The point of the cartoon seems to be exactly that: asserting the way the BPN was being conducted as a kind of soap-opera or drama in which the citizen/spectator could not envisage its end. We can extend the analogy and say that António Jorge Gonçalves is exploring the BPN case as having a similar nature of many television series with bizarre characters, intrigues, tragedy and twists. The "New Season" mention in the title only corroborates the temporal line it wants to stress: indeed, the BPN collapse had many surprises and unforeseen happenings as the hearings in the Commission of the National Assembly were taken place.

The main rhetorical device used to deliver its point is condensation. In fact, this cartoons differentiates itself by the juxtaposition of two separate universes: the political one and the fictional one. By putting political persons on 
the realm of a television show it merges the non-factual world with the factual one. The objective may be to imply that BPN collapse was being dealt in such a way that it was not far from many fictional stories we encounter in television series. This coincides exactly with the description Morris (1993: 199-202) gave of condensation: a combination of detached elements within a common singular frame. In this particular case, the frame used points to the entertainment industry and puts humorously the seriousness of political life in the frame of a comedy-drama series (Desperate Housewifes' style $A B C, 2004)$. A particular use of condensation lies in the intertextuality of the political cartoons (cf. Werner, 2004). BPN-new season borrows from prior visual texts and the reader has to interpret the cartoon as this light (in this case, through not against). The political cartoon mirrors the poses of many fashion models (looking the other way, raised foot, hands in hips) as well as the spatial organization of modern television series. The television show gives the cartoon its cultural background and situate the politicians according to the stereotype of comedy-drama characters and events.

The rhetorical condensation here present has a major feature: it incorporates political culture into popular culture facilitating the connection of disinterested citizens with politics. They do not expect to see politics tied to particular television shows but the unexpectedness may get their attention (Conners, 2007: 262). This may be accidental to António Jorge Gonçalves but creates a familiarity that enables an instant connection to the audience while cuts with the conventional dry discourse on politics. The cartoonist could state his opinion using distinguishing words. But by using visual rhetorical to transmit his message he is able to more easily make an allusion to popular mass culture. He uses images that linger because they resonate familiar and well-known ideas. Withdrawing from heavy verbiage, the image of the cartoons is organized following the television image. Condensation is, then, a rhetorical tool to reach readers in political cartoons. More exactly, the condensation forms a special kind of allusion to popular culture and fictional characters. The effect it to pass a message that is simple and visually based.

The prime value to frame politics according to popular culture is helping readers relating to the issues at debate on a given time. And that's why we have so much examples of this intersection between political culture and popular culture. 
Additionally, we can observe BPN-New Season trying to answer the question: do we have here an example of the double standard thesis?

A short reply could be: no and yes. Given the rhetorical effect of condensation and the intersection with popular culture, the particular politicians here represented are nor depreciated, mocked or scorned. What, above all, seem to be ridicularized is the political process itself and the way it develops in Portuguese society. It is politics (the political process) that is lampooned. Since the main focus of the political cartoons is the BPN collapse, the analogy to television series is between politics and entertainment, not between these particular personalities and entertainment. Given the allusion to popular culture, this political cartoon is not arguing these persons are in fault or were incapable of something. Instead, it makes a general comparison between two different domains of experience and, in doing so, it begins to bring close citizens and politics. In some sense, this cartoons performs, via rhetorics, a kind of translation of Portuguese political life.

Even if we take Dr. Vitor Constâncio as representing bankers (and by extension business men), we cannot establish that politics and business is being treated separately. In fact, political persons (Dr. Cavaco Silva and Dr. Durão Barroso) and Economy persons (Dr. Vitor Constâncio) are represented exactly in the same way. They are part of a condensation strategy mixing political culture and popular culture. They are in this together. There is no discrimination in the representations cartoonist does about politicians and business men.

By other hand, some might object that Dr. Cavaco Silva, Dr. Vitor Constâncio e Dr. Durão Barroso are key participants in the whole case of BPN's nationalization and the political process. In this case, if we abstract from politics and personalize those political characters, we can say that these particular politicians are being mocked through a comparison to women television stars. According to this interpretation, we are here facing an example of the double standard thesis where politicians are mocked (including Dr. Vitor Constâncio, that as president of National Portuguese Bank has a mixed role between Economy and Politics).

In sum, the double standard thesis, in this case, can be determined if we concentrate the analysis on the personal traits of these personalities. Politics is being compared to popular culture in a depreciation way. To some, this is the proof of negative despising representation of politicians. But for others, 
including us, this is just an efficient display of rhetorical condensations that, in itself, is not a bad thing.

So, the double standard thesis has, in this case, a double nature: if take the focus of the political cartoon to be the fusion of politics and popular culture we do not encounter it. But if we focus the analysis in these particular political persons, then, we must conclude that politicians are portrayed in a not-dignified, negative, adverse way. In so doing, the political cartoon confirms the concept of the double standard thesis.

\section{FMI prepares Portugal for a Meal By RODRIGO DE MATOS}

Published in January, 11th 2011 in the weekly national newspaper "Expresso", FMI ${ }^{1}$ prepares Portugal for a Meal political cartoon shows a glutton person, at a table, ready to starting eating a plate of salad, potatoes and a Portuguese man ("campino"). The knife and forks are at the plate's side. Attending to the symbols, we can apprehend that the gourmand represents the International Monetary Fund (IMF) putting some spice (money) in this appetizing meal that represents Portugal. By a series of visual metaphors, the cartoonist Rodrigo de Matos transmits the message that not just IMF is eager to eat, it starving (consider the tongue out of the mouth), but that will "eat" Portugal. This metaphor of eating is not without importance since the act implies a process of integration in one own body. This idea of integration or processing is key to understand the cartoon and may be read as an allusion to the dependency of Portugal to the IMF as if the International Monetary Fund absorbed the whole country.

The context is the 2011 financial intervention of the European Troika in Portugal. It pointed to the weight of the IMF in the country while it foretold what would be announced later in April. The European troika is the designation of the triumvirate representing the European Union (EU), the European Central Bank (ECB) and the International Monetary Fund (IMF). In April, 6th 2011, the Prime-Minister of Portugal, Dr. José Sócrates, announced the country would be object of a financial rescue by Troika after many years of structural deficit and successive increases in the interest rate of the loans to the market. The Troika, led by the International Monetary Fund, lent 78 billions

1. FMI stands for "Fundo Monetário Internacional", the portuguese initials to the IMF (International Monetary Fund). 
Euros to Portugal. Media newspapers covered the event with close attention and the whole new political-economical-financial context was name as "the Crisis".

The political cartoon was created in this time of "Crisis": unemployment rose, the salaries had decreased, PIB and exportations had retreated, and citizens did not know what to expect. Their trust in a prosper future had become just a hope. The public opinion climate was of apprehension and doubt, and it is this sentiment of incertitude that the cartoonist alludes to. The political cartoon's message reflects this attitude of vulnerability to the IMF and the idea Portugal was a country heavily dependent on the Troika's will. Since Portugal was condemned to follow the recommendations of IMF in order to keep receiving money to sustain the Portuguese State, public opinion at the time felt as entrapped or at the mercy of the whims of IMF. FMI prepares Portugal for a Meal exactly translates these worries to a graphic satire emphasizing the discomfort of Portugal and the satisfaction of the IMF with this situation (we must not forget the interest rates involved in the Troika's loan).

The symbols used are manifold and help to transmit the intended message. Hence, the cartoon present the dollar sign to indicate currency is involved in this process. It is the money over Portugal that, ultimately, will season the meal and satisfy the eager IMF. Another symbol present in the representation of Portugal is the "campino", the Portuguese peasant wearing the traditional green and red barrette ["barrete, in Portuguese]. The plate where the "campino" lies has also the inscription "Portugal" just to strengthen the association to the country. The IMF is represented by a large man in a dark suit with tie and top hat containing the initials IMF. The top hat and tie also indicates a relation to Business and Management since business men tend to be represented in that way. So, in this political cartoon are not the politicians that are framed but especially the bankers and financial organizations such as IMF.

The thesis of the political cartoons has to do with the public sentiment of impotency and vulnerability Portuguese public opinion felt about Troika and IMF. It may be stated as: "Portugal is vulnerable to IMF and will be totally incorporated in IMF 's will". It reinforces the negativity and embarrassment Portuguese citizen felt towards Troika's intervention and the power IMF had in the orientations of public policies. Public opinion somewhat felt overwhelmed by the influence of IMF in political decisions as well as surprised by the effect of financial organizations had in the political organization of Portugal. 
The tone is clearly satirical and comic. In fact, humor is a central aspect of this cartoon and it reiterates the common perception of the IMF intervention in Portugal as nefarious. Humor's tendency is to reinforce and strengthen already extant attitudes rather than change those attitudes (Gruner apud Anderson, 2007: 33). This capacity to support a public sentiment and to visually depict it is paramount in the effort to build a community sense. The political cartoon emphasizes unity by putting external organization as a threat to Portugal. Instead of contributing to ego-development, it sharpens Portuguese collective conscience to the effects of IMF may have in everyday life. It is as if there was an outside world and a foreign agenda that must be perceived in order to Portugal not become a victim and get eaten. The humor turns the political cartoons more persuasive in its message (Anderson, 2007: 28). It "shows" something that can be subtle and difficult to establish at first sight: the potential costs of the financial dependency to IMF.

The main rhetorical device here is, thus, domestication: the translation of distant events to concrete happenings of everyday experience. Hence, the political cartoon authored by Rodrigo de Matos frames the financial rescue of Portugal and its possible consequences in familiar terms. It represents them as meal where Portugal is the main-course. The country is not the main guest but the food that IMF will savor. It puts a complex political-economicalfinancial operation in a simpler frame: that of everyday meals. A frequent, tangible and acquainted action becomes visually the conceptual basis to think a very intricate process of financial rescue. The multiple consequences in the citizen's life (inflation, loss of revenues, etc) are, thus, synthetized in the act of eating someone.

In what respect can we attribute the double standard thesis in this case? If we take IMF as a symbol of Finances and Business (represented with suit, tie and top hat just as traditionally business man are portrayed) we can be in the presence of the confirmation of this double standard. There are no politicians involved in the cartoon but the IMF is nor ridiculed or mocked. Contrariwise, he is in the top of the situation, dominating the activity, being the one who benefits from it. It is represented as successful (look into the round, fat figure) perhaps because it is used to "eat" (intervene in) whole countries. So, if we take IMF as a distant insinuation to business men we see that the political cartoon does not represent business and financial organizations as vicious but as prosperous. It has a positive attitude towards it. In this sense, the double 
standard is confirmed by putting a financial institution on the upper-hand. This is in accordance with the first analyzed political cartoon where politicians are denigrated. So, once more, and despite being a political cartoon authored by a different person, it seems the double standard remains embedded in the way cartoonists see political reality.

\section{Mr. Mllionaire, Would you get me some coins to face the CRISIS? BY HENRIQUE MONTEIRO}

Henrique Monteiro's The Richest first appeared in Sapo Notícias, a news web portal in August, 25 ${ }^{\text {th }}, 2011$ and is since then available in the personal website of the cartoonist. It depicts a gigantic man wearing a suit and top hat while he smokes an also gigantic cigar. The huge man has a hand in his pocket and the other in his ear. He is bent over himself trying to hear a very small and tiny man that is looking upwards. Portuguese readers are able to relate this small man symbolically with the Portuguese people because it resembles Zé Povinho: the Portuguese everyman created in 1875 by Rafael Bordalo Pinheiro. He became first a symbol of the Portuguese working-class people, and eventually an unofficial personification of Portugal. The political cartoon has a subtitle explaining what the giant is saying: "what? I cannot hear anything from here". It is clear we facing the representation of miscommunication event, or at least, an act of difficult comprehension due to the great disproportion between those figures.

Symbolically we trace the cartoon to a face-off between the people (alluded by a figure closely associated with Zé Povinho) and the business/economical elite, this is, rich men (alluded by the man in a top hat and cigar). What we see is the imbalance between citizens and business men heights that may be symbolically represent the inequality between rich and poor. There's clearly a gap between them and the millionaire seem to be not in the mood to help. The utterance sounds as an excuse not to help. Or it can be just an honest answer since the difference of the way they both feel the "crisis" time. Given the context of external financial intervention of the European Troika, this political cartoon can be said to satirize the whole different perspective on the crisis felt by the business elite and the common, everyday people. It is as if business people where so distant of the economic difficulties of the people that almost could not sense it. This is symbolically given by the struggle to ear 
the demand of the Portuguese people. So, this is a political cartoon that can better be apprehended by Portuguese readers, especially those that have lived in those trouble political-economic times and that are able to identify with it.

The main focus of Henrique Monteiro's seems to draw attention to disparity between rich and poor and how European Troika had different effects on the business men and on the laymen. The frame is given by the dissimilarity between rich and poor, more exactly, how the same political-economical context was experienced in very dissimilar ways: business and bank elite had not trouble in it continuing to dispose of money to pursue their objectives, while the layperson was facing serious distresses to keep the life he had before of the so called "crises" and the external intervention of IFM and other institutions in Portugal.

The thesis or main point of this political cartoon lies precisely in here: the discrepancy of the consequences experienced between the business men and the common layperson: the rich man is represented as a tall person, untouchable by the crisis, having difficulties to empathize with the common, tiny people. So, there is a fierce critique in this cartoon concerning not just the different experience of the "Crisis", but also the attitude of millionaires regarding the neediest. Note that the millionaire is apparently depicted as continuing with his life as always, smoking the customary cigar. More, it seems the cartoons criticizes the business men attitude given that the tall, gigantic figure keeps his hand deep in his pocket. If it is to retain his money or nor to share it with the people, we do not know. All we see is that hands are kept on pockets. In the case of the Zé Povinho related figure he is also with his hand inside the pockets. But in this case we may argue contrariwise: it is because he has not job, nothing to do, nor any money left with him that he has his hands put away.

The rhetorical device in here is opposition. Henrique Monteiro's reduces the social complexity involved in the disparity between rich and poor to a conflicting occurrence where one does not seem to be understood by the other. We face, thus, a binary hostility between the Portuguese people's will to survive this special period of "crisis", and the rich men almost indifference to that struggle. All the inequalities between those two socio-economical statuses are here reduced to an economical or financial one.

Can we identify in this political cartoon the double standard thesis? Regarding how it depicts business men by being not affected by the crisis in the 
same way it affected the Portuguese people, we see that the double standard is validated. In this case, business and bank men are portrayed as being in a good, comfortable position. They still wear the suit and smoke the cigar. Nonetheless, morally they are highly satirized since the tall business figure respond with triviality to the people's demands. They are represented on the pedestal - confirming the double standard thesis - but in this case stand higher than the rest may mean a difficult to help those in need. There is, thus, a critique to the egoistical attitude: by being distant form the "crisis" business rich men do not relate to the common person and his struggle.

So, once again it can be said we are in the presence of the double standard thesis: in this case, politicians are nor negatively portrait but the business elite is depicted as being in control of the situation, on top, and having the upper hand.

It is not a straight confirmation of the double standard but we can see how rich men (visually associated with business men) are portrayed as dominant. Just like Morris advocated, it seems that both politics and business are represented in opposing ways.

\section{CONCLUSion}

The three examples of Portuguese political cartoons examined represent politic life and business life in heterogeneous terms. Even if each one works upon a specific rhetorical device (either condensation, domestication or opposition), the three have all in common the different treatment given to politicians and business, financial men despite the different frames they apply.

In the first cartoon authored by António Jorge Gonçalves, politicians are derided and compared to a television diva: as famous and successful women who are very attractive and fashionable. So, it confirms the wastage of politics and the wasteful use of something valuable: political power. It, thus, relates politics to something not just futile but also as vain. Each politician is described in vanity terms, interested in his appearance, not so much in BPN case. So, political activity is mocked as fruitless or unavailing.

In the IMF political cartoon authored by Rodrigo de Matos, we testify to the clear representation of the constructive efficiency of business (Morris, 1992: 2549. It is that proficiency that puts Portugal in a bad situation or in metaphorically terms, as a tempting meal. Business here refers to committed 
functioning of IMF and how money and finances may threat a country's way of life. So, taking the IMF as symbol of business endeavors we conclude that this second Portuguese political cartoon tend to reiterate the double standard thesis by highlighting the purposive effectiveness of business. In this case, it is represented as ruthless and focused, fulfilling a conscious objective. In the cartoon authored by Henrique Monteiro, we also confirm this tendency to depict business in hard-hearted and merciless terms as if business life was too distant from everyday life and could not listen or care for the common person.Deepening the analysis, we said that business is, in this case, showed as arrogant and incapable (or at least having much difficulty) of attending to the fragile situation the Portuguese people experienced. In the last two political cartoon we see how business is associated with purpose and efficiency, while in the first cartoon, politics is obviously given as an ineffective, otiose activity. Taking the three examples together we may say that it seems there is, at least, a tendency in Portuguese cartoons, to reiterate the double standard thesis.

As a whole, these three random examples present divergent ways to frame politics and business. This is very interesting since what was observed in a Canadian context, seems to be also plausible in the European, Portuguese context. But most importantly, the analysis seems to indicate that the double standard thesis can be actually applied to trans-national contexts. This means that the framing of politics and business may not be limited to one country but may reflect a political world-view occurring in contemporary societies. From the double standard standpoint, there are no fundamental differences in the way Canadian political cartoonists and Portuguese political cartoons assess politics and business life.

What this paper does, even if it alludes to it, is not to absolutely confirm the hypothesis the double standard thesis to be just one frame among possible others, or, as an alternative, if the double standard thesis is the main frames to represent an oppositional view on politics and business. Only further research can absolutely claim any of this possibilities. Our aim had not an empirical focus even if subsequent works may well fulfill this gap.

Nonetheless, by the analysis developed in this paper, we are inclined to posit that the double standard thesis is one of the main frames political cartoonist employ today. It functions as a rhetorical topos enabling an easy assimilation of two intricate and dynamic fields of activity. We saw how politicians, banker and business men are frequent characters in political cartoons. The way 
they tend to be represented points to this very real possibility of the double standard thesis be a frame wide-applied that performs a rhetorical function of providing a stable set of social meanings to apprehend two very different activities such as politics and business.

Of course, this sample is not representative of all the Portuguese production in political cartoons. Only subsequent studies on this subject would give us a full comprehension of this dialectical relation. But, by studying Portuguese political cartoons, we already put ourselves on the right tracks to evaluate this multifaceted problem.

This paper is giving us important clues to the framing operations, visual rhetorical devices and the kind of humor used in Portugal. These three aspects are crucial indications to the validation of the double standard thesis in other countries. Consequently, this paper opens the path to determine is the double standard thesis is one of the preferential framings to represent political, economic and social reality.

So, the double standard thesis dealing with an effective view of business and wasteful view of politics are a concrete possibility to consider regarding Portuguese political cartoons and may be a serious possibility to assume the place of one of the most frequent frames in political cartoons world-wide.

\section{BibliographicAl REFERENCES}

Anderson, M. C. P. (2007). A theory of rhetorical humor in american political siscourse. Phd thesis. University of Maryland.

Ashfaq, A. \& Bin Hussein, A. (2013). Political cartoonists versus readers: role of political cartoonists in building public opinion and readers' expectations towards print media cartoons in Pakistan. Mediterranean Journal of Social Sciences, 4(3): 265-272. DOI: 10.5901/mjss.2013.v4n3p265.

Cahn, D. (1984). The political cartoon as communication. Media Development, 4: 39-42.

Conners, J. L. (2007). Popular culture in political cartoons: analyzing cartoonist approaches. PS: Political Science \& Politics, 40(02): 261-265. DOI: 10.1017/S1049096507070400.

Danjoux, I. (2007). Reconsidering the decline of the editorial cartoon. PS: Political Science and Politics: 245-248. DOI: 10.1017/S1049096507070370. 
De Sousa, M. A. \& Medhurst, M. J. (1982). Political cartoons and american culture: significant symbols of campaign 1980. Studies in Visual Communication, 8: 84-97.

Entman, R. M. (1993). Framing: toward clarification of a fractured paradigm. Journal of Communication, 43(4): 51.

Giarelli, E. (2006). Images of cloning and stem cell research in editorial cartoons in the United States. Qualitative Health Research, 16(1): 61-78.

Greenberg, J. (2002). Framing and temporality in political cartoons: a critical analysis of visual news discourse. Canadian Review of Sociology and Anthropology, 39(2): 181-198.

Matthews, C. A. (2011). Witticism of transition: humor and rhetoric of editorial cartoons on journalism. MA thesis. University of MissouriColumbia.

Medhurst, M. J. \& DeSousa, M. A. (1981). Political cartoons as rhetorical forms: a taxonomy of graphic discourse. Communication Monographs.

Morris, R. N. (1989). Behind the jester's mask. Toronto: University of Toronto Press.

Morris, R. (1992). Cartoons and the political system: Canada, Quebec, Wales and England. Canadian Journal of Communication, 17(2): 253-258.

Morris, R. (1993). Visual rhetoric in political cartoons: a structuralist approach. Metaphor and Symbolic Activity, 8(3): 195-210.

Press, C. (1981). The political cartoon. Madison, NJ: Fairleigh Dickinson University Press.

Rosa, G. P. (2012). The swine flu pandemics in Portugal through newspaper humour. Journalism and Mass Communication, 2(7): 735-747. ISSN 2160-6579.

Walker, R. (2003). Political cartoons: now you see them!. Canadian Parliamentary Review: 16-21.

Werner, W. (2004). On political cartoons and social studies textbooks: visual analogies, intertextuality and cultural memory. Canadian Social Studies, $38(2)$. 


\section{Annexes}

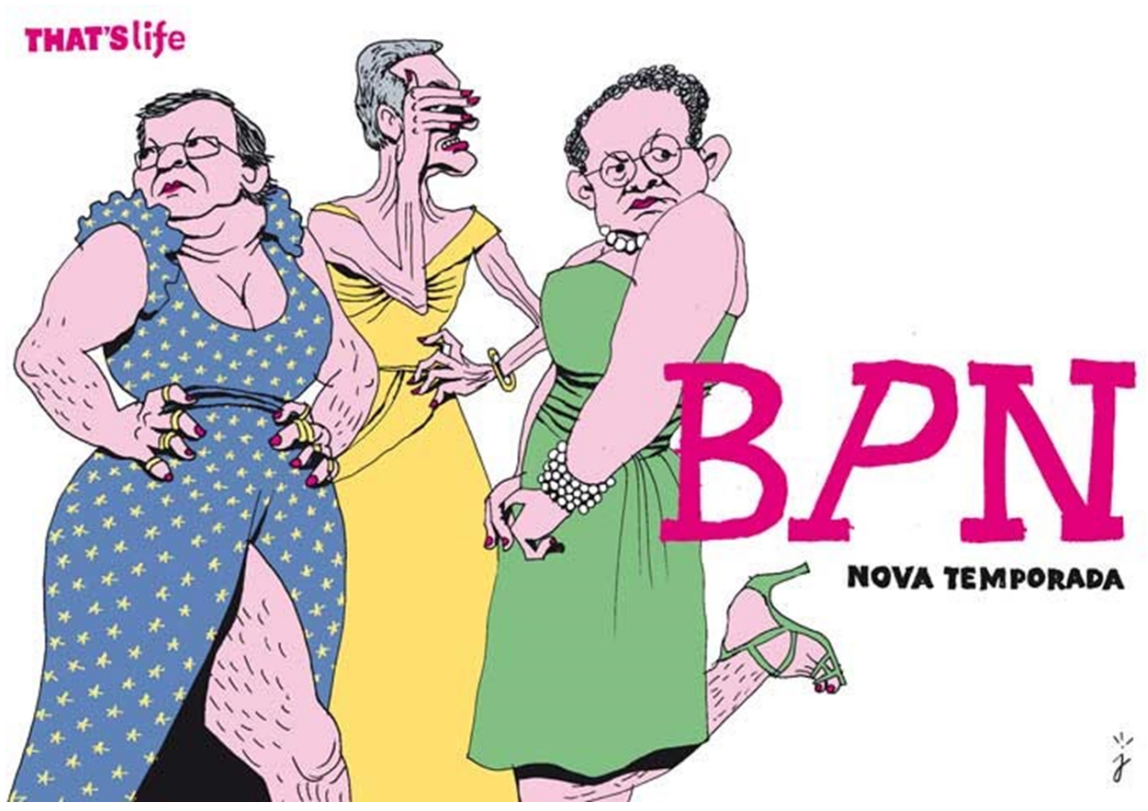

Cartoon 1. António Jorge Gonçalves, "BPN- nova temporada" (BPN-New Season), Inimigo Público, 7 de Abril de 2014;

www.antoniojorgegoncalves.com/archives/3594 


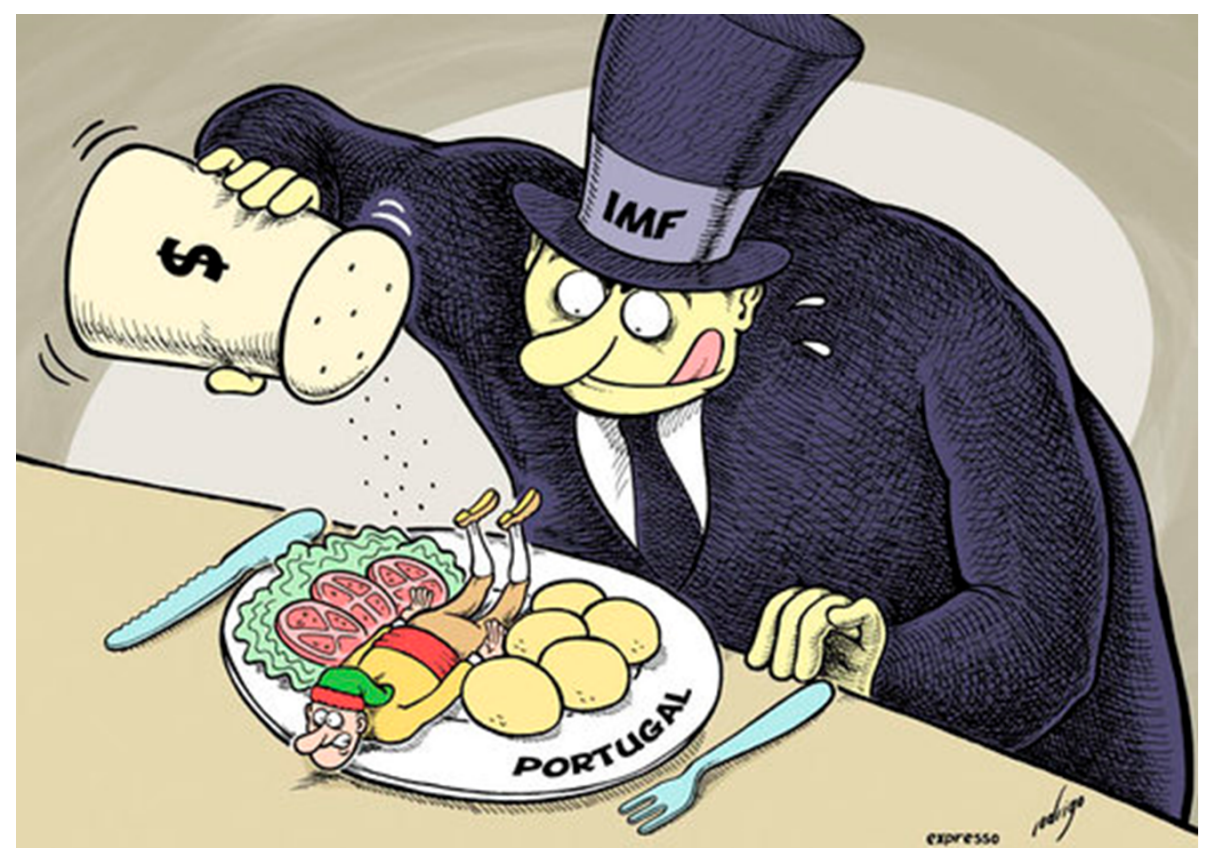

Cartoon 2. Rodrigo de Matos, FMI prepares Portugal for a Meal, Semanário Expresso, 11 de Janeiro de 2011; www.expresso.pt 


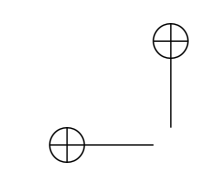

Political Cartoons as communicative weapons - the hypothesis of the "Double Standard Thesis" in three Portuguese cartoons

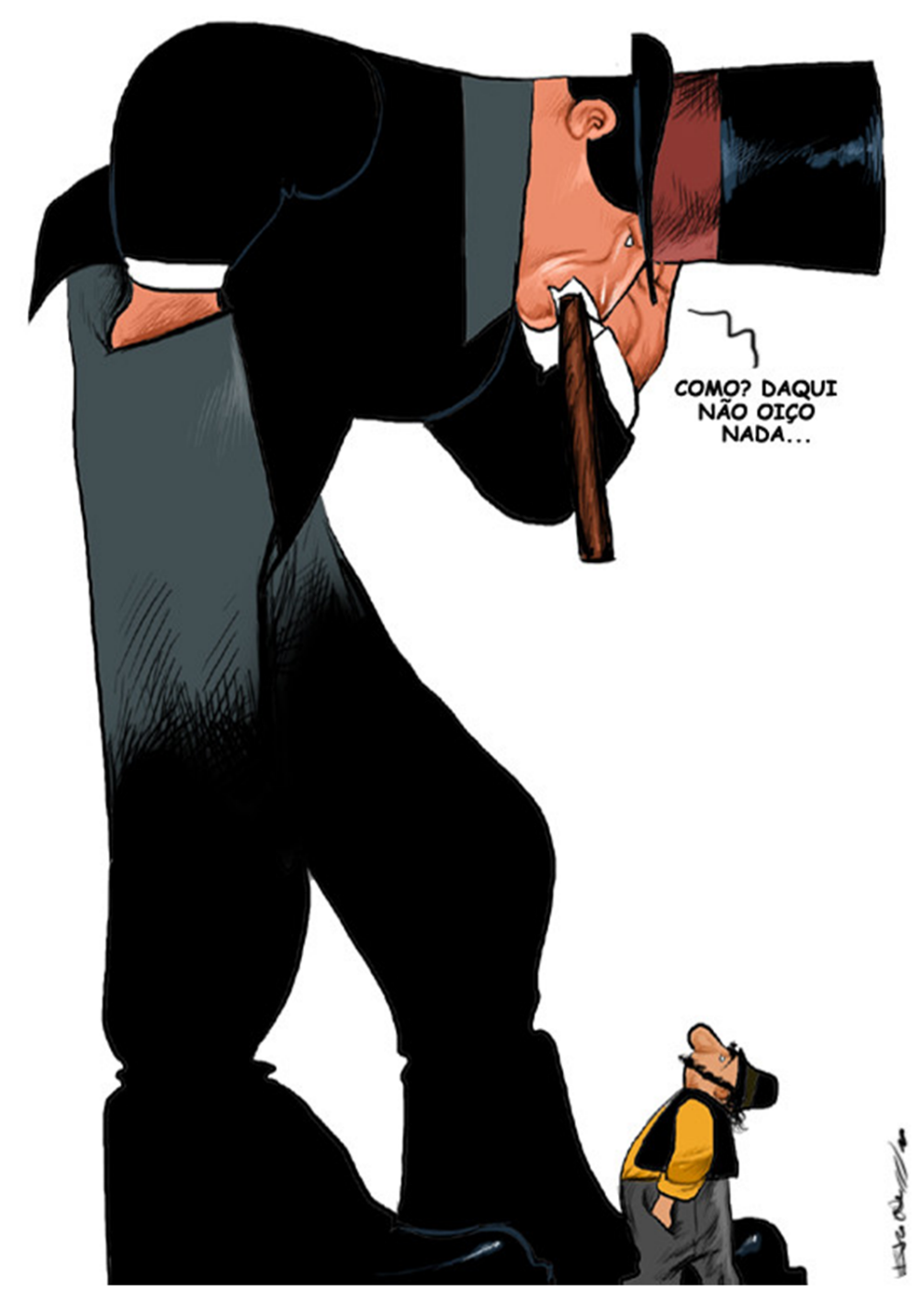

Cartoon 3. Henrique Monteiro, Senhor Rico, arranja-me uns trocos para a crise? (Mr. Mllionaire, would you get me some coins to face the crisis?) ), Sapo Notícias, 25 de Agosto de 2011; http://henricartoon.pt/389892.html 
$\bigoplus$

$\bigoplus$

$\oplus$ 


\title{
A corporeidade feminina na publicidade: algumas reflexões sobre representações normativas
}

\author{
Cristina Santos \\ Universidade Lusófona de Humanidades e Tecnologias \\ E-mail: cristina.afsantos@gmail.com
}

\begin{abstract}
RESUMO
Com o presente artigo pretende-se reflectir sobre a forma como a corporeidade feminina é representada através da publicidade. Paralelamente, procura-se perceber se o discurso publicitário poderá contribuir para o reforço ou para a ruptura de uma normatividade corporal da mulher, consolidando ou desvanecendo estereóti-

pos femininos. Para o efeito, efectuouse uma revisão da literatura, a qual permitiu detectar a particular preponderância de corpos que correspondem a uma suposta perfeição corporal. Desta forma, o ideal de beleza feminino aparenta assentar numa trilogia que concilia beleza, juventude e magreza.
\end{abstract}

Palavras-chave: corporeidade feminina; publicidade; representações corporais.

\section{Abstract}

With this article we intend to reflect how the female corporeality is represented through advertising. At the same time, we seek to realize if the advertising discourse can strengthen or break a body normativity of women, consolidating or fading stereotypes. For this purpose, it was carried out a literature review, which allowed detecting the particular preponderance of bodies that correspond to an

Data de submissão: 11-05-2016. Data de aprovação: 23-10-2016.

A Revista Estudos em Comunicação é financiada por Fundos FEDER através do Programa Operacional Factores de Competitividade - COMPETE e por Fundos Nacionais através da FCT - Fundação para a Ciência e a Tecnologia no âmbito do projeto Comunicação, Filosofia e Humanidades (LabCom.IFP) UID/CCI/00661/2013. 
alleged bodily perfection. So, the female trilogy that combines beauty, youth and ideal of beauty appears to be based on a thinness.

Keywords: female corporeality; advertising; body representations.

\section{INTRODUÇãO}

$\mathrm{O}$ presente ensaio tem dois objectivos principais: compreender como a corporeidade feminina é representada pela publicidade e perceber até que ponto o discurso publicitário explora uma normatividade corporal genderizada. Sabe-se que o corpo apresenta uma importância crucial para a mulher contemporânea, influenciando as suas vivências, e que a concepção de uma corporeidade feminina perfeita gira em torno de três características: beleza, magreza e juventude. Esta trilogia estética é explorada pela publicidade, cujas personagens personificam, maioritariamente, essa modelação corporal. São apresentados conteúdos padronizados, versões idealizadas da mulher, visualidades hegemónicas, aparências estereotipadas e arquétipos estandardizados. Aparentemente, assiste-se a uma emergente confluência normalizadora, a qual espelha a emergência de uma reflexão e discussão de uma problemática provavelmente enraizada na contemporaneidade.

\section{A CORPOREIDADE NA CONTEMPORANEIDADE}

Se outrora o corpo era usado como um instrumento de trabalho, na presente sociedade este é encarado como um objecto valioso, a ser trabalhado, 'mimado' e exibido, dado o poder que a corporeidade e a visualidade possuem na contemporaneidade. Assiste-se a uma hiperbolização da aparência, centrada na exibição e gestão de impressões, dada a tendência para correlacionar o aspecto exterior com a popularidade dos indivíduos (Maffesoli, 1990; Featherstone, 1991, 1994; Drotner, citada por Boëthius, 1995; Pais, 1995; Campbell, 2004; Alvarado, 2006; Fonseca, 2007; Dittmar, 2008; Veríssimo, 2008; Fehr, 2009; Januário e Cascais, 2012). A imagem dos sujeitos surge, pois, como um importante factor na avaliação que as pessoas efectuam umas das outras, sendo essa apreciação tanto mais positiva quanto maior a aproximação aos ideais de beleza vigentes (Pereira et al., 2011). 
Como consequência, existe uma propensão para o culto do corpo, que tende a ir ao encontro dos cânones estéticos prevalecentes (Henderson e DeLong, 2000; Pais, 2003, 2005; Veríssimo, 2008). Para o efeito, várias práticas corporais são postas em prática, como por exemplo, o consumo de produtos de beleza, a implementação de dietas; a ida a ginásios e a consultas de nutrição, a ingestão de esteróides ou a aposta na cirurgia estética. Como consequência, o corpo é palco de crescentes investimentos (Featherstone, 1991; Henderson e DeLong, 2000; Ferreira, 2004; Pais, 2003, 2005; Dens et al., 2008; Veríssimo, 2008; Dittmar, 2009; Mota-Ribeiro, 2010), dado que “(...) no imaginário corporal contemporâneo, o corpo deixa de ser tomado como um destino herdado ao qual cada um é abandonado (...)" (Ferreira, 2004: 58). Desta forma, a corporeidade torna-se numa realidade passível de opções e de escolhas, assistindo-se à respectiva emancipação “(...) relativamente à postura naturalista que o toma como mero adquirido, realidade geneticamente herdada, governada por processos biológicos incontornáveis" (Ferreira, 2004: 58).

\section{A IMPORTÂNCIA DA CORPOREIDADE EM CONTEXTO FEMININO}

Se a importância da corporeidade é transversal à sociedade, a problemática ganha um particular destaque em contexto feminino. A aparência é mais valorizada e associada à mulher, a qual aparenta concentrar mais as suas vivências em torno da própria fisionomia, que exercerá uma maior influência na forma como se auto-percepciona, mas também no modo como os outros a encaram. É ao sexo feminino que é exigido um maior cuidado e aprumo com o seu aspecto físico, sendo este, inclusive, a principal propriedade que define uma 'mulher interessante' (Pais, 1995). Mota-Ribeiro (2010) considera que a mulher que não cuidar do seu visual poderá não corresponder ao papel que supostamente deveria desempenhar, pelo que deve evitar "(...) ser vista como não atraente" (2010: 140), facto que ganha um maior protagonismo dada a visibilidade feminina: “(...) as mulheres têm a consciência de estar sempre em palco (...). Por isso, é necessário vigiar constantemente a apresentação da sua personagem em cena" (2010: 141). Neste enquadramento, o espelho desempenha um papel relevante nessa monitorização, dada a sua utilidade, pois o facto de ser encarado como um símbolo de feminilidade não se deve a uma 
pressuposta vaidade, mas pela auto-vigilância que a mulher executa (Berger, 1972, citado por Mota-Ribeiro, 2010).

Vários outros indicadores ilustram essa aparente prevalência feminina. Ollila (2008) (citada por Autio et al., 2013) constatou que para as raparigas o aspecto visual contribui para o sucesso juvenil. Na opinião destas jovens, é importante, para o sexo feminino, ter uma imagem cuidada. Rodrigues (2013) assinala que os seus entrevistados mencionam que as mulheres são mais centradas na fisionomia do que os homens. É mencionada a paciência feminina, percepcionada como sendo ilimitada, para com as rotinas de cuidados corporais mais exigentes em termos de tempo. Também na compra de vestuário, os participantes na pesquisa da investigadora consideraram as mulheres mais indecisas e demoradas. Aliás, a roupa aparenta ser um bem particularmente associado ao universo feminino, já que as mulheres valorizam e interessam-se mais pela indumentária, para além de apresentarem um maior envolvimento na respectiva aquisição (Corrigan, 1997; Veríssimo, 2008). A este propósito, assinalemos a maior apetência aquisitiva feminina, dada a sua privilegiada ligação ao consumo (Ganetz, 1995; Cardoso e Pinto, 2009; Deutsch e Theodorou, 2010; Ribeiro, 2010). Num inquérito realizado à população lisboeta, Pais (1995) detectou que um dos temas mediáticos com maior interesse para os jovens é a imagem e cuidados com o corpo, sendo mais significativo junto do público feminino. Desta forma, culturalmente a mulher está mais predisposta para a valorização da aparência, interiorizando essa ligação como algo 'natural' e que faz, inclusive, parte da sua identidade: “(...) women are (...)encouraged to believe it is important (...)to look good in order to be valued" (Dens et al., 2008: 417). Este panorama poderá contextualizar o facto de Brinkman et al. (2012) terem detectado que algumas das crianças participantes na sua investigação afirmarem ser conhecidas por desafiarem normatividades femininas associadas a uma expectável visualidade: “(...) one girl described (...) she was seen as being not very feminine and that people expected her to always conform to that identity" (Brinkman et al., 2012: 8).

A proeminente relevância corporal feminina poderá justificar o facto de o corpo ser um assunto mais sensível e problemático para o sexo feminino (Strandbu e Kvalem, 2014). Diversas pesquisas indicam que a mulher, comparativamente com o homem, apresenta maiores preocupações e é mais exigente e ansiosa com o seu aspecto físico, monitorizando, de forma mais vincada, o seu visual; que tende a ser mais insatisfeita com a sua imagem corporal e 
revela uma maior propensão para práticas que lhe permite melhorar a sua aparência (Ferreira, 2003; Holdorf, 2005; Veríssimo, 2008; Ashikali e Dittmar, 2012; Vilhjalmsson et al., 2012; Autio et al., 2013), como praticar exercício físico, iniciar uma dieta restritiva, usar cosméticos, depilar-se, usar roupas justas, esticar ou encaracolar o cabelo, fazer cirurgia estética ou lipo-aspiração. Este conjunto de práticas corresponde a uma 'disciplina feminina do corpo', que têm como principal objectivo a modelação ou transformação do espaço corporal feminino no sentido de se aproximarem de um modelo estandardizado de feminilidade (Magalhães, 2011).

Ciente da preponderância das práticas corporais para o sexo feminino, Pais (1996) recorre a uma analogia, numa equiparação de rituais: “(...) os ritos de beleza, para algumas mulheres, têm substituído os ritos religiosos ou adquirido um configuração de natureza parareligiosas: há verdadeiras cruzadas pelo controlo de peso; a comida e os doces são uma tentação a que se procura fugir; os jejuns religiosos dão lugar aos jejuns dietéticos; os regimes alimentares são objecto de crenças, de mistificações, de fé; aos esteticistas confessam-se as angústias das rugas, borbulhas e flacidez da pele; os Evangelhos são substituídos pelas revistas de beleza ("siga religiosamente as instruções"...); as balanças são os actuais confessionários de pecados alimentares; os ginásios são os locais de culto desse "deus" que nos reveste e é o nosso corpo e através do qual se protagoniza a sexualidade" (Pais, 2006: 4). Através desta "caricatura', o investigador mostra a relevância que a aparência tem para a mulher e o impacto que essa preponderância apresenta na sua vivência quotidiana.

A ligação existente entre o sentimento de satisfação com o corpo (autoestima corporal) e o de satisfação enquanto pessoa (auto-estima pessoal) indicia que as raparigas têm maiores probabilidades de possuírem baixos níveis de auto-estima, tal como dá conta a literatura (Ferreira, 2003; Dittmar, 2009; Ashikali e Dittmar, 2012; Dens et al., 2008; Vilhjalmsson et al., 2012; Chang et al., 2014). Ferreira (2003) frisa que a auto-estima identitária negativa é mais relevante nas mulheres; Dens et al. (2008) assinalam que é o sexo masculino que tem uma auto-estima mais alta; Pereira e Antunes (2008) realçam que a mulher possui um auto-conceito menos positivo e Silva (2011) detectou que, na Europa, as pessoas que vivem com um maior nível de bem-estar subjectivo 
(BES) ${ }^{1}$ são os indivíduos masculinos. Porém, a idade da mulher aparenta ser determinante. Twigg afirma que pesquisas recentes sugerem que "(...)older women are in fact happier with their bodies and appearance than younger ones (...)" (2009: 11). A autora avança com uma possível razão para este aparente paradoxo: "(...)the increasingly heavy pressure placed on younger women (...).Older women may be more satisfied because they are no longer subject to these stringent norms of femininity" (2009: 11-12).

Fannon (2016) quis conhecer as experiências de mulheres com deficiência visual relativamente aos ideais de beleza e verificou que não só tinham uma noção clara de uma suposta corporeidade ideal (corpo magro, bonito e jovem), como demonstraram preocupar-se com a questão estética: "Not unlike sighted women they too are acutely aware of the significance placed on female appearance; they feel pressure to meet feminine beauty norms; they work hard on their own appearance, using diet, fitness, fashion and grooming, to look and feel attractive; and they too wish to change their appearance in response to personal dissatisfaction about the shape and look of their bodies" (Fannon: 2016: $\mathrm{s} / \mathrm{p}^{2}$ ). A investigadora constatou, igualmente, que estas mulheres acreditam que o 'desvio' das normas visuais tem impactos pessoais e sociais, podendo fazer a diferença na obtenção de emprego; de ser promovida; de arranjar amigas ou um parceiro. Acrescente-se que os rituais de beleza e as práticas de gestão da aparência que desenvolvem poderão servir como um suporte importante para a inclusão, fazendo com que as mulheres portadoras de deficiência se sintam femininas e em igualdade entre os seus pares. No entanto, consideram que têm que dedicar uma maior atenção à sua aparência, comparativamente com as mulheres sem qualquer deficiência, pois consideram que só assim conseguirão transmitir a imagem de pessoas capazes e independentes. Por outro lado, a incapacidade para retribuir visualmente os olhares dos outros, para avaliar a sua aparência com facilidade e rapidez ou medir as reacções de outras pessoas quanto à imagem que transmitem são questões que poderão desencadear sentimentos de vulnerabilidade e de insegurança.

1. O BES traduz as respostas emocionais dos indivíduos nos seguintes domínios: satisfação com a vida, felicidade, saúde e relações interpessoais, para além das avaliações subjectivas relativamente à governação e à sociedade (Silva, 2011).

2. O artigo de onde foi retirada a citação encontra-se apenas disponível em formato HTLM, em 'texto corrido', sem qualquer paginação: http://dsq-sds.org/article/view/ $1366 / 1538$. 
Se a mulher é mais focada na sua aparência, esta particular incidência é justificada com base nos mais diversos argumentos. Segundo o testemunho de diversos autores, como Corrigan (1997) ou Pais (2003), os diferentes momentos históricos afectos ao género feminino acabam por determinar essa maior predisposição. Devido ao facto de as mulheres terem ocupado, historicamente, posições sociais menos reconhecidas e sedimentadas no costume, a moda permitia a conciliação entre o desejo de imitação geral com o de distinção, refere Simmel (1969, 1991, 2004). Por sua vez, Ganetz (1995) realça que, como a mulher foi sempre menos socialmente visível do que o homem, a moda ajudou a ultrapassar essa barreira sexista. Já Corrigan (1997) menciona o facto de o surgimento das lojas ter proporcionado uma escapatória à esfera doméstica feminina, concedendo à mulher um novo espaço no domínio público. Se antes da Revolução Industrial eram os homens quem mais investiam na sua imagem, por terem que rivalizar entre si para conquistarem as mulheres, é na alvorada da Revolução Industrial que o universo feminino adopta uma cultura galante, investindo na imagem e na moda ${ }^{3}$, menciona Pais (2003). Tal como no caso feminino, também o poder que a estetização e a visualidade apresentam no contexto juvenil é inequívoco (Gonçalves, 1995; Lehmann et al., 1998; Silva, 2001; Pais, 2003, 2005; Brull e Abeja, 2006; Nunes, 2007; Campos, 2010), inclusive para o desenvolvimento da respectiva auto-estima (Daters, 1996).

\section{OS DENOMINADORES DE UMA PERFEIÇÃO CORPORAL FEMININA}

A concepção de corpo ideal feminino está alocado a três eixos principais: beleza, magreza e juventude. A corporeidade perfeita assenta, desta forma, numa trilogia, que reflecte os ideais de beleza ocidentais e contemporâneos,

3. Esse investimento devia-se ao modelo de matrimónio adoptado na Idade Média, na Europa Ocidental, o qual assentava numa forte redução da nupcialidade e num adiamento da idade da contracção do casamento, para além de sacralizar o celibato e a virgindade feminina. Como consequência, as noivas escasseavam. Factor agravado por fenómenos à época recorrentes como o infanticídio e a poligamia. Um 'bom casamento' era aquele que dava direito a aceder à possessão de terras. Este modelo de matrimónio entra em declínio na alvorada da Revolução Industrial. Nesta fase, o emprego ganha um valor superior à terra. A competição masculina deixa de se centrar na união, mas na posse de um trabalho estável, pelo que os investimentos na indumentária são substituídos pelas qualificações educativas ou profissionais. Assim, as mulheres aspiram a relacionar-se com um jovem detentor de um 'bom emprego', passando a serem as próprias a preocuparem-se mais com a imagem (Pais, 2003). 
os quais são encarados como 'um capital' pessoal a conquistar e a manter. Debrucemo-nos, individualmente, sobre cada um dos três conceitos. Comecemos pelo enunciado primeiramente. A beleza corporal tem vindo a adquirir um crescente valor simbólico (Maffesoli, 1990; Featherstone, 1991, 1994; Drotner, citada por Boëthius, 1995; Campbell, 2004; Fonseca, 2007; Veríssimo, 2008), particularmente para a mulher, cuja conceptualização passa pela posse de um corpo bonito (Mota-Ribeiro, 2010). Pereira e Antunes (2008); Deutsch e Theodorou (2010) e Marion e Nairn (2011) detectaram que à feminilidade se associa a beleza.

Chan (2008), por sua vez, apurou que a ambição de ser bonita foi somente realçada pelas raparigas participantes na sua pesquisa, enquanto Ollila (2008) (citada por Autio et al., 2013) constatou que é relevante, para o sexo masculino, ter uma companheira bonita. Mota-Ribeiro reforça estes resultados, ao argumentar que a "(...) aparência física continua a ser mais determinante na escolha do parceiro para os homens do que para as mulheres" (2010: 152). Aliás esta centralidade ganha contornos deterministas, ao ponto de a própria feminilidade basear-se no atributo beleza, já que, quanto mais bonita for a mulher, mais percepcionada ela é como sendo feminina, processo que não ocorre na esfera masculina. Como perspectiva Mota-Ribeiro (2010), a beleza é uma característica contruída e atribuída socialmente à mulher, já que nada há de fisicamente inerente, de biológico, que torne a aparência feminina mais relevante do que a masculina.

No que concerne à magreza, verifica-se uma “(...) maior severidade para com a obesidade feminina" (Mota-Ribeiro, 2010: 152). O corpo magro é valorizado, ao contrário da gordura, a qual é associada à doença e à falta de controle, de disciplina e de vontade (Andrade, 2002, citada por Palacios, 2004; Mota-Ribeiro, 2010; Pereira et al., 2011; Januário e Cascais, 2012): "Tradicionalmente, o excesso de carne, os corpos volumosos ou fortes são conotados com masculinidade" (Mota-Ribeiro, 2010: 328). Actualmente, por exemplo, a uma silhueta esguia é associado reconhecimento, estatuto, sucesso pessoal, profissional e social (Agnew, 1984). Há várias implicações quando está em causa a obesidade na mulher, nomeadamente uma associação entre a perda de peso e a felicidade e uma relação entre o excesso de peso e a impossibilidade de ser encarada como atraente e de ter uma vida sexualmente activa (Mota-Ribeiro, 2010). Disso dá conta a investigação de Nielsen e Rudberg, a propósito de uma das jovens participantes na sua investigação: “(...) the sur- 
plus fat not only turns Eva into a failure as a sex object, but also indicates that she is a weak and worthless person" (1993: 46). São comuns as mensagens publicitárias em que se demonstra uma efectiva necessidade de as raparigas se tornarem apelativas fisicamente, se apresentarem disponíveis para serem olhadas e, supostamente, escolhidas por um parceiro (Magalhães, 2011).

Quanto à juventude, é almejado "(...) um corpo perfeito que não se degrada com a idade (...)" (Pereira et al., 2011: 162) e ambicionado "(..) manter a imagem corporal de um adolescente (...)" (Pereira et al., 2011: 162). O corpo jovem possui um valor e legitimidade social superior, surgindo, por isso, enquanto corporeidade modal ${ }^{4}$ (Ferreira, 2004, 2011). Para o efeito, concebem-se bens que materializam essa pretensão, implantando-se “(...)la tiranía indiscutible de milagrosos productos y de formulas mágicas capaces de prevenir el envejecimiento y de recuperar la belleza perdida a través del paso irreductible de los años" (Alvarado, 2006: 299). Alvarado (2006) afirma que, mais do que um mito, a busca da eterna juventude constitui, actualmente, uma realidade que mantém as sociedades apegadas à falácia da involução. Instituiu-se que os indivíduos podem enfrentar, com êxito, o irreversível efeito da evolução biológica.

De acordo com Veríssimo (2008), é o corpo feminino que repousa, particularmente, numa tríade do corpo perfeito: a juventude, a beleza e a saúde. Estas características representam as três condições culturais para a fecundidade e a perpetuação da espécie. Curiosamente, e a este propósito, Lipovetsky (2000) (citado por Mota-Ribeiro, 2010) refere que a actual apreciação da magreza da mulher faz eco de determinadas transformações sociais, na medida em que se assiste ao enfraquecimento da associação do corpo feminino à maternidade, consequência do decréscimo do valor social de ser mãe e à valorização da mulher activa e independente. É que o corpo feminino robusto era associado à reprodução (Magalhães, 2011). Já em 1995, Pais detectara essa tendência na população nacional: (...) entre as mulheres, o modelo da maternidade parece já estar cedendo lugar ao modelo da beldade. O ideal da mulher, provavelmente, já não é ter filhos e cuidar deles, numa lógica subordinada à domesticidade, mas fazer tudo para se manter bela" (Pais, 1996: 4).

4. A corporeidade modal é composta por um conjunto de traços e usos corporais socialmente mais valorizados e legitimados que outros (Ferreira, 2004, 2011). 
Acrescente-se que a publicidade contribui para a particular relevância detida pela corporeidade em contexto feminino, por explorar a importância que a aparência pode assumir nas suas vivências (Veríssimo, 2008; Mota-Ribeiro, 2010; Magalhães, 2011), facto que ganha uma maior dimensão quando existe uma relação privilegiada estabelecida pela mulher com a publicidade (Cardoso e Pinto, 2009; Crymble, 2012). Talvez por esse motivo, Magalhães (2014), na análise efectuada aos anúncios publicitários de uma revista feminina e outra masculina, verificou que a publicidade se encontrava em maior número na publicação destinada às mulheres. Aliás, uma das acusações apontadas às marcas e à publicidade decorre do facto de ambas reduzirem as mulheres à aparência. É que a noção ocidentalmente moderna de feminilidade ideal poderá ser entendida como um mecanismo normalizador que oprime o poder feminino, ao circunscrever as mulheres ao seu aspecto exterior (Fannon, 2016).

\section{A REPRESENTAÇÃo CORPORAL FEMININA NO DISCURSO PUbLICITÁ- RIO}

A concepção de uma corporeidade feminina ideal encontra-se presente na publicidade, ao ser dado um maior protagonismo a corpos belos, magros e jovens, já que as personagens que surgem nos anúncios publicitários aparentam materializar essa trilogia corporal. Vejamos de que forma. A beleza constitui um dos traços mais marcantes e transversais das imagens publicitárias (MotaRibeiro, 2003; Araújo, 2013). Veríssimo (2008) assinala que nos anúncios publicitários que analisou evidenciou-se a beleza e a sensualidade das personagens femininas, características que coabitam recorrentemente. Por sua vez, Mota-Ribeiro (2010) identificou expressões e poses femininas com um carácter erótico em que, por vezes, as roupas usadas pelas personagens davam destaque a partes do corpo consideradas essencialmente femininas, como os seios e as pernas. A pesquisa de Magalhães (2011) permitiu verificar que a construção discursiva 'Tornar-se sexy!' emerge sobretudo na publicidade direccionada às raparigas e traduz uma tendência actual de sexualização dos conteúdos e discursos mediáticos. Pons (2006) enumera diversas tipologias femininas presentes no discurso publicitário e que exemplificam, de alguma forma, essa ligação feminina à volúpia: a vampe, a femme enfant ou a pin up. 
A idade, por sua vez, é uma das variáveis mais homogéneas no discurso publicitário, já que a juventude é predominante, enquanto, contrariamente, se verifica a fraca expressividade da velhice (Rosales, 2002; Veríssimo, 2008; Mota-Ribeiro, 2010). A juventude talvez seja uma das maiores promessas que a publicidade faz, surgindo como um signo de narcisismo, aventura, diversão e sedução (Medeiros, 2004). Segundo Ferreira (2011), a publicidade capitaliza o corpo jovem, associando-o ao perfil de corporeidade perfeita. Esse corpo é, pois, fetichizado, cobiçado, obstinadamente desejado e mercantilizado, servindo de suporte figurativo a marcas e produtos. É estabelecida a ideia da perduração da juventude, crença alimentada pelas promessas mercantis da juvenilização dos corpos. De acordo com o investigador, a sociedade encontra-se contaminada “(...) por um complexo de Peter Pan profundamente enraizado" (2011: 260).

Também o peso da mulher parece ser um critério determinante no discurso publicitário (Mota-Ribeiro, 2003): “(...)the "body perfect"ideal is ultra-thin, and whose media models are typically underweight (...) (Dittmar, 2009: 2). Trata-se de uma visualidade que tem várias consequências. Queiroz e Otta (2000) (citados por Palacios, 2004) alegam ser comum que as mulheres se vejam acima do peso, mesmo quando efetivamente tal percepção não corresponde à realidade. De igual forma, a pesquisa de Cunha (2004) (citada por Ferreira, 2011) identificou a existência de uma sobrevalorização do peso real por parte das raparigas inquiridas. Poderá estar em causa uma distorcida concepção feminina de beleza (Ribeiro, 2011), situação para a qual a publicidade poderá contribuir: “(...)images of thin women (...)negatively impated mood and bodily perceptions (...)" (Dens et al., 2008: 415); “(...)exposure to thinideal images is an immediate cause of women's body dissatisfaction (...)" (Ashikali e Dittmar, 2012: 514). De acordo com Lysardo Dias (citada por Ribeiro, 2011), os anúncios publicitários têm vindo a explorar, fundamentalmente, dois tipos de estereótipos femininos, os quais se inter-relacionam: a beleza associada à magreza e a juventude à felicidade. Lipovetsky (2000) (citado por Mota-Ribeiro, 2010) afirma que existem duas normas que dominam a esfera feminina: o anti-peso e o anti-envelhecimento.

As personagens dos anúncios publicitários não são, por norma, uma representação realista, mas uma referência imaginária e idealizada, fazendo eco de padrões estéticos estereotipadamente ideais: "A pessoa ideal surge assim como uma metáfora, uma imagem mítica e mistificadora, representando os 
ícones contemporâneos aceites socialmente (...)" (Veríssimo, 2008: 83). As personagens são colocadas nos anúncios publicitários para terem um efeito de modelagem, ao suportarem a transformação do produto em símbolo. A aparência desses intervenientes transporta valores e atitudes com os quais o consumidor se identifica ou aspira atingir. Os corpos representados na imagem publicitária são, maioritariamente, signos de desejo, principalmente por uma motivação de natureza aspiracional (Medeiros, 2004; Pereira e Veríssimo, 2004; Veríssimo, 2008). Verifica-se a proliferação de "Personajes estereotipados que encarnan un prototipo (...)de feminidad de acuerdo con los ideales de belleza (...)" (Pons, 2006: 309-310), apostando-se, para o efeito, em modelos criados pela indústria de Hollywood. Prevalece a “(...) incorporação (...) de modelos de corporeidade ideal veiculada mediaticamente (...)" (Ferreira, 2003: 276). Diversas pesquisas comprovam essa tendência, dado que as celebridades, os manequins e os ídolos que surgem nos anúncios publicitários, muitos dos quais são ícones de beleza, são frequentemente encarados como uma referência (Ferreira, 2003; Dens et al., 2008; Pereira e Antunes, 2008).

Veríssimo constatou, na publicidade analisada, que esta ferramenta de comunicação “(...) não exterioriza um corpo qualquer, mas um cânone que "apela" a que cada uma das pessoas obtenha e assuma o corpo, não o seu, mas aquele que se vê nas imagens" (2008: 188). Como perspectiva o investigador, "A aceitação desta premissa acaba por "implicar" a negação do próprio corpo" (Veríssimo, 2008: 188). Saliente-se que uma eventual discrepância entre as duas imagens (a detida pelo consumidor e a projectada pela personagem) poderá originar problemas das mais diversas índoles, como a obesidade; a anorexia nervosa ou a bulimia; as frustrações; as depressões; a desilusão; a vergonha; uma baixa auto-estima; os conflitos familiares; a dependência de estupefacientes ou as fobias sociais (Bessenoff, 2006; Dens et al., 2008; Veríssimo, 2008; Dittmar, 2009). Ashikali e Dittmar (2012) fazem referência a essa problemática: "Body dissatisfaction (...)has been identified as a potent and consistent precursor of a range of mental and physical health problems (Ashikali e Dittmar, 2012: 514). Até porque, "Body image has emerged as a core aspect of mental and physical well-being (Dittmar, 2009: 1).

A literatura sublinha que as imagens idealizadas que surgem nos anúncios publicitários afectam a forma como os consumidores se auto-percepcionam (Dens et al., 2008). Ashikali e Dittmar mencionam que inúmeros estudos chegaram à mesma conclusão: “(...)the more time spent watching television 
and reading magazines, the higher the experience of body dissatisfaction" (2012: 515). A publicidade poderá contribuir, de alguma forma, para a já mencionada insatisfação física feminina, dadas as representações da corporeidade que veicula, assentes, maioritariamente, numa mesma referência estética. No entanto, numa pesquisa nacional, a maioria das entrevistadas afirmou que as imagens de mulheres 'ideais' presentes nos anúncios publicitários não tinham quaisquer efeitos ou mesmo que eram benéficas para as mulheres 'reais', já que a beleza pode provocar sensações positivas (Pinto-Coelho e Mota-Ribeiro, 2007). Não obstante a cultura consumista ter como um dos seus ideais o corpo perfeito, o qual é projectado e promovido pela publicidade, poderá haver, igualmente, uma pressão da família e dos pares para que o indivíduo tenha uma silhueta estandardizada, o que potenciará, eventualmente, sentimentos de insatisfação física (Ferreira, 2003; Dens et al., 2008; Ashikali e Dittmar, 2012). A exposição a este tipo de modelos corporais começa numa tenra idade e através dos brinquedos: "Body perfect"ideals are communicated (...)through dolls such as Barbie, and girls as young as 5 to 7 years reported lower body esteem and a greater desire for a thinner body directly after exposure to such doll images dissatisfaction" (Dittmar, 2009: 2). De facto, e ao longo da sua existência, a Barbie, que tem sido um símbolo e um ícone da beleza feminina, foi alvo de descontentamento, acusações e críticas, devido ao irrealismo do seu corpo. Assim, a Mattel alterou a sua estratégia e, no início do ano, procurou "reflectir melhor o mundo que as meninas vêem à sua volta" 5 , tendo sentido necessidade de reinventar os seus produtos, por forma a adaptarem-se à actualidade e a dar resposta às reivindicações da sociedade. No total, lançou trinta e três novas bonecas, na linha Fashionistas, com quatro tipos de corpo ${ }^{6}$.

É devido a esse maior protagonismo da corporeidade feminina que a publicidade a cosméticos é, maioritariamente, direccionada às mulheres, escrevem Rosales (2002); Alvarado (2006); Pereira e Antunes (2008) e Magalhães (2014). Veríssimo (2008) concluiu que, em Portugal, e de acordo com os resultados da sua pesquisa, o mercado de produtos relacionados com o corpo é maioritariamente dirigido à mulher. Nessa argumentação publicitária, dominam as mensagens assentes na beleza, invocando a perfeição física, a qual

5. Sara Marçal, responsável de marketing da Mattel Portugal.

6. Estes modelos poderão ser consultados em: www.barbie.com/en-us. 
poderá ser obtida através dos bens anunciados, particularmente através dos produtos para o tratamento do rosto e de fragrâncias. Lazar (2012) explora a forma como a beleza é metaforicamente conceptualizada na publicidade como uma luta. Através da metáfora conceptual 'embelezamento é guerra' são identificados, nos anúncios publicitários analisados, três dimensões: os problemas (os fenómenos que afectam, negativamente, o alcance de um corpo belo são considerados inimigos. Nesse sentido, o tempo, as agressões ambientais, como a poluição, ou o envelhecimento são considerados adversários femininos); as consumidoras (os corpos das mulheres são campos de batalha e as mulheres são combatentes) e as soluções (em que as marcas surgem como poderosas aliadas nessa luta, ao desenharem estratégias, com o intuito de apoiarem e ajudarem as mulheres nos seus esforços para alcançar a beleza corporal. Determinados produtos são apresentados como armamento 'topo de gama' na 'frente de combate'). Na associação entre guerra e beleza, poderá estar em causa uma abordagem menos positiva, uma vez que o campo de batalha é o corpo da mulher, encarado como um potencial adversário, o que poderá conduzir a uma identidade feminina eventualmente fracturada e à alienação da relação das mulheres com a sua corporeidade.

A publicidade é percepcionada como sendo perpassada por representações estereotipadas relativamente ao género (Jorge, 2014). Constata-se a permanência de diversos estereótipos no discurso publicitário, tal como ilustrado por Medeiros: “(...) são normalmente mãos femininas que nos anúncios lavam, cozinham e arrumam a casa (...)" (2004: 82). Constatação corroborada pela pesquisa de Rosales (2002). Medeiros justifica esta prevalência: “(...) também porque são ainda as mulheres as principais responsáveis pelas tarefas domésticas e pelas compras do lar" (2004: 82). Para Mota-Ribeiro (2010), esta variável de comunicação deveria afastar-se de protótipos femininos idealizados pela sociedade ocidental, de modelos de feminilidade centrados em representações irreais e idealizadas do corpo feminino e promover a divulgação de anúncios publicitários que mostrem “(...) as mulheres como realmente são, não as essencializando, e não as cristalizando em papéis estereotipados" (2010: 63). A investigação da autora, tal como a de Pinto-Coelho (2007) e a de Magalhães (2014), demonstram que a mulher que surge na publicidade é, maioritariamente, bela, jovem e magra, correspondendo ou construindo o ideal de beleza corporal feminino dominante na nossa sociedade. Evidenciase, por isso, a homogeneização da aparência das personagens femininas. São 
várias as marcas presentes em anúncios publicitários que pretendem passar a imagem do que é adequado e normal numa rapariga (Magalhães, 2011).

Esta supremacia visual, que encerra uma suposta perfeição corporal, é ainda ilustrada através do resultado da pesquisa de Mota-Ribeiro (2003). De um total de cento e nove anúncios publicitários de imprensa recolhidos das mais diversas marcas, a investigadora sublinha que apenas em três dessas imagens figuram mulheres teoricamente 'comuns', isto é, não representativas do tipo de fisionomia idealizada. Magalhães (2014) apurou que a maioria das personagens que surgiam nos anúncios publicitários analisados era magra, caucasiana e com cabelo liso, propriedades correspondentes aos estereótipos de ideais de beleza ocidentais ${ }^{7}$. A investigadora ironiza a valorização desse imagem normativa: "Estão assim vedadas possibilidades de sucesso a adolescentes e mulheres que se distanciem do ideal de mulher jovem, branca, magra, ocidental, heterossexual, classe média-alta, não portadora de deficiência" (Magalhães, 2011: 153). Existem, nesse sentido, pressões e sanções para quem não se adeque à norma estética em vigor (Mota-Ribeiro, 2010).

Como consequência, as mulheres que não se enquadram num padrão alocado a um pressuposto corpo belo, magro e jovem tornam-se 'invisíveis'. As 'imperfeições' corporais, dissidentes dos ideais de beleza, encontram-se praticamente ausentes do discurso publicitário. Constata-se a “(...) omissão social do corpo do deficiente, do idoso e do doente (...). Devido às suas enfermidades, que podem causar nos outros sensações desagradáveis, os seus corpos tendem a ser colocados à distância dos demais e até ignorados" (Veríssimo, 2008: 66). A publicidade apresenta “(...) o lado «cor-de-rosa» da vida (...)" (Pereira e Veríssimo, 2004: 183), explorando, precisamente, a positividade, dissipando as fragilidades do consumidor e exacerbando o seu lado narcísico. As dificuldades quotidianas e as restantes “(...) facetas negativas são atreladas ao não-ter o produto" (Camargo, 2013: 22), já que o discurso publicitário é maioritariamente simbólico, ao apresentar os bens como ícones, carregados de significados intangíveis (Santos, 2013). Na transmissão das suas mensagens, a publicidade constrói 'não-realidades', ignorando os aspectos negativos da sociedade, ao criar uma encenação bela e feliz (Veríssimo, 2008). Daí a linguagem publicitária operar enquanto uma vendedora de sonhos, como uma

7. Januário e Cascais (2012) colocam em evidência alguns padrões estéticos ocidentalmente apreciados, como a magreza; as formas rectilíneas; os tons de pele clara e os cabelos lisos. 
fábula e fantasia (Gay et al., 1997; Silva et al., 2011). Tal como poderá ilustrar a investigação desenvolvida por Yönet, Engin e Öztürk (2006) (citada por Pereira et al., 2011), os quais encontraram evidências empíricas de que, embora o sexo feminino afirme que quer ver mulheres comuns na publicidade, quando lhes é pedido para assinalarem as suas preferências de beleza, são escolhidas modelos ideais, em detrimento das 'reais'.

Mas não são somente as pessoas que não sejam bonitas, magras e jovens que se encontram, de alguma forma, menos presentes no discurso publicitário. De facto, a publicidade não explora, por norma, sectores 'minoritários' da sociedade (Medeiros, 2004), denotando-se a maior visibilidade de personagens caucasianas e de casais heterossexuais (Rosales, 2002; Mota-Ribeiro, 2010; Pinto-Coelho e Mota-Ribeiro, 2012). Hahn (1987) (citado por Haller e Ralph, 2001) argumenta que, ao se colocar ênfase na beleza e perfeição corporais, a publicidade exclui as pessoas com deficiência. Como são indivíduos que não se enquadram num padrão alocado a um pressuposto corpo belo, são ignorados pelo discurso publicitário. Porém, pontualmente, a publicidade utiliza corpos alvo de estigmatização para passar, igualmente, a mensagem, desafiando, dessa forma, as visibilidades dominantes, resistindo a uma estética normativa, como aconteceu, por exemplo, com a Desigual e a Dove.

A marca espanhola foi a primeira a escolher uma manequim com vitiligo ${ }^{8}$ para comunicar os seus produtos. Winnie Harlow foi seleccionada para ser a cara da colecção de Outono/Inverno transacta da Desigual. Em comunicado, a marca explicou a motivação da sua escolha, que recaíu sobre uma mulher com uma imagem incomum: "Desafiar os convencionalismos e questionar a normalidade" ${ }^{9}$, objectivo que espelha a própria estratégia e posicionamento da marca. Já a Dove, ao invés de recorrer a personagens com corpos que correspondem aos arquétipos corporais vigentes, que, no entender da marca, reflectem uma definição de beleza restrita e limitada, apostou em testemunhos de mulheres 'comuns', de diversas etnias, variadas faixas etárias e com corpos distintos entre si, numa clara alusão à diversidade corporal. Poderá estar em causa uma tipologia pouco convencional, uma vez que as intervenientes nos anúncios publicitários da marca poderão não encaixar-se no estereótipo tradicional do culto do corpo (Ribeiro, 2011).

8. Doença crónica que afecta a natural pigmentação da pele.

9. Fonte: www.movenoticias.com/2014/07/desigual-assina-contrato-com-modelo-comvitiligo/. 
E se Mota-Ribeiro (2010) encara a publicidade como uma área central na qual os discursos de género são comunicados nas sociedades contemporâneas, sustentando a respectiva desigualdade e hierarquia, a autora considera, igualmente, que se tratam de espaços privilegiados onde a mudança e a contestação de significados podem ocorrer. De facto, a publicidade apresenta uma dupla faceta, funcionando, simultaneamente, enquanto um discurso de reprodução e de transformação. A dimensão reflexiva surge quando, por exemplo, espelha estereótipos, dando-lhes continuidade e consolidando-os. Tal como escreve Cerqueira: "A publicidade tem acompanhado as mudanças sociais, mas continua a recorrer a visões limitadoras e muitas vezes estereotipadas no que concerne ao género" (2014: 8). A autora sublinha que investigações no campo publicitário apontam para o facto de a estereotipia permanecer persistente. Goffman (1979) (citado por Magalhães, 2014) argumenta que a publicidade influencia a forma como se constroem os ideais genderizados do que é a masculinidade e feminilidade.

Magalhães (2014) coloca a tónica na necessidade de compreender e explicitar os mecanismos sociais que mantêm os pressupostos usados e veiculados pela publicidade, como os estereótipos, já que está em causa um processo de influência multideterminado. No entanto, esta variável de comunicação também detém a capacidade para desconstruir concepções, numa ruptura com conceptualizações já enraizadas, dado o seu potencial interventivo. Portanto, a publicidade tanto espelha as dinâmicas sociais, funcionando como um barómetro socio-cultural, económico e político (Cerqueira, 2014), como as altera, agindo como uma força influenciadora, enquanto agente de construção social da realidade (Rosales, 2002) .

A prevalência de uma representação corporal feminina normativa na publicidade poderá ter como móbil o facto de ser importante optar-se por símbolos societais familiares, por promoverem, mais facilmente, a adesão aos produtos e serviços anunciados. Logo, preferem-se figuras entendidas como sendo 'normais', no sentido em que a maioria das pessoas (re)conhece, por já se encontrarem habituadas a esse registo, nomeadamente visual. Desta forma, o impacto criado junto do público-alvo poderá ser, potencialmente, mais mobilizador, dada a identificação promovida através do recurso a referências estéticas já assimiladas, valorizadas, interiorizadas e enraizadas, tais como os padrões de beleza ocidental. Desta forma, o uso de construções, narrativas e representações cristalizadas facilitaria a compreensão da mensagem publi- 
citária (Araújo, 2013). Frascara (1999, citado por Medeiros, 2004) afirma que os estereótipos ajudam a comunicação a ser eficaz, ao assegurarem que o processo de construção de significados pelo público-alvo não concede muito espaço a interpretações. Como consequência, poderá tornar-se mais fácil controlar a forma como o anúncio será desconstruído.

Realce-se que também o corpo masculino é submetido a um escrutínio visual, ainda que de forma assimétrica, quando comparado com o universo feminino. Curiosamente, se dois dos vectores alocados à perfeição corporal, a beleza e a juventude, são transversais aos indivíduos, independentemente do seu género (Dittmar, 2008; Veríssimo, 2008; Pereira et al., 2011), já a magreza só é associada ao corpo da mulher. No caso masculino, destaca-se um corpo musculado (Pereira et al., 2011). Veríssimo (2008) assinala que nos anúncios publicitários que analisou evidenciou-se o vigor físico e sexual das personagens masculinas, sendo mais valorizados o peito e os ombros largos, ao representarem a metáfora do triunfo profissional e sucesso. O sexo masculino começa a prestar uma cada vez maior atenção às questões estéticas (Dittmar, 2008; Mota-Ribeiro, 2010; Pereira et al. 2011).

\section{CONCLUSÃo}

A corporeidade apresenta uma particular importância na contemporaneidade, especialmente num contexto feminino. Trata-se de um processo bilateral: o corpo é, para a mulher, crucial na sua vivência quotidiana, centralidade essa igualmente reconhecida pela restante sociedade. A perfeição corporal feminina encerra uma trilogia: beleza, magreza e juventude. Este é o padrão visual dominante, o qual, teoricamente, despoletará a 'normalização' do indivíduo, através da adesão a uma normatividade estética. Para o efeito, recorrem-se às mais diversas práticas corporais, com o intuito de se obter a figura almejada. Estão em causa ideais de beleza interiorizados pelos consumidores e prioritizados pela publicidade, ao explorar dimensões aspiracionais, através de personagens que espelham corpos 'ideais', em detrimento de 'reais'. A representação corporal presente no discurso publicitário retrata, assim, uma aparência hegemónica, num discurso consentâneo com uma modelação imagética. Ainda que algumas marcas optem por comunicar novas visualidades, num discurso disruptivo para com uma estética massificada, tratamse de casos pontuais, pelo que pouco espaço é dado à pluralização visual. 
Evidencia-se a menor visibilidade de corpos 'imperfeitos': idosos, obesos, feios, doentes e com deficiência. Esperamos que o nosso artigo possa ter facultado, de alguma forma, pistas para futuras reflexões e discussões da problemática, cuja preponderância na actualidade é incontornável, pelo que urge existir um maior escrutínio sobre uma temática com repercussões directas na vivência dos indivíduos.

\section{BIBLIOGRAFIA}

Agnew, R. (1984). The effect of appearance on personality and behavior: are the beautiful really good?. Youth e Society, 15(3). Consultado em: http://yas.sagepub.com/content/15/3/285

Almeida, M. \& Tracy, K. (2003). Noites nômades: espaço e subjectividade nas culturas jovens contemporâneas. Rio de Janeiro: Rocco.

Alvarado, M. (2006). El mito de la eterna juventud: productos de belleza destinados a jóvenes. In Cardoso et al. (org.). Jovens, marcas e estilos de vida (pp. 299-308). Porto: Edições Universidade Fernando Pessoa.

Araújo, S. (2013). Príncipe ou sapo? Comparando os estereótipos masculinos na publicidade televisiva brasileira e portuguesa. Estudos em Comunicação, (13): 261-280. Covilhã: Universidade da Beira Interior. Consultado em: www.ec.ubi.pt/ec/13/pdf/EC13-2013Junho-10.pdf

Ashikali, E.-M. \& Dittmar, H. (2012). The effect of priming materialism on women's responses to thin-ideal media. British Journal of Social Psychology, 51: 514-533.

Autio, M. et al. (2013). Wealthy men and beautiful women? Constructing gender identity through consumption. In Jentl \& Kaskinen (ed.). To be young! Youth and the future, comunicação apresentada na conferência "To be Young! Youth and the Future", Finland Futures Research Centre, 6-8 de Junho de 2012. Turku, Finlândia, 133-143.

Bajoit, G. (2006). O papel da confiança na formação da identidade e do vínculo social. In Balsa (org.). Confiança e laço social (pp. 61-75). Lisboa: Edições Colibri.

Belleau et al. (2007). Theory of reasoned action: purchase intention of young consumers. Clothing and Textiles Research Journal, 25(3). Consultado em: http://ctr.sagepub.com/content/25/3/244.full.pdf 
Bessenoff, G. (2006). Can the media affect us? Social comparison, selfdiscrepancy, and the thin ideal. Psychology of Women Quarterly, (30): 239-251.

Boëthius, U. (1995). Controlled pleasures: youth and literacy texts. In Forñas \& Bolin (ed.), Youth culture in late modernity (145-168). Londres: Sage Publications.

Brinkman et al. (2012). Children's gender identity development: the dynamic negotiation process between conformity and authenticity. Youth Society, XX(X). Consultado em: http://yas.sagepub.com/content/early/2012/07/2 6/0044118X12455025.full.pdf+html

Brull, M. \& Abeja, D. (2006) El fenómeno dinki, un nuevo estilo de vida, lo último en target publicitario. In Cardoso et al. (org.). Jovens, marcas e estilos de vida (pp. 75-84). Porto: Edições Universidade Fernando Pessoa.

Buhrmester, D. \& Chow, C. (2009). Friendships in adolescence. In Reis H. \& Sprecher, S. (eds.). Encyclopedia of human relationships (pp. 718-721). Thousand Oaks: SAGE Publications. Consultado em: http://sk.sagepub. com/reference/humanrelationships/n230.xml

Camargo, H. (2013). O filme publicitário como mito atualizado: fantasia, ritual, tempo e totemismo. Biblioteca on-line de Ciências da Comunicação. Covilhã: Universidade da Beira Interior.

Campbell, C. (2004). I shop therefore I know that I am: the metaphysical basis of modern consumerism. In Ekström \& Brembeck (ed.). Elusive consumption in retrospect: report from the conference (pp. 10-21), CFK Rapport.

Campos, R. (2010). Juventude e visualidade no mundo contemporâneo: uma reflexão em torno da imagem nas culturas juvenis. Sociologia, Problemas e Práticas, (63): 113-137.

Cardoso, P. \& Pinto, S. (2009). Consumo hedónico e utilitário e atitude face à publicidade. Comunicação pública: Revista multidisciplinar de comunicação, 4(8): 99-117. Lisboa: Gabinete de Comunicação e Serviço de Informação e Documentação da Escola Superior de Comunicação Social.

Cerqueira, C. (2014). Os média, os públicos e os discursos de género: (in)visibilidades, linguagens e protagonistas. In Jorge, Sequeira \& Magalhães. 
PubliDiversidade. Representações sociais e igualdade de género na publicidade (7-16). Braga: União de Mulheres Alternativa e Resposta. Consultado em: http://repositorium.sdum.uminho.pt/bitstream/1822/381 06/1/CC_Representa\%c3\%a7\%c3\%b5es-Sociais-G\%c3\%a9nero-Public idade.pdf

Chan, K. (2008). Social comparison of material possessions among adolescents. Qualitative market research: an international journal, 11(3): 316330 .

Chang et al. (2014). Consumers with disabilities: a qualitative exploration of clothing selection and use among female college students. Clothing and Textiles Research Journal, 32(1). Consultado em: http://ctr.sagepub.com /content/32/1/34.full.pdf+html

Chidid, I. \& Leão, A. (2011). Atividades de consumo como recursos da construção da identidade pré-adolescente em interações verbais. Revista Organizações em contexto (Online), 7(13): 59-83.

Corrigan, P. (1997). The sociology of consumption: an introduction. Londres: Sage Publications.

Crymble, S. (2012). Contradiction sells: feminine complexity and gender identity dissonance in Magazine Advertising. Journal of Communication Inquiry, 3(1): 62-84.

Daters, C. (1986). A comparison of the importance of clothing and selfesteem by female adolescents from a metropolitan school district. ETD collection for University of Nebraska: Lincoln.

Dens, N. et al. (2008) Effects of nudity in advertising on consumers' body esteem. In Pereira et al. (ed.). New trends in advertising research (pp. 415-427). Lisboa: Edições Sílabo.

Deutsch, N. \& Theodorou, E. (2010). Aspiring, consuming, becoming: youth identity in a culture of consumption. Youth e Society, 42(2). Consultado em: http://yas.sagepub.com/content/42/2/229.full.pdf+html

Dittmar, H. (2008). Consumer culture, identity and well-being: the searche for "good life" and the "body perfect". Londres: Psychology Press.

Dittmar, H. (2009). How do "body perfect"ideals in the media have a negative impact on body image and behaviors? Factors and processes related to self and identity. Journal of Social and Clinical Psychology, 28(1): 1-8. 
Dittmar, H. et al. (2007). When a better self is only a button click away: associations between materialistic values, emotional and identity related buying motives, and compulsive buying tendency online. Journal of Social and Clinical Psychology, 26(3): 334-361.

Fannon, T. (2016). Out of sight, still in mind: visually impaired women's embodied accounts of ideal femininity. Revista Disability Studies Quarterly, 36(1). Consultado em: http://dsq-sds.org/article/view/4326/4210

Fehr, B. (2009). Friendship formation and development. Encyclopedia of human relationships. Sage Publications.

Featherstone, M. (1994). Consumer culture e postmodernism. Londres: Sage Publications.

Featherstone, M. (1991) The body in consumer culture. In Featherstone et al. (ed.). The body: social process and cultural theory (pp.170-196). Londres: Sage Publications.

Ferreira, P. (2000). Controlo e identidade: a não conformidade durante a adolescência. Sociologia, Problemas e Práticas, 33: 55-85.

Ferreira, V. (2003). Atitudes dos jovens portugueses perante o corpo. In Pais \& Cabral (coord.). Condutas de risco, práticas culturais e atitudes perante o corpo: resultados de um inquérito aos jovens portugueses em 2000 (pp. 265-366). Oeiras: Celta.

Ferreira, V. (2004). Da reflexividade corporal entre os jovens portugueses: uma realidade socialmente fragmentada. Actas dos ateliers do V Congresso Português de Sociologia, Sociedades Contemporâneas: Reflexividade e Acção. Atelier Corpo e sexualidade. Consultado em: www.aps.pt /cms/docs_prv/docs/DPR4616d905aae8b_1.pdf

Ferreira, V. (2011). Dar corpo à juventude: o corpo jovem e os jovens nos seus corpos. In Bendit, Pais \& Ferreira (orgs.), Jovens e Rumos (pp. 257-276). Lisboa: Imprensa de Ciências Sociais. Consultado em: http://vitorsergio ferreira.net/wp-content/uploads/2014/12/2011-Dar-corpo-\%C3\%A0-juv entude-Jovens-e-Rumos.pdf

Fonseca, R. (2007). A arte como discurso: a identidade como mercadoria. Sociologia, Problemas e Práticas, (53): 117-133. 
Ganetz, H. (1995). The shop, the home and femininity as a masquerade. in Forñas \& Bolin (ed.). Youth culture in late modernity (pp. 72-99) Londres: Sage Publications.

Gay, P. et al. (1997). Doing cultural studies: the story of the Sony Walkman. Londres: Sage Publications.

Gonçalves, A. (1995). Construção social de identidades juvenis em contexto de exclusão social. Dissertação de Mestrado em Sociologia do Território. Lisboa: ISCTE.

Gove, J. \& Watt, S. (2004). Identity and gender. In Woodward (ed.). Questioning identity: gender class, ethnicity (pp. 43-77). Londres: Routledge.

Green, L. (2004). Gender. In Taylor \& Spencer (ed.), Social identities: multidisciplinary approaches (pp.35-63). Nova Iorque: Routledge.

Gregson, K. (2006). Youth culture. Encyclopedia of children, adolescents, and the media. Sage Publications.

Gunter, B. \& Furnham, A. (1998). Children as consumers: a psychological analysis of the young people's market. Londres: Routledge. Consultado em: http://yas.sagepub.com/content/early/2012/07/26/0044118X124550 25

Haller, B. \& Ralph, S. (2001). Profitability, diversity, and disability images in advertising in the United States and Great Britain. Revista Disability Studies Quarterly, 21(2). Consultado em: http://dsq-sds.org/article/view/27 $6 / 301$

Halliwell, E. \& Dittmar, H. (2004). Does size matter? the impact of model's body size on women's body-focused anxiety and advertising effectiveness. Journal of Social and Clinical Psychology, 23(1): 104-122.

Henderson, B. \& DeLong, M. (2000). Dress in a postmodern era: an analysis of aesthetic expression and motivation. Clothing and Textiles Research Journal, 18(4). Consultado em: http://ctr.sagepub.com/cgi/content/abstr act/18/4/237

Hockey, J. \& James, A. (2003). Social identities across the life course. Hampshire: Palgrave Macmillan.

Holdorf, R. (2005). The role of teen oriented fashion magazine content on clothing purchase behaviors and attitudes of adolescents and teens. Florida State University D-Scholarship Repository. Consultado em: http://di 
gitool.fcla.edu/view/action/singleViewer.do?dvs=1346930142331606el ocale=pteVIEWER_URL=/view/action/singleViewer.do?eDELIVERY_ RULE_ID=7eadjacency=Neapplication=DIGITOOL-3eframeId=1euse $\mathrm{Pid} 1=$ trueeusePid2=true

Hosltein-Beck, S. (1995). Consistency and change in the lifeworld of young women. In Forñas \& Bolin (ed.), Youth culture in late modernity (pp. 100-119). Londres: Sage Publications.

Januário, S. \& Cascais, A. (2012), O corpo masculino na Publicidade: uma discussão contemporânea. Revista Comunicação e Sociedade, 21: 135148.

Jorge, A. (2014). "Mas se na sociedade também é assim ...”. Perceções face às representações de género na publicidade... In Jorge, Sequeira \& Magalhães. PubliDiversidade. Representações sociais e igualdade de género na publicidade (35-54). Braga: União de Mulheres Alternativa e Resposta. Consultado em: http://repositorium.sdum.uminho.pt/bitstream/18 22/38106/1/CC_Representa\%c3\%a7\%c3\%b5es-Sociais-G\%c3\%a9nero -Publicidade.pdf

Lazar, M. (2012), Género, guerra e políticas do corpo: uma análise crítica multimodal da metáfora na Publicidade. Comunicação e Sociedade, (19): 183-203, Braga: Centro de Estudos de Comunicação e Sociedade, Universidade do Minho. Consultado em: https://repositorium.sdum.uminho. pt/bitstream/1822/29818/1/Revista_Comunicacao_e_Sociedade_21.pdf

Lehmann, L. et al. (1998). Estetização do corpo: identificação e pertencimento na contemporaneidade. In Castro (org.). Infância e adolescência na cultura do consumo (pp.107-123), Rio de Janeiro, Nau.

Maffesoli, M. (1990). A física mística do corpo. Revista de comunicação e linguagens: o corpo, o nome, a escrita, 10/11: 33-40. Lisboa: Centro de Estudos de Comunicação e Linguagens, Faculdade de Ciências Sociais e Humanas.

Magalhães, S. (2014). Análise de anúncios publicitários em revistas estilo de vida portuguesas - Um estudo de caso. In Jorge, Sequeira \& Magalhães. PubliDiversidade. Representações sociais e igualdade de género na publicidade (17-34). Braga: União de Mulheres Alternativa e Resposta. Consultado em: http://repositorium.sdum.uminho.pt/bitstream/1822/381 
06/1/CC_Representa\%c3\%a7\%c3\%b5es-Sociais-G\%c3\%a9nero-Public idade.pdf

Magalhães, S. (2011). Como ser uma Ragazza. Discursos de sexualidade numa revista para raparigas adolescentes. Dissertação de Doutoramento em Psicologia. Braga: Universidade do Minho. Consultado em: http://re positorium.sdum.uminho.pt/bitstream/1822/19651/1/Sara\%2

OIsabel\%20Almeida\%20Magalh\%c3\%a3es.pdf

Marion, G. \& Nairn, A. (2011). We make the shoes, you make the story. Teenage girl's experiences of fashion: Bricolage tactics and narrative identity. Consumption, Markets e Culture, 14(1): 29-56.

Medeiros, C. (2001). Personagens, espaços e cenários na publicidade. In Pereira, F. \& Veríssimo, J. (coord.). Publicidade, o estado da arte em Portugal (pp. 73-91). Lisboa: Edições Sílabo.

Mota-Ribeiro, S. (2003). Corpos visuais: imagens do feminino na publicidade. In Macedo, A. \& Grossegesse, O. (org.). Re-presentações do corpo (pp. 115-132). Braga: Centro de Estudos Humanísticos da Universidade do Minho. Consultado em: http://repositorium.sdum.uminho.pt/handle/1 $822 / 5309$

Mota-Ribeiro, S. (2010). Do outro lado do espelho: Imagens e discursos de género nos anúncios das revistas femininas - uma abordagem sociosemiótica visual feminista. Dissertação de Doutoramento em Ciências da Comunicação, Especialidade de Semiótica Social. Braga: Universidade do Minho. Consultado em: http://repositorium.sdum.uminho.pt/handle/1 $822 / 12384$

Nielsen, H. \& Rudberg, M. (1993). Gender, body and beauty in adolescence: Three psychological portraits. Young, 1(2). Consultado em: http://you.sagepub.com/content/1/2/32

Nunes, B. (2007). Consumo e identidade no meio juvenil: considerações a partir de uma área popular do Distrito Federal. Sociedade e Estado, 22(3): 647-678.

Padilla-Walker, L. (2006). Adolescents, developmental needs of, and media. Encyclopedia of children, adolescents, and the media. Sage Publications.

Pais, J. (1995). Éticas e estéticas do quotidiano. In Santos (coord.), Cultura e Economia. Actas do Colóquio realizado em Lisboa, 9-11 de Novembro 
de 1994 (pp.129-152). Lisboa: Instituto de Ciências Sociais da Universidade de Lisboa.

Pais, J. (2003). Grupos juvenis: condutas e imagens. In Pais \& Cabral (coord.). Condutas de risco, práticas culturais e atitudes perante o corpo: resultados de um inquérito aos jovens portugueses em 2000 (pp. 367412). Oeiras: Celta.

Pais, J. (2005). Jovens e cidadania. Sociologia, Problemas e Prácticas, (49): $53-70$.

Pais, J. (2010). Lufa-lufa quotidiana: ensaios sobre cidade, cultura e vida urbana. Lisboa: ICS - Imprensa de Ciências Sociais.

Pais, J. (1996). Vivências sexuais: modos e diversidades. III Congresso Português de Sociologia, Práticas e Processos da Mudança Social. Consultado em: http://www.aps.pt/cms/docs_prv/docs/DPR492ede2664249_1. pdf

Palacios, A. (2004. As marcas na pele, as marcas no texto. Sentidos de tempo, juventude e saúde na publicidade de cosméticos em revistas femininas durante a década de 90. Pós-Graduação em Comunicação e Cultura Contemporâneas. Universidade Federal da Bahia. Consultado em: www.bocc.ubi.pt/pag/palacios-annamaria-marcas-na-pele.pdf

Pereira, F. \& Antunes, A. (2008). Trends in cosmetics advertising in Portugal. In Pereira et al. (ed.), New trends in advertising research (pp. 373-389). Lisboa: Edições Sílabo.

Pereira, F. \& Veríssimo, J. (coord.) (2004). Publicidade, o estado da arte em Portugal. Lisboa: Edições Sílabo.

Pereira, F. et al. (2005). Consumo e auto-estima. Comunicação Pública: Revista multidisciplinar de comunicação, 1(1): 135-157. Lisboa: Gabinete de Comunicação e Serviço de Informação e Documentação da Escola Superior de Comunicação Social.

Pereira, F. et al. (2011). O papel da publicidade na compra de produtos cosméticos. Comunicação e Sociedade, (19): 161-178, Braga: Centro de Estudos de Comunicação e Sociedade, Universidade do Minho.

Perse, E. (2006). Advertising, effects on adolescents. Encyclopedia of children, adolescents, and the media. Sage Publications. 
Pinto-Coelho \& Mota-Ribeiro (2012). Analisando os discursos de género das e sobre as imagens publicitárias de mulheres: como articular a análise sociosemiótica com a análise da recepção. Biblioteca on-line de Ciências da Comunicação. Covilhã: Universidade da Beira Interior. Consultado em: www.bocc.ubi.pt/pag/zara-pinto-coelho-silvanamota-ribeiro-discur sos-de-genero.pdf.

Pinto-Coelho \& Mota-Ribeiro (2012). O reino do casal heterossexual na publicidade: uma análise sociosemiótica das estratégias visuais e inscrições discursivas. Comunicação e Sociedade, (19): 161-178. Braga: Centro de Estudos de Comunicação e Sociedade, Universidade do Minho. Consultado em: http://revistacomsoc.pt/index.php/comsoc/article/view/709.

Pons, A. (2006). Los arquetipos cinematográficos, modelos para la publicidad y creadores de valores sociales. In Cardoso et al. (org.), Jovens, marcas e estilos de vida (pp. 309-316). Porto: Edições Universidade Fernando Pessoa.

Reimer, B. (1995). The media in public and private spheres. In Forñas \& Bolin (ed.), Youth culture in late modernity (pp. 58-71). Londres: Sage Publications.

Ribeiro, M. (2011). Beleza feminina e publicidade: um estudo sobre as campanhas da marca Dove. Dissertação de Doutoramento em Comunicação Social. Porto Alegre: Pontifícia Universidade Católica do Rio Grande do Sul. Consultado em: http://repositorio.pucrs.br/dspace/handle/10923/22 34.

Ribeiro, R. (2010). Sociologia do consumo: aplicado ao marketing e à comunicação. Lisboa: Instituto Superior de Ciências Sociais e Políticas.

Ritzer, G. (2005). Enchanting a disenchanted world: revolutionizing the means of consumption. California: Pine Forge Press.

Rodrigues, E. (2013). Dar corpo ao género: uma análise sociológica das masculinidades. Dissertação de Doutoramento em Sociologia. Lisboa: ISCTE.

Rosales, M. (2002). Temos o que procura. Coimbra: Minerva.

Santos, C. (2012). O poder simbólico do consumo: no trilho da génese do discurso publicitário. Revista Comunicando, SOPCOM, 1(1): 29-42. 
Santos, C. (2013). Publicidade e identidade: que relação?. Revista Comunicação Pública, 8(14): 37-55. Lisboa: Escola Superior de Comunicação Social.

Schmidt, L. (1989). O discurso publicitário e a construção da juventude como categoria social. Lisboa: Instituto de Ciências Sociais da Universidade de Lisboa.

Silva, C. (org.) (2001). Os jovens, o dinheiro e o crédito. Lisboa: Instituto do Consumidor.

Silva, R. (2011). Valores e felicidade no Séc. XXI: um retrato sociológico dos portugueses em comparação europeia. Dissertação de Doutoramento em Sociologia. Lisboa: ISCTE-IUL.

Simmel, G. (1969). Cultura feminina. Alfragide: Galeria Panorama.

Simmel, G. (1991). Fashion. In Ray (ed.), Formal Sociology: the sociology of Georg Simmel. Aldershot: Edward Elgar Publishing.

Simmel, G. (2004). Fidelidade e gratidão e outros textos. Lisboa: Relógio D'Água Editores.

Strandbu, A. \& Kvalem, I. (2014). Body talk and body ideals among adolescent boys and girls: a mixed-gender focus group study. Youth e Society, (46): 623-641.

Twigg, J. (2009). Clothing, identity and the embodiment of age. In Powell \& Gilbert (ed.) Aging and identity: a postmodern dialogue. Nova Iorque: Nova Science Publishers.

Veríssimo, J. (2008). O corpo na publicidade. Lisboa: Edições Colibri/Instituto Politécnico de Lisboa.

Vilhjalmsson, R. (2012). Bodily deviations and body image in adolescence. Youth e Society, 44(3): 366-384. 